
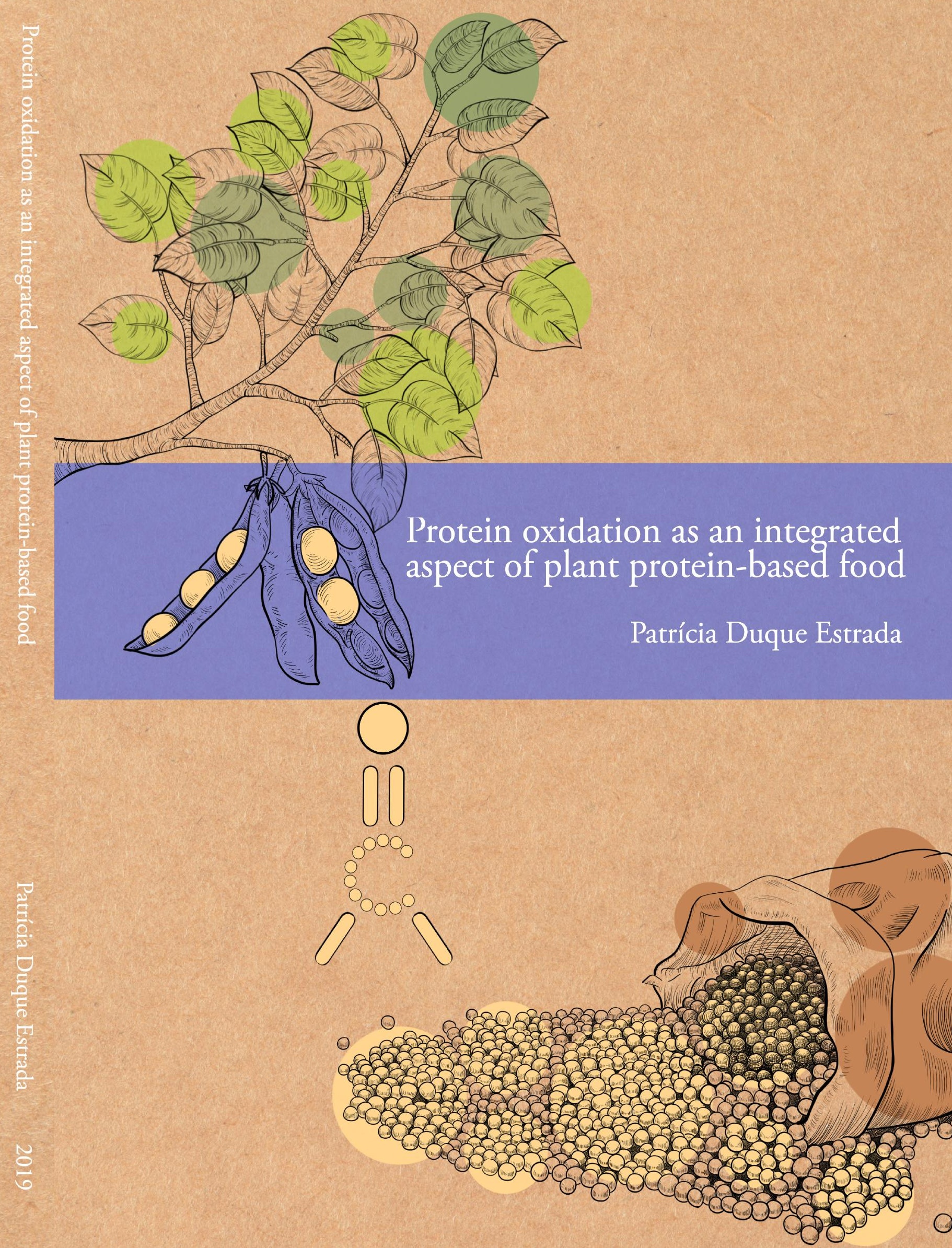


\section{Propositions}

1. Protein oxidation in plant protein-based ingredients can hamper food applications.

(this thesis)

2. The prooxidant effect of ferrous sulfate towards structured plant proteins is only the visible part of the iceberg.

(this thesis)

3. Just like in a hormesis process, competition promotes productivity in science, but only up to a certain limit.

4. Marketing can help good science, but cannot save weak science.

5. True integration starts once we all have experienced being foreigners.

6. Perseverance and success benefit from knowing when to stop working.

Propositions belonging to the thesis, entitled

Protein oxidation as an integrated aspect of plant protein-based food Patrícia Duque Estrada

Wageningen, 15 November 2019 
Protein oxidation as an integrated aspect of plant protein-based food

Patrícia Duque Estrada 


\section{Thesis Committee}

\section{Promotor}

Prof. Dr A.J. van der Goot

Personal chair at the Laboratory of Food Process Engineering

Wageningen University \& Research

\section{Co-promotor}

Dr C.C. Berton-Carabin

Associate Professor of Food Process Engineering

Wageningen University \& Research

\section{Other members}

Prof. Dr J.H. Bitter, Wageningen University \& Research

Prof. Dr J.M. Geleijnse, Wageningen University \& Research

Prof. Dr M. Heinonen, University of Helsinki, Finland

Dr N.J. Zuidam, Unilever, Vlaardingen

This research was conducted under the auspices of Graduate School VLAG (Advanced studies in Food Technology, Agrobiotechnology, Nutrition and Health Sciences). 


\title{
Protein oxidation as an integrated aspect of plant protein-based food
}

\author{
Patrícia Duque Estrada
}

Thesis

submitted in fulfilment of the requirements for the degree of doctor at Wageningen University

by the authority of the Rector Magnificus,

Prof. Dr A.P.J. Mol,

in the presence of the

Thesis Committee appointed by the Academic Board

to be defended in public

on Friday 15 November 2019

at 11 a.m. in the Aula. 
Patrícia Duque Estrada

Protein oxidation as an integrated aspect of plant protein-based food

190 pages.

$\mathrm{PhD}$ thesis, Wageningen University, Wageningen, the Netherlands (2019)

With references, with summary in English

ISBN 978-94-6395-108-1

DOI https://doi.org/10.18174/499098 


\section{Contents}

Chapter 1 Introduction and thesis outline 1

Double emulsions for iron encapsulation: is a high Chapter 2 concentration of lipophilic emulsifier ideal for physical and chemical stability?

Chapter 3 Protein oxidation in plant protein-based fibrous products: effects of encapsulated iron and process conditions

Protein oxidation and in vitro gastric digestion of Chapter 4 processed soy-based matrices

Chapter 5

Oxidative stability of soy proteins: from ground soybeans to structured products

Chapter 6 General discussion

References

Summary

Acknowledgments

About the author

List of publications

Overview of completed training activities 



\section{Chapter 1}

Introduction and thesis outline 


\subsection{Meat analogues: ingredients, process, and nutritional aspects}

Meat production is an inefficient way to make nutritious food products (Steinfeld et al., 2006). Among meat products, beef contributes most to a negative environmental impact (de Vries \& de Boer, 2010). Nevertheless, the worldwide consumption of meat is expected to increase by $73 \%$ by 2050 (FAO, 2011) and unless more efficient food products are developed, we may not be able to supply sufficient food based on a diet rich in animal proteins. However, a decrease in meat intake, and in particular red and processed meat, is related to beneficial health aspects, such as prevention of colorectal cancer (Boada, et al., 2016; Demeyer et al., 2016; Lippi et al., 2016).

Thus, it can be concluded that there is a need to lower meat consumption and to shift to a more plant protein-based diet (Stehfest et al., 2009) because the latter is expected to generate less effluent. However, switching to such a diet is a challenge among most meat eaters, because they highly appreciate the unique sensory attributes of meat, such as texture and taste (Grunert et al., 2004; Hoek et al., 2011; Lea \& Worsley, 2003). One strategy to decrease meat consumption is to develop plantbased products that closely resemble the texture and taste of meat: so-called meat analogues.

\subsubsection{Ingredients for making meat analogues}

Generally, meat analogues contain water, plant proteins (texturized or nontexturized), flavors, fat, binding and coloring agents (Kyriakopoulou et al., 2018). The most commonly used plant proteins are soy proteins because of their functional properties and low cost. Further, soy protein concentrate and isolate have a protein digestibility-corrected amino acid score (PDCAAS), close to 1 (Thrane et al., 2016), which is comparable with the scores for beef and egg proteins (Hughes et al., 2011). Soy flours are not suitable as a starting material for meat analogues, but protein concentrate and isolates derived from soy flours are. To obtain the ingredients, soybeans are first milled into a full-fat flour, which is then defatted using solvents such as hexane. Soy protein concentrate (SPC) can be prepared from defatted flour by aqueous alcohol extraction or isoelectric leaching, which consists of insolubilizing 
the protein and extracting soluble components (Johnson et al., 2008). The preparation of soy protein isolate (SPI) from the defatted flour involves separation steps under alkaline or acidic conditions (Alibhai et al., 2006; Lawhon et al., 1981).The final step to prepare both SPC and SPI is spray or freeze drying. About $80 \%$ of the proteins in SPI are storage globulin proteins: $\beta$-conglycinin, formed by three subunits $\alpha, \alpha^{\prime}$ and $\beta$; and glycinin, composed of acid and basic subunits linked by disulfide bonds (Nishinari et al., 2017). Typically, the protein yield is around 60\% of the protein present in the original soybeans (Johnson et al., 2008). Clearly, the isolation process requires a large amount of water and chemicals (van der Goot et al., 2016). Further, the process conditions applied to isolate proteins generally cause protein denaturation and loss of solubility (Jafari et al., 2016; Schutyser \& van der Goot, 2011).

Given the inefficiency of current fractionation route, there is an interest arising to develop more energy-efficient methods under less severe conditions, such as aqueous or dry fractionation (Geerts et al., 2018; Xing et al., 2018). Such methods do not yield high protein purity, however, some native components and structures are still present in protein-enriched fractions. Fractions obtained under such mild condition can be beneficial for structuring purposes, for instance when making meat analogues with a soy protein ingredient that intrinsically contains fat (Geerts et al., 2018).

Recent research has focused on the use of alternative plant protein sources, such as starch- or oil-rich plants (Schreuders et al., 2019). The use of alternatives could increase the variety of food products on the market, in terms of sensory properties and nutritional value. In addition, the use of alternatives would add value to these other crops. 


\subsubsection{Processes to make meat analogues}

To make meat analogues with a fibrous structures, the plant protein ingredients are exposed to processes that are able to align the protein domains and supramolecular structures in an anisotropic material. High temperatures and mechanical forces are often applied in these processes (Dekkers et al., 2018a).

About a decade ago, a novel technique was introduced to generate fibrous structures from dairy proteins based on the use of well-defined shear flow (Manski et al., 2007a,b, 2008). The technology makes use of so-called shearing devices that combine simple shear flow and large shear stresses with high temperatures in a cone-in-cone or Couette geometry device (van den Einde et al., 2003). Under heating and shearing conditions, the proteins form a gel, which can entrap the anisotropic structure formed during processing upon cooling (Dekkers et al., 2016). Fibrous structures have been obtained using blends of SPI and wheat gluten (Grabowska et al., 2014), SPC (Grabowska et al., 2016) and SPI with pectin (Dekkers et al., 2016).

\subsubsection{Nutritional aspects of meat analogues}

Meat provides high quality proteins, all essential amino acids, and a broad range of micronutrients. To make a meat analogue with a similar nutritional profile would require intensive processing of the ingredients, because plant materials contain carbohydrates in addition to proteins and lipids. However, intensive processing to make isolates might influence protein quality. For example, the processes could lead to protein denaturation, crosslinking, or oxidation. Milder processing could avoid some of those disadvantages, but it would be difficult to reach a similar nutritional value if some of the carbohydrates are still present. However, given that the average person consumes excess protein, a reduced protein intake and subsequent increase in dietary fiber might even contribute to a more balanced diet.

Another difference between plant protein-based products and meat is related to the content of micronutrients, especially iron and vitamin $B_{12}$. This explains why meat analogues are often fortified with iron, to mitigate the most common micronutrient 
deficiency (Blanco-Rojo \& Vaquero, 2018). The preferred choice of iron for food fortification is a water-soluble compound, e.g., ferrous sulfate, due to its high bioavailability (Hurrell et al., 2004). However, the incorporation of soluble iron in food products is still a challenge due to its prooxidant activity (Zuidam, 2012). This explains why products containing water-soluble iron have lower storage stability than products enriched with insoluble iron (Figure 1.1). In addition, water-soluble iron gives an undesirable metallic taste (Simiqueli, et al., 2019ab). Therefore, it is clear that inclusion of water-soluble iron in food products requires balancing the advantages and challenges for physicochemical stability and bioavailability. Encapsulation is often suggested as a route to optimize the balance.

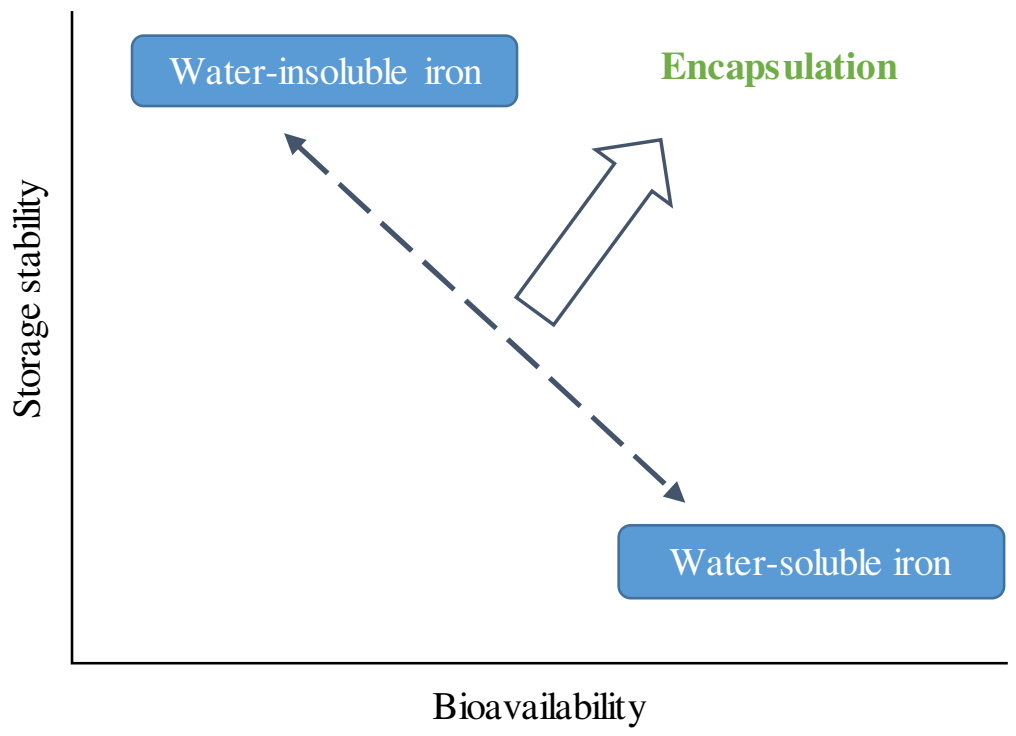

Figure 1.1. Conflicting requirements for incorporating water-insoluble or water-soluble iron in food: storage stability and bioavailability. Encapsulation of iron can be used to overcome those requirements. Adapted from Zuidam (2012). 
The process conditions used to make meat analogues generally comprise high temperatures. High temperature processing leads to nutritional and sensory changes in food products (Fellows, 2017). Part of the changes are beneficial such as improved protein digestibility by denaturation and inactivation of antinutritional factors and food pathogens (Alonso et al., 2000). However, heat processes can also decrease the amount of heat-sensitive vitamins and lead to loss of essential amino acids and the formation of toxic compounds such as acrylamide when reducing sugars react with amino acids by Maillard reaction (Singh et al., 2007). Lysine was the most affected amino acid during extrusion of wheat flour that contained egg albumen proteins and reducing sugars (Singh et al., 2007). High temperature processing can further induce oxidation of protein, which deteriorates the protein quality as well. The extent of those modifications described above depends on the composition of the food and the exact process conditions.

\subsection{Understanding oxidation in plant protein-based products}

The quality of protein-rich foods can change after processing and storage. In products of animal origin, oxidation is often taken as a measure of deterioration of protein quality. Plant-based protein products are rarely investigated based on those product characteristics. The main focus so far has been on the creation of novel, attractive structures and the development of novel ingredients. However, the process conditions used to make those ingredients and products are often harsh, which means oxidation of proteins and lipids is likely to occur. As described above, oxidation may even be enhanced when fortification with iron is applied. A good understanding of protein and lipid oxidation in this new category of products is therefore needed and could give rise to routes to prevent or reduce oxidation in plantbased products.

\subsubsection{Implications of oxidation for food products and human nutrition}

Many process conditions applied in industry and cooking processes used at home can induce protein oxidation (Gatellier et al., 2010; Gatellier et al., 2009b; Hu et al., 
2017; Jacobsen, 2016; Promeyrat et al., 2011). It has been shown that protein oxidation in meat depends on the temperature and time of the treatment. Some related findings are summarized in Table 1 . Protein oxidation increased with temperatures above $100{ }^{\circ} \mathrm{C}$ for all meat types. Noticeably, cooking bacon led to higher protein oxidation than other meat products and raw bacon already had a substantial level of oxidation.

Protein oxidation often leads to changes in the secondary and tertiary structures of proteins, altering their physical properties, such as solubility and hydrophobicity (Santé-Lhoutellier et al., 2007). Table 1, outline studies showing that cooking meat increased hydrophobicity, due to protein denaturation. In meat products, protein oxidation has been associated with a loss of water-holding and gelling capacities, modification in color and flavor, altered texture, loss of essential amino acids and impaired digestion (Decker et al., 1993; Estévez \& Luna, 2017; Lund et al., 2007; Santé-Lhoutellier et al., 2007; Xiong, 1994). The effect of oxidation on digestion depends on the level of oxidation (Davies, 2001; Grune et al., 2004). At a low level of oxidation, subtle changes in protein structure and partial unfolding can favor recognition through digestive enzymes, thus increasing digestion. Higher levels of oxidation induce protein aggregation and polymerization, which changes the recognition sites for digestive enzymes and decreases digestion (Bax et al., 2012; Santé-Lhoutellier et al., 2007; Santé-Lhoutellier et al., 2008a).

Apart from some research on the effects on in vitro protein digestion, studies on the effect of the intake of oxidized proteins in vivo are rare. The intake of unsaturated lipids and animal proteins has been associated with increased oxidation and inflammation markers in the blood of humans and of animals models (Estévez \& Xiong, 2019). In addition to the possible presence of oxidation products in those foods pre-ingestion, oxidation can occur during gastrointestinal digestion (Estévez \& Luna, 2017). 


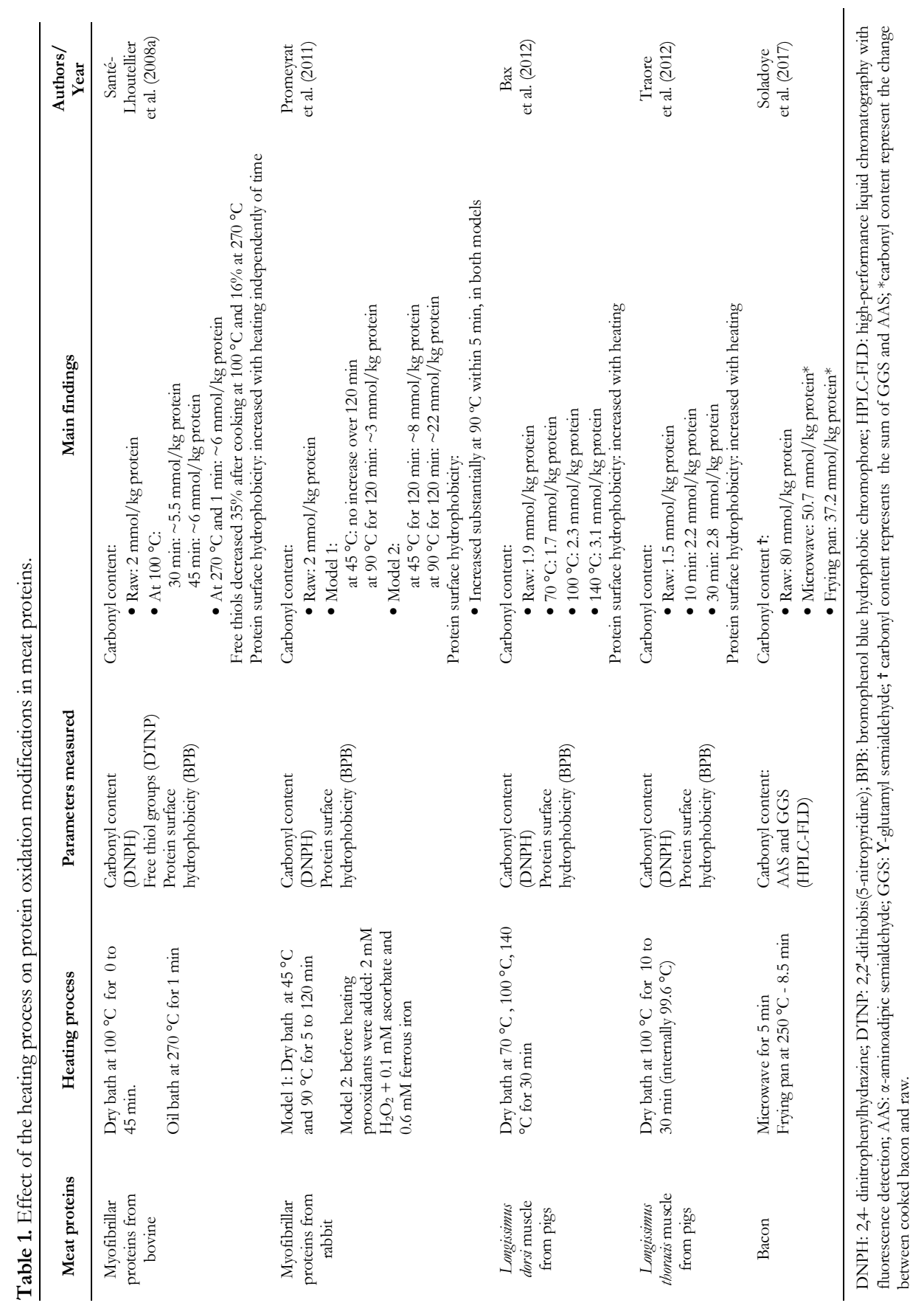


Furthermore, studies on experimental animals showed that there is a link between the intake of oxidized tyrosine proteins and organ dysfunction (Ding et al., 2017; Li et al., 2017; Yang et al., 2017) It should be noted though that the concentrations of oxidized tyrosine in those studies may be much higher than values normally reported for food products. Nevertheless, more studies are needed to understand the effect of oxidative modifications of proteins, regarding notably the concentration and bioavailability of the formed products, as a possible threat to human health.

\subsubsection{Mechanisms of protein oxidation and promoting factors}

Protein oxidation can be induced by two routes: (1) directly by reactive oxygen species (ROS), free or non-free radicals, and reactive nitrogen species (RNS); (2) indirectly by secondary products of oxidative stress, such as oxidized lipids (Lund et al., 2011). Each amino acid has a specific sensitivity to reactive species, which explains the formation of a wide variety of oxidation products. Rout 1 involves irreversible (mechanisms 1-3) and reversible modifications (mechanisms 4-6), as shown in Figure 1.2. Mechanism 1 is a reaction involving the protein backbone, whereby hydroxyl radicals $\left({ }^{\bullet} \mathrm{OH}\right)$ attack the amino acids via hydrogen abstraction, resulting in cleavage of the protein backbone and carbonyls $(\mathrm{C}=\mathrm{O})$ fragments. Mechanism 2 is also involved in the formation of protein carbonyls or nitration by metal-catalyzed oxidation reactions (MCOR) which occurs at metal chelating amino acids, such as lysine, threonine, arginine, and proline.

Mechanism 3 involves aromatic amino acids, such as tryptophan, tyrosine, phenylalanine, and histidine, and results in hydroxylated or nitrated residues, such as 3-nitrotyrosine (Figure 1.2). In addition, the oxidation of histidine can also lead to the formation of carbonyls. Mechanisms 4-6 involve amino acids containing sulfur groups, which are more susceptible to reaction with ROS and oxidizing lipids. Mechanisms 4 and 5 show the oxidation of cysteine, in this case of the thiol (R-SH) and thiolate (R-S ) residues by free radicals, which results in the formation of disulfide bonds or intermediate sulfenic acid (R-SOH). Further reactions can lead to sulfinic 
$\left(\mathrm{R}-\mathrm{SO}_{2} \mathrm{H}\right)$ and sulfonic acids $\left(\mathrm{R}-\mathrm{SO}_{3} \mathrm{H}\right)$. Mechanism 6 shows the oxidation of methionine, resulting in methionine sulfoxide (R-S=O) (Reiniers et al., 2014).

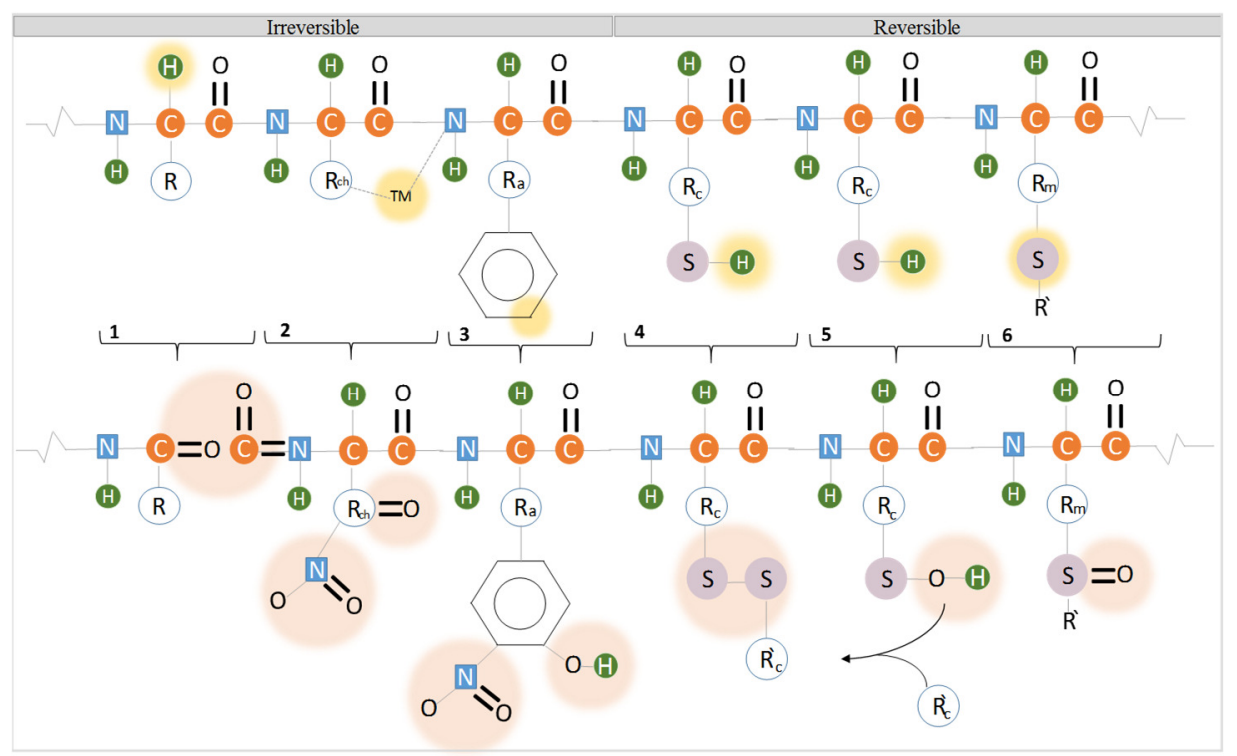

Figure 1.2. Mechanisms of protein oxidation (1-6) induced by ROS/RNS (top) and oxidation modifications (bottom). The top scheme shows the protein backbone with individual amino acid and the yellow shaded circles indicate the sites of oxidation. The bottom scheme shows the structural changes after oxidation (orange shaded circles). R, all amino acids; Rch, metal-chelating amino acids; Ra, aromatic amino acids; Rc, cysteine; $\mathrm{Rm}$, methionine; polygonal/circular form, aromatic structures on the respective amino acid residues. Adapted from Reiniers et al. (2014).

Furthermore, route 2 can lead to protein carbonylation through glycation in the presence of reducing sugars and their oxidation products, such as $\alpha$-dicarbonyls, with basic amino acids; and covalent binding to non-protein carbonyl compounds such as 4-hydroxyl-2-nonenal or malondialdehyde formed by lipid oxidation (Estévez, 2011). Protein-bound carbonyls are the most common protein oxidation markers investigated as a measure for protein oxidaation in biological samples and food proteins. 
In summary, protein oxidative modifications can occur in an amino acid side chain or in the protein backbone. The modifications lead to cleavage of peptides bonds and modification of the amino acid side chain, such as the formation of carbonyls. In addition, the formation of inter-molecular covalent cross-links, such as disulfide bonds and dityrosine, can occur, which induces polymerization of the proteins and eventually to formation of large and insoluble protein aggregates (Lund et al., 2011).

\subsubsection{Controlling the effect of iron on protein oxidation}

As stated earlier, iron is known for its prooxidant effect and participates in the MCOR, resulting in protein carbonylation (mechanism 2, Figure 1.2). In the MCOR, reduced forms of iron, but also other transition metals, can react with hydrogen peroxide $\left(\mathrm{H}_{2} \mathrm{O}_{2}\right)$, resulting in a reactive intermediate (hydroxyl radical, ${ }^{\bullet} \mathrm{OH}$ ) via the Fenton reaction (Reaction 1) (Stadman \& Levine, 2000).

$$
\mathrm{Fe}^{+2}+\mathrm{H}_{2} \mathrm{O}_{2} \rightarrow \mathrm{Fe}^{+3}+\mathrm{HO}^{\cdot}+\mathrm{HO}^{-}
$$

Several reducing agents (ascorbate, thiol compounds, superoxide anions, etc.) can recycle ferrous iron from ferric iron (Reaction 2) (Stadman \& Levine, 2000). Both reduced and oxidized forms of iron are able to promote protein carbonylation via ROS-mediated reactions in vitro conditions (Estévez et al., 2009). The presence of metal binding sites is the reason why some amino acid residues are more sensitive to MCOR.

$$
\mathrm{Fe}^{+2}+\mathrm{O}_{2} \rightarrow \mathrm{Fe}^{+3}+\mathrm{O}^{-}
$$

Most of the reactions described here are difficult to avoid, therefore a commonly proposed strategy is to prevent direct contact between iron and proteins of the product. Encapsulation of iron has been described as a strategy to improve iron stability in food products and to mask its metallic taste (Bonnet et al., 2009; Dickinson, 2011). Encapsulation consists of entrapment of an active compound within one or more shells made of food-grade and biodegradable materials to 
separate the internal phase and the surrounding matrix (Ye et al., 2018). In addition, encapsulation can be used to increase the bioavailability of an active compound by allowing controlled release in the gastrointestinal tract (Kuang et al., 2010). Among the techniques for iron encapsulation, spray drying has been reported to efficiently immobilize ferrous sulfate using pea protein as the wall material (Bittencourt et al., 2013; Ferreira et al., 2011). Other studies report on the potential of emulsions, more specifically water-in-oil and double emulsions, for iron encapsulation (Chang et al., 2016; Choi et al., 2009; Dubey \& Windhab, 2013; Prichapan et al., 2018; Simiqueli et al., 2019a;b), and indicate that those emulsions can encapsulate iron in concentrations that are relevant to food fortification, with a high and stable encapsulation efficiency.

\subsection{Aim and outline of this thesis}

The aim of this thesis was to assess and control protein quality in plant protein-based meat analogues, as a function of (i) the presence of soluble iron in free or encapsulated form, and (ii) the thermomechanical process conditions usually applied to make meat analogues. Two main hypotheses were proposed to motivate this research: (1) the encapsulation of iron could improve the chemical stability of meat analogues during the thermomechanical process, preventing or minimizing protein oxidation. However, we noticed that the starting protein ingredients (SPC, SPI) were already oxidized to various degrees and that protein oxidation was enhanced by further processing. This observation led to hypothesis 2: process conditions induce physicochemical protein modifications that can be detrimental to the protein quality of ingredients and final products. Figure 1.3 presents an overview of the different aspects covered in this thesis and the interplay between them.

The encapsulation of iron in double emulsions targeted for potential food applications is described in Chapter 2. In this chapter, the effect of the concentration of lipophilic emulsifier on the chemical stability of iron-enriched double emulsions was quantified. Chapter 3 describes the effects of iron incorporation and process conditions on protein oxidation in plant protein-based fibrous products (meat 
analogues). In this study, pea protein-based spray-dried particles were used for iron encapsulation, and commercial SPC was used as the protein source to make fibrous products. Chapter 4 describes the effects of the process conditions and the type of soy protein ingredients on protein oxidation induced by processing, and on gastric digestion in vitro. Chapter 5 describes the oxidative stability of soy ingredients commonly used to make soy-based food. This chapter focuses on the oxidative stability of proteins affected by: the processes used to obtain isolated proteins as a food ingredient and subjecting these ingredients to subsequent thermomechanical processes often used to make meat analogues.

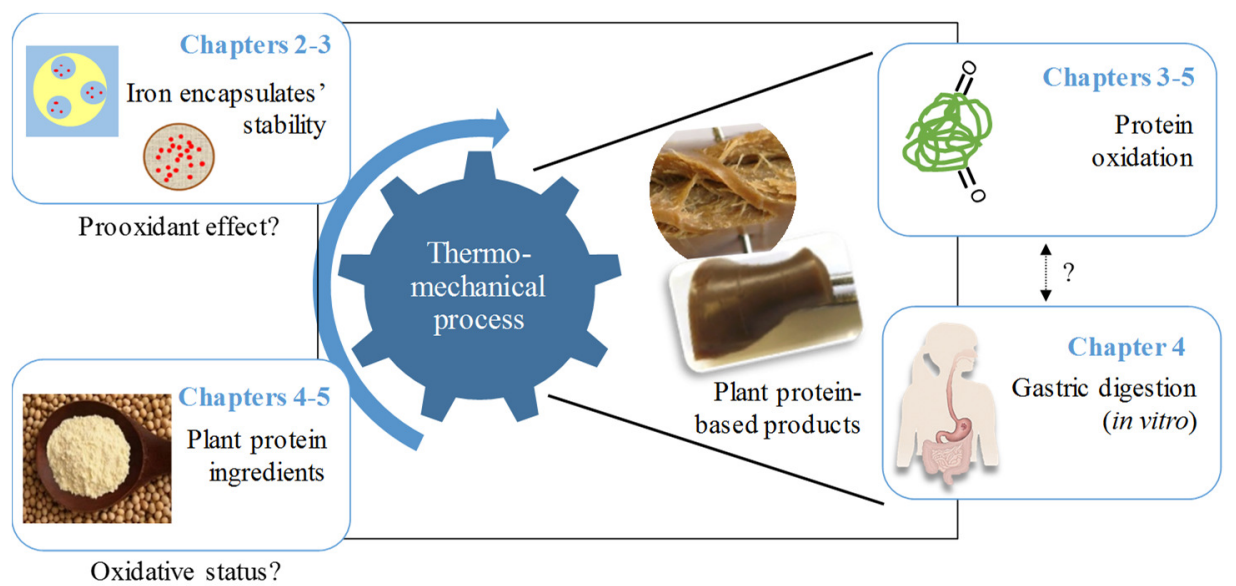

Figure 1.3. Graphical outline of the chapters in this thesis, and of their interplay.

The main findings of this thesis are discussed in Chapter 6. A critical overview of the methods and limitations in measuring protein oxidation in meat analogues is presented. The oxidation levels in plant protein-based ingredients and the suitability of the process conditions applied to make meat analogues are appraised, which puts the findings of this thesis into perspective regarding future research directions and potential applications. 


\section{Chapter 2}

Double emulsions for iron encapsulation: is a high concentration of lipophilic emulsifier ideal for physical and chemical stability?

This chapter has been published as: Duque-Estrada, P., School, E., van der Goot, A.J. \& Berton-Carabin, C.C. (2019). Double emulsions for iron encapsulation: is a high concentration of lipophilic emulsifier ideal for physical and chemical stability? Journal of the Science of Food and Agriculture, 99(10): 4540-4549. 


\begin{abstract}
Worldwide iron deficiency in diets has led to a growing interest in the development of food-compatible encapsulation systems for soluble iron, which are able to prevent iron's undesirable off-taste and prooxidant activity. Here, we explore the use of double emulsions for this purpose, and in particular, how the lipophilic emulsifier (polyglycerol polyricinoleate, PGPR) concentration influences the physicochemical stability of water-in-oil-in-water $\left(\mathrm{W}_{1} / \mathrm{O} / \mathrm{W}_{2}\right)$ double emulsions containing ferrous sulfate in the inner water droplets. Double emulsions were prepared with sunflower oil containing 10 to $70 \mathrm{~g} \mathrm{~kg}^{-1}$ PGPR in the oil phase, and were monitored for droplet size distribution, morphology, encapsulation efficiency (EE) and oxidative stability over time. Fresh double emulsions showed an initial EE higher than 88\%, but EE decreased upon storage, which occurred particularly fast and to a high extent in the emulsions prepared with low PGPR concentrations. All double emulsions underwent lipid oxidation, in particular those with the highest PGPR concentration, which could be due to the small inner droplet size and thus promoted contact between oil and the internal water phase. These results show that a too high PGPR concentration is not needed, and sometimes even adverse, when developing double emulsions as iron encapsulation systems.
\end{abstract}




\subsection{Introduction}

Iron deficiency is one of the most common global nutritional deficiencies and an important factor responsible for anaemia (WHO, 2017). To prevent iron deficiency, iron fortification in diets is one of the approaches that should be considered. Yet, iron fortification of food products is still a challenge, because of iron's prooxidant activity. Among the chemical forms of iron available for food fortification, watersoluble forms have the highest bioavailability. However, soluble iron can readily catalyse oxidation reactions, leading to detrimental sensory and nutritional changes (Cayot et la., 2013). Furthermore, soluble iron gives an undesirable metallic taste (Cayot et al., 2013). Therefore, encapsulation has been described as a strategy to improve iron stability in food products and to mask its metallic taste.

Among the plethora of food-compatible encapsulation systems, water-in-oil-in-water $\left(\mathrm{W}_{1} / \mathrm{O} / \mathrm{W}_{2}\right)$ double emulsions are suitable to encapsulate water-soluble compounds (McClements, 2015). Double emulsions combine a high encapsulation efficiency potential with the ability to mask undesirable tastes in a simple, low-cost method (Matos et al., 2015). Only a few studies have focused on encapsulating iron within water-in-oil (W/O) emulsions (Choi et al., 2009; Dubey \& Windhab, 2013; Prichapan et al., 2018) and within double emulsions (Chang et al., 2016; Choi et al., 2009; Hosseini et al., 2019; Simiqueli et al., 2019a;b). Although these studies have shown that double emulsions are suitable to encapsulate iron with a high and stable encapsulation efficiency (EE), and in amounts that are relevant to food fortification, they have also pointed out that the presence of iron in water droplets dispersed in oil largely favours lipid oxidation, which was to be expected due to the strong prooxidant activity of iron (Jacobsen, 2016; McClements \& Decker, 2000; Osborn \& Akoh, 2003).

Although attempts have been made at mitigating the prooxidant effect of encapsulated iron in such $\mathrm{W} / \mathrm{O}$ or double emulsions, for example by increasing the solid fat content of the lipid phase (Prichapan et al., 2018), the effect of other 
potentially determining factors, such as the water droplet size, remains unexplored. The contact area between oil and iron-loaded inner droplets in double emulsions is probably a factor that can affect lipid oxidation, and directly depends on the inner droplet size. The latter can be controlled by processing conditions, and by the type and concentration of lipophilic emulsifier (Weiss \& Muschiolik, 2007). The most frequently used lipophilic emulsifier to stabilize water droplets in oil, for food applications, is polyglycerol polyricinoleate (PGPR), which is known to facilitate the production of small water droplets with a narrow size distribution (Christiansen, 2015).

Although how PGPR concentration may affect the chemical stability of double emulsions (i.e. lipid oxidation) has not been investigated yet, it is well established that the PGPR concentration affects the EE value in such systems. For instance, a double emulsion is considered reasonably stable if $\mathrm{EE}$ is $~ 95 \%$ (or above) and decrease to 70-80\%, maximally, after a few weeks of storage (Dickinson, 2011). Su et al. (2006) found that in fresh double emulsions prepared with $80 \mathrm{~g} \mathrm{~L}^{-1}$ PGPR in the oil phase, the EE was almost $100 \%$ while with $5 \mathrm{~g} \mathrm{~L}^{-1}$ PGPR, almost $48 \%$ of the Poly R-478 dye remained encapsulated. Increased PGPR concentration can create a stable interfacial layer at the water-oil interface and increase the oil phase viscosity, which reduces coalescence of water droplets in the W/O emulsion. These aspects contributed to reducing the release of Poly R-478 dye at high PGPR concentration. It does not mean, however, that a very high PGPR concentration is necessarily better for high EE. In fact, the release of encapsulated compounds from the inner water droplets to the external aqueous phase can be due to coalescence of the inner water phase with the external water phase, or via diffusion through the oil phase, possibly via reverse micelles formed when there is an excess of lipophilic emulsifier in the oil phase (Benichou et al., 2007; Choi et al., 2009; Garti, 1997).

It is thus clear that some aspects still need to be elucidated in order to bring double emulsions towards food applications for soluble iron encapsulation: for instance, we 
should strive for minimizing PGPR concentration, since FAO regulations put a maximum on daily intake of $7.5 \mathrm{mg}$ of PGPR per kilogram of body weight (FAO/WHO, 1973), while still ensuring the emulsion's physical stability. In addition, the effect of PGPR concentration on lipid oxidation in iron-containing double emulsions has to be evaluated. Therefore, this research aimed to investigate the effect of PGPR concentration on the physicochemical stability of $\mathrm{W}_{1} / \mathrm{O} / \mathrm{W}_{2}$ double emulsions targeted to ferrous sulfate encapsulation.

\subsection{Material and methods}

\subsubsection{Material}

Sunflower oil was purchased from a local supermarket (Wageningen, The Netherlands) and used without further purification. Ferrous sulfate heptahydrate was obtained from Merck Millipore (Darmstadt, Germany). Para-anisidine of analytical grade, polyoxyethylenesorbitan monolaurate (Tween 20), and 2-propanol were purchased from Sigma-Aldrich (St Louis, MO, USA). PGPR was purchased from Quest International (Naarden, The Netherlands). D-Glucose monohydrate was purchased from VWR Chemicals (Leuven, Belgium) and n-hexane was purchased from Actu-ALL Chemicals (Randmeer, The Netherlands). Acetic acid (glacial) 100\% anhydrous was purchased from Merck Millipore (Darmstadt, Germany). Ultrapure water obtained from a Millipore Milli-Q system (Darmstadt, Germany) was used throughout the study.

\subsubsection{Preparation of $\mathrm{W}_{1} / \mathrm{O} / \mathrm{W}_{2}$ double emulsions}

For making the primary water-in-oil $\left(\mathrm{W}_{1} / \mathrm{O}\right)$ emulsion, the aqueous phase contained $1 \mathrm{~mol} \mathrm{~L}^{-1}$ ferrous sulfate heptahydrate. The oil phase was prepared by mixing sunflower oil with different PGPR concentrations: 10, 25, 50, and $70 \mathrm{~g} \mathrm{~kg}^{-1}$ in the oil phase, at $200 \mathrm{rpm}$ for $30 \mathrm{~min}$ at room temperature, followed by a $30 \mathrm{~min}$ rest. Then, $25 \% \mathrm{v} / \mathrm{v}$ of the inner aqueous phase was drop-wise dispersed into the oil phase using a rotor-stator homogenizer (IKA®T18Ultra Turrax, Staufen, Germany) at 11000 rpm for 4 min. 
The external aqueous phase was prepared with $2 \mathrm{~mol} \mathrm{~L}^{-1}$ glucose to balance the osmotic pressure difference. It was then added to $5 \mathrm{~g} \mathrm{~kg}^{-1}$ Tween 20 and stirred at $100 \mathrm{rpm}$ for $1 \mathrm{~h}$. To prepare a coarse $\mathrm{W}_{1} / \mathrm{O} / \mathrm{W}_{2}$ double emulsion, $5 \% \mathrm{v} / \mathrm{v}$ of $\mathrm{W}_{1} / \mathrm{O}$ emulsion was drop-wise dispersed into the external aqueous phase using a magnetic stirrer at $700 \mathrm{rpm}$ for $15 \mathrm{~min}$. The obtained coarse double emulsion was then passed through a premix membrane emulsification system three times (Sahin et al., 2014). This emulsification system consists of a pressured vessel connected to a polymethyl methacrylate column (Wageningen University) with a nickel sieve placed between two rubber O-rings at the bottom junction of the column. The nickel sieve had 500 $\mu \mathrm{m}$ thickness, $11.6 \mu \mathrm{m} \times 331 \mu \mathrm{m}$ pore size and an effective area of $1.43 \mathrm{~cm}^{2}$ (Stork Veco B.V., Eerbeek, The Netherlands). The pressure vessel was connected to a nitrogen source and set to $400 \mathrm{kPa}$.

The freshly made $\mathrm{W}_{1} / \mathrm{O} / \mathrm{W}_{2}$ double emulsions were kept in cylindrical plastic tubes at room temperature for further analysis. Samples to measure lipid oxidation were kept in the dark at room temperature.

\subsubsection{Droplet size distribution}

Droplet size distribution of the primary $\mathrm{W}_{1} / \mathrm{O}$ emulsion and $\mathrm{W}_{1} / \mathrm{O} / \mathrm{W}_{2}$ double emulsion was determined by static light scattering (Mastersizer 2000, Malvern Instruments Ltd, Malvern, UK). In the case of the primary $\mathrm{W}_{1} / \mathrm{O}$ emulsion, sunflower oil was used as the continuous phase and the following conditions were applied: particle refractive index of 1.330, droplet absorbance of 0.01 , dispersant refractive index of 1.465 (Grompone, 2011), obscuration between 5\% and 20\%. For the $\mathrm{W}_{1} / \mathrm{O} / \mathrm{W}_{2}$ double emulsion, ultrapure water was used as a continuous phase and the following conditions were applied: particle refractive index of 1.465 , droplet absorbance of 0.01 , dispersant refractive index of 1.330 , obscuration between $5 \%$ and $10 \%$. The droplet size distribution was measured in fresh $\mathrm{W}_{1} / \mathrm{O} / \mathrm{W}_{2}$ double emulsion and after 1 and 7 days of storage at room temperature. Before measuring, 
the samples were gently agitated to ensure homogeneity. Results were expressed as the Sauter mean diameter $\left(\mathrm{d}_{32}\right)$ and span value $(\delta)$.

\subsubsection{Emulsion morphology}

Light microscopy (Carl Zeiss Axio Scope, Jena, Germany) images were taken in primary $\mathrm{W}_{1} / \mathrm{O}$ emulsions, and in fresh $\mathrm{W}_{1} / \mathrm{O} / \mathrm{W}_{2}$ double emulsions, or after 1 and 7 days of storage at room temperature. The samples were gently agitated to ensure homogeneity. Then a drop of the sample was placed on a microscopic slide and covered with a slip. To visualize the primary emulsion the samples were diluted ten times with sunflower oil. Images were captured with an AxioCam MRc 5 camera at a magnification of $\times 400$.

\subsubsection{Calculation of excess PGPR}

We calculated the theoretical excess fraction of PGPR (EPGPR) in a given volume of $\mathrm{W}_{1} / \mathrm{O}$ emulsion, considering a theoretical PGPR surface coverage $\left(\Gamma_{\mathrm{PGPR}}\right)$ of 1.2 $\mathrm{mg} / \mathrm{m}^{2}$ (Marze, 2009), following the equation:

$$
E_{P G P R}(\%)=m_{P G P R \text { tot }}-\left(\left[3 V_{\text {water }} / r\right] \times \Gamma_{P G P R}\right) \text { Eq. } 1
$$

where MPGPR tot is the total mass of PGPR (in grams) in a given volume of emulsion, $\mathrm{V}_{\text {water }}$ is the volume of aqueous phase, and $\mathrm{r}$ is the water droplet radius $\left(\mathrm{d}_{32} / 2\right)$.

\subsubsection{Encapsulation efficiency}

The EE value was determined by direct conductivity measurements in the double emulsions (Hach HQ14d, Tiel, The Netherlands) according to Sahin et al. (2014). The conductivity meter was placed into $20 \mathrm{~mL}$ vessels filled with the $\mathrm{W}_{1} / \mathrm{O} / \mathrm{W}_{2}$ double emulsion and the emulsions were gently stirred. The conductivity was measured over time. The concentration of iron released in the external aqueous phase was determined using a calibration curve made with ferrous sulfate $\left(0\right.$ to $13.7 \times 10^{-3}$ mol L-1) in solutions of the same composition as the external aqueous phase (glucose and Tween 20). The EE value was calculated based on the concentration that was 
released in the external water phase $\left(\mathrm{C}_{\mathrm{w} 2}\right)$ relative to the maximum released concentration of iron $\left(\mathrm{C}_{\text {total }}\right)$, following the equation:

$$
\mathrm{EE}(\%)=\frac{\left(\mathrm{C}_{\text {total }}-\mathrm{C}_{\mathrm{w}_{2}}\right)}{\mathrm{C}_{\text {total }}} \times 100 \text { Eq. } 2
$$

where $\mathrm{C}_{\text {total }}$ was $12.9 \times 10^{-3} \mathrm{~mol} \mathrm{~L}^{-1}$, corresponding to a theoretical situation where all the iron would have been released in the external aqueous phase.

\subsubsection{Lipid oxidation}

Lipid oxidation was determined by measuring the amount of conjugated diene (CD) hydroperoxides (Berton et al., 2011) and the aldehyde content (mainly alkene-2-als) through the para-anisidine value (pAV) (AOCS, 2017). The pAV protocol was slightly modified according to Berghout et al. (2015b) and Cengiz et al. (2019).

For the determination of $\mathrm{CD}$ hydroperoxides, $50 \mu \mathrm{L}$ of $\mathrm{W}_{1} / \mathrm{O} / \mathrm{W}_{2}$ double emulsion were mixed with $950 \mu \mathrm{L} 2$-propanol. This first sample was further diluted ten-fold with 2-propanol. The obtained sample was centrifuged at $1200 \times \mathrm{g}$ for $4 \mathrm{~min}$. The absorbance spectrum of the supernatant was recorded between 200 and $310 \mathrm{~nm}$ with a UV-visible spectrophotometer (DU720, Beckman Coulter, Inc., Indianapolis, IN, USA), using a blank consisting of 2-propanol and water in the same ratio as in the measured sample. Measurements were done on fresh emulsions, after $4 \mathrm{~h}, 1$ day and 7 days storage at room temperature. The concentration of the $\mathrm{CD}$ hydroperoxides was calculated using the measured absorbance at $233 \mathrm{~nm}$ and their molar extinction coefficient at $233 \mathrm{~nm}\left(27000 \mathrm{M}^{-1} \mathrm{~cm}^{-1}\right)$, and expressed as mmol kg-1 of oil.

The determination of the pAV started with weighing $1 \mathrm{~g}$ of $\mathrm{W}_{1} / \mathrm{O} / \mathrm{W}_{2}$ double emulsion. Then the emulsion was mixed with $2.5 \mathrm{~mL}$ hexane/isopropanol $(3: 1, \mathrm{v} / \mathrm{v})$. The upper hexane phase was centrifuged at $1200 \times \mathrm{g}$ for $4 \mathrm{~min}$ and the supernatant was collected to measure the absorbance at $350 \mathrm{~nm}(\mathrm{Ab})$, using pure hexane as the 
blank. Then, $0.5 \mathrm{~mL}$ of the upper hexane phase was mixed with $0.1 \mathrm{~mL}$ of $2.5 \mathrm{~g} \mathrm{~L}^{-1}$ para-anisidine in acetic acid solution. The blank was hexane mixed with the same para-anisidine solution, in similar proportions. After $10 \mathrm{~min}$ the absorbance (As) of the samples was measured at $350 \mathrm{~nm}$. The pAV was calculated following the equation::

$$
\mathrm{pAV}=\frac{(1.2 \mathrm{As}-\mathrm{Ab})}{\mathrm{m}} \text { Eq. } 3
$$

where $m$ is the mass of oil per millilitre of hexane phase.

Double emulsions without iron were prepared as a control. Besides, a simple oil-inwater $(\mathrm{O} / \mathrm{W})$ emulsion $\left(37.5 \mathrm{~mL} \mathrm{~L}^{-1}\right.$ sunflower oil, $5 \mathrm{~g} \mathrm{~kg}^{-1}$ Tween 20 and $2 \mathrm{~mol} \mathrm{~L}^{-1}$ glucose in the aqueous phase) was prepared with $12.9 \times 10^{-3} \mathrm{~mol} \mathrm{~L}^{-1}$ iron in the aqueous phase (i.e. same as $\mathrm{C}_{\text {total }}$ used for EE measurements). Iron was dispersed at the aqueous phase under magnetic stirring at $100 \mathrm{rpm}$.

The aqueous phase was prepared as described earlier. The oil was drop-wise dispersed into the aqueous phase under magnetic stirring at $700 \mathrm{rpm}$ for $15 \mathrm{~min}$. The obtained coarse emulsion was then passed through a premix membrane emulsification system three times using the same parameters as described in earlier. This mixture corresponds to a situation in the $\mathrm{W}_{1} / \mathrm{O} / \mathrm{W}_{2}$ double emulsion where all the water and iron would have been released from the inner water droplets to the external aqueous phase.

\subsubsection{Experimental design and statistical analysis}

For each PGPR concentration, three double emulsion samples were prepared independently. To determine droplet size distributions, each sample was measured twice with an average of four readings. Microscopy images and EE were analyzed in duplicate per sample. Lipid oxidation measurements were taken in triplicate per each sample. 
Data are presented as a mean and standard deviation. Statistical analysis was done using the IBM SPSS software v. 23 (Statistical Package for the Social Sciences, SPSS Inc., Chicago, IL, USA). The normality of the data was tested with KolmogorovSmirnov test. Means from samples prepared with different PGPR concentrations within the same storage time were compared by one-way analysis of variance (ANOVA) with Tukey's post hoc test, with a significance level of $p<0.05$.

\subsection{Results and Discussion}

The physicochemical stability of $\mathrm{W}_{1} / \mathrm{O} / \mathrm{W}_{2}$ double emulsions prepared with different PGPR concentrations was monitored over storage time at room temperature. The physical stability was assessed considering droplet size distribution, microscopy images, and EE. The formation of primary and secondary lipid oxidation compounds.

\subsubsection{Physical properties of $\mathrm{W}_{1} / \mathrm{O}$ emulsions}

Figure 2.1.A,B shows optical microscopy images of $\mathrm{W}_{1} / \mathrm{O}$ emulsions prepared with the lowest and the highest PGPR concentrations tested. It is clear that $\mathrm{W}_{1} / \mathrm{O}$ emulsions prepared with $70 \mathrm{~g} \mathrm{~kg}^{-1}$ PGPR showed smaller droplets compared to $\mathrm{W}_{1} / \mathrm{O}$ with $10 \mathrm{~g} \mathrm{~kg}^{-1} \mathrm{PGPR}$. Figure 2.1.C shows the droplet size distribution of $\mathrm{W}_{1} / \mathrm{O}$ emulsions prepared with different PGPR concentrations. A bimodal distribution was seen for $\mathrm{W}_{1} / \mathrm{O}$ emulsions with higher PGPR concentrations, with a first peak between 0.1 and $0.14 \mu \mathrm{m}$ and a second peak between 1 and $1.5 \mu \mathrm{m}$. The polydispersity also increased when PGPR concentration was increased (Table 2). Emulsions prepared with 50 and $70 \mathrm{~g} \mathrm{~kg}^{-1}$ PGPR had the smallest $\mathrm{d}_{32}$ and the highest span values compared to lower PGPR-concentrations. 

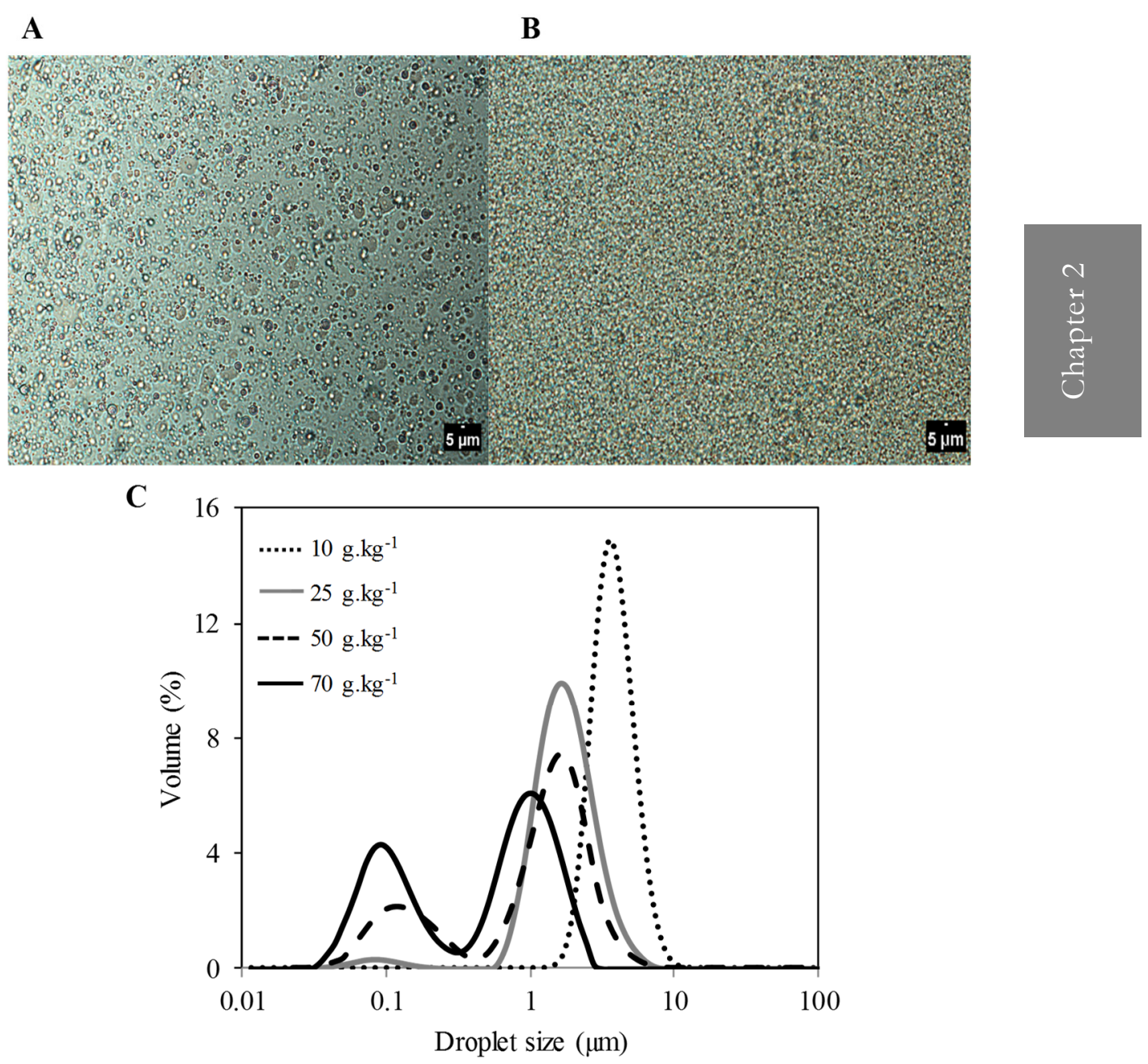

Figure 2.1. Microscopy images of fresh primary water-in-oil $\left(\mathrm{W}_{1} / \mathrm{O}\right)$ emulsions prepared with $10 \mathrm{~g} \mathrm{~kg}^{-1}$ (A) and $70 \mathrm{~g} \mathrm{~kg}^{-1}$ (B) polyglycerol polyricinoleate (PGPR). Droplet size distribution of $\mathrm{W}_{1} / \mathrm{O}$ emulsions prepared with different PGPR concentrations in the oil phase (C): 10, 25, 50 and $70 \mathrm{~g} \mathrm{~kg}^{-1}$. 
Table 2. Sauter mean diameter $\left(\mathrm{d}_{32}\right)$, span values and excess of polyglycerol polyricinoleate (PGPR) (\%) in primary water-in-oil $\left(\mathrm{W}_{1} / \mathrm{O}\right)$ emulsions prepared with various PGPR concentrations.

\begin{tabular}{cccc}
\hline $\begin{array}{c}\text { PGPR } \\
\text { concentration } \\
\left(\mathbf{g ~ k g}^{-1}\right)\end{array}$ & $\mathbf{d}_{32}(\boldsymbol{\mu m})$ & Span & $\begin{array}{c}\text { Excess of } \\
\text { PGPR (\%) }\end{array}$ \\
\hline 10 & $3.33 \pm 0.29 a$ & $0.84 \pm 0.04$ & 92.8 \\
25 & $1.45 \pm 0.43 b$ & $1.30 \pm 0.59$ & 93.4 \\
50 & $0.76 \pm 0.61 b c$ & $5.74 \pm 6.62$ & 93.7 \\
70 & $0.21 \pm 0.17 c$ & $2.28 \pm 0.37$ & 83.7 \\
\hline
\end{tabular}

Results of $d_{32}$ and span are expressed as mean \pm standard deviation $(\mathrm{n}=3)$. Lowercase letters indicate significant $(p<0.05)$ differences in $\mathrm{d}_{32}$ between $\mathrm{W}_{1} / \mathrm{O}$ emulsions prepared with different PGPR concentrations.

Márquez et al. (2010) also described a decrease in $\mathrm{d}_{32}$ and an increase in polydispersity in W/O emulsions prepared with increasing PGPR concentrations. Scherze et al. (2006) also observed that increasing PGPR concentration (25 to $40 \mathrm{~g} \mathrm{~kg}^{-1}$ in the oil phase) resulted in decreasing the droplet size of W/O emulsions. To make physically stable double emulsions, it is preferable to have $\mathrm{W}_{1} / \mathrm{O}$ emulsions with small droplet size, to avoid rapid droplet sedimentation. In fact, a slower sedimentation rate can prevent the water droplets coming into close contact with the sedimentation layer, which reduces coalescence rates (Ushikubo \& Cunha, 2014).

The peak around $0.1 \mu \mathrm{m}$ could correspond to reverse micelles (Figure 2.1.C) when there is an excess of PGPR in the oil phase. Ushikubo and Cunha (2014) also found a bimodal droplet size distribution with the first peak mode around 0.1 and $0.2 \mu \mathrm{m}$, in W/O phase. Moreover, the ability of free PGPR to aggregate and form reverse micelles has been described by the formation of spontaneous water droplets in oil phase even at low PGPR concentration $\left(5 \mathrm{~g} \mathrm{~kg}^{-1}\right)$ without homogenization (Eisinaite et al., 2018). 


\subsubsection{Physical properties and stability of $\mathrm{W}_{1} / \mathrm{O} / \mathrm{W}_{2}$ double emulsions}

\section{Droplet size distribution}

The droplet size distributions of $\mathrm{W}_{1} / \mathrm{O} / \mathrm{W}_{2}$ double emulsions prepared with different PGPR concentrations were monitored over time at room temperature. All fresh double emulsions had a bimodal droplet size distribution (Figure 2.2.A,B) and a main peak around $17 \mu \mathrm{m}$ with only slight changes depending on the PGPR concentration. The peak seen between 0.1 and $1 \mu \mathrm{m}$ can correspond to the scattering of inner water droplets. In a comparable way, Kaimainen et al. (2015) described a first peak at $0.31 \mu \mathrm{m}$ and a second at $6.6 \mu \mathrm{m}$ in the droplet size distribution of double emulsions. It was assumed that the first peak corresponded to the primary emulsion droplets ( $3 \mathrm{v} / \mathrm{w} \% \mathrm{~W}_{1} / \mathrm{O}$ in the double emulsions). Dickinson et al. (1991) argued that the complex geometry of double emulsions complicates the interpretation results of light scattering analysis because the results are obtained based on the assumption that the inner water droplets do not significantly change the refractive index of the oil droplets. Therefore, those measurements are useful to obtain an estimation about the size and size distribution of the droplets but should be interpreted with caution.

We checked the particle size distribution of $\mathrm{O} / \mathrm{W}$ emulsions prepared in the same conditions as the double emulsions, except that the dispersed phase was now only oil, instead of a W/O emulsion. The particle size distribution and corresponding $\mathrm{d}_{32}$ and $\mathrm{d}_{43}$ values are presented in the Appendix (Figure 2.6). As expected, the particle size distribution of these $\mathrm{O} / \mathrm{W}$ emulsions presented the same main peak as the $\mathrm{W}_{1} / \mathrm{O} / \mathrm{W}_{2}$ emulsions, centred around $20 \mu \mathrm{m}$, which is thus characteristic of the oil droplets. Although some smaller sizes were also detected, the small submicron droplet peak that was seen for the double emulsions was not present for the $\mathrm{O} / \mathrm{W}$ emulsions, confirming that this small peak indeed corresponds to the inner water droplets. 

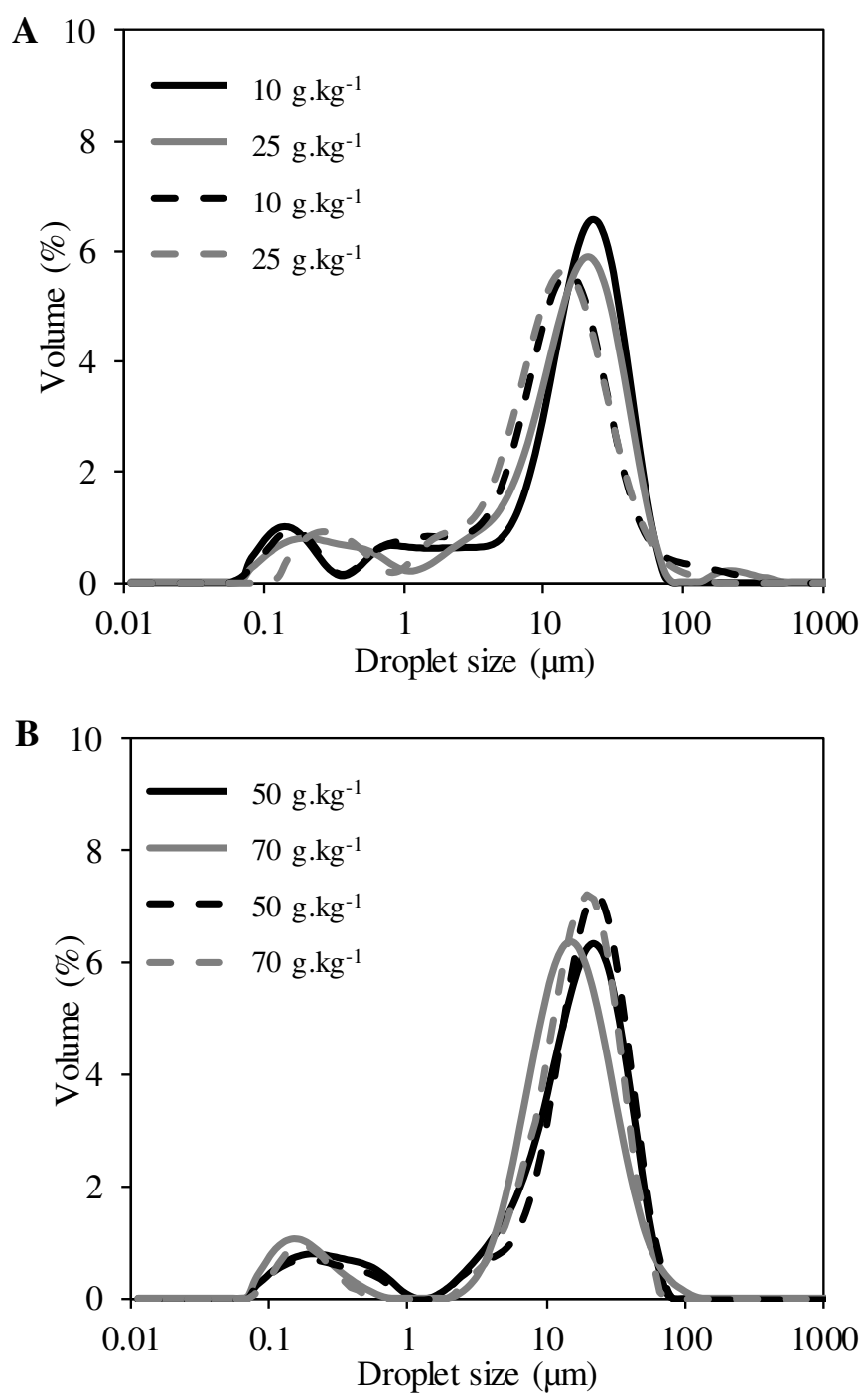

Figure 2.2. Droplet size distribution of fresh water-in-oil-in-water $\left(\mathrm{W}_{1} / \mathrm{O} / \mathrm{W}_{2}\right)$ double emulsions (solid line), and after 7 days (dashed line) of storage, prepared with different polyglycerol polyricinoleate (PGPR) concentrations in the oil phase: (A) 10 and $25 \mathrm{~g} \mathrm{~kg}^{-1}$, (B) 50 and $70 \mathrm{~g} \mathrm{~kg}^{-1}$.

There was a slight left-shift of the peak of double emulsions prepared with low PGPR concentrations after 7 days of storage at room temperature, which indicates a decrease in droplet diameter at these PGPR concentrations (Figure 2.2.A). This 
effect could possibly be due to the loss of the inner water droplets. The latter represents $25 \%$ of the volume of the oil droplets, meaning that, if this entire volume would be released to the outer aqueous phase, it would result in a $9 \%$-decrease in the oil droplet diameter.

\section{Morphology}

The morphology of double emulsions was studied by light microscopy, on fresh emulsions and emulsions after 7 days of storage (Figure 2.3). The inner water droplets could be clearly observed in the fresh emulsions (Figure 2.3.A,C,E,G). However, after 7 days of storage, those inner droplets were not clearly visible any more in the double emulsion with $10 \mathrm{~g} \mathrm{~kg}^{-1}$ PGPR (Figure 2.3.B). This suggests that the inner water droplets were not stable in this sample and that they were largely expelled to the external aqueous phase. A similar effect was observed, yet to a lower extent, in the double emulsions with $25 \mathrm{~g} \mathrm{~kg}^{-1}$ PGPR (Figure 2.3.D). These results could explain the left-shift of the main peak observed in the droplet size distribution of double emulsions prepared with low PGPR concentrations during storage (Figure 2.2.A). Conversely, the morphology of double emulsions with higher PGPR concentrations looked stable over storage (Figure 2.3.F,H). These results suggest that a certain minimum PGPR concentration is required to keep the inner water droplets stable along storage, even when no large osmotic pressure gradient is present. 


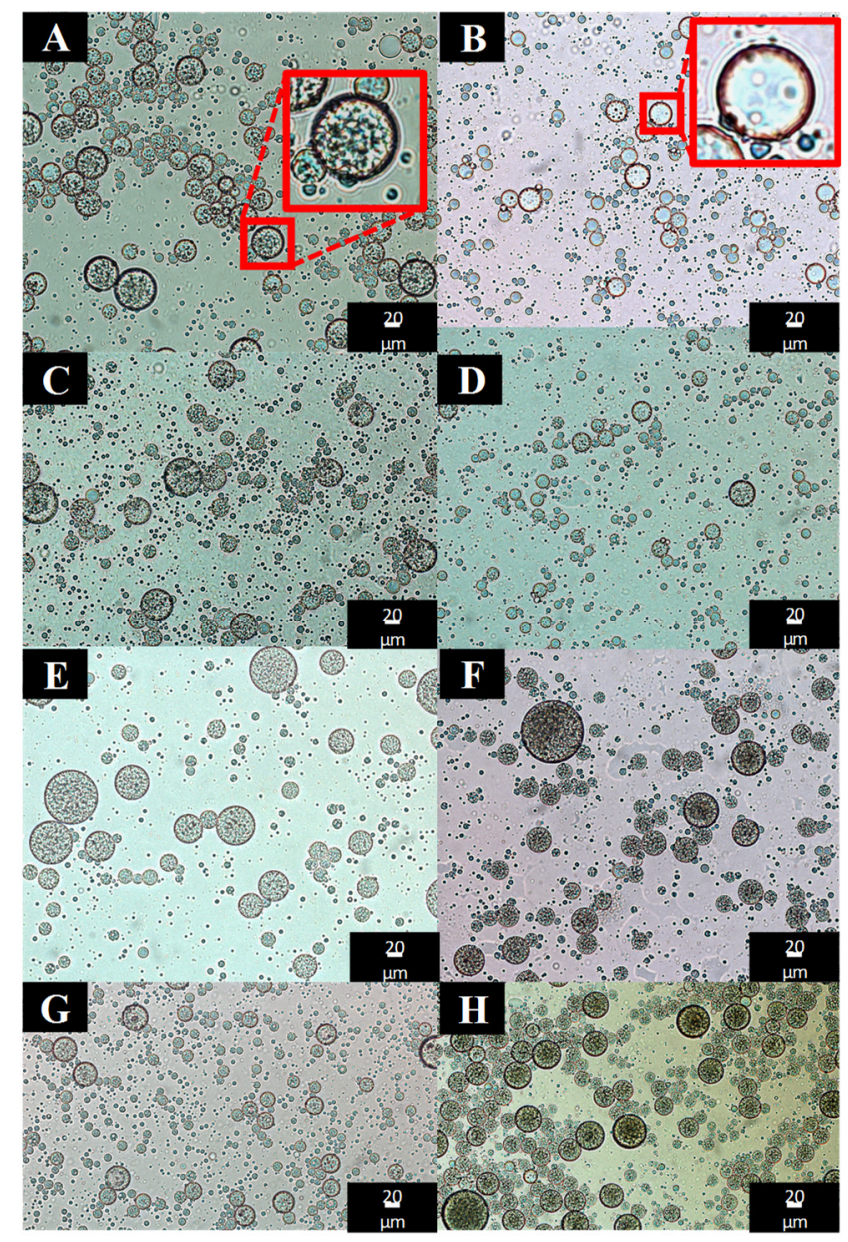

Figure 2.3. Microscopy images of water-in-oil-in-water $\left(\mathrm{W}_{1} / \mathrm{O} / \mathrm{W}_{2}\right)$ double emulsions freshly prepared (left) and after 7 days of storage (right) containing $10 \mathrm{~g} \mathrm{~kg}^{-1}$ PGPR (A, B), $25 \mathrm{~g} \mathrm{~kg}^{-1}$ PGPR (C, D), $50 \mathrm{~g} \mathrm{~kg}^{-1}$ PGPR (E, F) and $70 \mathrm{~g} \mathrm{~kg}^{-1}$ PGPR (G, H). On panels (A) and (B), the red squares show a magnification of typical droplets. 


\section{Encapsulation efficiency (EE)}

The EE value was determined in fresh double emulsions and after storage (Figure 2.4.A). All fresh double emulsions presented an EE between $88 \%$ and $96 \%$, depending on the PGPR concentration. After 1 day of storage, double emulsions prepared with $10 \mathrm{~g} \mathrm{~kg}^{-1}$ PGPR showed a decrease in the EE to 32\%, which further decreased to less than $10 \%$ after 7 days of storage. Double emulsions prepared with high PGPR concentrations (50 and $70 \mathrm{~g} \mathrm{~kg}^{-1}$ ) retained most of the iron encapsulated after 1 day. However, after 7 days of storage, the EE decreased to 50\% in these double emulsions. Therefore, it seems that low PGPR concentrations lead to rapid release of iron, but that beyond a certain PGPR concentration (here, $50 \mathrm{~g} \mathrm{~kg}^{-1}$ ) no further improvement can be achieved from an EE point of view. The pronounced release of iron in double emulsions prepared with low PGPR concentration after 7 days may be explained by sedimentation of larger water droplets within the oil droplets. Such a sedimentation would bring the water droplets closer to each other, and to the oil droplet surface, facilitating the release of water and iron to the external aqueous phase (Figure 2.4.B), which could explain the change in droplet morphology seen in Figure 2.3.A-D. Conversely, for high PGPR concentrations, we hypothesize that iron was predominantly released by reverse micelles, giving lower rates of iron release (Figure 2.4.C). Choi et al. (2009) described similar conclusions for iron transport in double emulsions prepared with $80 \mathrm{~g} \mathrm{~kg}^{-1}$ PGPR. The authors assumed that most of the water droplets remained within the oil droplets since there was no significant change in $d_{43}$ or in morphology over 7 days of storage. Therefore, most likely iron was transported by reverse micelles. In our work, we excluded the possibility of iron release due to insufficient coverage of the $\mathrm{W}_{1} / \mathrm{O}$ interface since for all PGPR concentrations there was largely enough emulsifier to cover all the water droplets. 


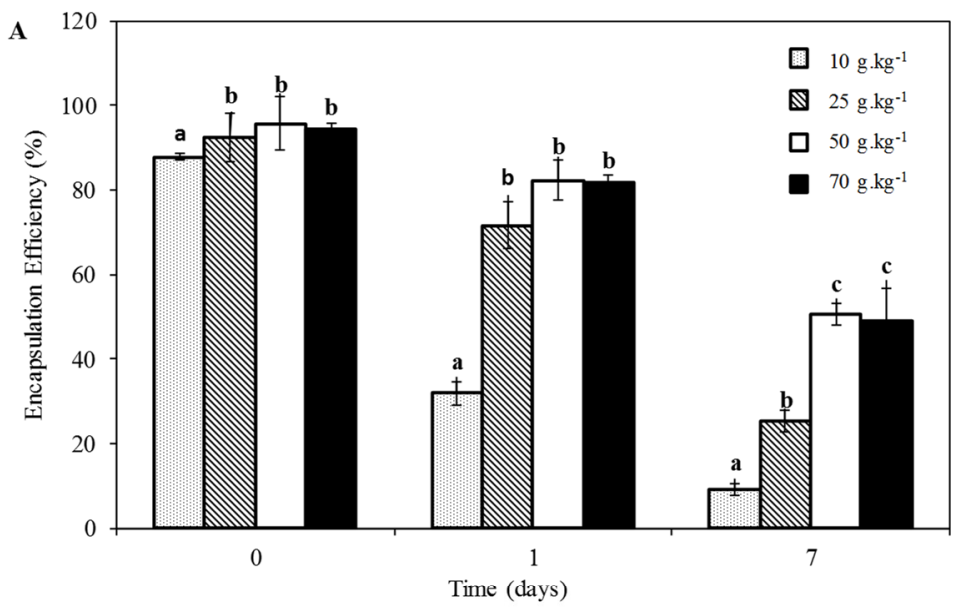

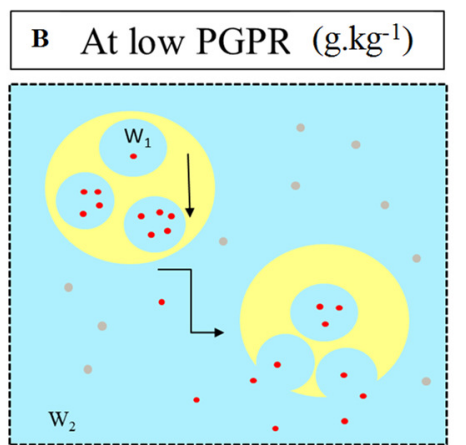

Coalescence $\mathrm{W}_{1}-\mathrm{W}_{2}$

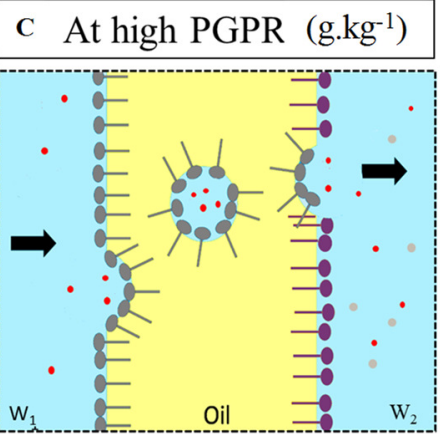

Reverse micelles

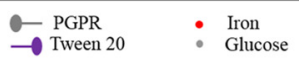

Figure 2.4. Encapsulation efficiency (\%) of water-in-oil-in-water $\left(\mathrm{W}_{1} / \mathrm{O} / \mathrm{W}_{2}\right)$ double emulsions prepared with different polyglycerol polyricinoleate (PGPR) concentrations in the oil phase, over storage time. Results are expressed as mean $(n=3)$ and standard deviation as error bars. Different letters means significant difference at $p<0.05$, within the same storage time (A). Proposed mechanisms of iron release in double emulsions stabilized with different PGPR concentrations. Iron release in double emulsions with low PGPR concentration (10-25 $\left.\mathrm{g} \mathrm{kg}^{-1}\right)$, mainly by the coalescence of the inner aqueous phase $\left(\mathrm{W}_{1}\right)$ with the external aqueous phase $\left(\mathrm{W}_{2}\right)(\mathrm{B})$. Iron release in double emulsions with high PGPR concentration (50-70 $\left.\mathrm{g} \mathrm{kg}^{-1}\right)$, mainly by the presence of reverse micelles in the oil phase $(\mathrm{C})$. 
To sum up, PGPR concentration can affect EE in double emulsions during storage via two effects: first, a minimal PGPR concentration is needed to ensure small enough water droplets that do not readily coalesce with the external aqueous phase. However, a too high a PGPR concentration is not recommended, as a large amount of reverse micelles in the oil phase can participate in releasing iron to the external aqueous phase.

\subsubsection{Chemical stability of $\mathrm{W}_{1} / \mathrm{O} / \mathrm{W}_{2}$ double emulsions: lipid oxidation}

The formation of primary lipid oxidation compounds was assessed by measuring $\mathrm{CD}$ hydroperoxides, and that of secondary lipid oxidation compounds by determining total aldehydes (pAV).

Lipid oxidation was first monitored in double emulsions without iron. In those emulsions, the initial $\mathrm{CD}$ hydroperoxide concentration was low, ranging from about 3 to $23 \mathrm{mmol} \mathrm{kg}^{-1}$ (Figure 2.5.B). Moreover, the pAV of these double emulsions (Figure 2.5.D) was very low, independently of the PGPR concentration. The CD hydroperoxide concentration in fresh sunflower oil was previously reported as 17.4 mmol equivalents CD hydroperoxides per kilogram of oil (Viau et al., 2016). The low $\mathrm{pAV}$ found was expected in the absence of iron, since iron can decompose CD hydroperoxides, which is the starting point for the formation of secondary lipid oxidation products (Chaiyasit et al., 2007). Overall, during storage, lipid oxidation in double emulsions without iron did not increase substantially PGPR concentrations at all.

The presence of iron in the water droplets increased the formation of $\mathrm{CD}$ hydroperoxides (29-39 $\mathrm{mmol} \mathrm{kg}^{-1}$ ) in fresh double emulsions compared to double emulsions without iron, independently of the PGPR concentration (Figure 2.5.A). The high CD hydroperoxide concentrations in fresh double emulsions with iron could indicate that lipid oxidation has already happened during the emulsification process. The incorporation of oxygen during the emulsification process has been reported to induce lipid oxidation (Berton-Carabin et al., 2014; Dridi et al., 2016). 
Despite the presence of natural antioxidants in the oil, we did not observe a lag phase of oxidation in double emulsions, both without and with iron.
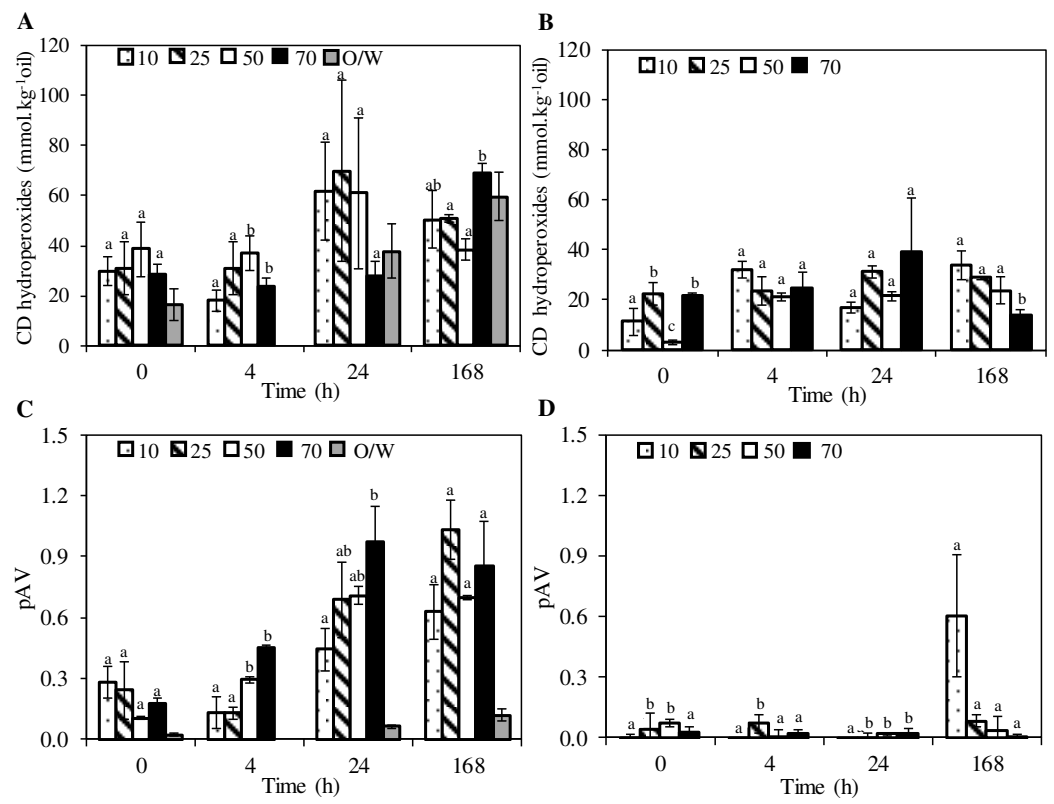

Figure 2.5. Lipid oxidation in double emulsions prepared with different polyglycerol polyricinoleate (PGPR) concentrations in the oil phase $\left(\mathrm{g} \mathrm{kg}^{-1}\right)$, and in a control oil-inwater $(\mathrm{O} / \mathrm{W})$ emulsion over $168 \mathrm{~h}$ storage at room temperature. Conjugated diene $(\mathrm{CD})$ hydroperoxides ( $\mathrm{mmol} \mathrm{kg}{ }^{-1}$ oil) in double emulsions and $\mathrm{O} / \mathrm{W}$ emulsion with iron (A) and without iron (B); para-anisidine value (pAV) in double emulsions and $\mathrm{O} / \mathrm{W}$ emulsion with iron (C) and without iron (D). Results are expressed as mean $(n=3)$ and standard deviation as error bars. Different letters mean significant difference at $p<0.05$, within the same storage time.

The formation of $\mathrm{CD}$ hydroperoxides was monitored over time in double emulsions with iron. After $4 \mathrm{~h}$ of storage, no substantial formation of $\mathrm{CD}$ hydroperoxides in double emulsions with iron could be detected, but after $24 \mathrm{~h}$ of storage CD hydroperoxide concentration increased significantly in double emulsions with 10 to $50 \mathrm{~g} \mathrm{~kg}^{-1}$ PGPR. Interestingly, at the highest PGPR concentration $\left(70 \mathrm{~g} \mathrm{~kg}^{-1}\right)$ the CD hydroperoxides only increased considerably after $168 \mathrm{~h}$ of storage. 
Nevertheless, there was no difference in the $\mathrm{pAV}$ in the fresh emulsions prepared with various PGPR concentrations (Figure 2.5.C). However, there was a more noticeable increase in pAV after $4 \mathrm{~h}$ of storage in double emulsions with higher PGPR concentrations (50 and $70 \mathrm{~g} \mathrm{~kg}^{-1}$ ) compared to double emulsions with lower PGPR concentrations, which continued to increase over time. At low PGPR concentrations, there was a significant increase only after $24 \mathrm{~h}$ of storage. For all double emulsions, the pAV seemed to level off after $24 \mathrm{~h}$ of storage.

The increase in lipid oxidation observed in our study was attributed to the presence of iron in the double emulsions, since it was substantially promoted compared to double emulsions with no iron. It is well known that the redox cycling of iron is a relevant mechanism to accelerate lipid oxidation. Ferrous iron $\left(\mathrm{Fe}^{2+}\right)$ in emulsion systems can accelerate the decomposition of pre-existing hydroperoxides, forming ferric iron $\left(\mathrm{Fe}^{3+}\right)$ and alkoxyl radicals. Furthermore, $\mathrm{Fe}^{3+}$ can further react with hydroperoxides to form $\mathrm{Fe}^{2+}$ and peroxyl radicals (Schaich, 1992). These radicals can react with unsaturated lipids within the droplet or at the interface, leading to the formation of new lipid radicals, thereby propagating lipid oxidation. Kristinova et al. (2014) described that the addition of $\mathrm{Fe}^{2+}$ to $\mathrm{O} / \mathrm{W}$ emulsions rapidly decreased the oxygen concentration compared to the addition of $\mathrm{Fe}^{3+}$, due to the fast rate of oxidation of $\mathrm{Fe}^{2+}$ to $\mathrm{Fe}^{3+}$ by pre-existing lipid hydroperoxides in the system. This can explain the fast decomposition of $\mathrm{CD}$ hydroperoxides seen for double emulsions with iron, followed by a level-off.

In addition, the structure of the emulsion can affect the prooxidant effect of iron. First, the emulsifier charge can affect iron location within the system. For instance, Mancuso et al. (2000) have shown that anionic surfactants attract iron ions to the droplet surface, increasing iron interaction with hydroperoxides. Second, surfactant micelles in the continuous phase may segregate iron and decrease lipid oxidation (Cho et al., 2002). In our study, we assume that at low PGPR concentration most of the iron was released to the external aqueous phase during storage, which may have 
minimized contact with hydroperoxides present in the oil. Conversely, at high PGPR concentrations most of the iron remained encapsulated over time (Figure 2.4.A), which promoted contact between iron and hydroperoxides. Third, the droplet size is also of importance: a larger interfacial area (smaller droplets) is often associated with a higher lipid oxidation rate due to an increased contact area between the oil and aqueous phase prooxidants. In our double emulsions, increasing PGPR concentration led to a substantial decrease of the inner water droplet size (Table 2), which resulted in a larger interfacial area. However, the effect of interfacial area and droplet size on oxidative stability is still contradictory in the literature and some studies have reported better oxidative stability in $\mathrm{O} / \mathrm{W}$ emulsions with smaller droplets (Berton-Carabin et al., 2014; Waraho et al., 2011). Therefore, there is evidence that the droplet size and interfacial area can affect lipid oxidation, but the mechanism of the reaction will depend on the emulsion composition.

To test the potential effect of iron release in the external aqueous phase on lipid oxidation, we prepared simple $\mathrm{O} / \mathrm{W}$ emulsions with iron present in the aqueous phase, to mimic a situation where all the inner water droplets would have been released to the external aqueous phase. We noticed that there was an increase in the formation of $\mathrm{CD}$ hydroperoxides over time (Figure 2.5.A), as much as for double emulsions with iron. Thus, the ability of iron to generate primary lipid oxidation products was found not only when present in the inner water droplets of the double emulsions but also when present in the external aqueous phase. However, the pAV in $\mathrm{O} / \mathrm{W}$ emulsions was lower than for all double emulsions containing iron. Therefore, we concluded that iron is less efficient at decomposing hydroperoxides into secondary oxidation products when diluted in the external aqueous phase than when concentrated in the inner water droplets. A previous study by Choi et al. (2009) also investigated the effect of iron location on lipid oxidation in a double emulsionbased system: the authors measured lipid oxidation in a simple fish $\mathrm{O} / \mathrm{W}$ emulsion, to which a double $\mathrm{W}_{1} / \mathrm{O} / \mathrm{W}_{2}$ emulsion containing iron, made with a less oxidizable oil (corn oil) was added. Surprisingly, they found that when iron was encapsulated in 
the inner droplets of the $W_{1} / O / W_{2}$ emulsion, i.e. separated from the $O / W$ fish oil droplets, the latter oxidized more than when iron was present in the external water phase, i.e. in direct contact with the fish oil droplets. Although no obvious explanation for this finding could be proposed, the authors hypothesized that corn oil itself could have oxidized because of the presence of iron in the inner water droplets, which could have catalysed the subsequent oxidation of the fish oil, although the latter was not in direct contact with iron.

Finally, it has also been described that surfactant micelles can remove hydroperoxides from the interface and limit lipid oxidation (Kristinova et al., 2014). Chen et al. (2012) described a reduction in the lag phase formation of lipid hydroperoxides in the presence of reverse micelles formed with phospholipids in bulk oil, which indicates the prooxidant activity of reverse micelles. Conversely, Yi et al. (2015) described that without iron, the oxidative stability of $\mathrm{W} / \mathrm{O}$ emulsions was improved at higher PGPR concentrations (3-10 $\mathrm{g} \mathrm{kg}^{-1}$ ), due to reverse micelles formed with nonadsorbed PGPR that removed hydroperoxides from the droplet surface. When iron $\left(\mathrm{Fe}^{2+}\right)$ was added to the $\mathrm{W} / \mathrm{O}$ emulsions the hydroperoxides decomposition went faster at lower PGPR concentrations, which supports the hypothesis of the partitioning of hydroperoxides into reverse micelles.

\subsection{Conclusions}

The present study investigated the physical and chemical stability of double emulsions containing iron in the inner water droplets. Regarding the physical stability, even a high PGPR concentration was not sufficient to fully prevent the release of iron to the external aqueous phase over storage. Yet increasing PGPR concentration did help in some respect, but only up to a certain concentration, above which no further increase in EE could be obtained. We hypothesized that the transport of iron was mostly due to the coalescence of the inner water droplets with the external aqueous phase at low PGPR concentration, and mostly due to transport via reverse micelles at high PGPR concentrations. The PGPR concentration also had an effect 
on lipid oxidation. The formation of $\mathrm{CD}$ hydroperoxides increased over time in all double emulsions, and pAV increased more substantially in double emulsions with $70 \mathrm{~g} \mathrm{~kg}^{-1}$ PGPR concentration. Double emulsions with high PGPR concentration had smaller water droplets, thus a larger interface area that probably promoted lipid oxidation. We conclude that from a physical stability perspective, a high PGPR concentration was enough to keep most of the iron encapsulated before 7 days of storage, after which the EE decreased. From a chemical stability perspective, all double emulsions were unstable. A higher PGPR concentration increased the formation of secondary lipid oxidation products. Therefore, we assumed that the physicochemical changes observed in these double emulsions certainly hamper their suitability as iron encapsulation systems. An optimal PGPR concentration needs to be combined with strategies to reduce iron lipid oxidation and increase EE. This could next be a basis to tailor a physicochemical stable $\mathrm{W}_{1} / \mathrm{O} / \mathrm{W}_{2}$ double emulsion for iron encapsulation.

\section{Acknowledgments}

The authors thank the Conselho Nacional de Desenvolvimento Científico e Tecnológico (CNPq/Brazil), for supporting P. Duque Estrada's PhD scholarship (process number 233663/2014-2). The authors are grateful to Jos Sewalt and Maurice Strubel for the support with the experimental work. 


\section{Appendix- supplementary information}

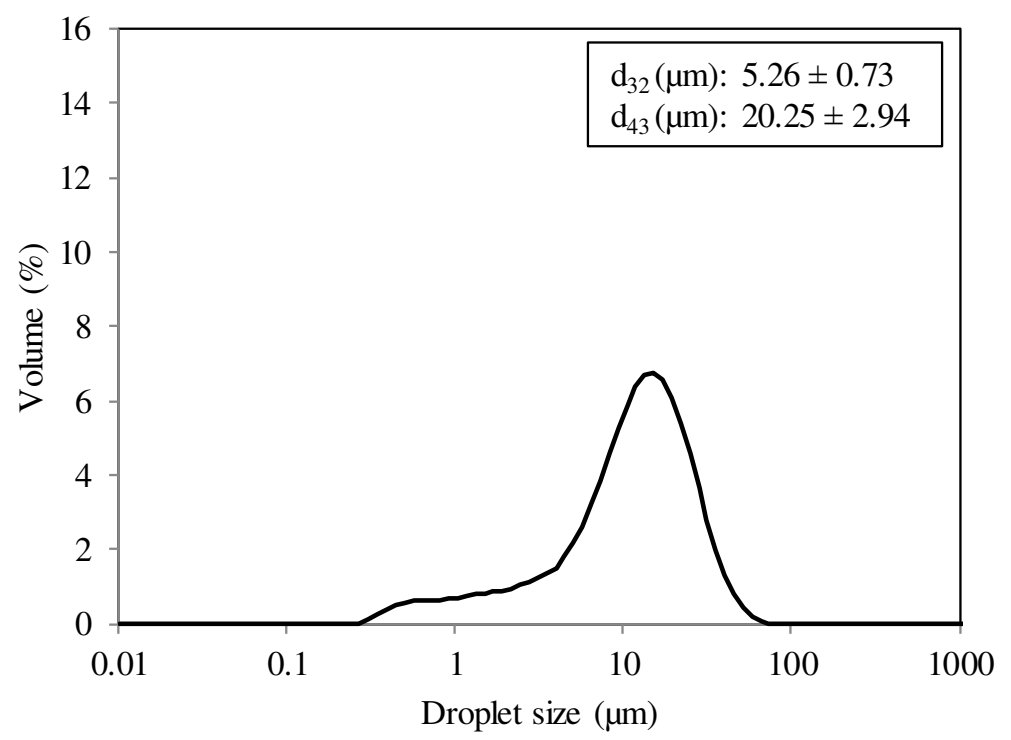

Figure 2.6. Droplet size distribution of fresh oil-in-water (O/W) emulsions with no polyglycerol polyricinoleate (PGPR), prepared with homogenization conditions similar to the second emulsification step for double emulsions (representative curve from measurements of three independent emulsions). 


\title{
Chapter 3
}

\author{
Protein oxidation in plant protein-based fibrous \\ products: effects of encapsulated iron and \\ process conditions
}

This chapter has been published as: Duque Estrada, P., Berton-Carabin, C.C., Schlangen, M., Haagsma, A., Pierucci, A.P.T.R .\& van der Goot, A.J. (2018). Protein oxidation in plant protein-based fibrous products: effects of encapsulated iron and process conditions. Journal of Agricultural and Food Chemistry, 66(42): 11105-11112. 


\begin{abstract}
Plant protein-based fibrous structures have recently attracted attention because of their potential as meat replacer formulations. It is, however, unclear how the process conditions and fortification with micronutrients may affect the chemical stability of such products. Therefore, we aimed to investigate the effects of process conditions and the incorporation of iron (free and encapsulated) on protein oxidation in a soy protein-based fibrous product. First, the physicochemical stability of iron-loaded pea protein particles, used as encapsulation systems, was investigated when exposed to 100 or $140{ }^{\circ} \mathrm{C}$. Second, protein oxidation was measured in the iron-fortified soy protein-based fibrous structures made at 100 or $140{ }^{\circ} \mathrm{C}$. Exposure to high temperatures increased the carbonyl content in pea protein particles. The incorporation of iron (free or encapsulated) did not affect carbonyl content in the fibrous product, but the process conditions for making such products induced the formation of carbonyls to a fairly high extent.
\end{abstract}




\subsection{Introduction}

Nowadays, there is a global trend to reduce meat consumption and move towards a more plant protein-based diet for environmental, health, and animal-welfare reasons (Graça et al., 2015). To help the population move towards such a transition, research has focused on developing products with fibrous structures similar to those in meat. At Wageningen University \& Research, a range of shearing devices have been developed to make fibrous structures using plant proteins by applying a simple shear flow and high temperatures $\left(100-140{ }^{\circ} \mathrm{C}\right)$ (Krintiras et al., 2014, 2015). Another technique widely applied to make meat analogues is extrusion. Here, materials are processed using a similar temperature range, giving this study potentially broader relevance. So far, most of this research has been done using soy protein ingredients (Dekkers et al., 2016; Grabowska et al., 2014; Grabowska et al., 2016). Although the structure formation in such fibrous products has already been well described, it is still unclear how the process conditions may affect the chemical stability and thus the sensory and nutritional quality of these products.

Oxidation is often associated with deterioration in food products (Zhang et al., 2013). Lipid oxidation in foods has been largely studied over the past decades, whereas protein oxidation has been considered to a much lower extent and mainly in meat (Lund et al., 2011). Protein oxidation results in a number of chemical modifications affecting both amino acid side chains and the peptide backbone. Such changes include thiol oxidation, aromatic hydroxylation, and formation of carbonyl groups (Armenteros et al., 2009; Davies, 2016). Moreover, oxidation can induce additional cross-links, backbone fragmentation, and conformational changes in the secondary and tertiary structure of the protein (Jongberg et al., 2011; Zhang et al., 2013). The formation of cross-links results in aggregation and reduces solubility (Luo \& Wehr, 2009; Soglia et al., 2016b; Stadman \& Levine, 2000). Despite the relevancy of such chemical modifications for food quality, protein oxidation in plant protein-based products is a rather new research topic that is now highly relevant given the increasing interest in the development and application of such products. 
In fact, it can be hypothesized that different factors may induce protein oxidation in plant protein-based fibrous structures: first, the process conditions, which often involves a thermomechanical process; and second, the incorporation of nutritionally relevant micronutrients, such as iron, which have a prooxidant activity. For instance, ferrous sulfate has commonly been used for food fortification because of its high bioavailability and low cost (Cayot et al., 2013), but its presence in food products can lead to lipid and protein oxidation. Besides, ferrous sulfate has an unpleasant metallic taste. To mitigate those undesirable effects, iron encapsulation could be a solution. Previous research has shown that encapsulating ferrous sulfate in pea protein spraydried particles is a promising method, considering the iron bioaccessibility (Bittencourt et al., 2013) and the potential to mask the metallic taste (Bittencourt et al., 2013; Ferreira et al., 2011). Moreover, the incorporation of such ferrous sulfate pea protein spray-dried particles (here referred to as iron-loaded pea protein particles) in cooked black beans (Ferreira et al., 2011) and in a banana candy (Bittencourt et al., 2013) showed good consumer acceptability. It should be noted, though, that the ironloaded pea protein particles were incorporated after the food was processed, which means that the iron-loaded pea protein particles were not exposed to further food process conditions. Therefore, it would be relevant to assess if additional processing can lead to undesirable chemical reactions, such as protein oxidation, when such particles are exposed to process conditions such as high temperatures, which can be necessary for making a food product.

In this work, we investigated protein oxidation in a plant protein-based fibrous product. We aimed to assess the effect of the process conditions used to make the fibrous product, and we quantified the effect of incorporation of iron-loaded pea protein particles on protein oxidation 


\subsection{Material and methods}

\subsubsection{Material}

Pea protein concentrate (PPC, $81 \%$ protein, $\mathrm{N} \times 6.25$ ) was obtained from Nutralys (S85F, Roquette). Soy protein concentrate (SPC, $63.20 \%$ protein, $\mathrm{N} \times 5.71$; Alpha 6 ZP) was obtained from Solae. Food-grade ferrous sulfate heptahydrate, 2-propanol, sodium chloride $(\mathrm{NaCl}, \mathrm{S} 9625)$, diaminoethane tetraacetic acid (EDTA), tris(hydroxymethyl) aminomethane (Tris), potassium chloride ( $\mathrm{KCl}$, 2,4dinitrophenylhydrazine (DNPH), trichloroacetic acid (TCA), sodium dodecyl sulfate (SDS), and guanidine hydrochloride $(\mathrm{CH} 5 \mathrm{~N} 3 \mathrm{HCl})$ were obtained from SigmaAldrich. Hydrochloric acid $(\mathrm{HCl}, 4 \mathrm{~N})$ was purchased from AVS Titrinorm (VWR Chemicals), and solvents such as ethanol (ACS 99\%) and ethyl acetate (ACS 99\%) were purchased from Emsure (Merck Millipore). A Bicinchoninic Acid (BCA) Protein Assay kit was obtained from Thermo Scientific (Pierce). Demineralized water was used to make the feed solution and to prepare the soy protein matrix. Ultrapure water obtained from a Millipore Milli-Q system was used for all the other experiments.

\subsubsection{Production of iron-loaded pea protein particles}

Iron-loaded pea protein particles were produced according to Bittencourt et al. (2013) with a few modifications. A feed solution (6.34\% solid content) with PPC as the wall material and ferrous sulfate heptahydrate as a core material was prepared. First, 10\% (w/v) PPC was slowly added to distilled water, and the $\mathrm{pH}$ was adjusted to 7.0 with $1 \mathrm{M} \mathrm{HCl}$. Then, the feed solution was heated to $80{ }^{\circ} \mathrm{C}$ for $30 \mathrm{~min}$ in a water bath. The feed solution was then homogenized with an IKA T18 Ultra-Turrax (Thermo Fisher Scientific, Inc.) at $8000 \mathrm{rpm}$ for $5 \mathrm{~min}$ and left overnight in a shaking water bath at $40{ }^{\circ} \mathrm{C}$ and $100 \mathrm{rpm}$. The next day, the feed solution was diluted to $9 \%$ $(\mathrm{w} / \mathrm{v}$ ) and homogenized at $9000 \mathrm{rpm}$ for $1.5 \mathrm{~min}$. The $\mathrm{pH}$ was adjusted to 6.5 with $1 \mathrm{M} \mathrm{HCl}$. A $1 \mathrm{M}$ ferrous sulfate solution was prepared with demineralized water and was slowly stirred in the feed solution to obtain a final concentration of $22.5 \mathrm{mM}$. Subsequently, the feed solution was homogenized at $9000 \mathrm{rpm}$ for $2 \mathrm{~min}$. A final 
dilution was made to $7 \%(\mathrm{w} / \mathrm{v})$ and stirred. The feed solution was then spray-dried using a Büchi B-290 Mini Spray Dryer (Büchi Labortechnik AG) with an inlet temperature of $180{ }^{\circ} \mathrm{C}$ and an outlet temperature of around $100{ }^{\circ} \mathrm{C}$. The aspirator was set at $90 \%$, the pump was set at $20 \%$, and the feed rate was $6 \mathrm{~mL} / \mathrm{min}$. The samples were stored in plastic vials in the dark and frozen prior to further analysis. Spray-dried particles without iron were prepared following the same procedures as described above, except that the ferrous sulfate solution was replaced with demineralized water. The yield defined as the ratio of solids in particles and solids in the feed solution was $54.5 \pm 2.4 \%$ for samples prepared with iron and $62.3 \pm 0.9 \%$ without iron.

\subsubsection{Exposure of iron-loaded pea protein particles to high temperatures}

Iron-loaded pea protein particles were exposed to different temperatures in a HeraTherm thermostat oven (Thermo Fisher Scientific, Inc.). Two grams of sample was evenly spread as a thin layer in an aluminum tin, after which the tin was put in the oven at 100 or $140{ }^{\circ} \mathrm{C}$ for $30 \mathrm{~min}$. These temperatures were chosen according to the temperatures applied to make plant protein-based fibrous products (Section: preparation of plant protein-based fibrous product). Pea protein particles samples without exposure to temperature were considered as controls. Afterward, the samples were analyzed for physicochemical characterization.

\subsubsection{Physical characterization of iron-loaded pea protein particles}

The morphology of the iron-loaded pea protein particles was analyzed by scanning electron microscopy (SEM). Samples were deposited on carbon conductive tape on aluminum SEM stubs and analyzed using a Phenom G2 Pure Semseo microscope (Thermo Fisher Scientific, Inc.). SEM pictures were analyzed with ImageJ software (version 1.40g, National Institutes of Health) to calculate the content of broken particles.

The particle-size distribution (PSD) was determined by a laser diffraction particlesize analyzer (Mastersizer 2000, Malvern Instruments Ltd.) using 2-propanol as the 
continuous phase, a particle refractive index of 1.45 , a particle-absorption index of 0.001 , and a dispersant refractive index of 1.39 . Samples were gently agitated to ensure homogeneity before measurements. Particles were analyzed for morphology and PSD just after spray-drying and after being exposed to temperature.

Iron retention in the particles was determined after spray-drying and after being exposed to temperature using inductively coupled plasma-optical-emission spectroscopy (ICP-OES, iCAP 6500 duo, Thermo Fisher Scientific, Inc.). First, 1\% $(\mathrm{w} / \mathrm{v})$ samples were suspended in $10 \mathrm{~mL}$ of aqua regia $(7.5 \mathrm{~mL}$ of $37 \% \mathrm{HCl}$ and 2.5 $\mathrm{mL}$ of $65 \% \mathrm{HNO} 3$ ), and the organic phase was digested in a microwave digestion system (Milestone Srl). After microwave digestion, the samples were diluted 200×. A calibration curve was prepared with an iron stock solution in aqua regia within a range that went up to $150 \mathrm{mg} / \mathrm{L}$. The samples were measured in the axial direction, and the wavelength of $240.88 \mathrm{~nm}$ was used for iron quantification. Iron retention was calculated with the following equation:

$$
\begin{aligned}
& \text { Iron retention }(\%)= \\
& \frac{\text { Iron content in pea protein particles }(\mathrm{g} \text { per } 100 \mathrm{~g} \text { solids })}{\text { Iron content in feed solution }(\mathrm{g} \text { per } 100 \mathrm{~g} \text { solids })} \times 100 \text { Eq. } 1
\end{aligned}
$$

\subsubsection{Preparation of a plant protein-based fibrous product}

The fibrous product was prepared using a high temperature shear cell (HTSC, Wageningen University \& Research) with SPC as the protein source. Samples were prepared with iron-loaded pea protein particles, with ferrous sulfate (considered free iron) solubilized in the water used to make the fibrous product, or without iron. The fibrous product was composed of $45 \mathrm{wt} \% \mathrm{SPC}, 54 \mathrm{wt} \%$ demi water, $1 \% \mathrm{NaCl}$, and $3.5 \mathrm{mg}$ of elemental iron per $100 \mathrm{~g}$ of product (except for the control with no iron). The iron content was based on $25 \%$ of the Nutrient Reference Value for female adults between 19 and 50 years, which is a high risk group for iron deficiency (Coad \& Conlon, 2011). Per run, $90 \mathrm{~g}$ of total weight were used. The model system was 
prepared according to Grabowska et al. (2014) at 100 or $140{ }^{\circ} \mathrm{C}$ and $30 \mathrm{rpm}$ for 15 min; this was followed by a 5 min cooling step at $25{ }^{\circ} \mathrm{C}$. After preparation, samples were prepared by cutting small pieces of $8 \mathrm{~mm}$ out of the product. The pieces were mixed to obtain a homogeneous distribution. Then, $9 \mathrm{~g}$ of samples were placed in a sous-vide bag and sealed using a V.300 Premium Line vacuum machine (Lava). Bags were placed in the oven at $35^{\circ} \mathrm{C}$ for accelerated storage-stability analysis and analyzed after 1 and 7 days.

\subsubsection{Quantification of protein-bound carbonyls: DNPH method}

We first measured the carbonyl contents in pea protein particles prepared with and without iron after exposure to 100 and $140{ }^{\circ} \mathrm{C}$. To investigate the effects of processing and iron incorporation, we quantified the carbonyl contents in fibrous products prepared with iron-loaded pea protein particles, with ferrous sulfate solution, or without iron. As a reference, the carbonyl content was measured in a 6 wt $\%$ protein suspension of PPC and SPC.

The carbonyl content was measured using the method described by Soglia et al. (2016b), with modifications to account for the low protein solubility of the samples (pea protein particles and fibrous products). Therefore, the samples were sequentially dispersed in buffers, which resulted in three different protein fractions: in fraction 1, the most soluble proteins were dissolved; in fraction 2, the salt-soluble proteins were dissolved; and in fraction 3, some less-soluble proteins were dissolved (Figure 3.1) (Soglia et al., 2016b).

The following procedure was applied to the pea protein particle samples. First, $2 \mathrm{~g}$ of sample was dispersed in $20 \mathrm{~mL}$ of buffer $1(100 \mathrm{mM}$ Tris and $5 \mathrm{mM}$ EDTA, $\mathrm{pH}$ 7.5) and left stirring overnight at $300 \mathrm{rpm}$ at $4{ }^{\circ} \mathrm{C}$. The samples were then centrifuged at $18000 \mathrm{~g}$ at $2{ }^{\circ} \mathrm{C}$ for $20 \mathrm{~min}$ (Sorval Lynx 4000, Thermo Fisher Scientific, Inc.). The supernatant was collected as protein fraction 1. Next, buffer $2(100 \mathrm{mM}$ Tris, $50 \mathrm{mM}$ $\mathrm{NaCl}$, and $5 \mathrm{mM}$ EDTA; $\mathrm{pH} 7.5)$ was added to the pellet (1:3, w/v) and vortexed for $30 \mathrm{~s}$ at $2500 \mathrm{rpm}$. The homogenate was centrifuged at $18000 \mathrm{~g}$ at $2{ }^{\circ} \mathrm{C}$ for $20 \mathrm{~min}$. 
The supernatant was collected as protein fraction 2. Further, $0.15 \mathrm{M} \mathrm{KCl}$ solution was added to the pellet $(1: 3, \mathrm{w} / \mathrm{v})$ and homogenized as described before, forming a suspension that constituted protein fraction 3 .

For the fibrous product, $9 \mathrm{~g}(9.5 \%, \mathrm{w} / \mathrm{v}$, protein) of sample was homogenized with buffer $1(1: 3, \mathrm{w} / \mathrm{v})$ using an Ultra Turrax at $13600 \mathrm{rpm}$ for $1 \mathrm{~min}$ in an ice bath. Samples meant to determine the effect of 7 days of storage were taken 1 day before measurement and soaked in buffer 1 at $4{ }^{\circ} \mathrm{C}$ overnight. The dispersion was centrifuged at $18000 \mathrm{~g}$ at $2{ }^{\circ} \mathrm{C}$ for $20 \mathrm{~min}$. The supernatant collected was protein fraction 1 . Next, buffer $2(1: 3, \mathrm{w} / \mathrm{v})$ was added to the pellet and homogenized at 13 $600 \mathrm{rpm}$ for $30 \mathrm{~s}$ in an ice bath. Afterward, the sample was centrifuged as described before. The supernatant was collected as protein fraction 2. Further, $0.15 \mathrm{M} \mathrm{KCl}$ solution was added to the pellet (1:3, w/v) and homogenized as described before, forming a suspension that constituted protein fraction 3 .

We attempted to accordingly analyze those three protein fractions from pea protein particles and fibrous product suspensions. However, the soluble-protein concentration was less than $1 \mathrm{~g} / \mathrm{L}$ in protein fraction 3 for pea protein particles and in protein fraction 2 for fibrous products. For this reason, for the quantification of protein-bound carbonyls, only protein fractions 1 and 2 were considered for pea protein particles, and only protein fractions 1 and 3 were considered for fibrous products. The soluble-protein concentration was determined in each fraction by the BCA method. Protein fractions were filtered with a $0.22 \mu \mathrm{m}$ syringe filter (Millex PES, Merck Millipore). Then, $1 \mathrm{~mL}$ of working reagent (50:1 reagent A/B) was added to $50 \mu \mathrm{L}$ samples, which were incubated in a Thermomix at $37^{\circ} \mathrm{C}$ and $300 \mathrm{rpm}$ for $30 \mathrm{~min}$. After incubation, the samples were cooled down and kept at $4{ }^{\circ} \mathrm{C}$ for $5 \mathrm{~min}$ and at room temperature for $10 \mathrm{~min}$. Calibration curves ( 0 to $1 \mathrm{~g} / \mathrm{L}$ ) with bovine serum albumin were prepared in the buffers used to separate the protein fractions and were prepared under the same conditions as the samples. Then, the absorbance was measured at $562 \mathrm{~nm}$ with a UV-visible spectrophotometer (HACH Lange DR 
3900) in polystyrene cuvettes. To calculate the percentage of soluble-protein concentration in each fraction, we assumed that all proteins in the fibrous product and pea particles were solubilized (Figure 3.1).

The carbonyl content was determined with the DNPH method adapted from Soglia et al. (2016b), Vuorela et al. (2005) and Levine et al. (1990). First, $0.8 \mathrm{~mL}$ of protein fraction 1 or $1 \mathrm{~mL}$ of protein fraction 2 from pea protein particle samples were precipitated with $40 \%$ TCA $(1: 1, \mathrm{v} / \mathrm{v})$. For the fibrous product, $1 \mathrm{~mL}$ of protein fractions 1 and 3 were precipitated with 20\% TCA (1:1, v/v). Then, the samples were centrifuged at $15000 \mathrm{~g}$ for $5 \mathrm{~min}$. The supernatant was removed with a Pasteur pipet, and $400 \mu \mathrm{L}$ of $5 \%(\mathrm{w} / \mathrm{v})$ SDS was added to the pellet. The samples were heated in a thermomixer (Eppendorf ThermoMixer C and Grant QBT4) at $99{ }^{\circ} \mathrm{C}$ for $10 \mathrm{~min}$ and then put in an ultrasonic bath (Elmasonic $\mathrm{P}$ and Branson 5210, Elma) at $40{ }^{\circ} \mathrm{C}$ for $30 \mathrm{~min}$ at $80 \mathrm{kHz}$ with $90 \%$ sweep. Afterward, $0.8 \mathrm{~mL}$ of $0.3 \%$ (w/v) DNPH in $3 \mathrm{M} \mathrm{HCl}$ was added to the samples, and $0.8 \mathrm{~mL}$ of $3 \mathrm{M} \mathrm{HCl}$ was added to the blanks. Then, the samples were incubated at room temperature in the dark for $60 \mathrm{~min}$ and vortexed at $2500 \mathrm{rpm}$ for $5 \mathrm{~s}$ every $10 \mathrm{~min}$. After incubation, $400 \mu \mathrm{L}$ of $40 \%$ (w/v) TCA was added to precipitate the proteins, and the samples were centrifuged at 15 $000 \mathrm{~g}$ for $5 \mathrm{~min}$. The supernatant was removed, and the samples were washed three times with $1 \mathrm{~mL}$ of ethanol/ethyl acetate (1:1) and centrifuged at $15000 \mathrm{~g}$ for $5 \mathrm{~min}$ every time. After the washing steps, the pellet was dissolved in $1.5 \mathrm{~mL}$ of $6 \mathrm{M}$ guanidine hydrochloride and vortexed at $2500 \mathrm{rpm}$ for $5 \mathrm{~s}$. Samples were incubated in a thermomixer at $37^{\circ} \mathrm{C}$ overnight.

Then, the samples were centrifuged at $5000 \mathrm{~g}$ for $10 \mathrm{~min}$, and the absorbance of the supernatant was measured at $370 \mathrm{~nm}$ using a UV-visible spectrophotometer and polystyrene cuvettes. Samples with absorbance outside the range of $0.12-0.55$ were diluted in $6 \mathrm{M}$ guanidine hydrochloride. The soluble-protein concentration in $6 \mathrm{M}$ guanidine hydrochloride was determined by the BCA method, as described previously. The carbonyl content was calculated with the following equation: 


$$
\text { Carbonyls }\left(\frac{\mathrm{mmol}}{\mathrm{kg}}\right)=\frac{\frac{\left(A B S_{\text {sample }}-A B S_{\text {blank }}\right)}{\varepsilon}}{\text { Soluble protein concentration }} \text { Eq. } 2
$$

where $\mathrm{ABS}$ is the absorbance of the sample and of the blank at $370 \mathrm{~nm}$, and $\varepsilon$ is the molar absorptivity coefficient of carbonyls, set as $22000 \mathrm{M}^{-1} \mathrm{~cm}^{-1}$.
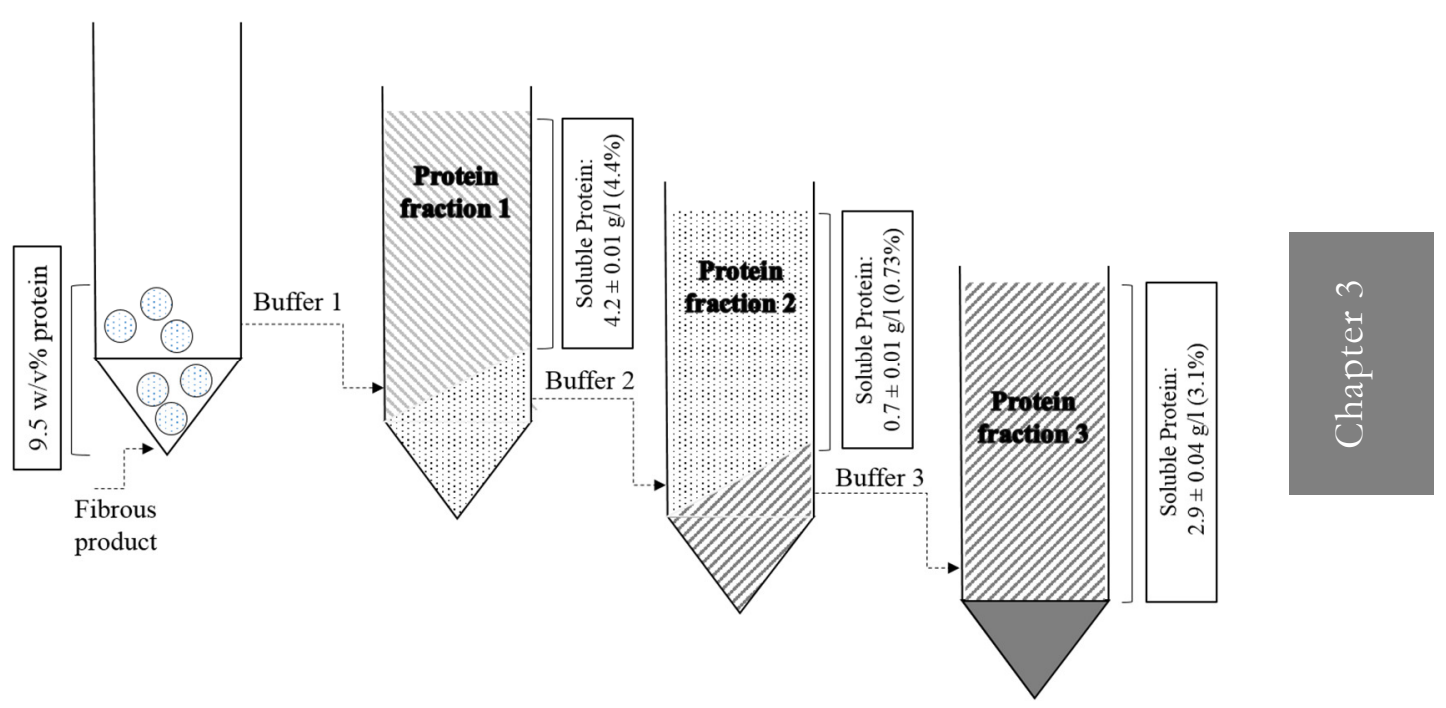

Figure 3.1. Schematic representation of the separation of protein fractions from fibrous product and average soluble-protein concentrations $(\mathrm{g} / \mathrm{L})$ per supernatant.

\subsubsection{Statistical Analysis}

Pea protein particle samples were prepared in duplicates. Samples exposed to temperatures were prepared in duplicate and used immediately. The sample was measured twice with an average of three readings from the Mastersizer to determined the particle-size distribution. Fibrous products were prepared in duplicates, and the DNPH method was done in triplicate per sample and per blank. The BCA assay was done in triplicate. Statistical analysis was done using the Statistical Package for the Social Sciences (SPSS software v. 23, IBM Inc.). Analysis of variance (ANOVA) with a post hoc Turkey test was performed to compare means of particle-diameter sizes from pea protein particle samples treated at different temperatures and to compare means of carbonyl contents (those of pea protein particles and the fibrous product) 
between samples. The one-sample $t$ test was performed to compare the means of samples prepared with and without iron exposed to the same temperature $(p<0.05)$.

\subsection{Results and discussion}

In this section, the properties of pea protein particles obtained after spray-drying are first characterized, followed by a description of the chemical stability of the particles. Then, the effect of particle addition to the fibrous product and the effect of thermal treatment on protein oxidation are presented and discussed.

\subsubsection{Characterization of iron-loaded pea protein particles}

The iron retention of the iron-loaded pea protein particles after spray-drying and exposure to 100 and $140{ }^{\circ} \mathrm{C}$ were $59.86 \pm 0.91,61.45 \pm 0.5$, and $61.71 \pm 0.58 \%$, respectively. Our iron-retention results were lower than the value of $67 \%$ described by Ferreira (2014) but higher than the value of $43.9 \%$ described by Bittencourt et al. (2013) The differences are probably due to adaptations in the spray-drying settings.

The morphology of iron-loaded pea protein particles was monitored just after particle preparation and after exposure to 100 and $140{ }^{\circ} \mathrm{C}$ for $30 \mathrm{~min}$ (Figure 3.2). Iron-loaded pea protein particles presented more invaginations, were less spherical, and had smoother surfaces compared with pea protein particles without iron. 


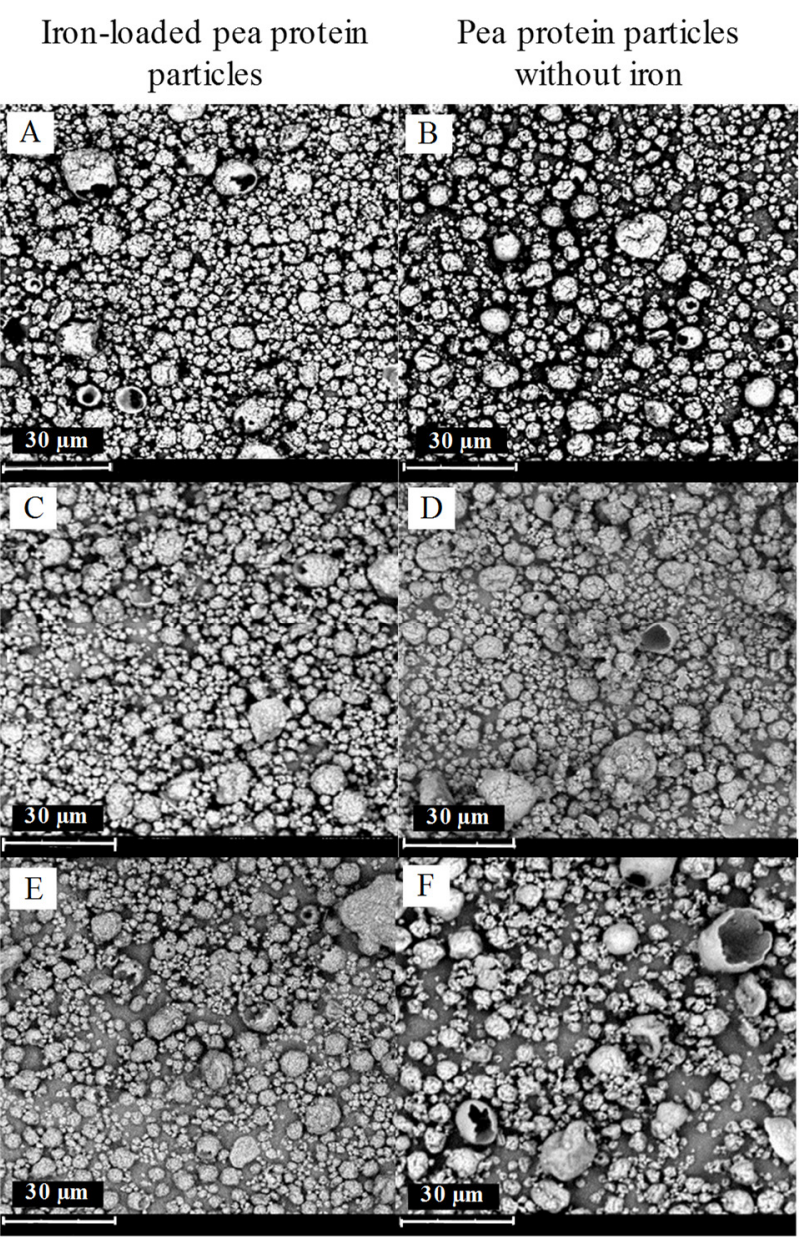

Figure 3.2. Scanning electron micrographs of pea protein particles with $(A, C, E)$ and without iron $(\mathrm{B}, \mathrm{D}, \mathrm{F})$ after spray-drying $(\mathrm{A}, \mathrm{B})$, after exposure to $100^{\circ} \mathrm{C}(\mathrm{C}, \mathrm{D})$, and after exposure to $140{ }^{\circ} \mathrm{C}(\mathrm{E}, \mathrm{F})$ for $30 \mathrm{~min}$. The magnification is $2500 \times$.

Pea protein particles exposed to 100 and $140^{\circ} \mathrm{Clooked} \mathrm{more} \mathrm{broken} \mathrm{than} \mathrm{the} \mathrm{control}$ samples. The roughness and invaginations found in our pea protein particles have been described by other authors as typical for particles made with PPC as encapsulation material (Costa et al., 2015; Pierucci et al., 2007). The authors argued that a high protein content can produce spray-dried particles with less invagination, suggesting that the presence of carbohydrates in protein concentrates can result in 
more invaginations. In the present work, we can see that the presence of iron also affected the particle morphology.

Directly after spray-drying, the PSD of pea proteins particles with and without iron (Figure 3.3.A) showed 3 peaks around 1, 0.18, and $10 \mu \mathrm{m}$. This result shows that pea protein particles were polydisperse, independent of the presence of iron. After exposure to high temperature, larger particle sizes were measured (Figure 3.3.B,C). Especially in case of iron-loaded pea protein particles, aggregation was observed after heating at $140{ }^{\circ} \mathrm{C}$. Several physical and chemical mechanisms, including protein oxidation induced by iron and heat, could cause protein aggregation seen in Figure 3.3.C. The average particles sizes, $\mathrm{d}_{32}$, of iron-loaded pea protein particles exposed to $140{ }^{\circ} \mathrm{C}(1.69 \pm 0.17 \mu \mathrm{m})$ or $100{ }^{\circ} \mathrm{C}(0.78 \pm 0.32 \mu \mathrm{m})$ were larger than that of the sample not exposed to heat $(0.37 \pm 0.03 \mu \mathrm{m})$. The span values also showed an increase in polydispersibility from $8.33 \pm 0.14$ (no heat) to $35.84 \pm 14.38$ (iron-loaded pea protein particles at $140{ }^{\circ} \mathrm{C}$ ). 

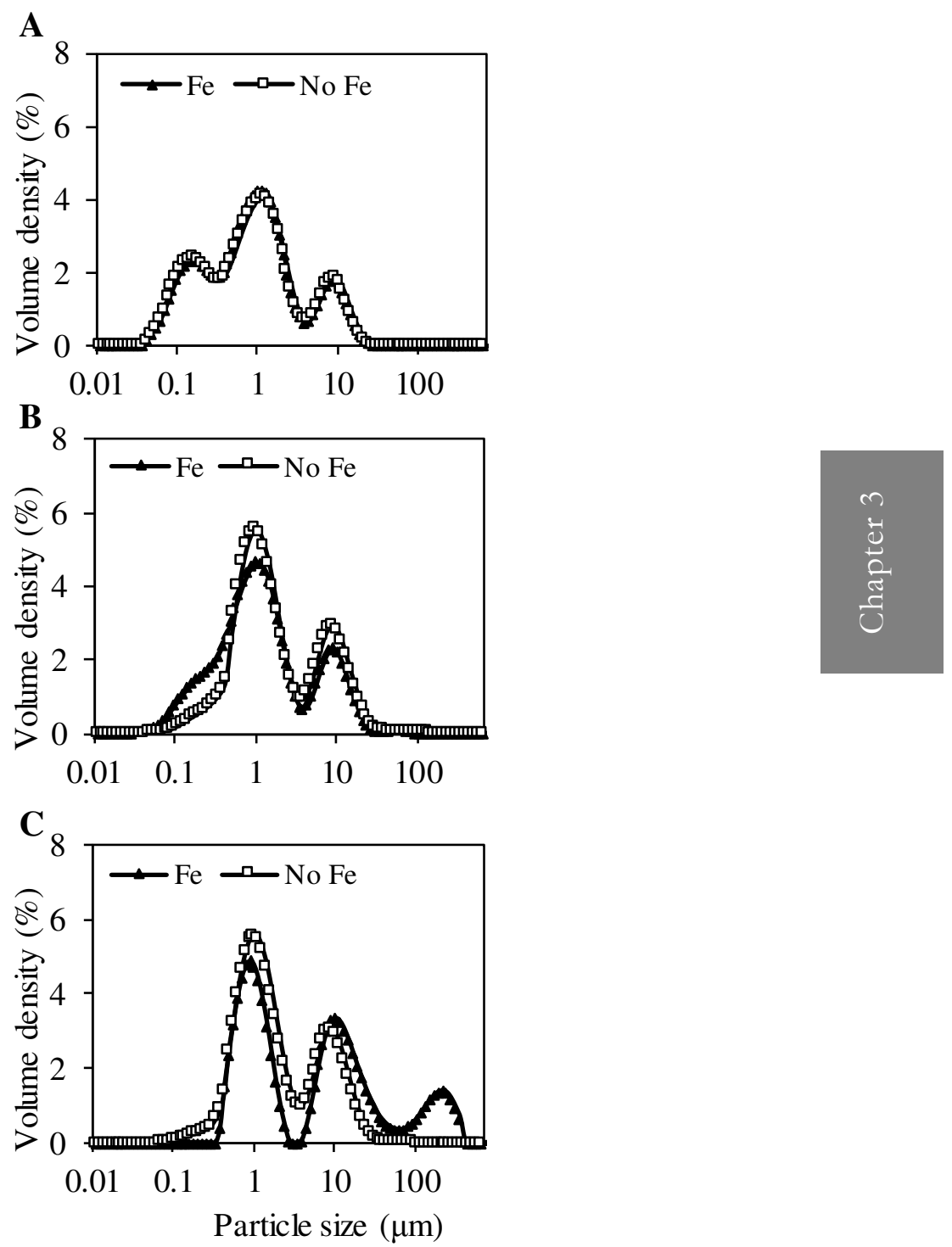

Figure 3.3. Particle-size distribution of pea protein particles prepared with and without iron just after spray-drying (A) and after exposure to $100^{\circ} \mathrm{C}(\mathrm{B})$ and $140{ }^{\circ} \mathrm{C}(\mathrm{C})$ for 30 min. For clarity, only one representative curve is shown per sample, but similar trends were observed for the replicates $(n=2$ independent replicates, 2 measurements per sample). 


\subsubsection{Chemical characterization of iron-loaded pea protein particles: protein} oxidation

Carbonyl content was determined as a measure of protein oxidation to assess the chemical stability of iron-loaded pea protein particles being exposed to 140 and 100 ${ }^{\circ} \mathrm{C}$ for $30 \mathrm{~min}$ (Figure 3.4.A,B). Here, we present the results of carbonyl contents in protein fractions 1 and 2 only, because the soluble-protein concentration was too low in fraction 3 .

In both protein fractions (Figure 3.4.A,B), the carbonyl content was higher after spray-drying than in the starting PPC suspension: for the latter, values of about 12.7 mmol of carbonyl per kilogram of soluble protein (protein fraction 1) and $9.7 \mathrm{mmol}$ of carbonyl per kilogram of soluble protein (protein fraction 2) were obtained, represented as dotted lines in graphs Figure 3.4.A,B. After exposure of the pea protein particles to high temperature $\left(100\right.$ or $140{ }^{\circ} \mathrm{C}$ for $\left.30 \mathrm{~min}\right)$, there was an increase in carbonyl contents for both protein fractions, without significant differences between the heat treatments (Figure 3.4.A). The presence of iron in the pea protein particles clearly decreased protein solubility, which in fact could be due to protein aggregation as a result of protein oxidation. However, we could not see any increase in carbonyl content compared with that of the pea protein particles without iron. Considering that only a small fraction of the protein in the iron-loaded pea protein particles was soluble in guanidine hydrochloride, most probably there were more carbonyls formed than in particles without iron. For protein fraction 2, iron-loaded pea protein particles exposed to $140{ }^{\circ} \mathrm{C}$ had a significantly higher carbonyl content compared with those of the samples exposed to $100{ }^{\circ} \mathrm{C}$ and the control (Figure 3.4.B). However, there was no effect of temperature on carbonyl content for the pea protein particles without iron.

Protein oxidation values for iron-loaded pea protein particles were only significantly different from those of the pea protein particles without iron in protein fraction 2 at $140^{\circ} \mathrm{C}$. 
A

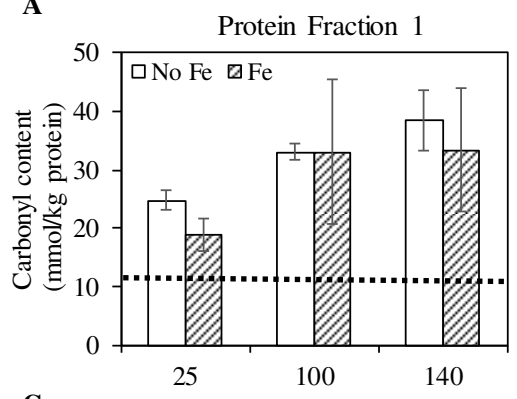

C

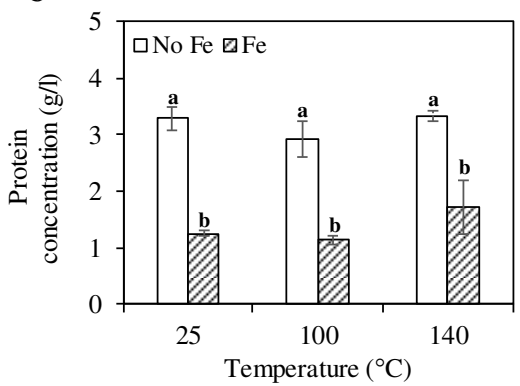

B

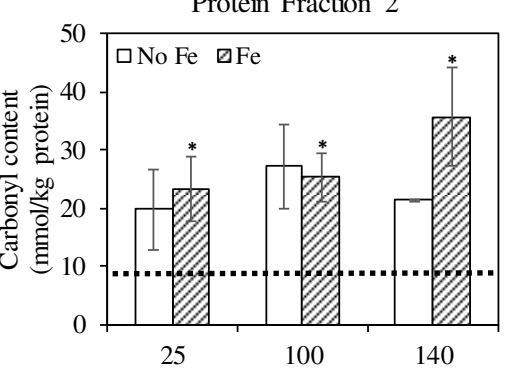

D

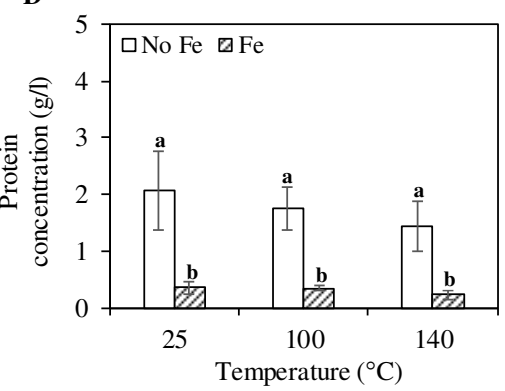

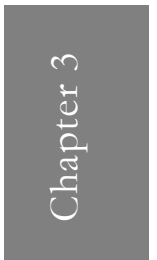

Figure 3.4. Carbonyl contents ( $\mathrm{mmol}$ per kilogram of soluble protein) and solubleprotein concentrations $(\mathrm{g} / \mathrm{L})$ in $6 \mathrm{M}$ guanidine hydrochloride for the iron-loaded pea protein particles (Fe, dashed bars) and the control without iron (No Fe, white bars). (A) Carbonyl content in protein fraction 1, (B) carbonyl content in protein fraction 2, (C) soluble-protein concentration in protein fraction 1, and (D) soluble-protein concentration in protein fraction 2. The dotted line represents the carbonyl content for the starting PPC suspension. Results are expressed as means, and error bars are standard deviations. A significant difference $(p<0.05)$ at different temperatures for each sample is expressed with an asterisk $\left(^{*}\right)$. Different letters mean significant differences $(p<0.05)$ between samples with iron and without iron.

As described above, spray-drying temperature $\left(180^{\circ} \mathrm{C}\right)$ alone induced protein oxidation in the PPC used as a wall material to encapsulate the iron. Costa (2014) showed that spray-drying reduced free sulfhydryl contents in pea protein isolates, which could be an indication of protein oxidation. Comparable to our findings, Tang et al. (2012) described a similar increase in carbonyl content when heating soy proteins at $100{ }^{\circ} \mathrm{C}$ for $30-90$ min compared with that of the no-heat treatment. However, the values found were much lower than ours: $\sim 3 \mathrm{mmol}$ of carbonyl per 
kilogram of soluble protein for proteins not heated and $\sim 6 \mathrm{mmol}$ of carbonyl per kilogram of soluble protein for soy proteins heated for $90 \mathrm{~min}$. In our study, PPC itself was already oxidized and then exposed first to the spray-drying temperature and later to further heat treatment, which also increased protein oxidation.

These results showed that spray-drying leads to less chemically stable iron-loaded pea protein particles and that the presence of iron reduces the soluble-pea protein concentration. Some improvement might be necessary to increase the particles' oxidative stability; the chemical status of the starting protein material also seems important because the PPC powder was already oxidized, which indicates that protein oxidation started either during the protein fractionation process or during storage of the powders.

\subsubsection{Chemical stability of fibrous products with iron incorporation: protein} oxidation

Plant protein-based fibrous products prepared with a HTSC at different temperatures were used as model products to study fortification with iron either as free iron or as encapsulated iron (iron-loaded pea protein particles), as described in the previous sections. Sequential suspensions of the fibrous products were prepared in different buffers, and three protein fractions were obtained. Protein fractions 1 and $3 \mathrm{had}$ more soluble proteins than fraction 2, and for this reason, carbonyl contents were only measured in fractions 1 and 3.

Figure 3.5 shows the carbonyl contents in protein fractions 1 and 3 of fibrous products prepared at 100 or $140{ }^{\circ} \mathrm{C}$. The presence and form of iron (free versus encapsulated) did not seem to substantially affect carbonyl formation in the fibrous product: the only significant difference was found in protein fraction 1 with samples prepared at $140{ }^{\circ} \mathrm{C}$. 


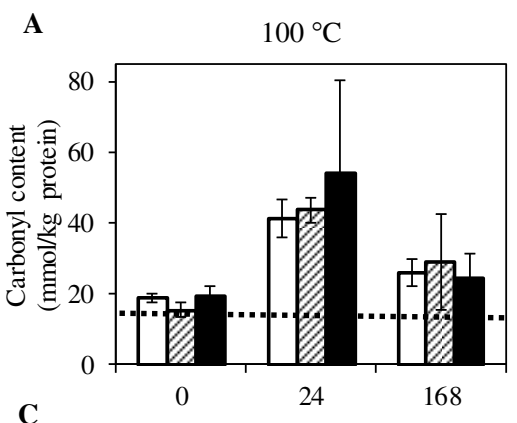

B

$140{ }^{\circ} \mathrm{C}$

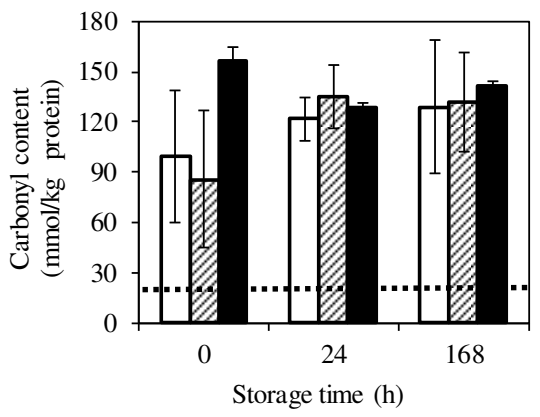

D
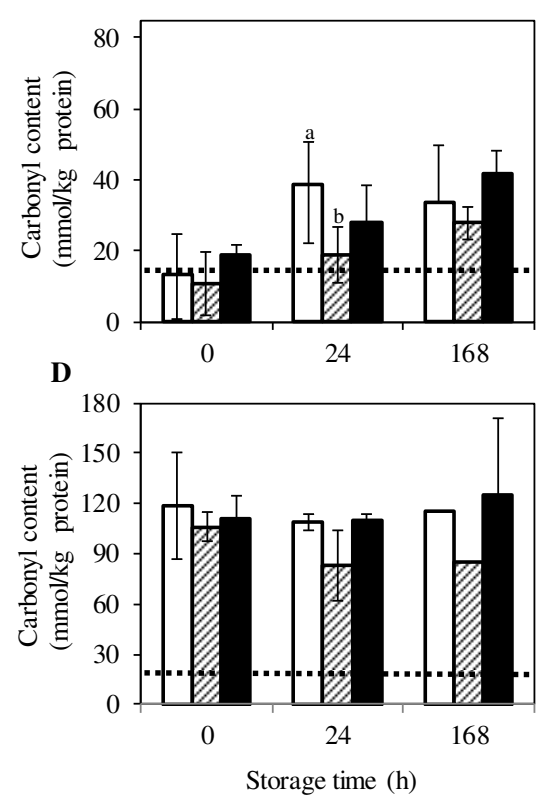

口No Fe

$\mathrm{BFe}$

- Fe-pea protein particles

$\square \mathrm{No} \mathrm{Fe}$

$\square \mathrm{Fe}$

- Fe-pea protein particles

Figure 3.5. Carbonyl content ( $\mathrm{mmol} / \mathrm{kg}$ soluble protein) in protein fractions 1 and 3 of fibrous products prepared at 100 and $140{ }^{\circ} \mathrm{C}$ at $30 \mathrm{rpm}$ for $15 \mathrm{~min}$. Samples were prepared with no iron (No Fe, white bars), free iron (Fe, dashed bars), or iron-loaded pea protein particles ( $\mathrm{Fe}-$ pea protein particles, black bars). (A) Protein fraction 1 at $100{ }^{\circ} \mathrm{C}$, (B) protein fraction 1 at $140{ }^{\circ} \mathrm{C}$, (C) protein fraction 3 at $100{ }^{\circ} \mathrm{C}$, and (D) protein fraction 3 at $140{ }^{\circ} \mathrm{C}$. The dotted line represents the carbonyl content for the starting SPC suspension. Results are expressed as means, and error bars are standard deviations ( $\mathrm{n}=$ 2 independent replicates, 3 measurements per sample). Different letters indicate significant differences between samples within the same storage time. The data series that do not include letters did not show any significant differences $(p<0.05)$.

Carbonyl content increased significantly over storage time (up to $168 \mathrm{~h}$ ) in protein fraction 1 of the samples prepared without iron (only at $100{ }^{\circ} \mathrm{C}$ ) and with encapsulated iron (at both temperatures). The effect of temperature was only 
pronounced in protein fraction 1 for samples prepared with encapsulated iron after $24 \mathrm{~h}$ of storage.

Protein fraction 3 showed higher carbonyl contents compared with those of protein fraction 1 of samples prepared at both temperatures. Our results show that the process used to make the fibrous products increased carbonyl content in this fraction for both temperatures tested. Interestingly, protein oxidation did not increase with the incorporation of free or encapsulated iron into the product. This result was not expected, because studies have shown that even low iron concentrations can increase protein oxidation in meat, especially after heat treatment (Promeyrat et al., 2011). As an example, Promeyrat et al. (2013) showed that heat treatment $\left(45-90^{\circ} \mathrm{C}\right)$ affected carbonyl contents in myofibrillar protein suspensions only weakly. However, in the presence of heat and a mix of prooxidants (iron, hydrogen peroxide, and ascorbate) there was a synergistic effect on oxidation. In this study, iron was applied without such synergistic prooxidant components, which suggested that iron alone is not a powerful prooxidant in these fibrous plant protein-based products. Besides, carbonyls are often measured in only one protein fraction using a salt rich buffer $(\mathrm{NaCl}$ or $\mathrm{KCl})$ to allow for the extraction of myofibrillar proteins in meat products.

The chemical status of the starting plant protein ingredient and the effect of processing on protein oxidation in fibrous products were determined via the carbonyl content in the commercial SPC powder (6 wt \% protein suspension). We observed that all fibrous products had higher carbonyl contents than the SPC suspension: the latter showed values about $15 \mathrm{mmol}$ of carbonyl per kilogram of soluble protein for protein fraction 1 and $20 \mathrm{mmol}$ of carbonyl per kilogram of soluble protein for protein fraction 3. For protein fraction 1 at day 0 , all samples had similar carbonyl contents compared with that of the SPC suspension. Conversely, protein fraction 3 had a substantially higher carbonyl content compared with that of the SPC suspension. This shows that protein fraction 3 was the most oxidized protein fraction, and that both of the temperatures applied in the HTSC increased the 
carbonyl content. We conclude that commercial SPC was readily oxidized and that when process conditions are applied, such as temperatures above $100{ }^{\circ} \mathrm{C}$, the formation of carbonyls further increased. Chen et al. (2013b) found quite a low carbonyl content of $5.78 \mathrm{mmol}$ of carbonyl per kilogram of soluble protein in noncommercial soy protein isolate (SPI). Most noncommercial SPI and SPC are prepared by freeze-drying, whereas commercial processes for SPC and SPI use spraydrying (Wagner et al., 2000). As we showed before (Section 3.3.2), the spray-drying temperature induces protein oxidation. So far, there is no literature associating spraydrying with protein oxidation, but this process has been associated with other protein modifications, resulting in protein denaturation, reduced protein solubility, and altered surface hydrophobicity (Wagner et al., 2000).

The results on carbonyl contents in SPC and PPC commercial powders, pea protein particles, and a fibrous product demonstrate the need to find, first, how protein oxidation starts during production of the ingredients and how to control it; second, efficient antioxidant strategies for the production of spray-dried particles; and third, a mild process to generate fibrous products. Protein oxidation is an important parameter for controlling the quality and safety of food products. In the current study, the addition of iron did not result in clear additional oxidation.

\subsubsection{On the interpretation of the DNPH-method results}

The protein oxidation values reported above should be interpreted carefully, because of the low protein solubilities of most samples. The average soluble-protein concentration was $4.2 \pm 0.01 \mathrm{~g} / \mathrm{L}$ in buffer $1(4.4 \%)$ and $2.9 \pm 0.04 \mathrm{~g} / \mathrm{L}$ in buffer 3 (3.1\%, Figure 3.1) for the fibrous products tested. However, the soluble-protein concentration in $6 \mathrm{M}$ guanidine hydrochloride for protein fraction 1 was reduced to half (Figure 3.0). 

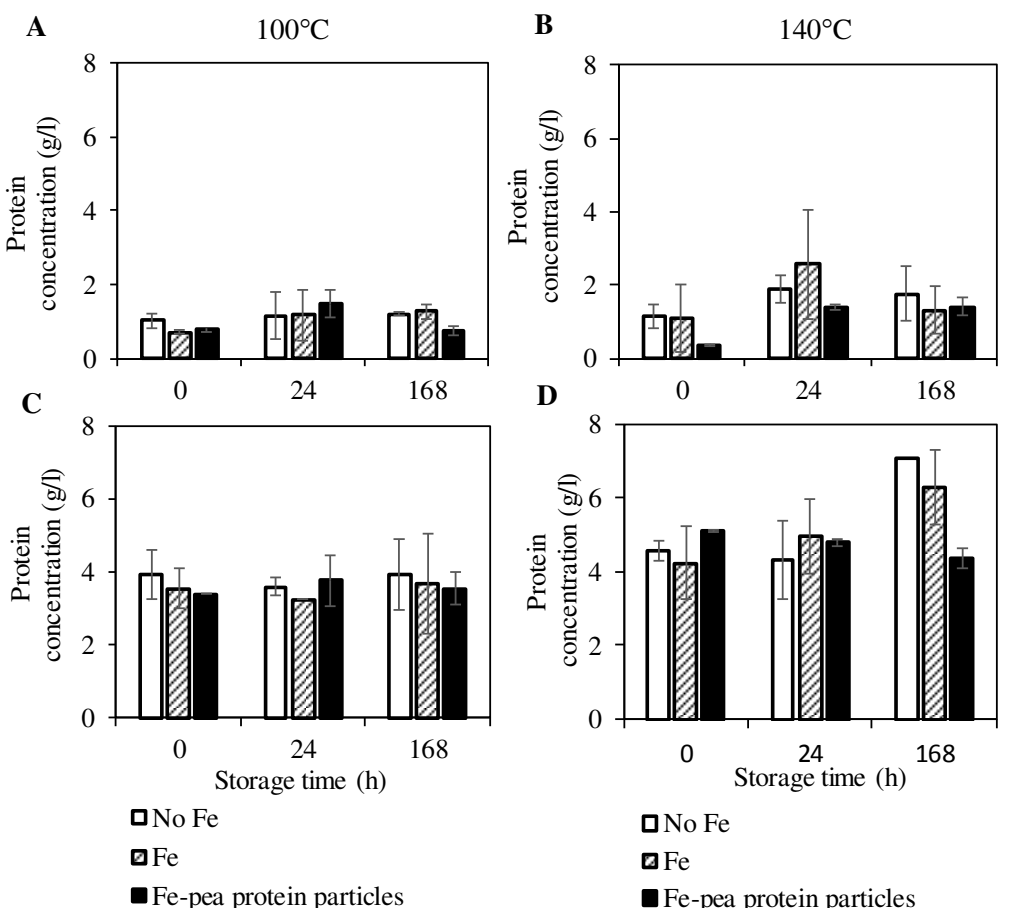

Figure 3.6. Soluble-protein concentrations $(\mathrm{g} / \mathrm{L})$ in $6 \mathrm{M}$ guanidine hydrochloride for protein fractions obtained from the fibrous products. Samples were prepared with no iron (No Fe, white bars), free iron (Fe, dashed bars), or iron-loaded pea protein particles $(\mathrm{Fe}-$ pea protein particles, black bars). (A) Protein fraction 1 of samples prepared at $100{ }^{\circ} \mathrm{C}$, (B) protein fraction 1 of samples prepared at $140{ }^{\circ} \mathrm{C}$, (C) protein fraction 3 of samples prepared at $100{ }^{\circ} \mathrm{C}$, and (D) protein fraction 3 of samples prepared at $140{ }^{\circ} \mathrm{C}$. Results are expressed as means, and bars are standard deviations ( $\mathrm{n}=2$ independent replicates, 3 measurements per sample).

Protein loss during the washing steps of the DNPH method is reported as expected, which increases the standard deviation and lowers the reproducibility (RogowskaWrzesinska et al., 2014). In samples with very low solubility, such as with our fibrous product, we only measured carbonyls in a small fraction of the total proteins, and the extent of protein oxidation in the insoluble-protein fraction (i.e., the majority of proteins) remained unknown. Fibrous products were already quite insoluble. That 
fact alone could be a sign of oxidation because protein oxidation induces protein aggregation and can decrease solubility as a result of that.

The modifications included in the DNPH method have contributed to increased carbonyl detection, especially in protein fraction 3. The improvement in DNPH was described by Soglia et al. (2016b) as beneficial for increasing protein solubility and the exposure of carbonyls buried within the protein structure, which resulted in a 3fold higher carbonyl content compared with that from the traditional DNPH method. Ooizumi and Xiong (2004) described the formation of oxidized aggregates as a reason for decreased myosin solubility from chicken muscle. Even though the modifications in the DNPH method increased the detection of carbonyls, this method has some points of attention. The DNPH method measures total carbonyl content, and it is not possible to determine which amino acid was oxidized. According to Estévez (2017) most of the carbonyls are derived from the oxidation of proline, threonine, lysine, and arginine, which are higher in soybeans (mg per 100 $\mathrm{g}$ of food) than in beef (except proline) (FAO, 1981).

\subsection{Conclusions}

Protein oxidation in fibrous products and in plant protein concentrate-based materials has been shown to be a relevant measurement for investigating the chemical stability of these protein-rich products when submitted to process conditions used to make meat analogue products. In the current study we found that spray-drying increased protein oxidation in pea protein particles, with or without iron. The presence of iron decreased pea protein solubility, which may be associated with protein oxidation. Moreover, the starting PPC powder obtained from the manufacturer presented a certain level of protein oxidation, which could be due to the protein fractionation process and the storage conditions. In the fibrous products, the presence of iron-loaded pea protein particles and free iron did not increase protein oxidation at either process temperature $\left(100\right.$ or $\left.140{ }^{\circ} \mathrm{C}\right)$. However, these high temperatures applied to make fibrous products substantially increased protein 
oxidation compared with that in the SPC powder, which was already oxidized but to a lower extent.

\section{Abbreviations used}

ABS, absorbance; BCA, bicinchoninic acid; DNPH, 2,4-dinitrophenylhydrazine; $\varepsilon$, molar absorptivity; EDTA, diaminoethanediaminoethane tetraacetic acid; $\mathrm{HCl}$, hydrochloric acid; HTSC, high-temperature shear cell; ICP-OES, inductively coupled plasma-optical-emission spectroscopy; $\mathrm{KCl}$, potassium chloride; $\mathrm{NaCl}$, sodium chloride; PPC, pea protein concentrate; PSD, particle-size distribution; SDS, sodium dodecyl sulfate; SEM, scanning electron microscopy; SPC, soy protein concentrate; TCA, trichloroacetic acid; Tris, tris-(hydroxymethyl) aminomethane. 


\section{Chapter 4}

Protein oxidation and in vitro gastric digestion of processed soy-based matrices

This chapter has been published as: Duque-Estrada, P., Berton-Carabin, C.C., Nieuwkoop, M., Dekkers, B .L., Janssen, A.E.M., \& van der Goot, A.J. (2019). Protein oxidation and in vitro gastric digestion of processed soy-based matrices. Journal of Agricultural and Food Chemistry, 67(34): 9591-9600. 


\begin{abstract}
Process conditions applied to make structured soy protein-based food commonly include high temperatures. Those can induce protein oxidation, leading to a decrease in their susceptibility to proteolysis by digestive enzymes. We aimed to investigate the effect of thermomechanical process on oxidation and on the in vitro gastric digestion of commercial soy proteins ingredients. Samples were sheared at 100 to 140 ${ }^{\circ} \mathrm{C}$, and characterized for acid uptake, carbonyl content, electrophoresis and surface hydrophobicity. The enzymatic hydrolysis was determined in simulated gastric conditions. Protein ingredients were already oxidized and showed higher surface hydrophobicity and hydrolysis rate compared to those of the processed matrices. However, no clear correlation between the level of carbonyls and the hydrolysis rate was found. Therefore, we conclude that gastric digestion is mostly driven by the matrix structure and composition, and the available contact area between the substrate and proteolytic enzymes.
\end{abstract}




\subsection{Introduction}

The interest in using plant proteins as an alternative to animal proteins in foods has raised over the past years for environmental, health and animal welfare reasons (Day, 2013). Currently, many plant protein-based products have been developed to substitute meat, and are available on the market. Those products are known as meat analogues. The most common ingredient used in that respect is soy proteins, often combined with polysaccharides (Dekkers et al., 2016; Grabowska et al., 2016). Some techniques, such as extrusion and shear cell technology, are based on applying deformation at high temperatures, allowing for making fibrous plant-based products that aim at mimicking whole muscle meat products. However, temperature affects the physiochemical status of the proteins, which can result in protein denaturation, protein oxidation, loss of essential amino acids, change in surface-exposed hydrophobicity and aggregation. Protein oxidation in foods can be induced directly by free radicals, and indirectly by lipid and Maillard reaction products, such as $\alpha$ dicarbonyls (Luna \& Estévez, 2018). It can notably lead to amino acid side chain or protein backbone modifications, such as the formation of carbonyls, loss in thiol groups and in tryptophan, and crosslinks between amino acids residues (Estévez, 2011; Hu et al., 2017). These modifications can result in fragmentation of the protein backbone, protein aggregation and polymerization. Consistently, protein carbonyls are commonly analyzed as markers of the oxidative damage to food proteins (Estévez, 2011).

Protein oxidation is temperature- and prooxidant concentration-dependent and can alter protein digestion in different ways. For instance, at low prooxidant concentration or temperatures below $100{ }^{\circ} \mathrm{C}$, minor modifications and partial unfolding of proteins can enhance digestion by exposure of susceptible sites of the proteins to digestive enzymes. These modifications have been described to increase the protein digestibility value of extrudates compared to non-extruded products (Singh et al., 2007). However, high prooxidant concentrations or heating proteins above $100{ }^{\circ} \mathrm{C}$ can induce extensive protein oxidation. This, in turn, decreases protein 
susceptibility to digestive enzymes, due to amino acid side-chain modifications or protein aggregation (Santé-Lhoutellier et al., 2007; Santé-Lhoutellier et al., 2008b). Though it is known that in vivo oxidation is related to aging and diseases (Estévez \& Luna, 2017), exposure to dietary oxidized proteins may also have adverse impacts on human health. Recent studies have shown that dietary oxidized proteins may promote some organ dysfunctions using in vitro and animal models (Estévez \& Xiong, 2019). However oxidized protein levels used in those studies have not been reported in food so far.

Besides the chemical status of the proteins, gastric protein digestion can be affected by food structure, matrix composition (e.g., other ingredients) and $\mathrm{pH}$ (Laguna et al., 2017). Protein digestion is promoted by pepsin activity (optimal activity between $\mathrm{pH}$ 1.5 and 2.5) and mechanical forces, which help to grind and disintegrate the food into smaller particles (Piper \& Fenton, 1965; Singh et al., 2015). The rate of disintegration indicates how fast food is broken down into small particles. The breakdown is a result of surface erosion and texture softening (Lorieau et al., 2018). The effect of food structure on pepsin hydrolysis has been shown for protein gels already, in which hydrolysis was limited to a thin layer at the surface of the gel. Therefore, the main constraints for pepsin hydrolysis were proven to be the surface area and surface erosion rate of the gels (Luo et al., 2015; Luo et al., 2017).

In this study, we investigate the effect of thermomechanical processing on the oxidation of commercial soy proteins ingredients, which may contain pre-formed protein-bound carbonyls (Duque Estrada et al., 2018). The subsequent impact of processing on the in vitro gastric digestion of soy protein-based matrices was also assessed. 


\subsection{Material and methods}

\subsubsection{Materials}

Soy protein isolate (SPI, 83.4\% protein, SUPRO 500E IP) and soy protein concentrate (SPC, 59.4\% protein, ALPHA $8 \mathrm{ZP}$ ) (N x 5.7) were obtained from Solae (St Louis, MO, US). Pectin from citrus peel (P9135), pepsin from porcine gastric mucosa (400-800 units/mg, P1725), $\mathrm{NaCl}$ (ReagentPlus ${ }^{\circledR}, \geq 99 \%$ ), sodium tetraborate decahydrate (Borax, $\geq 99.5 \%$ ), DL-dithiothreitol (DTT) $(\geq 98 \%$ ), ophtaldialdehyde (OPA) $(\geq 97 \%)$, trifluoracetic acid (TFA), acetonitrile (ACN), 8anilino-1-napthalenesulfonic acid ammonium salt (ANSA, $\geq 97 \%$ ), $\beta$ mercaptoethanol, sodium phosphate monobasic dihydrate $(\geq 99 \%)$, sodium phosphate dibasic $(\geq 99 \%)$, diaminoethane tetraacetic acid (EDTA), tris(hydroxymethyl) aminomethane (Tris), $\mathrm{KCl}, \quad 2,4-$ dinitrophenylhydrazine (DNPH), trichloroacetic acid (TCA), sodium dodecyl sulfate (SDS), and guanidine hydrochloride were obtained from Sigma-Aldrich (Darmstadt, Germany). $\mathrm{HCl}$ 37\% was purchased from VWR Chemicals (Fontenay-sous-Bois, France), and solvents such as ethanol (ACS 99\%) and ethyl acetate (ACS 99\%) were purchased from Emsure (Merck Millipore, Darmstadt, Germany). A bicinchoninic acid (BCA) protein assay kit was obtained from Thermo Scientific (Pierce, Rockford, US). MiniProtean TGX gels, Bio-safe Coomassie G-250 stain, 2x Laemmli sample native buffer: 10x Tris/glycine/SDS buffer (25 mM Tris, $192 \mathrm{mM}$ glycine and $0.1 \mathrm{w} / \mathrm{v} \%$ SDS, 1x solution, $\mathrm{pH}$ 8.3) and Precision plus protein dual color standard were purchase from Bio-Rad Laboratories (Munchen, Germany). L-serine was purchase from Alfa Aesar (99\%, Thermo Fisher Scientific, Kandel, Germany). Ultrapure water obtained from Millipore Milli-Q system was used for all experiments, unless otherwise mentioned. 


\subsubsection{Preparation of unheated protein suspensions and processed samples}

Soy ingredients (SPC and SPI) were used to prepare the unheated $6 \mathrm{wt} \%$ protein suspensions (based on protein content in dry basis) in $100 \mathrm{mM}$ Tris/5 mM EDTA buffer $\mathrm{pH}$ 7.5. Four independent suspensions were prepared and left rotating at 40 rpm, at $4{ }^{\circ} \mathrm{C}$ overnight. The suspensions were analyzed on the following day.

Processed protein-based matrices were prepared using a high temperature shear cell (HTSC). Samples based on SPC were made with $45 \mathrm{wt} \% \mathrm{SPC}, 1 \mathrm{wt} \% \mathrm{NaCl}$ and 54 wt $\%$ demineralized water as described by Grabowska et al. (2016). Samples with SPI were prepared with $44 \mathrm{wt} \%$ SPI, or $41.8 \mathrm{wt} \%$ SPI with $2.2 \mathrm{wt} \%$ pectin; $1 \mathrm{wt} \% \mathrm{NaCl}$ and $55 \mathrm{wt} \%$ demineralized water (Dekkers et al., 2016). Samples were sheared in the HTSC using different temperatures $\left(100,120\right.$ and $\left.140{ }^{\circ} \mathrm{C}\right)$ at $30 \mathrm{rpm}$ for $15 \mathrm{~min}$ and cooled down to $25{ }^{\circ} \mathrm{C}$ in $5 \mathrm{~min}$. After preparation, samples were stored at $-18{ }^{\circ} \mathrm{C}$ prior to further analysis. Processed samples were prepared in duplicate per condition.

\subsubsection{Determination of protein-bound carbonyl content}

The separation of protein fractions from processed protein-based matrices to measure the protein-bound carbonyl content and the 2,4-dinitrophenylhydrazine (DNPH) method were done according to Soglia et al. (2016b), with minor modifications as described previously (Duque Estrada et al., 2018).

Processed protein-based matrices were cut into cylinders of $8 \times 8 \mathrm{~mm}$ size, with sampling at various locations in the matrix, then $9 \mathrm{~g}$ of sample was homogenized with $100 \mathrm{mM}$ Tris $/ 5 \mathrm{mM}$ EDTA buffer $\mathrm{pH} 7.5$ (1:3 w/v) using a rotor-stator homogenizer (IKA T18 UltraTurrax, Thermo Fisher Scientific, Staufen, Germany) at 13,600 rpm for $1 \mathrm{~min}$ in an ice bath. Then, the samples were centrifuged at 18,000 $\mathrm{x} g$ at $2{ }^{\circ} \mathrm{C}$ for $20 \mathrm{~min}$. The supernatant was collected as the soluble fraction. Since previous research (Duque Estrada et al., 2018) showed low protein solubility in Tris/EDTA/NaCl buffer, we suspended the remaining pellet in $0.15 \mathrm{M} \mathrm{KCl}$ solution $(1: 3, w / v)$ and homogenized the mixture using the same rotor-stator homogenizer at $13,600 \mathrm{rpm}$ for $30 \mathrm{~s}$ in an ice bath. This final suspension was called the pellet fraction. 
Afterward, both fractions were filtered with a $0.2 \mu \mathrm{m}$ syringe filter and the soluble protein concentration was determined by the BCA method (Duque Estrada et al., 2018). The same procedure was done for the unheated protein suspensions.

Aliquots from the protein fractions (1-6 $\mathrm{mg}$ of soluble protein) were taken to measure the carbonyl content by the DNPH method. After hydrazone derivatization samples were incubated at $37^{\circ} \mathrm{C}$ overnight in $6 \mathrm{M}$ guanidine hydrochloride prepared in 20 $\mathrm{mM}$ sodium phosphate buffer $\mathrm{pH}$ 6.5. Then, the absorbance was measured at 370 $\mathrm{nm}$ using a UV-visible spectrophotometer (DR-3900, HACH Lange, Germany) using $6 \mathrm{M}$ guanidine hydrochloride as a blank. A control was prepared for all samples following the same procedure, expect no DNPH was added. The soluble protein concentration in $6 \mathrm{M}$ guanidine hydrochloride was determined by the BCA method. The carbonyl content was calculated with the following equation:

$$
\text { Carbonyl content }\left(\frac{\mathrm{mmol}}{\mathrm{kg}}\right)=\frac{\frac{A B S_{\text {sample }}-A B S_{\text {control }}}{\varepsilon}}{\text { soluble protein concentration }} \text { Eq. } 1
$$

Where, $A B S_{\text {sample }}$ is the absorbance of the sample, $A B S_{\text {control }}$ the absorbance of the control and $\varepsilon$ is the molar extinction coefficient of carbonyl, set as $22,000 \mathrm{M}^{-1} \mathrm{~cm}^{-1}$. The carbonyl content was measured in independent samples, each one measured in triplicate (per sample and per blank).

It should be noted that all measurements were done on soluble fractions, which is about 0.8 to $6 \%$ of the total protein in the processed protein-based matrices. The measurement on the soluble protein fraction is a fair representation of the levels of carbonyl protein-bounds and it has been commonly used to determine protein oxidation in a broad range of protein-based samples (Berardo et al., 2015; Berghout et al., 2015b; Berton-Carabin et al., 2016; Berton et al., 2012b; Colombo et al., 2016; Duque Estrada et al., 2018; Luo \& Wehr, 2009; Santé-Lhoutellier et al., 2008b; Semedo Tavares et al., 2018; Soglia et al., 2016b). 


\subsubsection{Molecular weight distribution profile: electrophoresis}

The protein fractions were characterized by their molecular weight profile by $12 \%$ sodium dodecyl sulphate-polyacrylamide gel electrophoresis (SDS-PAGE) under reducing conditions. The reducing sample buffer was prepared with $950 \mu \mathrm{L}$ native buffer and $50 \mu \mathrm{L} 2$-mercaptoethanol. Only the soluble fraction was diluted to a final concentration of $3 \mathrm{mg} / \mathrm{mL}$. Then, samples were mixed with the reducing buffer in a ratio 1:1, heated at $95^{\circ} \mathrm{C}$ for $5 \mathrm{~min}$ in an Eppendorf thermomixer and cooled at room temperature for $30 \mathrm{~min}$. Afterwards the samples were centrifuged using 10,000 $\mathrm{x} g$ for $5 \mathrm{~min}$. Then, $15 \mu \mathrm{L}$ of samples and molecular weight standards were placed in the gels and 10x Tris/Glycine/SDS running buffer was used. The electrophoresis was carried out at $200 \mathrm{~V}$ for approximate $30 \mathrm{~min}$. Subsequently, the gel was washed 3 times with ultrapure water and then stained with Bio-safe Coomassie Stain overnight. The next day the gel was washed with ultrapure water for $30 \mathrm{~min}$ before gel images were taken using a GS-900 Calibrated Densitometry System (Bio-Rad Laboratories, Inc., US). The gel images were analyzed using the Image Lab (version 2.0.1, Bio-Rad Laboratories, Munchen, Germany). Two independent samples were analyzed per SDS-PAGE, done in duplicate.

\subsubsection{Protein surface-exposed hydrophobicity}

The surface-exposed hydrophobicity was determined in ground processed proteinbased matrices according to Berton-Carabin et al. (2016). The samples were ground with four cycles of $10 \mathrm{~s}$ each using a kitchen mixer (Multiquick 5, Braun, Kronberg, Germany) (Freitas et al., 2018). The average size of ground samples was determined with measuring the smallest $(0.64 \pm 0.25 \mathrm{~mm})$ and largest $(1.46 \pm 0.37 \mathrm{~mm})$ dimension of the particles from pictures obtained with an automated digital 3D microscope Smartzoon 5 (Carl Zeiss, Breda, The Netherlands). Then ground samples were homogenized in $10 \mathrm{mM}$ sodium phosphate buffer $\mathrm{pH} 7.0$ at 13,600 rpm for $1 \mathrm{~min}$ in ice bath using an Ultra Turrax. As a next step, the samples were centrifuged at $18,000 \mathrm{x}$ and $2^{\circ} \mathrm{C}$ for $20 \mathrm{~min}$ and the soluble fractions were collected. Suspensions of unheated soy protein-ingredients were prepared with $6 \mathrm{wt} \%$ protein 
net (dry basis) in the $10 \mathrm{mM}$ sodium phosphate buffer, as described in the section 4.2.2. The soluble protein concentration was measured with BCA method and samples were diluted to obtain a final concentration of $1 \mathrm{mg} / \mathrm{ml}$ soluble protein. The anionic fluorescence ANSA probe $(2.4 \mathrm{mM})$ was prepared in $10 \mathrm{mM}$ sodium phosphate buffer at $\mathrm{pH} 7.0$ and stirred overnight at $4^{\circ} \mathrm{C}$. The fluorescence emission spectra were measured between 400 and $650 \mathrm{~nm}$ with steps of $0.5 \mathrm{~nm}$ using a RF6000 spectrofluorometer (Shimadzu Corporation, Kyoto, Japan). The excitation wavelength was set at $385 \mathrm{~nm}$ and the emission was measured at $480 \mathrm{~nm}$, with a scan rate of $60 \mathrm{~nm} / \mathrm{min}$ and spectral bandwidth of $5.0 \mathrm{~nm}$. For this measurement, quartz cuvettes with dimensions $10 \times 10 \mathrm{~mm}$ were used (Hellma Analytics, Müllheim, Germany). Then, $1 \mathrm{~mL}$ of sample was mixed with $10 \mu \mathrm{L}$ ANSA for $1 \mathrm{~min}$ and the spectra were recorded until the signal reached ANSA saturation. The two blanks were pure buffer with added ANSA with the same concentration as reached in the sample and a sample without ANSA. The results were expressed as the maximum fluorescence intensity at $480 \mathrm{~nm}$, which represents the number of exposed hydrophobic sites of the protein. The experiment was done with two independent samples.

\subsubsection{Acid titration}

A titration with $\mathrm{HCl}$ was done using an automatic titrator (877 Titrino plus, Metrohm, Herisau, Switzerland) to estimate the acid uptake by protein ingredients and processed protein-based matrices according to Luo et al. (2018), with a few modifications. The titration was performed by adding ground processed proteinbased matrices containing $1 \mathrm{~g}$ of net protein (dry basis) to $25 \mathrm{~mL}$ ultrapure water with $\mathrm{NaCl}(0.8775 \% \mathrm{w} / \mathrm{v})$ in a jacketed vessel connected to a thermostat bath set at $37^{\circ} \mathrm{C}$ and stirred at $100 \mathrm{rpm}$. Before titration, the samples were soaked in the solution for 30 minutes. The titration was done stepwise from their original $\mathrm{pH}$, which was around 7, to $\mathrm{pH} 2$ by adding $0.05 \mathrm{~mL}$ of $0.5 \mathrm{M} \mathrm{HCl}$, in a minimum interval of $1 \mathrm{~s}$ and a maximum waiting time of $25 \mathrm{~s}$. The experiment was performed in two independent samples, measured twice for each sample. 


\subsubsection{Preparation of samples for in vitro gastric digestion}

The suspensions of unheated protein ingredients (SPC, SPI or SPI with pectin (1:19)) were prepared with $5 \mathrm{w} / \mathrm{v} \%$ protein in ultrapure water according to Luo et al. (2015). After stirring at room temperature for $30 \mathrm{~min}$, the samples were used for in vitro gastric digestion experiments. Samples were prepared in duplicate. The processed protein-based matrices were cut into cylinders of 3 x $3 \mathrm{~mm}$ size (Peyron et al., 2004) or ground as previously described in section 4.2.5.

\subsubsection{In vitro gastric digestion set-up}

A static soaking in vitro set-up was used to simulate the gastric digestion process. Simulated gastric fluid (SGF) was prepared with pepsin (1 g/L) and NaCl $(8.775 \mathrm{~g} / \mathrm{L})$ in ultrapure water according to Luo et al. (2015) with few modifications. The $\mathrm{pH}$ of the SGF was adjusted to 2 with $2 \mathrm{M} \mathrm{HCl}$. Then, processed protein-based matrices or the suspensions of unheated protein ingredients containing $0.1 \mathrm{~g}$ of protein (dry basis) were added to $50 \mathrm{~mL}$ of the $\mathrm{SGF}$ pre-heated at $37^{\circ} \mathrm{C}$ in a jacketed vessel while stirring at $100 \mathrm{rpm}$. The vessels were sealed with parafilm to avoid evaporation. One $\mathrm{mL}$ of sample was taken after 5, 20, 30, 60, 120 and $180 \mathrm{~min}$ for further analysis. To inactive the pepsin activity the samples were heated at $90{ }^{\circ} \mathrm{C}$ (Casey \& Laidler, 1951) and mixed at $1400 \mathrm{rpm}$ for $5 \mathrm{~min}$ in a pre-heated Eppendorf thermomixer (Eppendorf AG, Germany). After the inactivation step, samples were cooled down. The hydrolysis experiments were carried out with two independent samples and each sample was tested in duplicate, resulting in a total of four digestion experiments per processing condition tested.

\subsubsection{Determination of the degree of hydrolysis}

The degree of hydrolysis (DH) was measured by the o-phthalaldehyde (OPA) method according to Luo et al. (2015). The OPA reagent was prepared by first dissolving $3.81 \mathrm{w} / \mathrm{v} \%$ Borax and $0.1 \mathrm{w} / \mathrm{v} \%$ SDS in ultrapure water, then $0.08 \mathrm{w} / \mathrm{v} \%$ OPA pre-dissolved in $2 \mathrm{~mL}$ ethanol was added to the Borax-SDS solution, and lastly $0.088 \mathrm{w} / \mathrm{v} \%$ DTT was added and the solution was filled up to $150 \mathrm{~mL}$ with ultrapure 
water. The solution was filtered through a $0.45 \mu \mathrm{m}$ syringe filter and protected from light exposure.

A calibration curve with L-serine was prepared in a concentration range of 50-400 $\mathrm{mg} / \mathrm{L}$. Digestion samples were first centrifuged at 14,000 x g for $1 \mathrm{~min}$. Then 200 $\mu \mathrm{L}$ of sample, blank or calibration sample was mixed with $1.5 \mathrm{~mL}$ OPA reagent for 3 minutes and the absorbance was measured at $340 \mathrm{~nm}$ with a spectrophotometer UV-vis spectrophotometer (DU720, Beckman Coulter, Inc., Indianapolis, IN, US). Each sample was measured in triplicate. Free amino groups values from digestion samples were corrected by subtracting the contribution of free amino groups from the SGF before digestion without sample addition.

The DH was determined as the percentage of peptide bonds cleavage regarding a total number of peptide bonds, following the equations:

$$
\begin{array}{ll}
D H(\%)=\frac{h}{h_{\text {tot }}} \times 100 & \text { Eq. } 2 \\
h=\frac{\text { Serine } \mathrm{NH}_{2}-\beta}{\alpha} & \text { Eq. } 3
\end{array}
$$

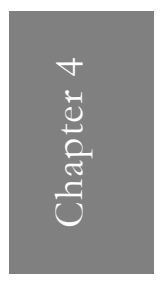

Where $b$ is the number of peptide bonds cleavage in $1 \mathrm{~kg}$ protein, $b_{t o t}$ as the total number of peptide bonds in $1 \mathrm{~kg}$ protein set as $7.8 \mathrm{meq} / \mathrm{g}$ for soy proteins, serine $\mathrm{NH}_{2}$ as free amino groups as serine amino equivalents obtained from the calibration curve, $a$ was 0.970 and $\beta$ was 0.342 for soy proteins (Adler-Nissen, 1993).

\subsubsection{Size-exclusion chromatography}

The peptide size distribution profile was measured with a high-performance sizeexclusion chromatography (HPSEC) using TSKgel G3000SWxl column $(7.8 \mathrm{~mm}$ x $300 \mathrm{~mm}$ ) and TSKgel G2000SWxl (7.8 mm x 300 mm) (Tosoh Bioscience LLC, King of Prussia, PA, USA.) in an Ultimate 3000 UHPLC system (ThermoFisher Scientific Inc., USA). Digested samples were first filtered using a $0.2 \mu \mathrm{m}$ Spartan 13/0.2 R 6 Whatman filter (VWR), and then $10 \mu \mathrm{L}$ of sample was injected for each 
measurement. The mobile phase was made with 30\% acetonitrile, $0.1 \%$ trifluoroacetic acid and 70\% ultrapure water. Signals were measured with a UV detector set at $214 \mathrm{~nm}$, at $30^{\circ} \mathrm{C}$ and with a flow rate of $1.5 \mathrm{~mL} / \mathrm{min}$. The calibration was performed with standard solutions of $\alpha$-lactalbumin, aprotinin, insulin, bacitracin, phenylalanine, g-globulin, and ovalbumin. Then the calibration curve was made by plotting the retention time of each standard solution as a function of the protein's molecular weight. Data analysis was performed in Dionex Chromeleon 7.2 Chromatography Data System software (ThermoFisher Scientific Inc., USA). A chromatogram from the system resulted in peaks showing the amount of molecules with the sizes $>50 \mathrm{kDa}, 50-10 \mathrm{kDa}, 10-4 \mathrm{kDa}, 4-2 \mathrm{kDa}$ and $<2 \mathrm{kDa}$. The experiments were done in duplicate per digestion sample, resulting in four experiments per sample.

\subsubsection{Statistical analysis}

Statistical analysis was done using the Statistical Package for the Social Sciences (SPSS software v. 23, IBM Inc.). The Mann-Whitney test was used to compare the results pertaining to the degree of hydrolysis. One way-ANOVA with post hoc analysis using Tukey's multiple comparison test was used to compare the means pertaining to carbonylation level, soluble protein concentration, maximum fluorescence intensity and peptide size distribution profile regarding processing conditions and ingredients. An independent T-test was performed to compare the maximum fluorescence intensity of samples processed with the same conditions, but starting from different ingredients. The significance level was set at $p<0.05$. 


\subsection{Results and discussion}

\subsubsection{Physicochemical characterization}

\section{Protein-bound carbonyl content}

The effect of process conditions on protein oxidation was quantified through measuring the protein-bound carbonyl content. The soluble protein fraction of all unheated protein ingredients had a carbonyl content between 12.9 and $20.2 \mathrm{mmol}$ carbonyl $/ \mathrm{kg}$ soluble protein (Figure 4.1.A), which did not increase further with processing at $100{ }^{\circ} \mathrm{C}$ and $120^{\circ} \mathrm{C}$, independently of the matrix. However, processing at $140{ }^{\circ} \mathrm{C}$ increased the carbonyl content in SPC- and SPI/pectin-based matrices significantly $(\phi<0.05)$ when compared to samples that were unheated or processed at lower temperatures (Figure 4.1.A). Figure 4.1.B shows the carbonyl content of the pellet fractions. The carbonyl content of the unheated protein ingredients was above $30 \mathrm{mmol}$ carbonyl $/ \mathrm{kg}$ soluble protein, which was higher than in the soluble fraction. However, there was no significant increase in carbonyl content in this fraction with processing, whatever the applied temperature. In addition, the carbonyl content in the pellet fractions was similar for all tested ingredients (SPC, SPI and $\mathrm{SPI} /$ pectin).

Heat- and shear-based process significantly decreased the soluble protein concentration in the processed SPC-based matrices compared to the starting ingredient, especially in the soluble fraction (Figure 4.1.C). Processing SPI and SPI/pectin at $140{ }^{\circ} \mathrm{C}$ caused a small increase in the soluble concentration compared to lower temperatures, but not significant compared to unheated protein ingredient. For all samples, the soluble protein concentration in the pellet fraction was lower than that in the soluble fraction. Processing SPI at higher temperatures caused an increase in the soluble concentration in the pellet fraction compared to unheated protein ingredient. Overall, we see that heat- and shear-based process can promote soy protein oxidation, which is in line with previous research (Duque Estrada et al., 2018). 
A

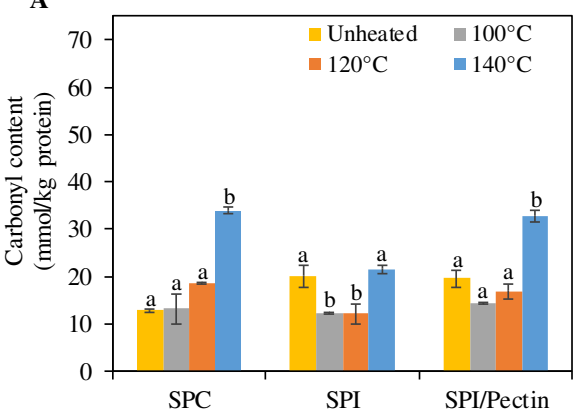

B
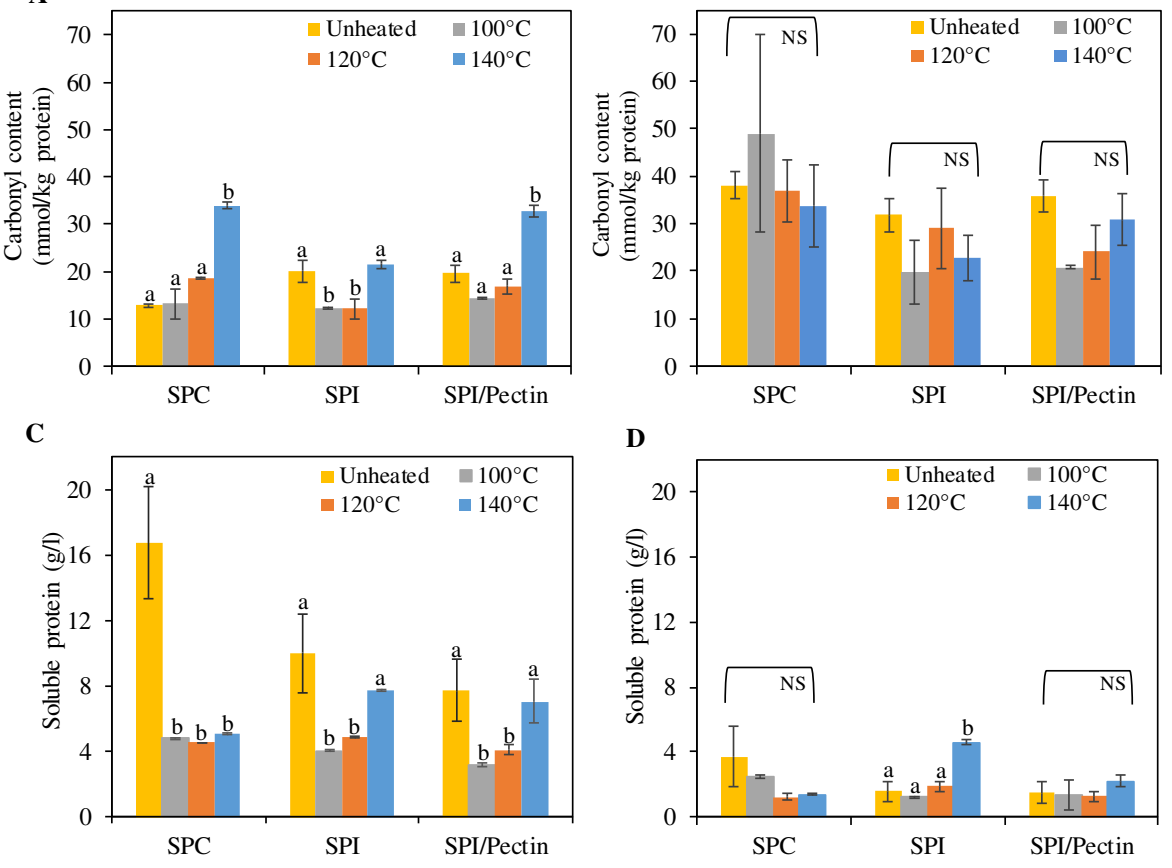

Figure 4.1. Carbonyl content (mmol per kg soluble protein) (A, B) and soluble protein concentration $(\mathrm{g} / \mathrm{L})$ in Tris/EDTA $(\mathrm{C})$ or $\mathrm{KCl}(\mathrm{D})$ buffers of unheated protein ingredients suspensions and processed protein-based matrices (100, 120 and $\left.140{ }^{\circ} \mathrm{C}\right)$ : soluble fraction (A and C) and pellet fraction (B and D). Different letters indicate a significant difference between unheated protein ingredients and processed protein-based matrices made with the same ingredient. Significance level at $p<0.05$. NS: no significant difference.

Although the effect of handling, processing, and storage on protein oxidation is largely unexplored for plant protein-based ingredients and foods, such data are readily available for muscle protein-based foods. For example, in processed meat, Soladoye et al. (2017) reported carbonyl content of $80 \mathrm{mmol}$ carbonyl $/ \mathrm{kg}$ soluble protein in raw bacon, which further increased with cooking. These results suggested that the quality of the raw material, the use of additional ingredients in formulated products, and the processing conditions largely determine protein oxidation and can 
lead to high levels of oxidation. Regarding the ingredients of processed food, the presence of reducing sugars and their oxidation products, such as $\alpha$-dicarbonyl compounds, can induce oxidative deamination of basic amino acids resulting in protein carbonylation via a Maillard-mediated mechanism (Poulsen et al., 2013). For instance, Luna \& Estévez (2018) found that in SPI glycation reaction formed more carbonyls than metal catalyzed hydroxyl-radical generating system, while a combination of both oxidation systems increased further carbonylation. Nevertheless, such reactions are probably highly dependent on the ingredient's composition, notably regarding reducing sugars, which may largely vary between different ingredients and supplier.

Furthermore, we found that the proteins in the starting ingredients used (i.e., unheated SPC or SPI) were already oxidized to a certain extent. We made similar observations in a previous study using commercial soy ingredients (Duque Estrada et al., 2018). Likewise, Chen et al. (2015) reported a carbonyl content of $15.1 \mathrm{mmol}$ carbonyl $/ \mathrm{kg}$ soluble protein in commercial SPI, which increased to $22.4 \mathrm{mmol}$ carbonyl $/ \mathrm{kg}$ soluble protein upon dry heating at $100{ }^{\circ} \mathrm{C}$ for $8 \mathrm{~h}$. The fractionation process and/or storage conditions applied to protein ingredients could have caused protein oxidation. In industrial processes, spray drying is often used as the final drying step to obtain the SPC and SPI, and pre-heating treatments may be applied prior to drying, which can promote protein oxidation (Duque Estrada et al., 2018). Conversely, the carbonyl content of lab-made SPI is often lower, with typical value range of 1.65 to $6.5 \mathrm{mmol}$ carbonyl $/ \mathrm{kg}$ soluble protein reported in different studies (Chamba et al, 2014; Chen et al., 2013b,c; Huang et al., 2006; Wu et al., 2009b,c). This may be because those SPI samples were prepared with freeze drying as the final drying step. Pre-heating SPI suspensions from 5 to $30 \mathrm{~min}$ at $90^{\circ} \mathrm{C}$ followed by spray drying resulted in increased protein carbonyls and decreased protein solubility during 8 weeks of storage (Guo et al., 2015). The fractionation process prior to drying also seems of importance. For example, Wu et al. (2009c) prepared a low-oxidized SPI (1.7 mmol carbonyl $/ \mathrm{kg}$ soluble protein) by using soybeans with low moisture content 
and isolating proteins by fractionation process under low oxygen conditions. This suggests that a large variability in that respect may exist from one plant protein material to another and that considering the oxidative status of protein ingredients is relevant to control oxidation during processes.

Moreover, information regarding the consequences of dietary oxidized proteins on human health is still limited. The effect of postprandial protein oxidation causing cellular and tissue damage has been related to contribute to the progress of diseases such as inflammatory bowel disease, diabetes, and fibrosis (Estévez \& Luna, 2017). Studies with in vitro and animal models have shown that dietary oxidized proteins may promote some organ dysfunctions (Estévez \& Xiong, 2019). For instance, animal studies showed that the intake of oxidized tyrosine ( 2 to $8 \mathrm{~g} / \mathrm{kg}$ diet for 24 weeks) resulted in oxidative stress and dysfunction of kidney and pancreas cells, combined with inflammation (Ding et al., 2017; Li et al., 2017). However, the doses used in these studies are much higher than values typically reported in food proteins, and thus more studies are needed to elucidate dose-related effects to establish whether usual oxidation levels occurring in foods could give rise to similar consequences.

\section{Molecular weight distribution profile: SDS-PAGE}

The molecular weight distribution of proteins in the soluble fractions (Figure 4.2.AC) and pellet fractions (Figure. 4.2.D-F) was determined with SDS-PAGE under reducing conditions. For all samples we see differences in the protein molecular weight distribution between the unheated ingredients and the processed matrices, for both fractions (Figure 4.2). In the soluble fraction of unheated SPC (Figure 4.2.A), $\beta$-conglycinin and glycinin subunits, the major constituents of soy proteins, are present, but the intensity of the bands corresponding to the $\alpha$ and $\alpha^{\prime}$ subunits of $\beta$ conglycinin decreased after processing at $140{ }^{\circ} \mathrm{C}$. The soluble fraction of unheated SPI and SPI/pectin ingredients had similar molecular weight distribution. The same was observed when comparing SPI and SPI/pectin-based matrices processed at temperatures below $140^{\circ} \mathrm{C}$ (Figure 4.2.B,C). This findings were was expected since 
both matrices were prepared with the same source of protein ingredient. However, the bands around $75 \mathrm{kDa}$ in SPI/pectin-based matrices processed at $140{ }^{\circ} \mathrm{C}$ were not visible anymore.
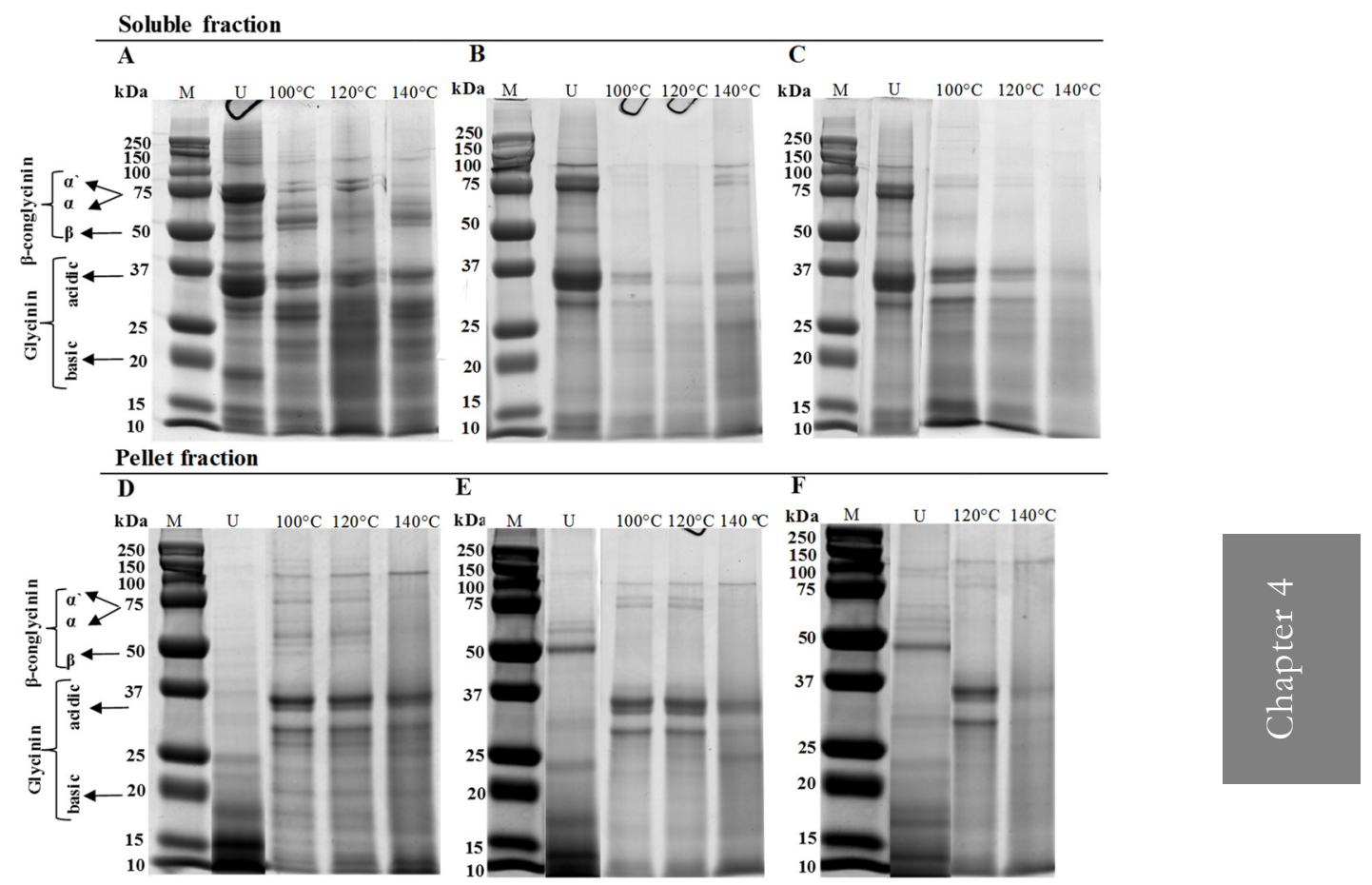

Figure 4.2. SDS-PAGE under reducing conditions of the soluble fraction and pellet fraction of unheated protein ingredients and processed protein-based matrices at different temperatures. A and D, SPC samples; B and E, SPI samples; C and F, SPI/pectin samples. $\mathrm{U}$, unheated ingredients; $\mathrm{M}$, molecular weight standard; $\alpha / \alpha / \beta$, peptides of $\beta$-conglycinin.

The molecular weight distribution profiles of the pellet fractions of unheated samples were different from those of the soluble fractions (Figure 4.2.D-F), for a given sample. In the pellet fractions, bands around $75 \mathrm{kDa}$ were not visible and an accumulation of low molecular weight components appeared. For unheated SPI and SPI/pectin samples (Figure 4.2.E,F) the band around $50 \mathrm{kDa}$ was still visible as seen in the soluble fraction (Figure 4.2.B,C). The pellet fraction of all processed 
samples at $140{ }^{\circ} \mathrm{C}$ did not show bands around $75 \mathrm{kDa}$, which represents the molecular weight of $\alpha$ - and $\alpha^{\prime}$ subunits of $\beta$-conglycinin.

Overall we observed a systematic difference between unheated and processed samples with a decrease in the intensity of some particular bands after processing, regardless of the protein fraction. In addition, bands at molecular weights above 37 $\mathrm{kDa}$ for the pellet fractions appeared as faded, or were not even visible sometimes, compared to the soluble fraction.

\section{Protein surface-exposed hydrophobicity}

Figure 4.3 shows the maximum fluorescence intensity $\left(F_{\max }\right)$ of unheated protein ingredients and processed protein-based matrices made with different ingredients, which represents the number of surface-exposed hydrophobic sites in the protein. In the case of unheated protein ingredients, we found that SPC had more exposed hydrophobic sites than SPI and SPI/pectin. All processed protein-based matrices showed a strong and significant decrease in the number of surface-exposed hydrophobic sites compared to unheated protein ingredients $(p<0.05)$. SPC-based matrices processed at $100{ }^{\circ} \mathrm{C}$ had a $90 \%$ decrease on $F_{\max }$ compared to unheated SPC ingredient. For all three starting ingredients, the temperatures applied had only a minor additional effect on protein hydrophobicity.

The protein surface hydrophobicity in the processed SPI/pectin-based matrices decreased further upon processing at a higher temperature. It seems therefore that the presence of pectin decreases protein hydrophobicity. A possible explanation could be that pectin would interact with proteins via hydrophobic interactions involving the methoxyl groups of pectin (Wang et al., 2018). It is, however, difficult to generalize this effect, as opposite trends were also reported in literature (Benjamin et al., 2012). Presumably, the type of pectin (and notably its degree of methoxylation), the type of protein, and the probe used to assess surface-exposed hydrophobicity are of importance in that respect. Previous studies showed that protein oxidation is also a relevant parameter that affects surface hydrophobicity. We observed a substantial 
formation of protein-bound carbonyls in processed SPC- and SPI/pectin-based matrices made at $140{ }^{\circ} \mathrm{C}$ (Figure 4.1.A), which could reduce the number of exposed hydrophobic sites. Likewise, studies have shown that at low levels of carbonyl content, the surface hydrophobicity was higher compared to high levels of carbonyl content (Berton-Carabin et al., 2016; Shao et al., 2016; Sun et al., 2011; Tan et al., 2016; Wu et al., 2009b).

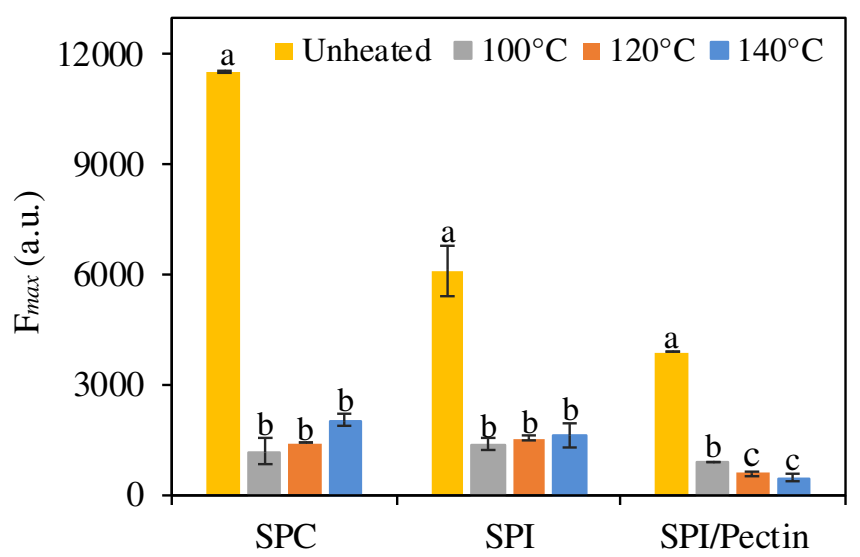

Figure 4.3. Maximum fluorescence intensity $\left(F_{\max }\right)$ based on ANSA probe of unheated protein ingredients and processed protein-based matrices made with different ingredients and process conditions. Excitation wavelength set at $385 \mathrm{~nm}$ and emission at $480 \mathrm{~nm}$. Results are expressed as mean and error bars as standard deviation. Different letters indicate significant difference among unheated protein ingredients and processed protein-based matrices, made with the same ingredient. Significance level at $p<0.05$.

In this study, heat- and shear-based process decreased surface-exposed hydrophobicity in protein-based matrices compared to protein ingredients, which is a result of protein rearrangements induced by processing and protein oxidation. The reduced hydrophobicity of the proteins can decrease the proteolytic susceptibility of the proteins (Filgueras et al., 2011; Santé-Lhoutellier et al., 2008a).

\section{$\underline{\text { Acid uptake }}$}

We investigated the volume of acid $(\mathrm{HCl})$ uptake by unheated protein ingredients and ground processed protein-based matrices made with the different ingredients, 
necessary to reach $\mathrm{pH} 2$ (Figure 4.4). The volume of $\mathrm{HCl}$ solution needed to reach pH 2.0 was higher for SPC-based suspensions than for SPI- and SPI/pectin-based ones. The patterns for unheated protein ingredients and processed protein matrices were similar for SPI and SPI/pectin, implying that the presence of pectin did not affect acid uptake, and hence the protein buffering capacity. Processing can modulate acid uptake, but the temperature treatment did not have a large effect. A higher acid uptake is a measure for a strong buffer capacity, which can affect the gastric digestion rate since the activity of pepsin is highly pH-dependent (Kondjoyan et al., 2015). Therefore, differences in gastric digestion are expected in case of different ingredients and due to heating. However, the exact process conditions are likely to have a limited effect in that respect.
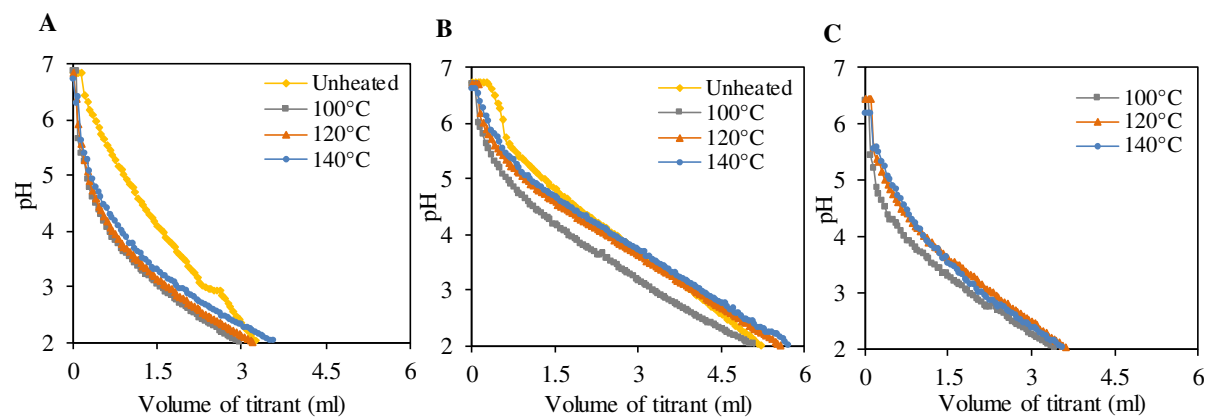

Figure 4.4. $\mathrm{pH}$ as a function of the volume of titrant $0.5 \mathrm{M} \mathrm{HCl}$ of suspensions of unheated protein ingredients or of ground processed protein-based matrices made with (A) SPI, (B) SPC and (C) SPI/pectin at different temperatures. The protein content (dry basis) in all samples is similar.

\subsubsection{In vitro gastric digestion}

\section{Degree of hydrolysis}

First, we investigated the effect of process conditions, the effect of grinding the processed protein-based matrices, and the effect of the starting protein ingredient on the degree of hydrolysis using in vitro gastric conditions. Second, we aimed to correlate the obtained results with protein oxidation. 
Figure 4.5 shows that all unheated protein ingredients had a rapid increase in $\mathrm{DH}$ within the first 5 minutes of simulated gastric digestion. Then proteolysis slowed down, before reaching a plateau. This fast increase within the first minutes of digestion is in line with previous studies with proteins suspensions (Luo et al., 2015; Opazo-Navarrete et al., 2018; Yang et al., 2016). Processed protein-based matrices (cylinder-shaped) showed a slower increase in $\mathrm{DH}$ and lower final value than unheated protein ingredients after $180 \mathrm{~min}$. After 5 minutes of gastric digestion, samples were hardly digested, indicating a long sample disintegration time. The combination of pepsin diffusion, hydrolysis rate, microstructure, and mechanical strength was previously used to explain differences in disintegration and subsequent digestion of whey protein isolate gels (Luo et al., 2017). The pepsin diffusion was limited to a depth of $2 \mathrm{~mm}$ within the gels, explaining why hydrolysis only occurred in the thin layer at the surface of the gels. Thus, the digestion rate was constrained by the surface area of the gel and the surface erosion.

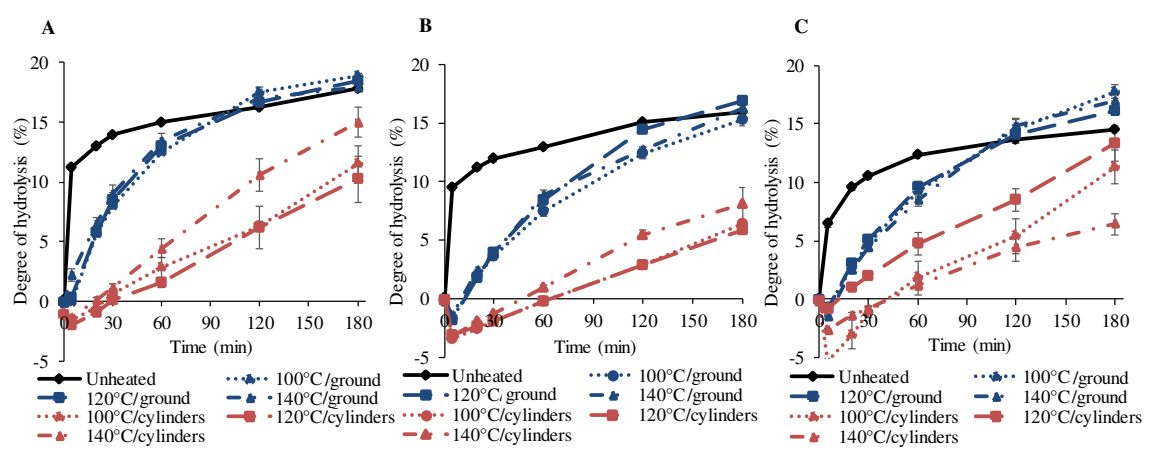

Figure 4.5. The degree of hydrolysis (\%) of unheated protein ingredients and processed protein-based matrices made with SPC (A), SPI (B) and SPI/pectin (C) prepared at different temperatures. The processed matrices cut as small cylinders are represented by red lines, and the processed ground samples are represented as blue lines. Error bars represent the standard deviation (two independent samples, each digested in duplicate). 
After cutting the processed protein-based matrices into cylindrical shapes, the SPIbased one (Figure 4.5.B) had slower disintegration than SPC- and SPI/pectin-based ones, which could be associated to a higher sample hardness. Previous research revealed that SPI-based matrices processed at $140{ }^{\circ} \mathrm{C}$ had higher tensile stress compared to SPC- and SPI/pectin-based ones (Dekkers et al., 2018c; Dekkers et al., 2016; Grabowska et al., 2016). The lower tensile stress in processed SPI/pectin-based matrices is associated with the presence of pectin, which forms a weaker and elongated separated phase, and induces air pockets within the matrix, resulting in fiber formation at $140{ }^{\circ} \mathrm{C}$ (Dekkers et al., 2018c; Dekkers et al., 2016; Grabowska et al., 2016). The results apply with the general observation that soft protein gels can be subjected to faster disintegration in digestive conditions compared to hard gels (Opazo-Navarrete et al., 2018).

Besides the sample texture, the sample size could influence the rate of hydrolysis. To test this hypothesis we ground the processed protein-based matrices. Unfortunately, the broad particle size distribution obtained and the roughness of the samples prevented calculation of the exact surface area. Ground processed protein-based matrices had significantly $(p<0.05)$ higher DH than cylinder-shaped ones, but a slower rate of hydrolysis than unheated protein ingredients. Most likely, the reduced sample size facilitated disintegration and the diffusion of pepsin and $\mathrm{HCl}$ into the samples, increasing the DH. Interestingly, ground SPI/pectin-based matrices had equal or even higher DH than unheated protein ingredients after $180 \mathrm{~min}$ of digestion. The exact reason for this effect is not clear yet.

Although the applied processing temperature seemed to influence the $\mathrm{DH}$ of the processed protein matrices, no generic trend across the different materials could be observed. After grinding the products, the differences due to processing became small. Regarding the effect of the starting protein ingredient, ground SPC-based matrices had faster increase in the DH compared to SPI and SPI/pectin-based matrices. Since the buffering capacity of SPC was largest among the tested 
ingredients, this could have led to a lower digestibility. However, this was clearly not the case. Nevertheless, increased surface-exposed hydrophobicity in SPC might have increased the exposure of hydrophobic sites in which pepsin has more affinity. The excess of gastric juice is most probably able to compensate for the effect and to keep the conditions favorable for pepsin to be active. The fractionation process applied to obtain concentrated and isolated proteins could be another factor that can affect the status of the proteins and as a consequence the digestion rate. Opazo-Navarrete et al. (2019) reported a lower degree of protein hydrolysis in isolated quinoa protein obtained by wet fractionation than in the protein-enriched quinoa fraction obtained by dry fractionation. They suggested that the changes in $\mathrm{pH}$ and the thermal treatment during the drying step involved in the wet fractionation process affect the protein conformation and supramolecular structures, which would impact protein digestibility.

When carbonyl levels of all samples were related to $\mathrm{DH}$, we concluded that oxidation had no obvious relationship with the DH (Figure 4.7. supplementary information). Likewise, Chen et al. (2013a) found no significant difference in the DH after $1 \mathrm{~h}$ pepsin digestion of SPI samples treated with increasing concentration of prooxidants. We also did not observe a relationship between the $\mathrm{DH}$ and surfaceexposed hydrophobicity or carbonyl content and hydrophobicity (Figure 4.8 and 4.9 in supplementary information). Santé-Lhoutellier et al. (2008b) did not find a correlation between carbonyl content an pepsin activity in miofribrillar proteins from pork, which was attributed to the level of protein oxidation and the oxidative susceptibility of amino acids that pepsin has preference for cleaves, for instance aromatic amino acids. Therefore, the physicochemical modifications induced by shear- and heat-based process of soy protein ingredients contributed to slowing down the degree of hydrolysis, but did not impair the DH after 120 min of digestion. 


\section{Peptide size distribution (HPSEC)}

The peptide size distribution of unheated SPC and SPI ingredients showed more peptides larger than $10 \mathrm{kDa}$ compared to the SPI/pectin ingredient $(p<0.05)$ (Figure 4.6.A). Additionally, the SPI/pectin ingredient had more peptides smaller than $2 \mathrm{kDa}(p<0.05)$. Overall the peptide size distribution of the unheated protein ingredients seemed already quite stable after 20 min incubation in simulated gastric conditions, which is in agreement with the fast digestion observed in Figure 4.5. This is different for the processed protein-based matrices, either in a cylinder-shape or ground. Figure 4.6.B shows that more small peptides were present in digested ground samples over time compared to the digested cylinder-shaped samples $(p<$ 0.05). These results are in line with the lower digestion rate found for the cylindershaped samples in Figure 4.5. However, after 180 min of digestion there was no difference for peptides smaller than $4 \mathrm{kDa}$ between digested cylinder-shaped and ground samples made of processed SPC-based matrices at $140{ }^{\circ} \mathrm{C}(p>0.05)$.

When comparing the different starting ingredients, SPC-based matrices processed at different temperatures showed a similar peptide distribution, though the amounts formed were distinct (Figure 4.6.B). This suggests that the same reaction products are formed, regardless of the reaction rate of pepsin. The higher digestion rate of cylinder-shaped of those samples processed at $140{ }^{\circ} \mathrm{C}$ as shown in Figure 4.5.A is nicely confirmed by the higher amount of peptides present in the gastric juice after $180 \mathrm{~min}$ of digestion. Interestingly, the digestion of ground SPI/pectin-based matrices resulted in more peptides between $2-4 \mathrm{kDa}$ than SPC and SPI-based matrices $(p<0.05)$ when processed at 120 and $140{ }^{\circ} \mathrm{C}$. Conversely, SPC-based matrices (cylinder-shape and ground) processed at 120 and $140{ }^{\circ} \mathrm{C}$ had more peptides lower than $2 \mathrm{kDa}$ than both SPI and SPI/pectin $(p<0.05)$. 


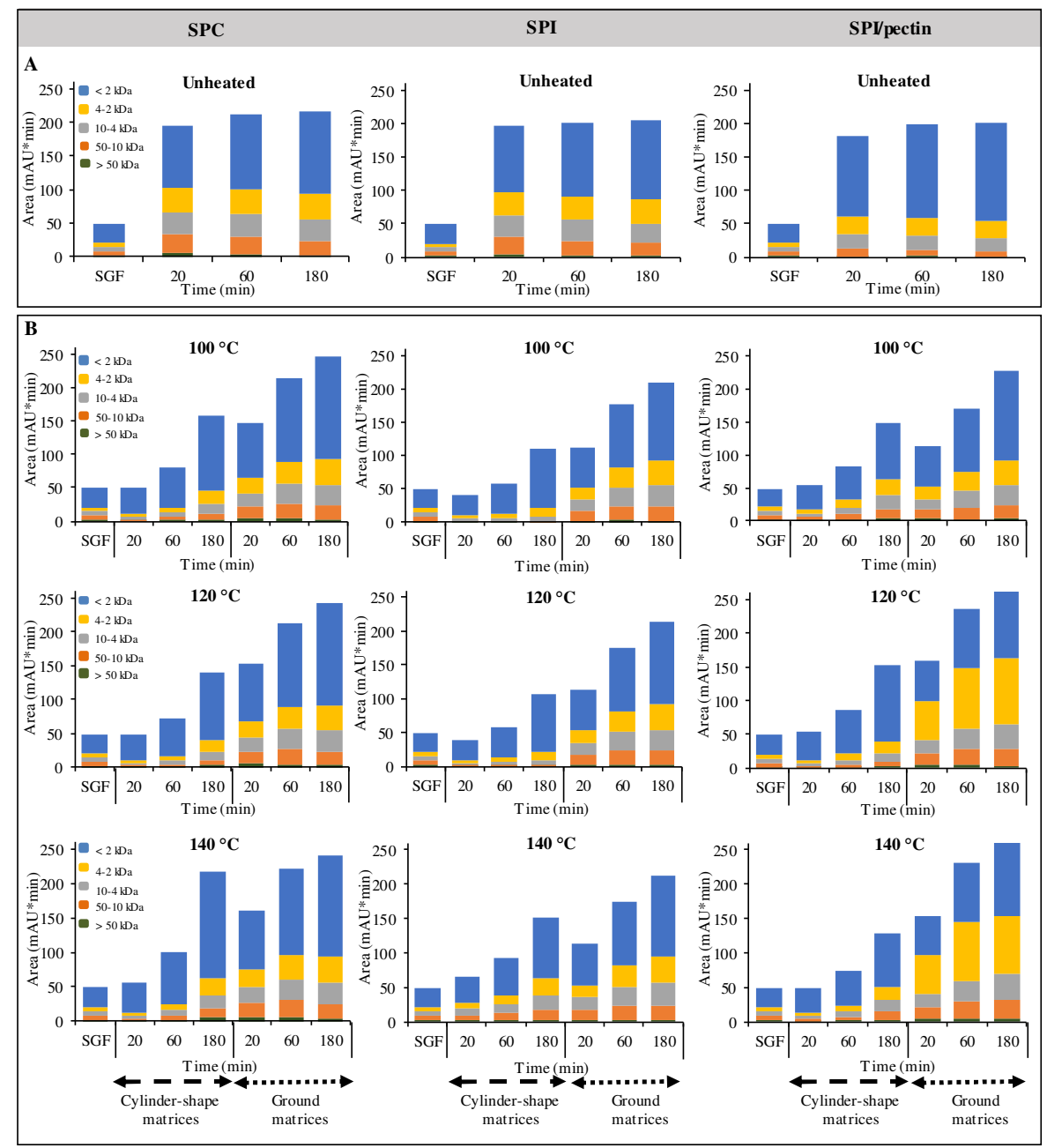

Figure 4.6. Peak area (mAU*min) of peptides distribution after 20, 60 and $180 \mathrm{~min}$ gastric digestion of unheated SPC, SPI, SPI/pectin ingredients (A) and protein-based matrices processed at different temperatures (cylinder-shape and ground matrices) (B). SGF: simulated gastric fluid. Results are shown as mean values (two independent samples, measured in duplicate). The mean values, standard deviations and statistics results are shown in table 4.1 and 4.2 in the supplementary information.

Even though after 180 min of gastric digestion SPC and SPI/pectin-based matrices reach similar DH (Figure 4.5.A,C) the distribution of their peptides was different, confirming relativity faster rate of hydrolysis of SPC-based matrices. This can be 
related to the reduced hydrophobicity of SPI/pectin-based matrices at 120 and 140 ${ }^{\circ} \mathrm{C}$ or to the presence of pectin hindering pepsin activity. The effect of polysaccharides on protein digestion was previously investigated for protein solutions (Mouécoucou et al., 2004; Zhang \& Vardhanabhuti, 2014); for instance, the presence of $1 \% \mathrm{w} / \mathrm{w}$ pectin in whey protein isolate solutions $(\mathrm{pH} 7.0)$ heated at 85 ${ }^{\circ} \mathrm{C}$ for $30 \mathrm{~min}$ has been shown to form aggregates due to extensive intragastric gelation, which were not digested after $2 \mathrm{~h}$ under in vitro conditions (Zhang \& Vardhanabhuti, 2014). Most of the pectin and more than half of the protein remained in the gels. Therefore, the presence of pectin decreased the digestion rate of whey protein.

\subsection{Conclusions}

The commercial soy protein ingredients used in this work contained a substantial amount of pre-formed protein-bound carbonyls, revealing a certain initial degree of protein oxidation. Application of a thermomechanical process to make structured matrices resulted in additional protein oxidation in SPC- and SPI/pectin-based matrices at $140{ }^{\circ} \mathrm{C}$. The process also led to reduced protein surface-exposed hydrophobicity. Structuring the starting ingredients via this process slowed down proteolysis, even though the actual rate showed no correlation with the level of carbonyls, nor with the applied temperature during processing. The peptide distribution during simulated gastric digestion was not affected by the process conditions, but the presence of pectin resulted in the formation of larger peptides. Therefore, we foresee that developing fractionation and storage methods to yield plant protein ingredients with a low level of protein oxidation is becoming an essential matter in the current transition to more plant protein-based food products.

\section{Abbreviations used}

ABS, absorbance; ACN, acetonitrile; ANSA, 8-anilino-1-napthalenesulfonic acid ammonium salt; $\mathrm{BCA}$, bicinchoninic acid; Borax, sodium tetraborate decahydrate; DNPH, 2,4- dinitrophenylhydrazine; DT'T, DL-dithiothreitol; \&, molar absorptivity; 
EDTA, diaminoethane tetraacetic acid; $F_{\max }$, maximum fluorescence intensity; $\mathrm{HCl}$, hydrochloric acid; HTSC, high temperature shear cell; $\mathrm{KCl}$, potassium chloride; $\mathrm{NaCl}$, sodium chloride; OPA, o-phtaldialdehyde; SDS, sodium dodecyl sulfate; SPC, soy protein concentrate; SPI, soy protein isolate; TCA, trichloroacetic acid; TFA, trifluoracetic acid; Tris, tris-(hydroxymethyl) aminomethane.

\section{Supplementary information}

Correlation graphs and statistics of peptide size distribution results (HPSEC).
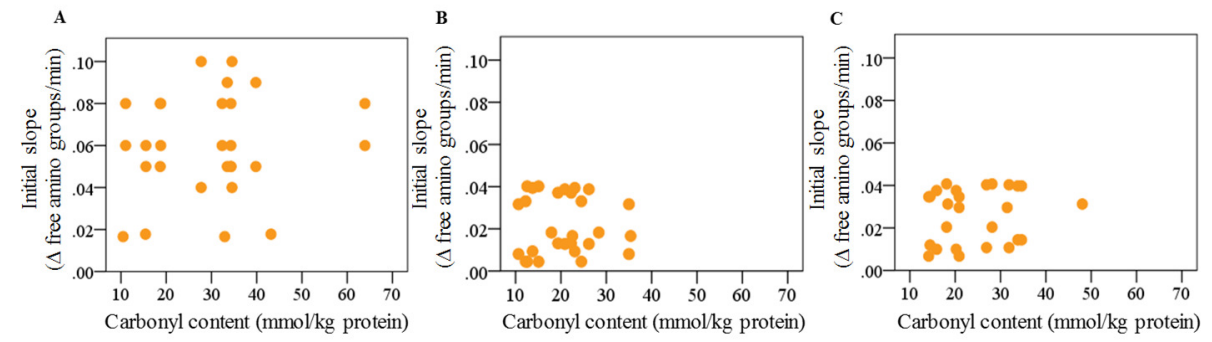

Figure 4.7. Relationship between initial slope ( $\Delta$ free amino groups $/ \mathrm{min})$ and carbonyl content (mmol $/ \mathrm{kg}$ protein) of SPC (A), SPI (B) and SPI/pectin (C) samples (protein ingredients and processed matrices).
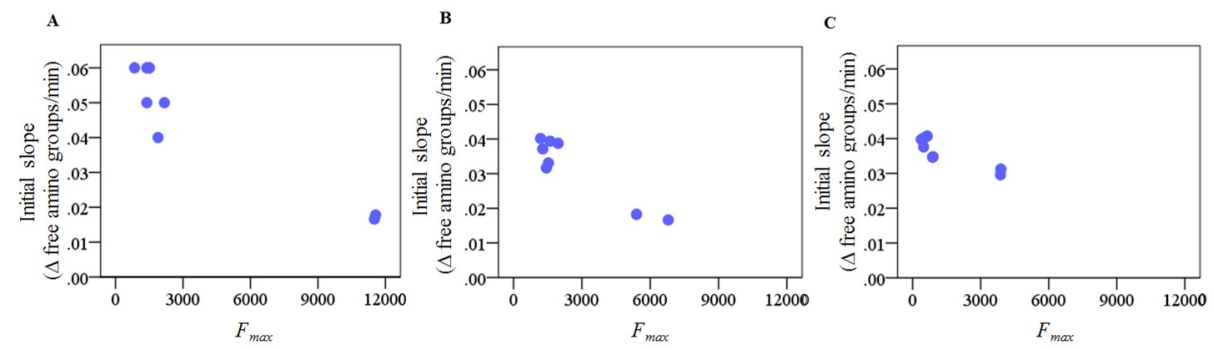

Figure 4.8. Relationship between initial slope ( $\Delta$ free amino groups $/ \mathrm{min})$ and exposedsurface hydrophobicity $\left(F_{\max }\right)$ of SPC (A), SPI (B) and SPI/pectin (C) samples (protein ingredients and processed matrices). 

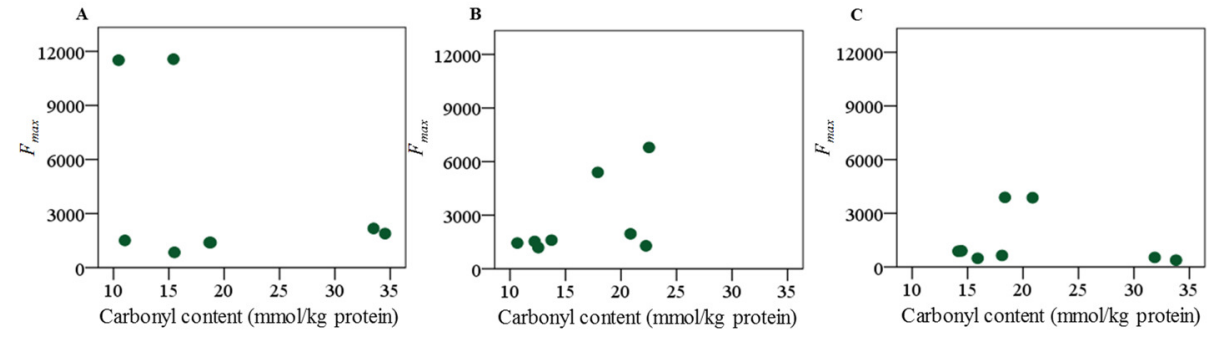

Figure 4.9. Relationship between exposed-surface hydrophobicity $\left(F_{\text {max }}\right)$ and carbonyl content ( $\mathrm{mmol} / \mathrm{kg}$ protein) in the soluble fractions of SPC (A), SPI (B) and SPI/pectin (C) samples (protein ingredients and processed matrices).

Table 4.1. Peptides size $(\mathrm{kDa})$ distribution of unheated soy ingredients (protein suspensions) obtained by size-exclusion chromatography.

\begin{tabular}{|c|c|c|c|c|}
\hline \multirow{2}{*}{$\begin{array}{c}\text { Peptides } \\
\text { size }(k D a)\end{array}$} & \multicolumn{4}{|c|}{ SPC } \\
\hline & \multicolumn{2}{|c|}{$20 \min$} & $60 \mathrm{~min}$ & 180 min \\
\hline$>50$ & 6.01 & \pm 0.28 a & $3.80 \pm 0.06 a$ & $2.55 \pm 0.21 \mathrm{a}$ \\
\hline $50-10$ & 27.57 & $\pm 2.21 \mathrm{a}$ & $25.09 \pm 0.12 a$ & $21.51 \pm 0.41$ \\
\hline $10-4$ & 33.43 & $\pm 3.05 \mathrm{a}$ & $34.17 \pm 0.20 a$ & $31.92 \pm 0.60 a$ \\
\hline $4-2$ & 36.06 & $\pm 0.00 \mathrm{a}$ & $37.39 \pm 0.28 a$ & $37.93 \pm 0.75$ \\
\hline \multirow[t]{2}{*}{$<2$} & 92.62 & $\pm 9.49 \mathrm{a}$ & $110.81 \pm 0.99 a$ & $122.45 \pm 2.18 a$ \\
\hline & \multicolumn{4}{|c|}{ SPI } \\
\hline$>\mathbf{5 0}$ & 4.22 & $\pm 0.90 \mathrm{a}$ & $2.79 \pm 0.38 a$ & $2.15 \pm 0.07 a$ \\
\hline $50-10$ & 25.50 & $\pm 1.54 \mathrm{a}$ & $21.91 \pm 0.93 b$ & $19.13 \pm 0.80 b$ \\
\hline $10-4$ & 33.36 & $\pm 1.83 \mathrm{a}$ & $31.69 \pm 1.51 \mathrm{a}$ & $29.49 \pm 1.41 a$ \\
\hline $4-2$ & 34.70 & $\pm 1.89 \mathrm{a}$ & $35.49 \pm 1.74 a$ & $35.71 \pm 1.72$ \\
\hline \multirow[t]{2}{*}{$<2$} & 98.69 & $\pm 5.45 \mathrm{a}$ & $108.57 \pm 5.84 a$ & $118.91 \pm 4.62$ \\
\hline & \multicolumn{4}{|c|}{ SPI/pectin } \\
\hline$>\mathbf{5 0}$ & 1.07 & $\pm 0.48 b$ & $1.39 \pm 0.21 b$ & $0.86 \pm 0.60 a$ \\
\hline $50-10$ & 11.78 & $\pm 0.84 \mathrm{~b}$ & $10.35 \pm 0.22 c$ & $8.50 \pm 0.36 c$ \\
\hline $10-4$ & 21.57 & $\pm 1.01 b$ & $20.85 \pm 0.17 b$ & $18.54 \pm 0.29 b$ \\
\hline $4-2$ & 25.97 & $\pm 1.18 b$ & $26.76 \pm 0.21 b$ & $25.15 \pm 0.04$ \\
\hline$<2$ & 120.29 & $\pm 5.77 \mathrm{a}$ & $138.47 \pm 1.81 \mathrm{~b}$ & $147.64 \pm 0.06 b$ \\
\hline
\end{tabular}

Results are expressed as mean \pm standard deviation $(\mathrm{n}=2$ independent samples measured in duplicate). Different letters per column refers to significant difference among samples within the same digestion time and peptide size $(\phi<0.05)$. Peptide size distribution of the simulated gastric fluid: > 50kDa: $1.62 \pm 0.68$; 50-10 kDa: $6.3 \pm 0.52 ; 10-4 \mathrm{kDa}: 6.52 \pm 0.29$; 4-2 kDa: $6.13 \pm 0.26 ;<2 \mathrm{kDa}: 28.28 \pm 1.17 \mathrm{kDa}$. 
Table 4.2. Peptides size $(\mathrm{kDa})$ distribution of processed soy-based matrices obtained by size-exclusion chromatography.

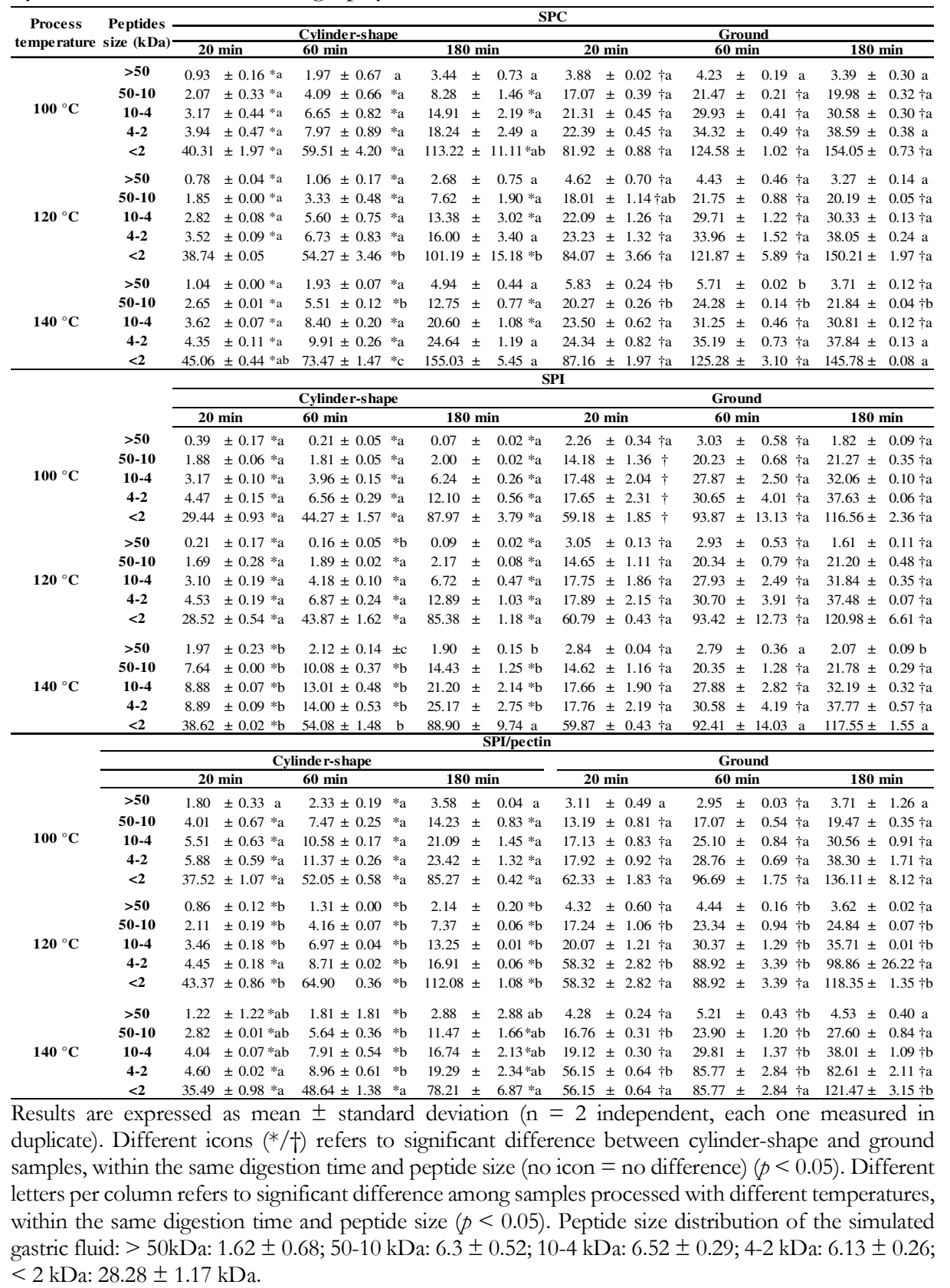

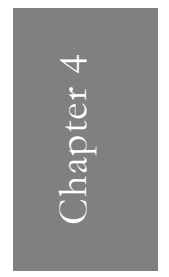




\section{Chapter 5}

Oxidative stability of soy proteins: from ground soybeans to structured products

This chapter has been submitted as: Duque-Estrada, P., Kyriakopoulou, K., de Groot, W., van der Goot, A.J, \& Berton-Carabin, C.C. Oxidative stability of soy proteins: from ground soybeans to structured products. 


\begin{abstract}
The production of soy protein-based foods requires multiple-step, intensive processing and storage of intermediate soy ingredients, which can increase the product's susceptibility to oxidation. Therefore, we investigated the oxidative stability of soy protein-based products subjected to different relevant conditions or treatments: over storage of soy flours, over fractionation to yield soy protein isolate (SPI), and over subsequent thermomechanical processing to yield a model structured food product. Soy flours were stable to lipid and protein oxidation over 250 days storage in chilled or ambient conditions. The fractionation process applied to make SPI did not increase substantially protein carbonylation, but increased surfaceexposed hydrophobicity and decreased free thiols, compared to the starting defatted flour. Subsequent processing of hydrated SPI powder at $140{ }^{\circ} \mathrm{C}$ further increased protein carbonylation to a high extent. Therefore, we conclude that soy flours can be stable over long storage times, but processing to yield structured foods products promote protein oxidation.
\end{abstract}




\subsection{Introduction}

Soy proteins have been widely used in food industry due to their functionality and high nutritional value (Kumar et al., 2017; Nishinari et al., 2017). Different soy protein ingredients can be obtained through processing of soybeans in various conditions: full-fat soy flour (FFSF) is obtained through soybean milling; defatted soy flour (DSF) is obtained after oil extraction from FFSF, and lastly soy protein concentrate (SPC) and isolate (SPI) are obtained after wet fractionation processes. For instance, SPC is obtained by an aqueous alcohol process (Johnson et al., 2008), while SPI is obtained by sequential steps of solubilization under alkali and precipitation under acid conditions (Assatory et al., 2019). The final stage of the fractionation process involves drying, which is usually done by spray-drying (large scale) or freeze-drying (lab-scale). The final soy protein ingredients, SPC and SPI, contain the major soybean storage proteins, $\beta$-conglycinin and glycinin (Paulsen, 2008). SPC usually contains $>65 \%$ proteins in dry basis and SPI $>90 \%$ proteins (Thrane et al., 2016).

The interest in soy protein ingredients aligns with the increased demand for alternatives to meat proteins, as soy proteins can be used as the main source of protein in the final product. Therefore, it is key to control the sensory, nutritional and functional properties of soy protein ingredients. One determining factor for the quality of lipid- and protein-containing ingredients is their oxidative status and stability. In soy flours, both lipids and proteins can be subjected to oxidation. Lipid oxidation is caused by a free radical chain reaction, which leads to primary and secondary oxidation products, of which the latter are responsible for off-flavors (Johnson \& Decker, 2015). In plant-derived ingredients, lipid oxidation can be initiated via different pathways: autoxidation, which can be promoted by traces of transition metals and high temperature (Schaich, 2005); photooxidation, which involves the production of singlet oxygen (Schaich et al., 2013); or enzymatic oxidation, which involves the presence of the enzyme lipoxygenase (LOX). 
Lipid oxidation products, as well as reactive oxygen species, can react with proteins, leading to protein oxidation (Min \& Ahn, 2005). Such co-oxidation phenomenon is relevant to FFSF, but may also play a role in DSF in which traces of unsaturated lipids can be present still. Studies have shown that adding unsaturated lipids to DSF or directly to the SPI induced protein oxidation in SPI (Boatright \& Hettiarachchy, 1995a; Huang et al., 2006). Protein oxidation results in modifications of amino acid side chains and of the protein backbone, such as carbonylation, which can lead to both fragmentation or crosslinking (Estévez, 2017). Protein oxidative modifications can thus lead to changes in protein structure and conformation. Some of these modifications involve changes in protein hydrophobicity and loss of essential amino acids, which can affect protein solubility, nutritional value, and recently a few studies have even associated it to harmful effects in vivo (Estévez \& Xiong, 2019).

So far, most of the research on the oxidative stability of SPI has focused on the ability of lipid oxidation products to induce protein oxidation (Chen et al., 2013c; Cucu et al., 2013; Huang et al., 2006; Wu et al., 2009b), but limited information is available about how the processes applied to obtain soy flours and derived protein ingredients affect protein oxidation. In our lab, we recently measured the protein-bound carbonyl content of several commercial SPC and SPI powders, and compared it to values reported in literature for different plant and animal proteins (Figure 5.7 in supplementary information). All the tested commercial ingredients had a higher carbonyl content than e.g., lab-made SPI as reported in literature (Chen et al., 2013b; Wu et al., 2009c). Compared to these commercial soy protein ingredients, the carbonyl contents for lupine protein isolate, whey protein isolate (WPI), raw chicken and bovine meat were also lower (Berghout et al., 2015b; Berton-Carabin et al., 2016; Santé-Lhoutellier et al., 2008a; Soyer et al., 2010). Such a variability in the proteinbound carbonyl levels suggests that either the process to obtain soy protein ingredients, and/or the subsequent storage conditions promote protein oxidation. Interestingly, it was previously reported that SPI flours have more carbon-centered radicals than animal protein ingredients such as WPI (Boatright et al., 2008; Boatright 
et al., 2012; Boatright et al., 2009; Lei et al., 2010). The release of those radicals increased during storage (Boatright et al., 2009) and upon hydration (Boatright et al., 2008). These results suggest that soy protein ingredients may be particularly prone to oxidation, especially in hydrated form.

Soy protein ingredients are frequently used to formulate structured food products, which involves further processing. These processes often use high temperatures, which can promote lipid and protein oxidation. Recently, we found that the carbonyl content increased in hydrated SPC when subjected to a thermomechanical process (Duque Estrada et al., 2018). It is therefore questionable if most of the protein oxidation products found in the final matrix are formed during the initial ingredient fractionation, or during processing to form the final structured product. It is also of high interest to know if the oxidation reactions occurring at both stages are rather independent, or if protein oxidation occurring in the final structuring process depends on the initial oxidative state of the ingredient.

We therefore investigated the oxidative stability of house-made FFSF and DSF stored at different temperatures for up to 250 days; and protein oxidation upon wet fractionation process of DSF to yield lab-made SPI. Finally, we also investigated how protein oxidation in SPI was further affected by applying a thermomechanical process, which would be the ultimate step towards final product fabrication.

\subsection{Material and methods}

\subsubsection{Materials}

Soybeans were obtained from FRANK Food Products (Twello, The Netherlands) and stored for less than 1 year at $4{ }^{\circ} \mathrm{C}$. According to the manufacturer, soybeans did not receive any post-harvesting treatment. SPI (SUPRO ${ }^{\circledR} 500 \mathrm{E}-80.16 \%$ protein) was obtained from Danisco (Copenhagen, Denmark) ( $\mathrm{N} \times$ 5.7). 8-Anilino-1napthalensulfonic acid ammonium salt (ANSA, $\geq 97 \%$ ), $\beta$-mercaptoethanol, sodium phosphate monobasic dihydrate $(\geq 99 \%)$, sodium phosphate dibasic $(\geq 99 \%), 2,4-$ dinitrophenylhydrazine (DNPH), trichloroacetic acid (TCA), sodium dodecyl sulfate 
(SDS), guanidine hydrochloride $\left(\mathrm{CH}_{5} \mathrm{~N}_{3} \mathrm{HCl}\right)$, cumene hydroperoxide solution (80\%), n-hexane, $p$-anisidine, Ellman's reagent or 5,5'-dithiobis (2-nitrobenzoic acid) (DTNB) and Bis-TRIS buffer were obtained from Sigma-Aldrich (Germany, Darmstadt). Hydrochloric acid ( $\mathrm{HCl}, 37 \%)$ was purchased from VWR Chemicals (Fontenay-sous-Bois, France). Ethanol (ACS 99\%), ethyl acetate (ACS 99\%), barium chloride $\left(\mathrm{BaCl}_{2} \cdot 2 \mathrm{H}_{2} \mathrm{O}\right)$, sodium hydroxide $(\mathrm{NaOH})$, ammonium thiocyanate $\left(\mathrm{NH}_{4} \mathrm{SCN}\right.$ ), 1-butanol, acetic acid (glacial) 100\% were purchased from Emsure (Merck Millipore, Darmstadt, Germany). Ferrous sulfate heptahydrate $\left(\mathrm{FeSO}_{4} \cdot 7 \mathrm{H}_{2} \mathrm{O}\right)$ and methanol were obtained from Actu-All Chemicals B.V. (Oss, The Netherlands). Petroleum ether was obtained from Avantor Performance Materials B.V. (Deventer, The Netherland). The bicinchoninic acid (BCA) protein assay kit was obtained from Thermo Scientific (Pierce, Rockford, US). Mini-Protean TGX gels (12\%), Bio-safe Coomassie G-250 stain, 2x Laemmli sample buffer, 10x Tris/Glycine/SDS buffer (25 mM Tris, $192 \mathrm{mM}$ glycine and $0.1 \mathrm{w} / \mathrm{v} \%$ SDS, 1x solution, $\mathrm{pH}$ 8.3) and precision plus protein dual color standard were purchase from Bio-Rad Laboratories (Munchen, Germany). Ultrapure water obtained from Millipore Milli-Q system was used for all experiments, unless otherwise stated.

\subsubsection{Preparation of soy flours: FFSF and DSF}

Soybeans were pre-milled using a pin mill (Condux-Werk LV 15 M, Wolfgang bei Hanau, Germany), followed by milling using a ZPS 50 impact mill (HosokawaAlpine, Augsburg, Germany). The conditions were set to: classifier wheel speed at $2500 \mathrm{rpm}$, air flow of $80 \mathrm{~m}^{3} / \mathrm{h}$, mill speed of $8000 \mathrm{rpm}$ and feed rate of 2-5 rpm (Geerts et al., 2018). Part of the obtained FFSF was immediately defatted using an automated Buchi extraction system B-811 LSV (BÜCHI Labortechnik AG, Flawil, Switzerland) according to AACC method 30-25 (AACC, 1983). We performed a short standard Soxhlet procedure according to Berghout et al. (2015b) with slight modifications, in which the heating step of the standard procedure was reduced to 3 $\mathrm{h}$ to avoid that long extraction and solvent evaporation. The oil was extracted with petroleum ether $(1: 3.5 \mathrm{w} / \mathrm{w})$ for $3 \mathrm{~h}$ followed by 20 min solvent removal in a rotor 
evaporator RC900 (KNF, Trenton, US) at $65{ }^{\circ} \mathrm{C}, 160 \mathrm{rpm}$ and $50 \mathrm{bar}$. The oil recovered was stored in plastic containers covered with aluminium foil and stored at $4{ }^{\circ} \mathrm{C}$ for analysis on the next day. The remaining solvent present in the DSF was evaporated overnight at room temperature while being protected from light exposure. On the next day, part of the obtained DSF was used for wet fractionation process.

Regarding storage conditions, both FFSF and DSF were stored in individual plastic containers covered with aluminium foil and stored at room temperature, $4^{\circ} \mathrm{C}$ and $20{ }^{\circ} \mathrm{C}$ for 250 days. During storage conditions experiments, the same defatting procedure was repeated at different time points to extract the oil from FFSF and analyze it.

\subsubsection{Wet fractionation process}

Wet fractionation was performed to prepare SPI from DSF according to Jiang et al. (2009) with some adjustments. After solvent evaporation, DSF was suspended in ultrapure water $(1: 9 \mathrm{w} / \mathrm{v})$ and the $\mathrm{pH}$ was adjusted to 8.0 using $1 \mathrm{M} \mathrm{NaOH}$. The sample was stirred for $3 \mathrm{~h}$, followed by centrifugation at 10,000 rpm corresponding to $17,217 \mathrm{~g}$ for $30 \mathrm{~min}$ at $4{ }^{\circ} \mathrm{C}$ using a Sorvall Lynx 4000 centrifuge (radius of 15.4 $\mathrm{cm}$ ) (Thermo Fisher Scientific, Waltham, MA, USA). The supernatant was collected and adjusted to $\mathrm{pH} 4.5$ with $1 \mathrm{M} \mathrm{HCl}$. After $1 \mathrm{~h}$ stirring the suspension was centrifuged at $17,217 \mathrm{~g}$ at $4{ }^{\circ} \mathrm{C}$ for $30 \mathrm{~min}$. The protein pellet was washed with ultrapure water $(1: 4 \mathrm{w} / \mathrm{v})$ twice and stirred for $1 \mathrm{~h}$. Subsequently, the suspension was centrifuged at $8000 \mathrm{rpm}$ corresponding to $11,019 \mathrm{~g}$ for $30 \mathrm{~min}$ at $4{ }^{\circ} \mathrm{C}$. The protein pellet was suspended $(1: 4 \mathrm{w} / \mathrm{v})$ in ultrapure water and the $\mathrm{pH}$ was adjusted to 7.0 using $1 \mathrm{M} \mathrm{NaOH}$. This protein suspension was left stirring (with regular $\mathrm{pH}$ adjustments to 7.0 if necessary) at $1000 \mathrm{rpm}$ for $2-3 \mathrm{~h}$, until the $\mathrm{pH}$ was stable. The suspension was frozen overnight, and on the next day, freeze-dried for $72 \mathrm{~h}$ using a Christ Epsilon 2-6D freeze-dryer (Martin Christ Gefriertrocknungsanlagen GmbH, Osterode am Harz, Germany). After freeze-drying, SPI was then pulverized by using 
a Rotor Mill Pulverisette 14 (Fritsch GmbH, Idar-Oberstein, Germany) with a sieving ring with diameter $0.5 \mu \mathrm{m}$ and a speed of $6000 \mathrm{rpm}$. The samples were stored at 4 ${ }^{\circ} \mathrm{C}$ for further analysis.

\subsubsection{Chemical and physical properties of soy flours}

The moisture content of FFSF, DSF and SPI was determined by drying $3 \mathrm{~g}$ sample at $105^{\circ} \mathrm{C}$ until constant weight in an oven (Binder $\mathrm{GmbH}$, Tuttlingen, Germany). The total protein content was determined by nitrogen content with the Dumas method using a Flash EA 1112 series N-analyzer (Thermo Fisher Scientific, Waltham, MA, USA) with a nitrogen conversion factor of 5.7. The soluble protein concentration was determined by bicinchoninic acid (BCA) assay. The oil content was determined by Soxhlet as described in section 5.2.2. The ash content was determined in $1 \mathrm{~g}$ of sample heated at $525^{\circ} \mathrm{C}$ for $5 \mathrm{~h}$ using ashing furnace $\mathrm{AAF} 11 / 3$ (Carbolite-Gero Ltd., Hope, UK), with a ramp rate of $15^{\circ} \mathrm{C} / \mathrm{min}$. Afterward, the samples were left in a desiccator until constant weight. The water activity of FFSF, DSF, and SPI was measured at $25^{\circ} \mathrm{C}$ in an Aqualab water activity meter (Decagon Devices Inc., Pullman, WA, US). The results of the analysis are presented in Table 5 in supplementary information. All measurements were done in triplicate on two independent batches, except for water activity for which independent batches were measured in duplicate.

\subsubsection{Thermomechanical process of SPI}

SPI samples were submitted to shear and heat-process in a closed cavity (disk geometry) rheometer (CCR) (RPA elite, TA instruments, US) to mimic a shearing at high-temperature processing, often used to produce plant protein-based products (Dekkers et al., 2018b). The hydrated powders were prepared with $44 \mathrm{wt} \%$ SPI, 55 $\mathrm{wt} \%$ demineralized water and $1 \mathrm{wt} \% \mathrm{NaCl}$, following the formulation determined by Dekkers et al. (2016). After mixing the ingredients and resting for $30 \mathrm{~min}$, approximately $3 \mathrm{~g}$ of the mixture were placed in the CCR, which was sealed with a closing pressure of 4.5 bar to prevent water evaporation. A time-sweep was 
performed at $80 \%$ strain and $10 \mathrm{~Hz}$ frequency while heating at 100 or $140{ }^{\circ} \mathrm{C}$ for 15 min. The resulting samples were then cooled down to room temperature and stored at $4{ }^{\circ} \mathrm{C}$ until further analysis.

\subsubsection{Preparation of soy protein suspensions to measure protein oxidation}

Suspensions of the soy protein ingredients (FFSF, DSF and SPI) were prepared with $6 \mathrm{wt} \%$ protein (based on protein content in dry basis) in ultrapure water or in $10 \mathrm{mM}$ sodium phosphate buffer $\mathrm{pH}$ 7.0, when mentioned. The samples were quickly vortexed at $2500 \mathrm{rpm}$ and then mixed at $1980 \mathrm{rpm}$ in a Multi Reax shaker (Heidolph Instruments $\mathrm{GmbH} \& \mathrm{CO}$, Schwabach, Germany) for $2 \mathrm{~h}$ at $4{ }^{\circ} \mathrm{C}$. After $2 \mathrm{~h}$ the samples were centrifuged at $18,000 \mathrm{~g}$ for $2{ }^{\circ} \mathrm{C}$ for $20 \mathrm{~min}$ and the soluble fraction was recovered.

The processed SPI-based samples were first cut into small pieces, then homogenized with ultrapure water to prepare a $6 \mathrm{wt}^{\%} \%$ protein suspension using a rotor-stator homogenizer (IKA T18 UltraTurrax, Thermo Fisher Scientific, Staufen, Germany) at $13600 \mathrm{rpm}$ for $1 \mathrm{~min}$. Afterwards the homogenate was centrifuged at $18,000 \mathrm{~g}$ at 2 ${ }^{\circ} \mathrm{C}$ for $20 \mathrm{~min}$ and the supernatant was recovered. The soluble protein concentration was measured with the BCA assay as described in section 5.2.4. The percentage of soluble protein in the supernatant compared to the initial total protein content (based on protein content in dry basis) was determined (Figure 5.8, supplementary information).

\subsubsection{Determination of protein-bound carbonyl content}

The determination of protein-bound carbonyl content was done according to Soglia et al. (2016b) with modifications previously described by Duque Estrada et al. (2018). In the current paper, only the fraction obtained after the first centrifugation step was considered since solubilization of soy flours was not an issue. Aliquots from the protein fractions (section 5.2.6) (at least $4 \mathrm{mg} / \mathrm{mL}$ soluble protein) were taken to measure the carbonyl content by the DNPH method. After the hydrazone derivatization, the pellets were suspended in $1.5 \mathrm{~mL}$ of $6 \mathrm{M}$ guanidine hydrochloride 
prepared in $20 \mathrm{mM}$ sodium phosphate buffer $(\mathrm{pH}$ 6.5) and incubated in an Eppendorf thermomixer (Eppendorf AG, Germany) at $37{ }^{\circ} \mathrm{C}$ overnight. Then, the absorbance was measured at $370 \mathrm{~nm}$ using a UV-visible spectrophotometer $(\mathrm{HACH}$ Lange DR 3900). A blank was prepared by following the exact same procedure, but without DNPH. The soluble protein concentration in $6 \mathrm{M}$ guanidine hydrochloride was determined by the BCA method. The carbonyl content was calculated with the following equation:

$$
\text { Carbonyl content }\left(\frac{\mathrm{mmol}}{\mathrm{kg}}\right)=\frac{\frac{A B S_{\text {sample }-A B S_{\text {blank }}}}{\varepsilon}}{\text { soluble protein concentration }} \quad \text { Eq. } 1
$$

Where, $A B S_{\text {sample }}$ is the absorbance of the sample, $A B S_{\text {blank }}$ the absorbance of the blank and $\mathcal{E}$ is the molar extinction coefficient of carbonyls set as $22000 \mathrm{M}^{-1} \mathrm{~cm}^{-1}$.

\subsubsection{Lipid oxidation: primary and secondary products}

\section{Hydroperoxide concentration}

The formation of hydroperoxides in the oil extracted from FFSF, freshly prepared or upon storage in various conditions, was measured according to Berghout et al. (2015b). The oil was mixed with $\mathrm{n}$-hexane in a 1:60 w/v ratio. Then the solution was vortexed for $30 \mathrm{~s}$. The assay reagent was prepared as follows: equal volumes of 0.144 $\mathrm{M}$ ferrous sulfate heptahydrate $\left(\mathrm{FeSO}_{4} \cdot 7 \mathrm{H}_{2} \mathrm{O}\right)$ were mixed with $0.132 \mathrm{M} \mathrm{BaCl}_{2}$ in $0.4 \mathrm{M} \mathrm{HCl}$, then centrifuged for $3 \mathrm{~min}$ at 20,238g using the Eppendorf Centrifuge 5424 (Eppendorf AG, Hamburg, Germany). The supernatant was collected and mixed with $3.94 \mathrm{M}$ ammonium thiocyanate in equal volumes. The later solution was the assay reagent. Then, $1.40 \mathrm{~mL}$ methanol-butanol $(3: 1 \mathrm{v} / \mathrm{v})$ was mixed with 0.10 $\mathrm{mL}$ oil/n-hexane sample and $15 \mu \mathrm{L}$ assay reagent. The samples were covered, mixed and incubated for $20 \mathrm{~min}$. After the $20 \mathrm{~min}$ incubation, the absorbance was measured at $510 \mathrm{~nm}$ using a Beckman Coulter DU 720 UV/VIS spectrophotometer (Beckman Coulter, Brea, CA, USA) in polystyrene cuvettes. A calibration curve was prepared from a stock $5.26 \mathrm{mM}$ cumene peroxide solution $(80 \%)$ with a concentration range 
of $0-160 \mu \mathrm{M}$ to calculate the amount of peroxide in the oil samples. The hydroperoxide concentration $\left(C_{H P X}\right)$ was then calculated with the following equation:

$$
C_{H P X}(\text { meq } / \mathrm{kg} \text { oil })=\frac{\text { mmol peroxide }}{2 * k g \text { of oil }} \text { Eq. } 2
$$

in which 2 was the conversion factor from $\mathrm{mmol}$ to meq $\mathrm{O}_{2}$.

\section{p-Anisidine value}

The p-anisidine value (pAV) was determined according to Berghout et al. (2015b). The oil/n-hexane mixture was prepared as described previously. First, the absorbance of $1.2 \mathrm{~mL}$ of the oil/n-hexane mixture was measured at $350 \mathrm{~nm}$ using a Beckman Coulter DU 720 UV/VIS spectrophotometer (Beckman Coulter, Brea, CA, USA) in quartz cuvettes. A blank of pure $\mathrm{n}$-hexane was used. Then, $1 \mathrm{~mL}$ of oil/n-hexane mixture was mixed with $0.2 \mathrm{~mL}$ of $2.5 \mathrm{~g} / \mathrm{L}$ p-anisidine/acetic acid solution. The resulting mixture was vortexed at $2500 \mathrm{rpm}$ for $10 \mathrm{~s}$ and incubated for $10 \mathrm{~min}$ in the dark. The blank was pure $\mathrm{n}$-hexane with $\mathrm{p}$-anisidine. After $10 \mathrm{~min}$ incubation, the absorbance was measured at $350 \mathrm{~nm}$. To calculate the pAV (arbitrary units), the following equation was used:

$$
\mathrm{pAV}=\frac{1.2 A s-A b}{m} \mathrm{Eq} \cdot 3
$$

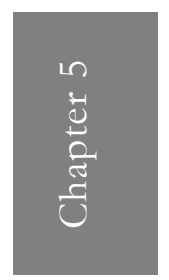

in which $A s$ is the absorbance of the sample, $A b$ is the absorbance of the blank and $m$ the mass (g) of oil per $\mathrm{mL} n$-hexane.

\subsubsection{Determination of thiol groups (free sulfhydryl groups)}

The free thiol group concentration was measured according to Berghout et al. (2015a). The supernatants of FFSF, DSF and SPI suspensions prepared as described in section 5.2.6 were diluted to a final soluble protein concentration of $5 \mathrm{~g} / \mathrm{L}$. Then, in a $15-\mathrm{mL}$ tube, $0.2 \mathrm{~mL}$ sample was added to $2.55 \mathrm{~mL}$ of $50 \mathrm{mM}$ Bis-TRIS buffer (pH 7.0) and to $0.25 \mathrm{~mL}$ DTNB solution ( $0.1 \%$ (w/v) Bis-TRIS buffer). The tubes 
were protected from light and mixed. After a total incubation time of $15 \mathrm{~min}$, the absorbance was measured at $412 \mathrm{~nm}$ with a spectrophotometer UV-VIS Beckman Coulter DU-720 (Woerden, the Netherlands). Two blanks were prepared to correct the absorbance value, in which buffer was used to replace DTNB in the sample blank $\left(S_{B}\right)$ and to replace the sample in the reagent blank $\left(R_{B}\right)$.

The concentration of thiol groups ( $C_{S H}, \mu \mathrm{mol} / \mathrm{g}$ soluble protein) was calculated using the following equation 4 :

$$
C_{S H}=\frac{\left(\frac{A b s}{\varepsilon * \mathrm{z}}\right) * D F * 10^{6}(\mu \mathrm{mol} / \mathrm{L})}{\text { Soluble protein concentration }(g / L)} \quad \text { Eq. } 4
$$

Where $A b s$ is the net absorbance value after blank correction $\left(A b s=\right.$ sample $A b s-S_{B}$ $\left.-R_{B}\right), \mathcal{E}$ is the molar extinction coefficient for DTNB $\left(13,600 \mathrm{M}^{-1} \mathrm{~cm}^{-1}\right)$, $z$ the path length, $D F$ is the dilution factor of the sample and $10^{6}$ is to convert $\mathrm{mol} / \mathrm{L}$ to $\mu \mathrm{mol} / \mathrm{L}$.

\subsubsection{Sodium dodecyl sulphate polyacrylamide gel (SDS-PAGE)}

The molecular weight distribution of proteins in the different samples was assessed by performing SDS-PAGE in non-reducing and reducing conditions. First, the FFSF and DSF supernatants (section 5.2.6) were diluted to obtain a protein concentration of around $1 \mathrm{~g} / \mathrm{L}$, and the SPI supernatant was diluted to obtain a protein concentration of $2.5 \mathrm{~g} / \mathrm{L}$. For non-reducing conditions, samples were mixed with the 2x Laemmli buffer (1:1). For reducing conditions the sample buffer was prepared by mixing $950 \mu \mathrm{L}$ of $2 \mathrm{x}$ Laemmli buffer with $50 \mu \mathrm{L}$ of $\beta$-2-mercaptoethanol. Samples were then mixed with the reducing sample buffer (1:1). All samples were heated at $95{ }^{\circ} \mathrm{C}$ for $5 \mathrm{~min}$ in an Eppendorf thermomixer (Eppendorf AG, Germany) and cooled at room temperature for $30 \mathrm{~min}$. After cooling down, the samples were centrifuged using 10,000g for $5 \mathrm{~min}$. Then, $15 \mu \mathrm{L}$ of samples or molecular weight standard were deposited on top of the gels. The electrophoresis was carried out at $200 \mathrm{~V}$ for approximately $30 \mathrm{~min}$. Afterwards, the gels were washed 3 times with ultrapure water and stained with Bio-safe Coomassie stain overnight. The gels were 
then washed with ultrapure water for 30 min before scanning using a GS-900 Calibrated Densitometry System (Bio-Rad Laboratories, Inc., USA). The gel images were analyzed using the Image Lab (version 2.0.1, Bio-Rad Laboratories). SDSPAGE was done in duplicate in 2 independent samples.

\subsubsection{Protein surface-exposed hydrophobicity}

The protein surface-exposed hydrophobicity was determined according to BertonCarabin et al. (2016). Supernatants of samples prepared in $10 \mathrm{mM}$ sodium phosphate buffer $\mathrm{pH}$ 7.0, (section 5.2.6) were diluted to a final concentration of $1 \mathrm{~g} / \mathrm{L}$ soluble protein. A solution of the anionic fluorescence probe 8-anilino-1-napthalensulfonic acid ammonium salt (ANSA) (2.4 mM) was prepared in $10 \mathrm{mM}$ sodium phosphate buffer at $\mathrm{pH} 7.0$ and mixed overnight at $4{ }^{\circ} \mathrm{C}$. The fluorescence emission spectra were measured between 400 and $650 \mathrm{~nm}$ with steps of $0.5 \mathrm{~nm}$ using a RF-6000 spectrofluorometer (Shimadzu Corporation, Kyoto, Japan). The excitation wavelength was set at $385 \mathrm{~nm}$ and the emission was measured at $480 \mathrm{~nm}$, with a scan rate of $60 \mathrm{~nm} / \mathrm{min}$ and spectral bandwidth of $5.0 \mathrm{~nm}$. For this measurement, quartz cuvettes with dimensions $10 \times 10 \mathrm{~mm}$ were used (Hellma Analytics, Müllheim, Germany). Then $1 \mathrm{~mL}$ of sample was mixed with $10 \mu \mathrm{L}$ ANSA for $1 \mathrm{~min}$ and the spectrum was recorded. ANSA was added to the sample until it reached saturation. The results are expressed as the maximum fluorescence intensity $\left(F_{\text {max }}\right)$ at $480 \mathrm{~nm}$, corrected after blanks subtraction: sample with no ANSA and buffer with the same ANSA concentration. Measurements were done in 2 independent samples.

\subsubsection{Study design}

In Figure 5.1 we show a schematic representation of the different soy-based ingredients and products prepared, stored and analyzed for lipid and protein oxidation. 


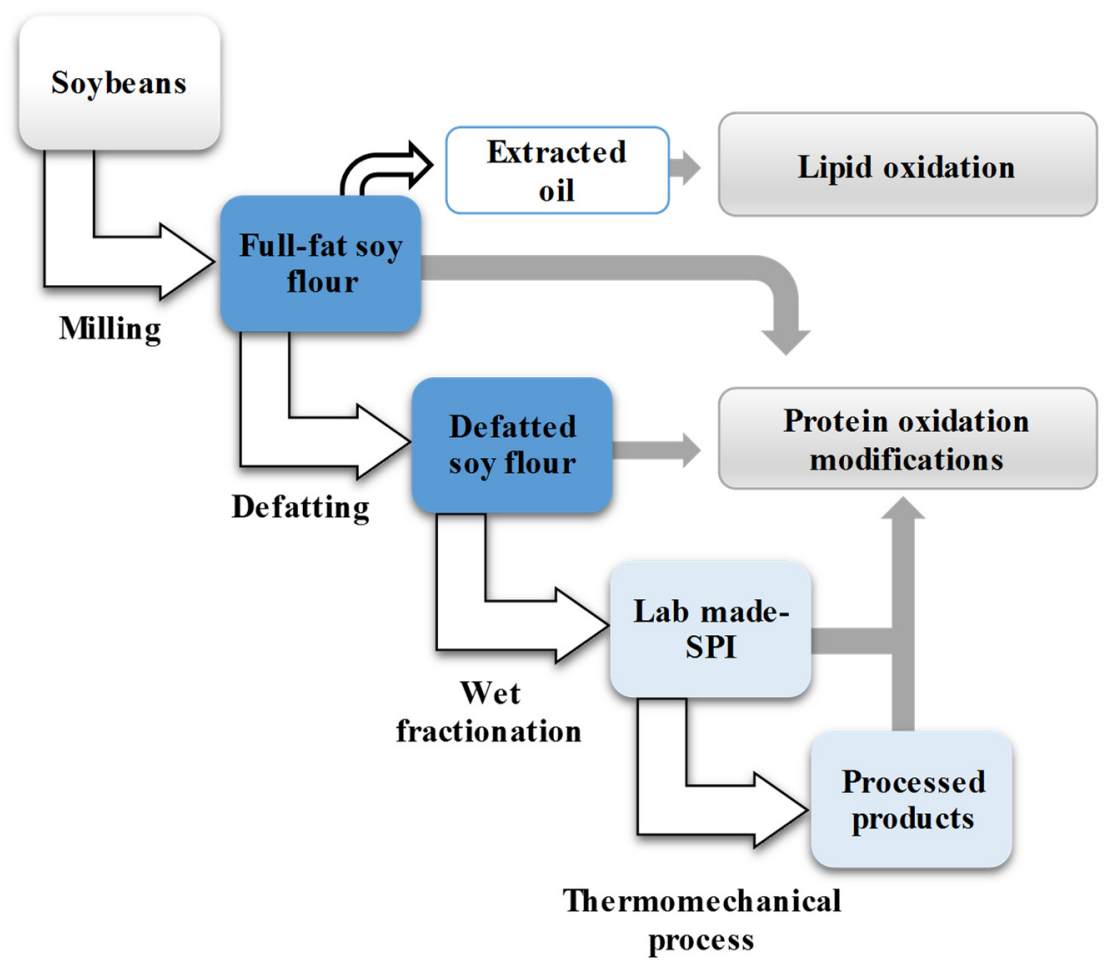

Figure 5.1. Schematic representation of the study design. Blue boxes represents the samples that we analyzed. Darker blue boxes represents samples that were stored for 250 days at room temperature, $4{ }^{\circ} \mathrm{C}$ and $-20^{\circ} \mathrm{C}$. White arrows indicates processing and grey arrows indicates oxidation measurements. SPI: soy protein isolate.

\subsubsection{Statistical analysis}

All the data are expressed as the mean and standard deviation of independent samples, which were measured in triplicate per experiment, unless otherwise stated. Statistical analysis was done using the Statistical Package for the Social Sciences (SPSS software v. 23, IBM Inc.). One way-ANOVA with a post hoc Turkey test was done to compare means of carbonyl content of FFSF and DSF stored at different temperatures within the same storage day; carbonyl content of unheated and thermomechanical treated SPI; and means of protein surface-exposed hydrophobicity and thiol groups among soy protein ingredients. T-Test for independent samples was used to compare means of carbonyl content between lab- 
made SPI and commercial, within the same process conditions. Significant level was set at $p<0.05$.

\subsection{Results and discussion}

First, the effect of storage temperature on the chemical stability of FFSF and DSF was determined over 250 days. This was assessed by measuring primary and secondary lipid oxidation products, and protein-bound carbonyls and protein molecular weight distribution as markers for protein oxidative modifications. Second, the oxidative status of SPI was determined, considering the effects of wet fractionation and of thermomechanical process.

\subsubsection{Effect of storage conditions on the oxidative stability of FFSF and DSF}

\section{Lipid oxidation}

The formation of lipid hydroperoxides in the soybean oil extracted from FFSF is shown in Figure 5.2.A. The hydroperoxide concentration in the fresh samples was $2.55 \pm 1.25$ meq.kg- ${ }^{-1}$ of oil, and this concentration did not significantly increase over the 250 days of storage, whatever the storage temperature. The concentration of hydroperoxides in crude soybean oil extracted by organic solvent has been reported to be around 0.6 meq.kg- ${ }^{-1}$ (De Moura Bell et al., 2013) or 2 meq.kg-1 (Alencar et al., 2010). These values correspond to our findings, albeit slightly lower, which could be due to some variability in moisture and lipid content in the soybeans, and in the extraction conditions (Crowe et al., 2002). According to the Codex Alimentarius, peroxide values that are considered acceptable for human consumption are up to 10 meq. $\mathrm{kg}^{-1}$ of refined oil and 15 meq. $\mathrm{kg}^{-1}$ of cold pressed and virgin oil (FAO, 1999). This means that the oil present in FFSF stored at different temperatures for up to 250 days is still acceptable according to these standards. 
A

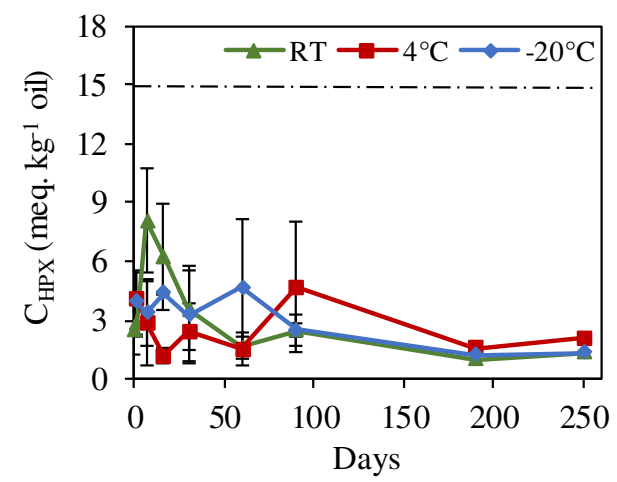

B

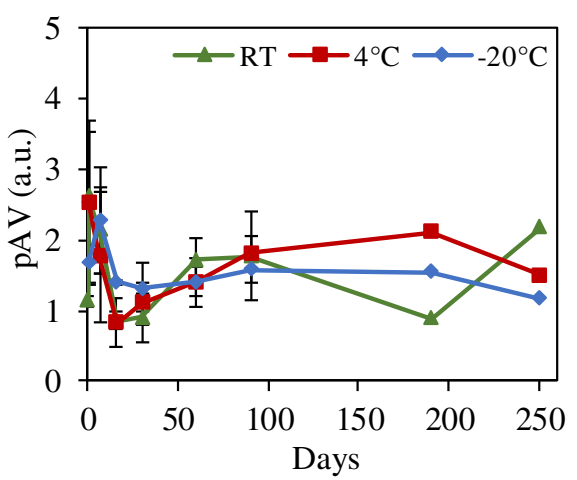

Figure 5.2. Hydroperoxide concentration ( $\mathrm{C}_{\mathrm{HPX}}$, meq. $\left.\mathrm{kg}^{-1} \mathrm{oil}\right)(\mathrm{A})$ and p-anisidine value (pAV) (B) of soybean oil contained in full-fat soy flour during 250 days of storage at room temperature $(\mathrm{RT}), 4^{\circ} \mathrm{C}$ and $-20^{\circ} \mathrm{C}$. Data points represent mean ( $\mathrm{n}=2$ independent batches, measured in triplicate) and standard deviations shown as error bars. Data points at 190 and 250 days represent results of 1 batch measured in triplicate. The dotted line represents acceptable $\mathrm{C}_{\mathrm{HPx}}$ for edible vegetable oils according to Codex Alimentarius (A).

The formation of secondary oxidation products measured by pAV was also minimal over the 250 days of storage, and no effect of temperature was observed (Figure

5.2.B). The oil extracted from fresh FFSF had a pAV value of $1.13 \pm 0.08$. Likewise, De Moura Bell et al. (2013) found a pAV value of 1.88 for crude soybean oil extracted with an organic solvent. Although lower pAV values of $0.28-0.47$ have been described for vegetable oils, such as rapeseed, sunflower and kiwiseed oil, those were freshly stripped by means of an adsorbent material (Viau et al., 2016). Overall, we can thus conclude that our FFSF was stable to lipid oxidation over the tested storage period, whatever the temperature. This may be due to the low moisture content and water activity of this ingredient (Table 5, supplementary information). In those conditions, lipid oxidation is in fact expected to be low (Schaich et al., 2013). 


\section{Protein-bound carbonyl content}

The protein-bound carbonyl content in FFSF and DSF, measured over 250 days of storage at different temperatures, is shown in Figure 5.3. Fresh FFSF had a carbonyl content of $5.87 \pm 1.80 \mathrm{mmol}$ carbonyl $/ \mathrm{kg}$ soluble protein (Figure 5.3.A), which moderately increased over 60 days of storage at room temperature. However, due to variability among batches, this increase was not significant $(p>0.05)$. The differences among batches might be due to the fact that radical chain reactions are auto-catalytic, and inherently difficult to control and reproduce, especially when no catalyst is purposely added (Schaich, 2005).
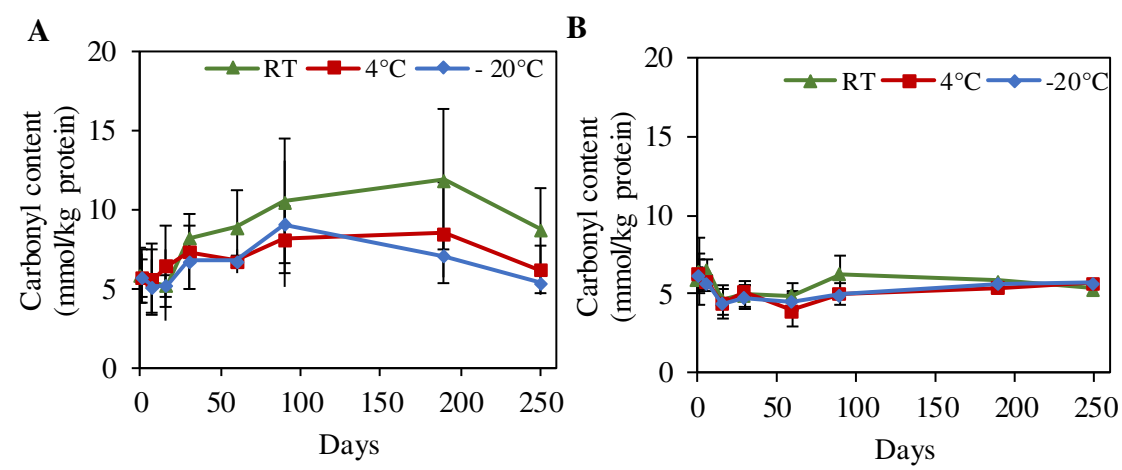

Figure 5.3. Carbonyl content per soluble protein $(\mathrm{mmol} / \mathrm{kg})$ in full-fat soy flour $(\mathrm{A})$ and defatted soy flour (B) stored for 250 days at room temperature (RT), $4{ }^{\circ} \mathrm{C}$ and $-20^{\circ} \mathrm{C}$. Data points represent mean and standard deviations are shown as error bars $(\mathrm{n}=4$ independent batches of FFSF and 2 independent batches of DSF, measured in triplicate).

Fresh DSF had a carbonyl content of $5.92 \pm 0.76 \mathrm{mmol}$ carbonyl $/ \mathrm{kg}$ soluble protein (Figure 5.3.B) which did not increase over storage (Figure 5.3.B). Lower carbonyl content of $2.79 \pm 0.06 \mathrm{mmol}$ carbonyl $/ \mathrm{kg}$ soluble protein was previously reported for full-fat lupin flour submitted to the same milling process as our FFSF and stored for 2 weeks at $20^{\circ} \mathrm{C}$ (Berghout et al. 2015b). Differences in carbonyl content between the full-fat lupin flour and FFSF may be attributed to oil fatty acid composition, as soybean oil usually contains around $50 \%$ polyunsaturated fatty acids and lupine oil 
only around 30\% (Johnson et al., 2008; Sbihi et al., 2013). Differences in microconstituent composition (e.g., transition metals such as iron) could also play a role.

Furthermore, it is relevant to mention that the carbonyl content was measured in the soluble fraction (i.e., supernatant) of FFSF and DSF, which represents half of the total protein suspended in water (Figure $\mathbf{5 . 8}$ in supplementary information). Measurement of carbonyls in the non-soluble proteins cannot be accessed by DNPH method. More generally, most of the methods available to monitor general or specific protein oxidation markers give information only on the protein fraction that can be re-solubilized, which hampers the characterization of the proteins that cannot, although they may be highly chemically altered.

It is interesting to speculate on the reasons that may explain why FFSF seemed slightly more prone to protein carbonylation upon storage, compared to DSF (Figure 5.3). The presence of lipids is the most logical reason, because protein carbonylation is influenced by presence of unsaturated oil and its oxidation level (Cucu et al., 2013). To prove this effect, Cucu et al. (2013) prepared emulsion-based model systems with SPI and different oils, regarding composition and oxidation level. Carbonylation increased from $\sim 3 \mathrm{mmol}$ carbonyl $/ \mathrm{kg}$ soluble protein to $\sim 12 \mathrm{mmol}$ carbonyl $/ \mathrm{kg}$ soluble protein in SPI incubated with highly oxidized soybean oil (pAV value around 94) and fish oil (pAV value around 13) compared to fresh olive oil, sunflower oil and soybean oil with lower oxidation level (pAV value around 4 to 10). Therefore, we assume that the presence of oil in the FFSF contributed to the moderate carbonylation over time. The low levels of oxidation in the oil extracted from FFSF are in line with the limited protein oxidation in those samples. 


\section{Molecular size distribution by SDS-PAGE: FFSF and DSF}

We performed SDS-PAGE to investigate the molecular weight distribution of proteins in FFSF and DSF (Figure 5.4), freshly prepared, and upon storage (7, 90 and 250 days at $-20^{\circ} \mathrm{C}$; similar trends were observed at the other temperatures tested, data not shown). All major soy protein subunits, namely $\alpha, \alpha, \beta$ subunits of $\beta$ conglycinin and acidic and basic subunits of glycinin, were present in both soy flours as previously reported (Lamsal \& Johnson, 2007; Ribotta et al., 2004). Bands with high molecular weights such as $100 \mathrm{kDa}$ ascribed to LOX, and those higher than 100 $\mathrm{kDa}$ are interpreted as aggregates between $\alpha$ and $\alpha$ ' subunits through disulfide bonds (Janve et al., 2014; Qi et al., 2011). The presence of aggregates between $\alpha$ and $\alpha$ ' subunits is in line with the fact that they were not seen any more when the SDSPAGE was performed in reducing conditions (Figure 5.4). We did not detect differences among storage days and between FFSF and DSF samples under nonreducing conditions. Therefore, both flours were relatively stable over time with regard to protein molecular weight distributions, without any unexpected aggregation or fragmentation phenomena. 


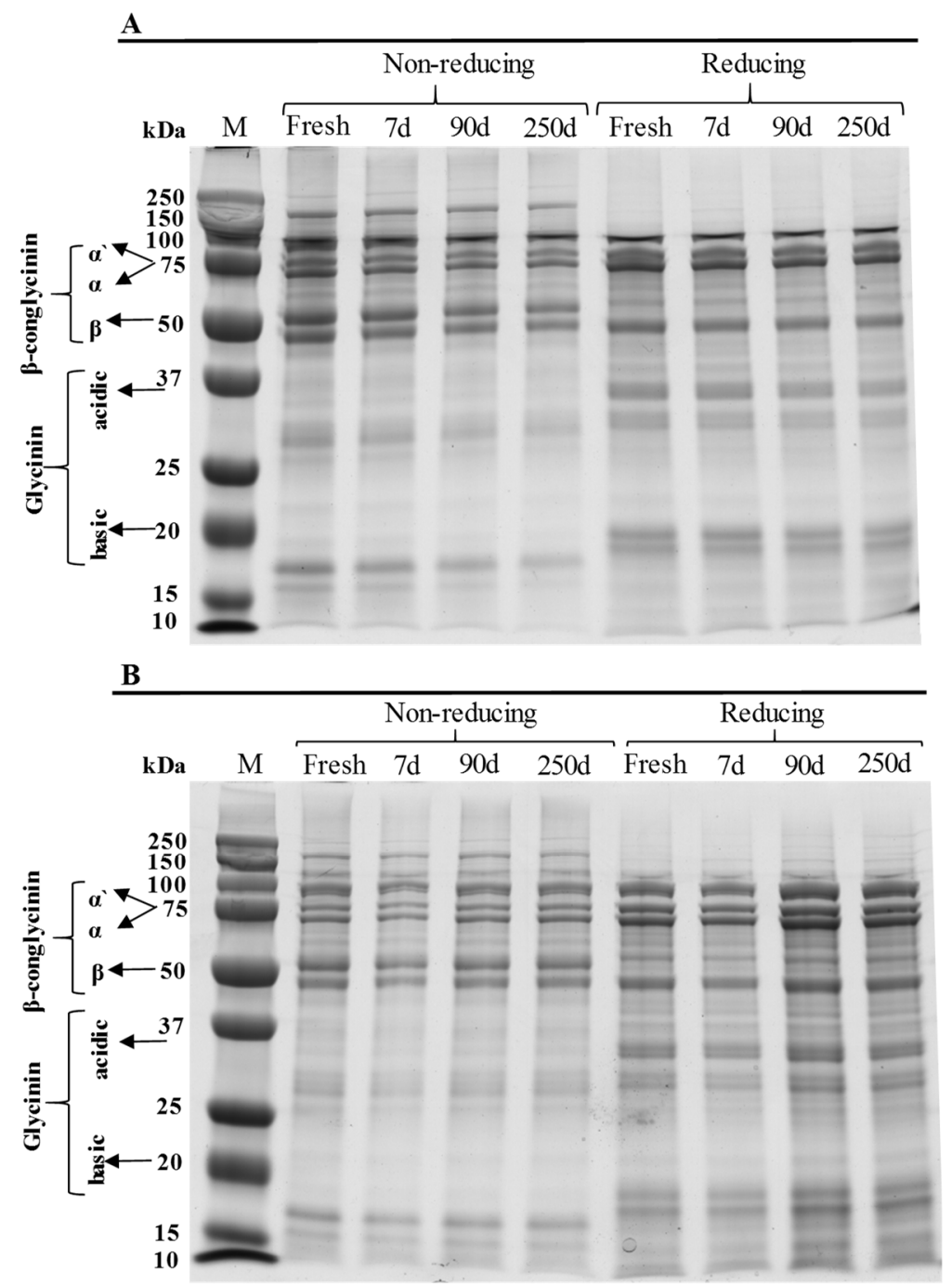

Figure 5.4. SDS-PAGE of FFSF (A) and DSF (B) fresh and stored for 7, 90 and 250 days at $-20^{\circ} \mathrm{C}$, under non-reducing and reducing conditions $\mathrm{M}$, molecular weight marker; $\mathrm{d}$, days of storage, $\alpha / \alpha / \beta$, subunits of $\beta$-conglycinin. 


\subsubsection{Effect of fractionation process on the oxidative status of SPI}

The effect of wet fractionation process on the physicochemical properties of proteins in SPI was assessed by determining protein surface-exposed hydrophobicity, thiol groups, and protein-bound carbonyl content. The molecular weight distribution was determined by SDS-PAGE. We compared our lab-made SPI to a commercial SPI.

The protein surface-exposed hydrophobicity in DSF was lower than that in FFSF, suggesting protein conformational changes induced by the solvent-based extraction. Both the lab-made and commercial SPIs had higher surface-exposed hydrophobicity than FFSF and DSF (Figure 5.5.A), indicating that more hydrophobic segments were exposed in these purified ingredients. Protein conformational changes could be induced by denaturation, but also, protein oxidation can affect the surface-exposed hydrophobicity. For instance, Berton-Carabin et al. (2016) found a decrease in surface-exposed hydrophobicity of whey proteins incubated in prooxidant conditions, which was related to extensive protein aggregation. Even though there was no significant difference in the surface-exposed hydrophobicity observed between the SPI samples (lab-made and commercial), we observed a large variability between the independent lab-made SPI samples obtained from different batches of DSF (Figure 5.5.A).

The concentration in thiol groups, or free sulfhydryl groups, was similar in FFSF and DSF (Figure 5.5.B). This shows that the defatting process did not induce thiol oxidation. However, the lab-made SPI had the lowest thiol group concentration, showing that during wet fractionation a loss of thiol groups happened, which may be associated to their oxidation ( $\mathrm{Li}$ et al., 2013; Rysman et al., 2014). Berghout et al. (2015a) reported a slightly lower thiol concentration of $10.6 \mu \mathrm{mol} / \mathrm{g}$ protein in a commercial SPI, using the same method as reported here. Meanwhile, studies on labmade SPIs have found lower concentrations of thiols, ranging from 3.08 to 8.32 $\mu \mathrm{mol} / \mathrm{g}$ protein (Boatright \& Hettiarachchy, 1995b; Chamba et al., 2014; Chen et al., 2013b; Huang et al., 2006; Liu et al., 2000; Wu et al., 2009b,c). The broad range in 
thiol concentration described in the literature can be explained by the biological variability in the starting soybeans, as well as by differences in the processes applied to yield SPI.
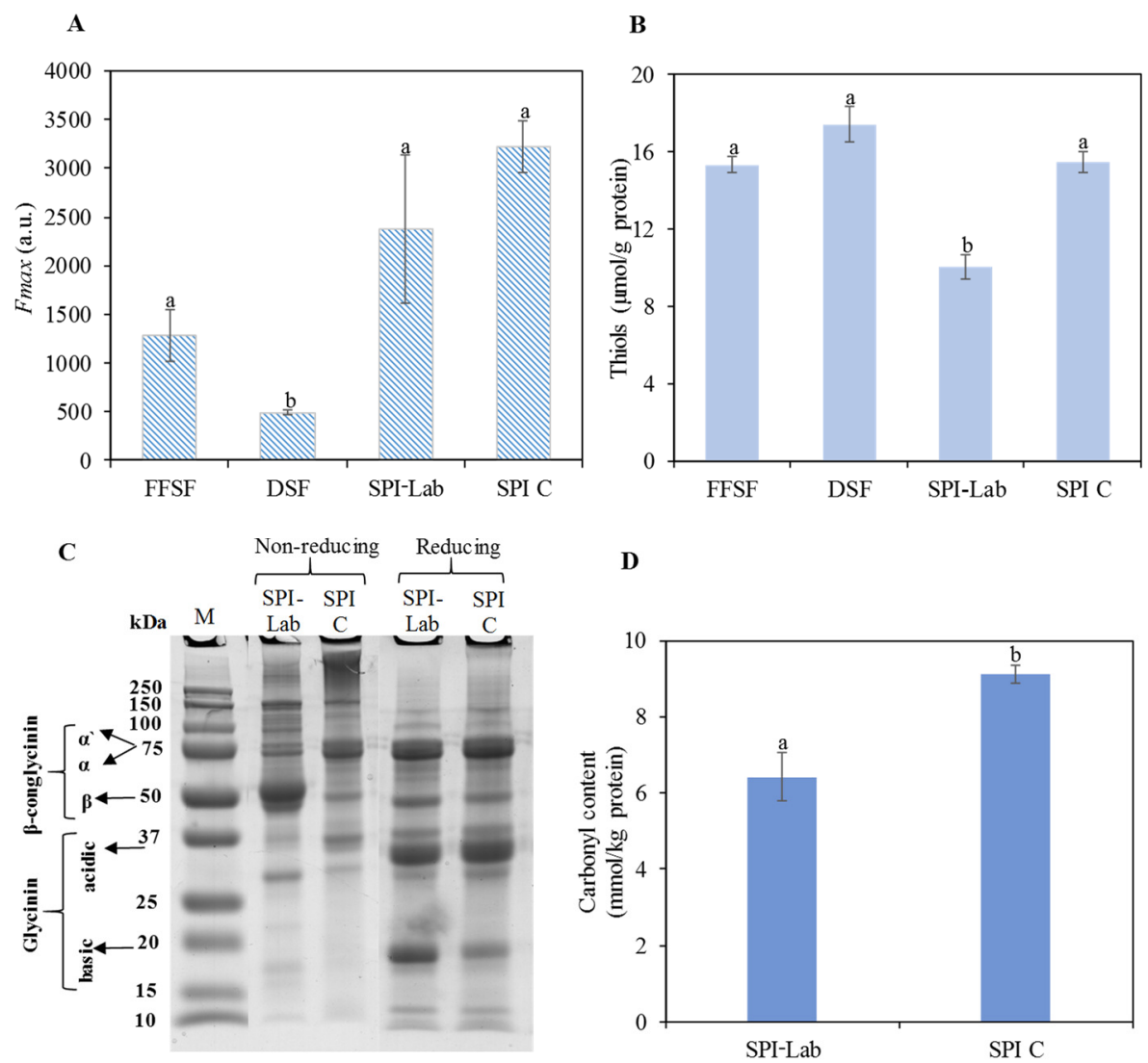

D

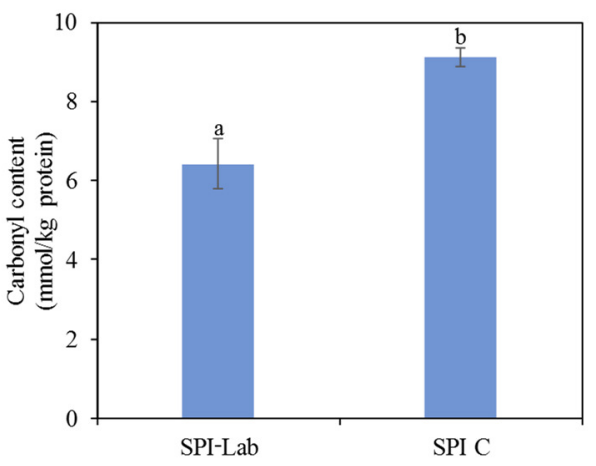

Figure 5.5. (A) Maximum fluorescence intensity $\left(F_{\max }\right)$ of the ANSA probe at $480 \mathrm{~nm}$, indicative of the protein surface-exposed hydrophobicity and (B) thiol group concentration ( $\mu \mathrm{mol} / \mathrm{g}$ soluble protein) of FFSF, DSF, lab-made SPI (SPI-lab) and commercial SPI (SPI C). (C) SDS-PAGE of SPI samples; M: molecular weight marker; $\alpha / \alpha^{\prime} / \beta$ : subunits of $\beta$-conglycinin. (D) Carbonyl content of lab-made SPI and commercial SPI. Results are expressed as mean and standard deviation (error bars) $(\mathrm{n}=$ 3 independent lab-made SPI samples and 2 independent commercial SPI samples, measured in triplicate). 
We analyzed the protein molecular weight distribution of the SPI samples (lab-made and commercial) by SDS-PAGE under non-reducing and reducing conditions (Figure 5.5.C). Under non reducing conditions bands between 100 and $150 \mathrm{kDa}$ were observed in both SDS-PAGE profiles of lab-made SPI and commercial SPI, which were less intense under reducing conditions. This indicates that some aggregates were formed and stabilized by disulfide bonds. However, under reducing conditions there was no difference between the SDS-PAGE profiles of the lab-made and commercial SPIs, despite the aforementioned difference in thiol group concentration. It is thus possible that other oxidation products of the thiol groups were formed in the lab-made SPI, or that the extent of disulfide bond formation in this sample was too low to be accurately detected by this method.

The carbonyl content of freshly prepared lab-made SPI was $6.41 \pm 0.63 \mathrm{mmol}$ carbonyl $/ \mathrm{kg}$ soluble protein (Figure 5.5.D), which corresponds to an increase of only $8 \%$ compared to the carbonyl content in DSF. Therefore, the fractionation process did not substantially promote carbonylation of soy proteins. Likewise, carbonyl content of $6.4 \mathrm{mmol}$ carbonyl $/ \mathrm{kg}$ soluble protein (Liu et al., 2000) and 5.78 $\mathrm{mmol}$ carbonyl $/ \mathrm{kg}$ soluble protein (Chen et al., 2013b) has been reported for a labmade SPI. Conversely, lower carbonyl contents ranging from $1.65 \pm 0.06$ to $4.31 \pm$ $0.02 \mathrm{mmol}$ carbonyl $/ \mathrm{kg}$ soluble protein were reported for lab-made SPI prepared by wet fractionation (Chamba et al., 2014; Chen et al., 2013b,c; Huang et al., 2006; Liebold et al., 2011; Wu et al., 2009a,b,c). Variations in the carbonyl content of different lab-made SPIs could be associated with the presence of remaining lipids combined with residual LOX activity, even though a decrease in LOX activity is expected after fractionation process (Huang et al., 2006).

The commercial SPI had a significantly higher carbonyl content than the lab-made SPI, reaching $9.12 \pm 0.25 \mathrm{mmol}$ carbonyl $/ \mathrm{kg}$ soluble protein (Figure 5.5.D). One of the possible explanations is related to the drying process to obtain the final powder. 
In large-scale processes, spray-drying is commonly used, which has been shown to promote protein oxidation in pea protein powders (Duque Estrada et al., 2018).

\subsubsection{Effect of thermomechanical process on protein oxidation of SPI}

We finally investigated the effect of a thermomechanical process on protein oxidation in lab-made and commercial SPI hydrated powders. The protein-bound carbonyl content was measured as the main marker of protein oxidation, while the molecular weight distribution by SDS-PAGE was used to assess possible protein fragmentation and aggregation (Figure 5.6).

The applied shear- and heat-based process at $140{ }^{\circ} \mathrm{C}$ increased the carbonyl content in the lab-made SPI sample from $6.41 \pm 0.63$ to $16.47 \pm 0.94 \mathrm{mmol}$ carbonyl $/ \mathrm{kg}$ soluble protein (157\% increase) (Figure 5.6.A). This process also increased the carbonyl content in the commercial SPI sample, from $9.12 \pm 0.25$ to $17.36 \pm 1.43$ $\mathrm{mmol}$ carbonyl $/ \mathrm{kg}$ soluble protein ( $90.5 \%$ increase). At a process temperature of 100 ${ }^{\circ} \mathrm{C}$, the carbonyl content increased by $52 \%$ and $40.6 \%$ in the lab-made and commercial SPIs, respectively, indicating that the extent of protein carbonylation upon processing is temperature-dependent. Remarkably, the level of carbonyls became similar for both SPIs after processing at the highest temperature, despite differences in initial levels (unheated samples). The prooxidant effect of thermomechanical processes was previously observed for commercial SPC with increased carbonyl content after hydration and shearing at 100 and $140{ }^{\circ} \mathrm{C}$; however, in that case, there was no effect of the actual temperature (Duque Estrada et al., 2018). In line with these results, $\mathrm{Lu}$ et al. (2017) found an increase of $57.5 \%$ in carbonyl content of DSF dry-heated at $100{ }^{\circ} \mathrm{C}$ for $8 \mathrm{~h}$ compared to unheated DSF. Guo et al. (2015) also found that pre-heating SPI suspensions at $80^{\circ} \mathrm{C}$ or $90{ }^{\circ} \mathrm{C}$ for 5 to $30 \mathrm{~min}$ before spray drying increased carbonylation compared to spray dried powders with no pre-treatment. 
A

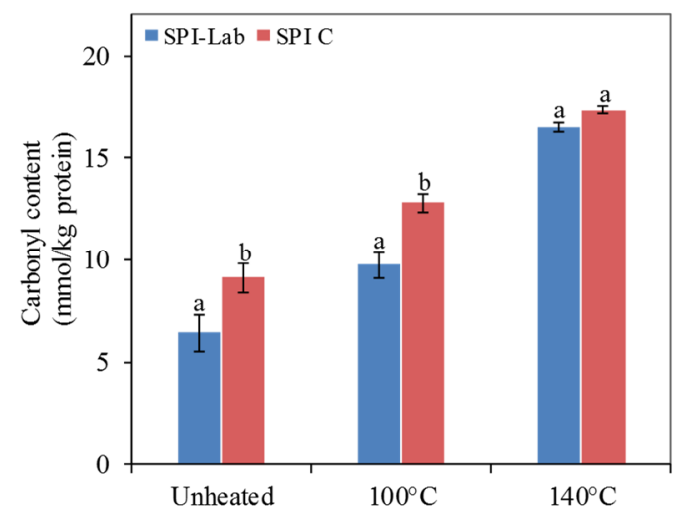

B

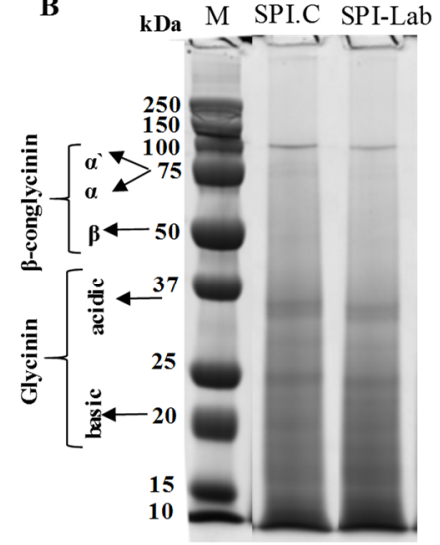

Figure 5.6. (A) Carbonyl content per soluble protein ( $\mathrm{mmol} / \mathrm{kg}$ ) of unheated and heated lab-made SPI (SPI-Lab) and commercial SPI (SPI C). Results are expressed as mean and standard deviation (error bars) ( $\mathrm{n}=3$ independent SPI-lab and 2 independent SPI C, all measured in triplicate). Different letters stand for a significant difference between SPI samples within the same condition $(p<0.05)$. (B) SDS-PAGE profiles under reducing conditions of lab-made SPI and commercial SPI thermomechanically treated at $140{ }^{\circ} \mathrm{C}$. $\mathrm{M}$, molecular weight marker; $\alpha / \alpha^{\prime} / \beta$, subunits of $\beta$-conglycinin.

To put these results into perspective, it is worth mentioning that the carbonyl content of processed SPI samples at $100{ }^{\circ} \mathrm{C}$ is similar to values found in meat cooked by different methods but with lower internal temperature. For instance, Hu et al. (2017) showed that roasting fish at $200^{\circ} \mathrm{C}$ for $10 \mathrm{~min}$ or frying it at $180^{\circ} \mathrm{C}$ for $5 \mathrm{~min}$ (internal temperature of $85 \pm 5^{\circ} \mathrm{C}$ for both methods) resulted in carbonyls contents around $10 \mathrm{mmol}$ carbonyl/kg soluble protein, representing a 4-fold increase compared to raw fish. In processed meat products, the carbonyl content can also be substantially high. Soladoye et al. (2017) reported a total carbonyl content around $80 \mathrm{mmol}$ carbonyl $/ \mathrm{kg}$ soluble protein in bacon, which further increased after cooking. The authors explained that the extent of carbonylation may be related to the nature of the raw material, added ingredients and processing of the bacon. It can, therefore, be concluded that the initial disadvantage of plant proteins ingredients with respect to oxidation levels can however by counterbalanced by the fact that meat products, 
especially processed meat, can contain high oxidation levels as well. These levels can be explained by the fact that meat products usually need a cooking step as well and contain strong prooxidant factors such as heme iron in addition (Baron \& Andersen, 2002).

The SDS-PAGE profiles of lab-made and commercial SPIs processed at $140{ }^{\circ} \mathrm{C}$ are shown in Figure 5.6.B. The individual bands are not well-visible anymore, especially the ones corresponding to $\beta$-conglycinin subunits, which is clearly different from the profiles previously depicted for unheated SPIs (Figure 5.5.C). Likewise, Cucu et al. (2013) showed that $\alpha$ subunits of $\beta$-conglycinin and glycinins' subunits were more prone to oxidation since there was a loss in the intensity of those bands with increased prooxidant concentration. The disappearance of the bands could be a result of protein oxidation inducing irregular covalent protein aggregation and therefore change their molecular weight distribution. Wang et al. (2007) showed that all bands either disappeared or were much lighter in SDS-PAGE of preheated SPI at $130{ }^{\circ} \mathrm{C}$ compared to SPI heated at lower temperatures and unheated samples, which the authors attributed to less accumulation in the loading well than samples heated at lower temperatures. Ma et al. (2018) showed that $\alpha$ and $\alpha$ 'subunits of $\beta$-conglycinin were not detected in the SDS-PAGE profile of a SPI made from extruded FFSF at 90 and $100{ }^{\circ} \mathrm{C}$. The authors suggested that the proteins with a molecular weight between 48-100 kDa might have been hydrolyzed into molecules of lower molecular weight (Ma et al., 2018). In addition, a similar pattern of faint bands on a SDS-PAGE profile of SPI suspensions heated at $140{ }^{\circ} \mathrm{C}$ was observed in the study of OpazoNavarrete et al. (2018). The fainted bands were attributed to the formation of large protein-protein complexes that were not able to dissolve in the sample buffer (Opazo-Navarrete et al., 2018). Similar findings were reported for soy and whey proteins after extrusion. The combined heat and shear treatment during extrusion also resulted in the formation of larger protein aggregates that were unable to penetrate the gel and thus resulted in no distinct band separation (Chen et al., 2011; Li \& Lee, 1996). 


\subsection{Conclusions}

Soy flours were chemically stable to lipid and protein oxidation during 250 days of storage in chilled or ambient conditions. When DSF was subjected to wet fractionation to yield SPI, some physicochemical changes pertaining to the proteins were detected, including an increase in surface-exposed hydrophobicity and a decrease in thiol groups. However, no substantial increase in protein carbonylation occurred upon long storage. When SPI was subjected to a thermomechanical treatment mimicking the processes typically used to produce structured plant protein-based products, i.e., shearing at $140{ }^{\circ} \mathrm{C}$, substantial protein oxidation was induced. We thus conclude that the thermomechanical process used to structure the product has a predominant effect in promoting protein carbonylation in plant protein-based foods, implying that the effect of ingredient fractionation is less relevant in that respect. Therefore, we motivate further research to focus on milder food structuring processes to yield soy protein-based food products with a low protein oxidation level.

\section{Acknowledgments}

The authors thank the financial support from Conselho Nacional de Desenvolvimento Científico e Tecnológico (CNPq/Brazil) (process number 233663/2014-2).

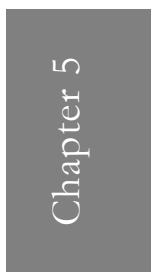




\section{Supplementary information}

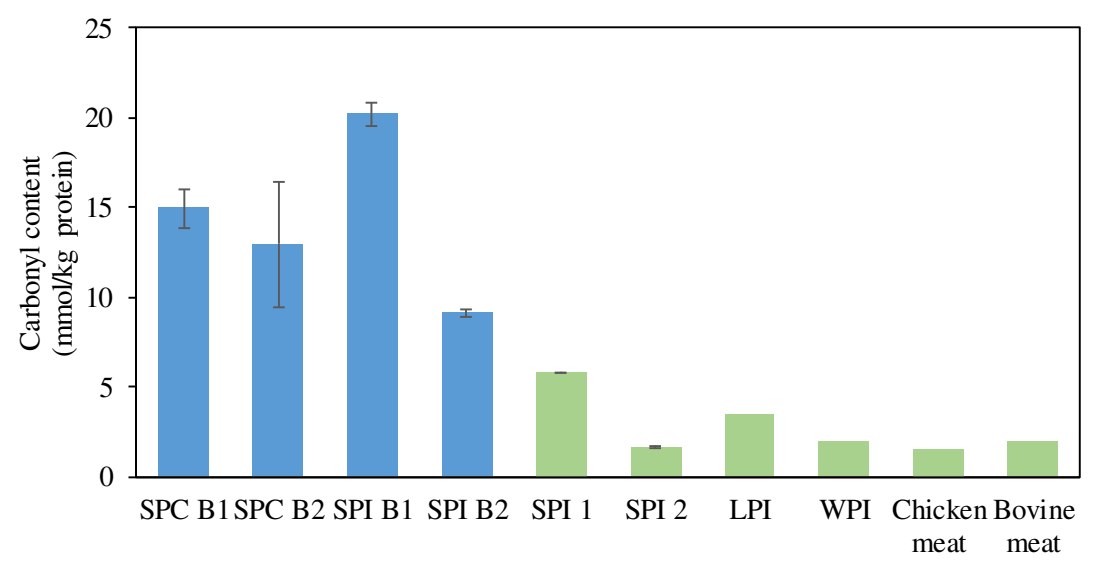

Figure 5.7. Carbonyl content ( $\mathrm{mmol} / \mathrm{kg}$ soluble protein) in different protein sources. The blue bars represent carbonyl contents measured in our lab: commercial soy protein concentrate (SPC) and soy protein isolate (SPI). SPC B1 (Duque Estrada et al., 2018); SPC B2 and SPI B1 (Chapter 4) and SPI B2 (Chapter 5). The green bars represent the data from literature: lab made SPI 1 (Chen et al., 2013b) and SPI 2 (Wu et al., 2009b); lab-made lupin protein isolate (LPI) (Berghout et al., 2015b); commercial whey protein isolate (WPI) (Berton-Carabin et al., 2016); raw chicken meat (Soyer et al., 2010) and raw bovine meat (Santé-Lhoutellier et al., 2008a). B: batch. Results are expressed as mean and standard deviation as error bars, when the information was given. 
Table 5.1. Physical and chemical characterization of full-fat soy flours (FFSF), defatted soy flour (DSF), lab-made soy protein isolate (SPI-Lab) and commercial SPI (C).

\begin{tabular}{cccccc}
\hline $\begin{array}{c}\text { Soy- } \\
\text { based } \\
\text { flours }\end{array}$ & $\begin{array}{c}\text { Protein } \\
\mathbf{( \% )}\end{array}$ & $\begin{array}{c}\text { Moisture } \\
\mathbf{( \% )}\end{array}$ & $\mathbf{a}_{\mathbf{w}}$ & $\begin{array}{c}\text { Lipid } \\
\mathbf{( \% )}\end{array}$ & $\begin{array}{c}\text { Ash } \\
\mathbf{( \% )}\end{array}$ \\
\hline FFSF & $38.81 \pm 1.03$ & $7.73 \pm 0.51$ & $0.44 \pm 0.04$ & $21.68 \pm 0.48$ & $3.84 \pm 0.00$ \\
& & & & & \\
DSF & $46.71 \pm 0.59$ & $8.44 \pm 0.22$ & $0.42 \pm 0.01$ & $0.70 \pm 0.33$ & $5.02 \pm 0.00$ \\
& & & & ND & $4.39 \pm 0.01$ \\
SPI- & $75.31 \pm 1.02$ & $3.32 \pm 0.64$ & $0.68 \pm 0.08$ & & \\
Lab & & & & ND & $4.67 \pm 0.58$ \\
SPI C & $80.16 \pm 0.67$ & $6.61 \pm 0.61$ & $0.42 \pm 0.00$ & &
\end{tabular}

Results are expressed as mean and standard deviation. ND: not determined.
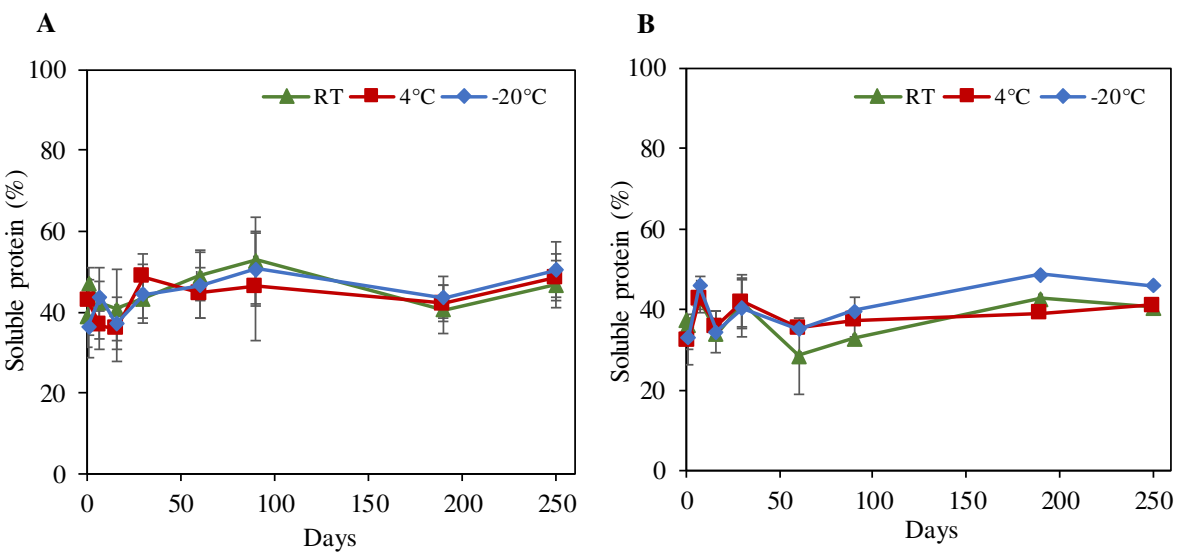

Figure 5.8. Soluble protein percentage of the supernatant obtained from protein suspensions of full-fat soy flour (A) and defatted soy flour (B). Data points represent mean and standard deviations are shown as error bars $(n=4$ independent batches of FFSF and 2 independent batches of DSF). 


\section{Chapter 6}

General discussion 


\subsection{Introduction}

The aim of this thesis was to assess protein quality in plant protein-based ingredients and meat analogues as a function of the presence of soluble iron or encapsulated iron, and of the thermomechanical process conditions applied to make meat analogues. The physicochemical stability of potential iron encapsulates was assessed in Chapters 2 and 3. The fortification of the meat analogues with iron-loaded pea protein particles was described in Chapter 3. We showed that the prooxidant effect of iron on plant proteins was marginal compared with the effect of the thermomechanical process. The associated physicochemical changes due to protein oxidation and processing were not detrimental to gastric digestion in vitro (Chapter 4). In Chapter 5, we reported the oxidative stability of soy proteins throughout the processing steps needed to convert soybeans to meat analogues, which included wet fractionation of soy flours to soy protein isolate, and the thermomechanicallly processed product. This Chapter $\mathbf{6}$ summarizes the main findings and conclusions and discusses the challenges in measuring protein oxidation in complex food products such as meat analogues. Lastly, the outlook for further research on better understanding of plant protein quality in meat analogue type applications is discussed.

\subsection{Main findings and conclusions}

Double emulsions have been used to encapsulate hydrophilic compounds and to mask undesirable taste. Because encapsulation of iron in double emulsions has not been studied extensively, we first explored how the formulation of these systems could be adjusted to reach high encapsulation efficiency and oxidative stability (Chapter 2). To do so, we tested different concentrations of the lipophilic emulsifier polyglycerol polyricinoleate (PGPR) to stabilize the water-in-oil emulsion $\left(\mathrm{W}_{1} / \mathrm{O}\right)$ and assessed its effect on the physicochemical stability of iron-loaded double emulsions. We found that low PGPR concentrations (1 and $2.5 \mathrm{wt} \%$ ) resulted in high release of iron to the external aqueous phase. The release of iron was explained by coalescence of the inner water droplets with the aqueous external phase at these low concentrations. At high PGPR concentrations, iron was mainly released through 
transport via reverse micelles in the oil phase. Remarkably, the use of higher PGPR concentrations promoted lipid oxidation. This was explained by the presence of smaller water droplets, giving a larger oil-water surface area and thus enhanced contact of the oil phase with iron. Therefore, it was concluded that an optimal concentration of PGPR should be balanced with the use of less unsaturated oil to make physicochemical stable iron-loaded double emulsions.

In Chapter 3, we described the oxidative stability of iron-loaded pea protein particles submitted to high temperatures compared with pea protein particles without iron. Protein oxidation increased in all pea protein particles after spray-drying, regardless of the presence of iron. However, the presence of iron decreased protein solubility in the pea protein particles. We noticed that the starting material, pea protein concentrate (PPC), was already oxidized to a certain extent, and oxidation increased when the PPC was exposed to spray drying and later to heating at $100{ }^{\circ} \mathrm{C}$ and 140 ${ }^{\circ} \mathrm{C}$. In this chapter, we also investigated the oxidative stability of meat analogues, with incorporated free or encapsulated iron over 7 days of storage. We did not find a significant effect of the incorporation of iron, either free or encapsulated, on protein oxidation. Similar to PPC, we found that the starting soy protein concentrate (SPC) was also oxidized. Further, the protein oxidation levels in both PPC and SPC substantially increased on processing at high temperatures.

In Chapter 4, we investigated the effect of the thermomechanical processing on protein oxidation and gastric digestion in vitro in commercial soy protein-based products, referred to as soy-based matrices. Protein oxidation in SPC-based products was higher than in soy protein isolate (SPI)-based products after processing at 140 ${ }^{\circ} \mathrm{C}$. In contrast to the findings in Chapter 3, we did not observe the same substantial increase in protein oxidation after processing, especially for the least soluble protein fraction. We further noticed that processing slowed down the rate of protein hydrolysis under in vitro gastric conditions, but the final degree of hydrolysis was not influenced by products with reduced surface area. The slower rate of hydrolysis was 
partly attributed to the structural densification of the product, which hinders the penetration of the digestive fluid into the product.

Chapter 5 describes protein oxidation occurrence in all stages of the production chain from ground soybeans to final structured products. We first investigated the effect of storage conditions on the oxidative stability of full-fat soy flour (FFSF) and defatted soy flour (DSF). Then, we investigated the effect of a wet fractionation process on the chemical stability of SPI. Lastly, the effect of a thermomechanical processing applied to SPI (shearing at $100{ }^{\circ} \mathrm{C}$ and $140{ }^{\circ} \mathrm{C}$ ) on protein oxidation and aggregation was determined. We found that both FFSF and DSF were oxidatively stable after 250 days of storage at room temperature, at $4{ }^{\circ} \mathrm{C}$ and at $-20{ }^{\circ} \mathrm{C}$. Wet fractionation did not significantly increase protein oxidation in SPI compared with the starting material (DSF). However, shearing at $140{ }^{\circ} \mathrm{C}$ increased the carbonyl content by more than $150 \%$ in SPI compared with unprocessed samples. In future research, it will be relevant to systematically investigate how the initial levels of protein carbonyls affects the final oxidation status after processing.

\subsection{Challenges in determining protein oxidation in meat analogues}

The amount of carbonyls is generally considered to be a good global marker of protein oxidation in biological samples and foods. Carbonylation is an irreversible and non-enzymatic modification of proteins to form carbonyl moieties; lysine, arginine, proline, and threonine are the amino acids most prone to such modification (Soladoye et al., 2015). A routine method to quantify protein-bound carbonyls is the detection of the adduct 2,4-dinitrophenylhydrazone formed when carbonyls react with 2,4-dinitrophenylhydrazine (DNPH), which is measured spectrophotometrically at $370 \mathrm{~nm}$ (Estévez, 2011). This so-called DNPH method has been applied to assess protein-bound carbonyls in beef (Zakrys-Waliwander et al., 2012), pork (Morzel et al., 2006), chicken (Soyer et al., 2010), fish (Eymard et al., 2009), and in some processed meat products (Ganhão et al., 2010; Koutina et al., 2012). 
An important drawback of the DNPH method is that the method only determines the level of carbonylation of soluble proteins. Clearly, this presents a challenge in interpreting the outcomes, because of the insoluble nature of many muscle and meat proteins (Soglia et al., 2016b). A similar issue arises when analyzing plant-based protein-rich products, such as meat analogues. To increase the solubility of proteins present in meat analogues and the detection of buried protein-bound carbonyls, we followed the modifications to the traditional DNPH method proposed by Soglia et al. (2016b). The authors described a 2- to 4-fold increase in carbonyl content in meat samples using their novel procedure compared with the traditional method, which can be explained by the increased solubilization and unfolding of oxidized proteins, promoting exposure of carbonyls. In conclusion, the authors recommended the use of their novel method especially if the samples have low solubility. The improved DNPH method was recently used to detect carbonyls in meat proteins from different animal species (Baldi et al., 2018; Bao et al., 2018; Gan et al., 2019; He et al., 2019; Soglia et al., 2016a; Wang et al., 2018). Unfortunately, even this method does not allow for full resolubilization of proteins, meaning that a fraction of insoluble proteins is still present, of which the level of oxidation remains unknown. The use of the DNPH method with complementary techniques, such as measurement of loss in free thiol groups, formation of covalent cross-links or oxidation of aromatic amino acid residues, can provide a better overview of the extent and pathways of protein oxidation. Nevertheless, the DNPH method is still a relevant and widely used method in biomedical and food science applications despite the fact that it does not provide information about the mechanisms involved in the formation of carbonyls (Bao et al., 2018; Gan et al., 2019; He et al., 2019; Martinez \& Kannan, 2018).

\subsection{Protein oxidation in plant protein-based ingredients}

In this thesis, we noticed that commercial plant protein ingredients already had a certain level of protein oxidation. Figure 6.1 shows the values obtained for the soluble fractions (referred to as fraction 1 in Chapter 3) of the materials used in this thesis. PPC had a similar protein-bound carbonyl content as the SPC used in 
Chapter 4. Protein oxidation measured in PPC stored for more than 3 years at room temperature in the dark resulted in higher carbonyl content., indicating that plant protein-based ingredients are not fully oxidatively stable at room temperature.

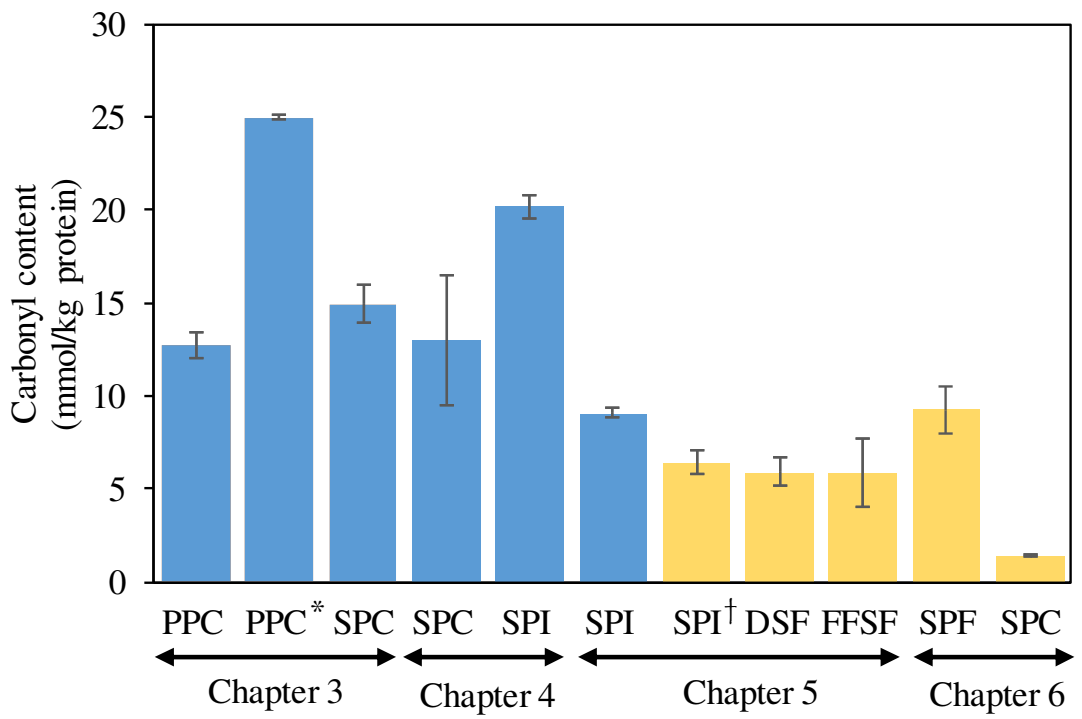

Figure 6.1. Carbonyl content ( $\mathrm{mmol} / \mathrm{kg}$ soluble protein) of the soluble fraction of commercial (blue bars) and lab-made (yellow bars) soy and pea protein ingredients used in each chapter of this thesis. Chapter 3: PPC, pea protein concentrate stored for $\sim 1$ and half years; PPC*, pea protein concentrate stored for $\sim 3$ and half years; SPC, soy protein concentrate batch 1. Chapter 4: SPC, soy protein concentrate batch 2; SPI, soy protein isolate batch 1. Chapter 5: SPI, soy protein isolate batch 2; SPI + , soy protein isolate made by wet fractionation; DSF, freshly made defatted soy flour; FFSF, freshly made full-fat soy flour. Chapter 6: SPC, soy protein concentrate ( $45 \%$ protein on dry basis) made by dry fractionation according to Xing et al. (2018); SPF, soy protein fraction (67.4\% protein on dry basis) made by aqueous fractionation according to Geerts et al. (2018). Results are expressed as mean and error bars as standard deviation. 
We further noticed variability between SPI batches obtained at different times, even when obtained from the same manufacturer. Those differences could be caused by different storage times. SPI used in Chapter 4 had been stored at room temperature for a few years, whereas the SPI used in Chapter $\mathbf{5}$ had been stored at room temperature for less than 1 year. Considering the results for PPC, the variability observed between SPI batches can probably be attributed to the storage time and conditions. Guo et al. (2015) showed that protein oxidation and aggregation increased in SPI prepared by spray drying during storage at $37^{\circ} \mathrm{C}$ for 8 weeks. Although the SPCs used in Chapters $\mathbf{3}$ and $\mathbf{4}$ were different samples (e.g., different protein content), both had similar protein-bound carbonyl content.

The information given above makes it clear that it is important to consider the effect of the fractionation process and storage conditions on possible oxidation of proteins and lipids. We measured the protein-bound carbonyl content from a soy protein fraction (SPF) obtained from aqueous fractionation and SPC obtained by dry fractionation (Figure 6.1). SPC from dry fractionation had the lowest protein-bound carbonyl content compared with all protein ingredients, whereas the SPF had similar carbonyl content to the commercial SPI (Chapter 5) but higher than lab-made SPI. These results suggest that SPF obtained by aqueous fractionation is less oxidatively stable than SPI prepared by wet fractionation, and that keeping the lipids in the ingredients can enhance protein oxidation in soy protein fractions (Cucu et al., 2013; Huang et al., 2006). Berghout et al. (2015b) found that the protein-bound carbonyl content on lupine protein isolate (LPI) obtained by aqueous fractionation was $4 \mathrm{mmol}$ carbonyl $/ \mathrm{kg}$ soluble protein, which is not high, but still suggests that protein oxidation did occur. The authors also detected the formation of secondary lipid oxidation products, which could have reacted with proteins and formed proteinbound carbonyls in the LPI. Conversely, all commercial soy protein ingredients, which usually contain low amounts of lipids, had higher protein oxidation than soy ingredients containing lipids (FFSF). This suggests that endogenous lipids can promote protein oxidation in soy flours and SPF., but that the drying step seems to 
predominate for the formation of protein-bound carbonyls in commercial SPI and SPC.

The use of soy ingredients containing endogenous lipids, though, is interesting for the formulation of meat analogues from a structure (Geerts et al, 2018) and sensorial perspective (Savell \& Cross, 1988). Geerts et al. (2018) showed that mixing soy flours with SPF obtained by aqueous fractionation resulted in fibrous structures similar to those formed using commercial SPC as the main protein ingredient. However, they did not check protein oxidation levels. Based on the information above, it can be expected that the levels might be higher than when processing those products without lipids. Despite the sustainability-related advantage of keeping lipids in the product, it is worth investigating whether it is better to process defatted protein ingredients and add lipid afterward or to maintain the lipids in the protein-rich fraction, which requires that we can mitigate the potential issue of pre-processing oxidation.

So far, studies have mainly focused on the potential of secondary lipid oxidation products or glycation reactions to induce protein oxidation in SPI (Chen et al., 2013c; Huang et al., 2006; Luna \& Estévez, 2018; Wu et al., 2009b). However, our work clearly indicates the importance of considering the initial oxidative status of plant protein-based ingredients and their subsequent storage for further food applications. The use of oxidized ingredients could hamper food application. When only structure formation is considered, the presence of pre-formed protein carbonyls may not be detrimental, because low solubility is desired for structuring (Geerts et al., 2018). In contrast, regarding nutritional aspects, this might be a concern, as discussed later in this chapter. 


\subsection{Protein oxidation in lab-made and commercial plant-based products}

The results presented in this thesis revealed that processing at high temperatures had a substantial contribution to increasing carbonyl content when using SPCs. Because protein oxidation in processed plant protein products is a new topic, we did not have a reference in the literature with which to compare to our results. Therefore, we measured the carbonyl content in commercial meat analogues bought in a local supermarket (Figure 6.2). We then compared our results with those reported in the literature for meat proteins and processed meat. The mechanisms of formation of protein-bound carbonyls during the cooking of meat have already been elucidated as resulting mainly from the release of heme iron and a decrease in physiological antioxidant defense (Bax et al., 2012; Gatellier et al., 2009ab; Mitra et al., 2018; Traore et al., 2012).

In Figure 6.2, we present the carbonyl contents in the soluble fractions of soy ingredients processed at $140{ }^{\circ} \mathrm{C}$ using commercial (Chapters 3-5) and lab-made soy protein ingredients (Chapters 5). Processed SPC and SPI/pectin products described in Chapter 4 had more carbonyls than the other lab-made products (Chapters 35). The results shows that differences in composition or ingredient mix used probably contributed to the different carbonyl levels after processing. Regarding the use of commercial soy ingredients to obtain structured products, we concluded that less purified ingredients, e.g., SPC, will result in increased protein oxidation. The presence of remaining reducing sugars in SPC might react with amino acids, resulting in the formation of carbonyls by the Maillard reaction. To substantiate this hypothesis, we did a short experiment in which commercial SPI $(\sim 10 \mathrm{mmol}$ carbonyl $/ \mathrm{kg}$ soluble protein) was combined with glucose (1:1 ratio) followed by freeze-drying and incubation at $60{ }^{\circ} \mathrm{C}$ for $24 \mathrm{~h}$. A carbonyl content of $45.2 \pm 0.1$ $\mathrm{mmol}$ carbonyl $/ \mathrm{kg}$ soluble protein was obtained, indicating the contribution of the Mallard reaction to the formation of carbonyls. 


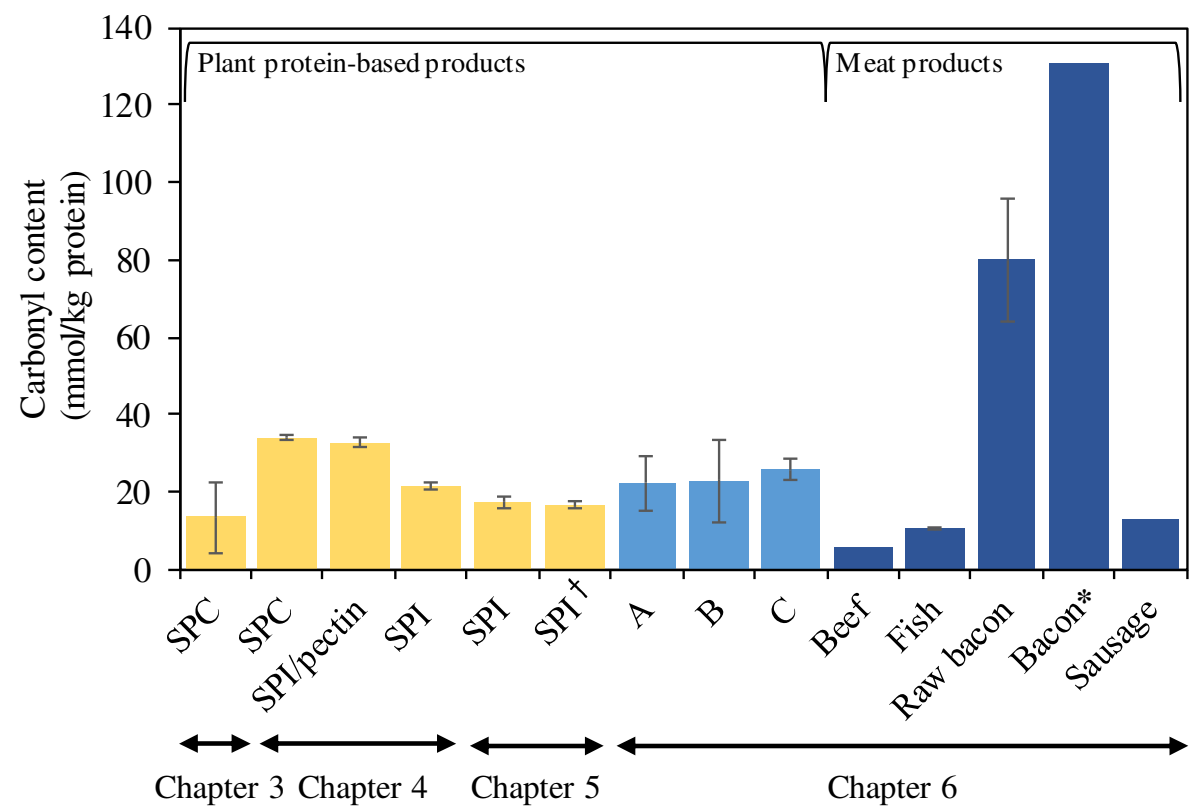

Figure 6.2. Carbonyl content ( $\mathrm{mmol} / \mathrm{kg}$ soluble protein) in the soluble fraction of processed soy protein products, lab-made (yellow bars) and commercial (light blue bars), and data from the literature on cooked and processed meat products (dark blue bars). Lab-made soy products were thermomechanically processed at $140{ }^{\circ} \mathrm{C}$. Chapter 3: SPC, soy protein concentrate batch 1. Chapter 4: SPC, soy protein concentrate batch 2; SPI, soy protein isolate batch 1 . Chapter 5: SPI, soy protein isolate batch 2; SPI†, soy protein isolate made by wet fractionation. Chapter 6: samples $\mathrm{A}, \mathrm{B}$, and $\mathrm{C}$ represent three different types of commercial meat analogues, for each type, 2 lots obtained at different periods were analyzed and shown as an average. Data from the literature: beef, cooked at $100{ }^{\circ} \mathrm{C}$ for $45 \mathrm{~min}$ (raw, $2 \mathrm{mmol}$ carbonyl $/ \mathrm{kg}$ soluble protein) (Santé-Lhoutellier et al., 2008b); fish, cooked in an oven at $200{ }^{\circ} \mathrm{C}$ for $20 \mathrm{~min}$ (raw, $2 \mathrm{mmol}$ carbonyl $/ \mathrm{kg}$ soluble protein) (Hu et al., 2017); bacon*, cooked in a microwave for 5 min (Soladoye et al., 2017); sausage, commercial cooked sausage (Armenteros et al., 2009). Carbonyl content was measured by DNPH for all data points, unless mentioned. For the data of Soladoye et al. (2017), the total carbonyl content in bacon represented the sum of $\alpha$-amino adipic semialdehyde and glutamic semialdehyde measured by HPLC-FLD. 
The initial carbonyl levels in the ingredients (Figure 6.1) did not seem to have a clear link with the levels of carbonyls formed during processing. Processed products made with lab-made SPI and commercial SPI (Chapter 5) had similar carbonyl content, even though the commercial SPI had a higher carbonyl content initially (Figure 6.1).

To see if the initial oxidative status in plant protein ingredients would clearly affect the protein oxidation levels in the final product, a study with different levels of protein oxidation before processing should be conducted as a follow-up study. The lack of an increase in protein oxidation after processing can be associated with the fact that some carbonyls are not stable and can be involved in further reactions. For instance, protein semialdehydes can react with non-modified amino acids residues and form cross-links and Schiff bases (Estévez et al., 2009).

The carbonyl content of the commercial meat analogues was measured to put our results into perspective (Figure 6.2). The measured carbonyl contents were comparable with the values found for the soluble fractions of our samples. Even though samples A and B contained sunflower oil, the carbonyl content was not higher than that in sample $C$, which also contained sugars (Table 6.1).

Table 6.1. Chemical composition and ingredients of commercial meat analogues (A, $\mathrm{B}$, and $\mathrm{C})$; the information was obtained from the label.

\begin{tabular}{|c|c|c|c|c|}
\hline Sample & Ingredients & $\begin{array}{l}\text { Proteins } \\
(\mathrm{g} / 100 \mathrm{~g})\end{array}$ & $\begin{array}{c}\text { Lipids } \\
(\mathrm{g} / 100 \mathrm{~g})\end{array}$ & $\begin{array}{l}\text { Carbohydrates } \\
\text { (g/100 g) }\end{array}$ \\
\hline A & $\begin{array}{l}88 \% \text { soy structure (water, soy protein), } \\
\text { onion extract, sunflower oil, natural } \\
\text { aromas. }\end{array}$ & 19.9 & 4.4 & 5.0 \\
\hline B & $\begin{array}{c}\text { Water, } 27 \% \text { soy protein concentrate, } \\
\text { sunflower oil, salt, aromas, spices. }\end{array}$ & 19.4 & 2.3 & 1.8 \\
\hline $\mathrm{C}$ & $\begin{array}{c}95 \% \text { soy structure (water and soy } \\
\text { protein), potassium lactate, barley malt } \\
\text { extract, glucose syrup, soy protein } \\
\text { hydrolyzed, aromas, spices, caramel, salt, } \\
\text { iron, vitamin } \mathrm{B}_{12} \text {. }\end{array}$ & 24.3 & 0.2 & 2.8 \\
\hline
\end{tabular}

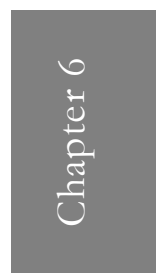


Meat proteins, raw beef, and fish meat had $\sim 2 \mathrm{mmol}$ carbonyl $/ \mathrm{kg}$ soluble protein, which increased to $\sim 6 \mathrm{mmol}$ carbonyl $/ \mathrm{kg}$ soluble protein in beef (Santé-Lhoutellier et al., 2008b) and to $10.6 \mathrm{mmol}$ carbonyl $/ \mathrm{kg}$ soluble protein in fish (Hu et al., 2017), after cooking. The exact level of protein oxidation during cooking depended on the temperature and time applied (Mitra et al., 2018). Protein oxidation has been described for processed meat, such as bacon, sausages, ham. Cooking bacon in a microwave increased the level of carbonyls to $130 \mathrm{mmol}$ carbonyl $/ \mathrm{kg}$ soluble protein, considering that there was already $80 \mathrm{mmol}$ carbonyl $/ \mathrm{kg}$ soluble protein in the raw bacon. The high carbonyl content found in raw bacon was associated with the nature of raw material, the ingredients used, and the processing of bacon. Most of the ingredients added have been associated with protein carbonylation such as salt, nitrite, and sugars (Soladoye et al., 2017).

To sum up, protein oxidation in processed products containing soy ingredients depends on the process temperature and the composition of the ingredients. The carbonyl content in our processed samples and commercial meat analogues was higher the than values reported for raw and cooked meat, but within the range of levels reported for processed meat such as bacon.

\subsection{Future research}

Protein oxidation in plant protein-derived foods requires further study. Most studies in the past have focused on evaluating the effect of lipids and oxidized lipid radicals combined with lipoxygenase activity on SPI oxidation and linked to emulsifying properties and digestibility (Chen et al., 2013a; Chen et al., 2013b; Cucu et al., 2013; Huang et al., 2006; Li et al., 2019; Wu et al., 2009a,b). However, the effect of process conditions on protein oxidation of soy-based food is still largely uncharted territory. Therefore, we discuss the importance of further characterization of the mechanisms and product formation under the process conditions, the development of strategies to control protein oxidation, and finally, provide a summary about the consequences of oxidized protein intake on human health. 


\subsubsection{Mechanisms and products formed during protein oxidation}

In this thesis, we have identified the presence of carbonyls in various soy protein ingredients: soy flours, concentrates and isolates. In addition, subjecting those ingredients to a thermomechanical process increased the amount of carbonyls. However, there is still much more to be understood regarding protein oxidation in plant protein-based ingredients and products.

Protein carbonylation can occur via different pathways: direct oxidation of side chains of amino acids residues, non-enzymatic glycation, oxidative cleavage of the polypeptide backbone, and covalent binding to non-protein carbonyl compounds from lipid oxidation (Estévez et al. 2011). So far, it is not clear which of these pathways is the most relevant to induce the formation of carbonyls in food products, such as meat analogues. For this reason, identification of the specific amino acids involved in the formation of carbonyls in soy proteins help us understand the mechanisms behind the initiation of protein oxidation. In parallel, the specific Maillard reaction products should be identified.

In oxidized meat proteins, the formation of specific products such as $\alpha$-amino adipic semialdehyde (AAS) and glutamic semialdehyde (GGS) has been shown to account for $30 \%-60 \%$ of the total protein carbonyls in different meat products (Utrera et al., 2011) and up to $90 \%$ in oxidized bovine serum albumin (BSA) (Requena et al., 2001). AAS is formed through oxidation of lysine residues and GGS from that of arginine and proline residues, both of which induced by metal-catalyzed oxidation reactions (MCOR). Estévez et al. (2009) reported that after 10 days of MCOR incubation, BSA ( $\sim 50 \mathrm{mmol}$ carbonyl $/ \mathrm{kg}$ soluble protein) had the highest formation of total carbonyls followed by myofibrillar proteins ( $\sim 40 \mathrm{mmol}$ carbonyl $/ \mathrm{kg}$ soluble protein), $\alpha$ lactalbumin ( $\sim 35 \mathrm{mmol}$ carbonyl $/ \mathrm{kg}$ soluble protein), and commercial SPI $(\sim 20$ $\mathrm{mmol}$ carbonyl $/ \mathrm{kg}$ soluble protein). The authors explained their results based on the protein structure, whereby amino acids that are more exposed due to the protein's structural conformation can be prone to oxidation. The lower formation of protein- 
bound carbonyls in SPI suggested that soy proteins were less susceptible to metalcatalyzed oxidation than the animal proteins studied in the study by Estévez et al (2009). In addition, in meat the presence of heme iron, such as in myoglobin, has an important prooxidant effect (Baron \& Andersen, 2002; Berton et al. 2012a; Estévez, 2017). In addition to the formation of AAS and GGS in meat proteins, other studies have shown the contribution of histidine-derived carbonyls in the oxidation of meat proteins (Bao et al., 2018).

In Table 6.2, we compare studies that have induced protein oxidation in SPI by the presence of unsaturated lipids and/or their oxidation products, or free radicals. The use of $5 \mathrm{mmol}$ hypochlorous acid $(\mathrm{HClO})$ per $\mathrm{g}$ of soy protein incubated at $30^{\circ} \mathrm{C}$ for $10 \mathrm{~min}$ induced the formation of $50 \mathrm{mmol}$ carbonyl $/ \mathrm{kg}$ soluble protein, and the incubation of soy proteins with oxidized soybean oil with $\mathrm{CuSO}_{4}$ (p-anisidine value, 93.9) for $50 \mathrm{~h}$ resulted in the formation of $12 \mathrm{mmol}$ carbonyl $/ \mathrm{kg}$ soluble protein (Cucu et al. 2013). The authors reported that $\mathrm{CuSO}_{4}$ alone had no effect on protein carbonylation. However, SPI incubated with malondialdehyde (MDA) also led to carbonyl content similar to that obtained when incubated with $\mathrm{HClO}$, as shown by Chen et al. (2013c). Wu et al. (2009b) found lower carbonyl content in SPI incubated with MDA at 10 times higher concentration than Chen et al (2013c). Overall, the actual reaction routes and oxidation products formed depend on the target, oxidizing system and intensity of the oxidation conditions (Estévez, 2011). 
Table 6.2. Carbonyl content as a result of induced oxidation in soy protein isolate (SPI) using different prooxidants conditions.

\begin{tabular}{|c|c|c|c|c|}
\hline \multirow{2}{*}{$\begin{array}{l}\text { Soy protein } \\
\text { substrate }\end{array}$} & \multirow{2}{*}{$\begin{array}{c}\text { Induced } \\
\text { oxidation } \\
\text { conditions }\end{array}$} & \multicolumn{2}{|c|}{$\begin{array}{c}\text { Carbonyl content }{ }^{\dagger} \\
\text { (mmol/kg soluble } \\
\text { protein) }\end{array}$} & \multirow{2}{*}{ Reference } \\
\hline & & Control & Oxidized & \\
\hline $\begin{array}{c}10 \mathrm{mg} / \mathrm{mL} \text { SPI } \\
\text { suspension }\end{array}$ & $\begin{array}{c}100 \mathrm{mmol} / \mathrm{L} \\
\mathrm{MDA} \text { at } 25^{\circ} \mathrm{C} \text { for } \\
24 \mathrm{~h}\end{array}$ & $1.7 \pm 0.06$ & $16.6 \pm 0.20$ & $\begin{array}{l}\text { Wu et al. } \\
\text { (2009b) }\end{array}$ \\
\hline $\begin{array}{c}10 \mathrm{mg} / \mathrm{mL} \text { SPI } \\
\text { suspension }\end{array}$ & $\begin{array}{l}25 \mathrm{mmol} / \mathrm{L} \\
\text { AAPH at } 37^{\circ} \mathrm{C} \\
\text { for } 24 \mathrm{~h}\end{array}$ & $1.7 \pm 0.12$ & $10.1 \pm 0.18$ & $\begin{array}{l}\text { Wu et al. } \\
\text { (2009c) }\end{array}$ \\
\hline $\begin{array}{l}10 \mu \mathrm{g} / \mu \mathrm{L} \text { SPI } \\
\text { suspension }\end{array}$ & $\begin{array}{l}5 \mathrm{mmol} \mathrm{HClO} / \mathrm{g} \\
\text { protein at } 30^{\circ} \mathrm{C} \\
\text { for } 10 \mathrm{~min}\end{array}$ & $\sim 3$ & 50 & \multirow{2}{*}{$\begin{array}{l}\text { Cucu et al. } \\
\text { (2013) }\end{array}$} \\
\hline $\begin{array}{c}10 \mathrm{mg} / \mathrm{mL} \mathrm{SPI} \\
\text { suspension }\end{array}$ & $\begin{array}{c}5 \mathrm{mg} / \mathrm{mL} \text { soybean } \\
\text { oil }(\mathrm{pAV}, 93.9) \text { and } \\
10 \mu \mathrm{mol} / \mathrm{L} \mathrm{CuSO}{ }_{4} \\
\text { for } 50 \mathrm{~h}\end{array}$ & $\sim 3$ & $\sim 12$ & \\
\hline $\begin{array}{c}40 \mathrm{mg} / \mathrm{mL} \text { SPI } \\
\text { suspension }\end{array}$ & $\begin{array}{l}10 \mathrm{mmol} / \mathrm{L} \mathrm{MDA} \\
\text { at } 25^{\circ} \mathrm{C} \text { for } 24 \mathrm{~h}\end{array}$ & $5.3 \pm 0.32$ & $50.3 \pm 0.95$ & $\begin{array}{l}\text { Chen et al. } \\
\text { (2013c) }\end{array}$ \\
\hline $\begin{array}{l}5 \mathrm{wt} \% \mathrm{SPI} \\
\text { suspension }\end{array}$ & $\begin{array}{c}8.5 \mathrm{~mL} \text { linoleic } \\
\text { acid and } 10 \mathrm{~mL} \\
\mathrm{LOX} \text { at } 25^{\circ} \mathrm{C} \text { for } \\
6 \mathrm{~h}\end{array}$ & $4.3 \pm 0.02$ & $5.9 \pm 0.02$ & $\begin{array}{l}\text { Huang et al. } \\
\quad(2006)\end{array}$ \\
\hline SPI* $^{*}$ & $\begin{array}{c}2 \% \text { soybean oil at } \\
100{ }^{\circ} \mathrm{C} \text { for } 8 \mathrm{~h}\end{array}$ & 7.2 & 10.4 & $\begin{array}{l}\text { Zhang et al. } \\
\quad(2017)\end{array}$ \\
\hline \multicolumn{5}{|c|}{$\begin{array}{l}\text { Results are expressed as the mean } \pm \text { standard deviation, when given. MDA, malondialdehyde; } \\
\text { AAPH, 2,2'-azobis (2-amidinopropane) dihydrochloride; } \mathrm{HClO} \text {, hypochlorous acid; pAV, p- } \\
\text { anisidine value; } \mathrm{CuSO}_{4} \text {, copper sulfate; LOX, lipoxygenase enzyme. } \\
\text { † Measured by the DNPH method. } \\
\text { *Commercial SPI. }\end{array}$} \\
\hline
\end{tabular}




\subsubsection{Strategies to control protein oxidation in plant protein-based ingredients and foods}

Milling is the first process to obtain flour from soybeans. Rupture of the cells can put the lipoxygenase enzyme (LOX) into contact with unsaturated lipids (Alhendi et al., 2018) and, autooxidation can occur via a non-enzymatic pathway when the lipids come into contact with atmospheric oxygen (Doblado-Maldonado et al., 2012). Milling under a controlled oxygen atmosphere could prevent autooxidation of lipids combined with inactivation of LOX activity. Non-thermal treatments to inactivate LOX have been reported, such as the use of pulsed light (Alhendi et al., 2018).

Recently, the use of alternative fractionation processes has been explored, with emphasis on milder processing. A consequence of this approach is that less pure protein-rich fractions will be obtained. Therefore, these complex fractions should be investigated for their ability to mitigate oxidation during processing. Strategies to improve the oxidative stability of meat proteins via the use of natural antioxidants have also been gaining increased interest. The different routes include: (i) introducing antioxidants in the animal diet, (ii) directly enriching the meat products during formulation, or (iii) coating the packaging material with plant extracts (Ribeiro et al., 2019). The use of natural antioxidants has been motivated by the desire of consumers for less synthetic additives in food products (Asioli et al., 2017). Studies have shown the potential of essential oils; extracts from fruits, herbs and seeds; and peptides and protein hydrolyzates on reducing carbonyl formation and thiol losses during storage of meat and processed meat products (Estévez et al., 2006; Utrera et al., 2012; Jiang \& Xiong, 2016; Xu et al., 2018). However, for processed plant proteins, oxidation increases during processing; and for this reason, the stability of natural antioxidants submitted to high temperature processes and their ability to suppress protein and lipid oxidation are interesting topics for further investigation. On the other hand, mild fractionation results in protein-rich fractions containing a certain level of lipids. As discussed previously, the higher content of lipids might enhance protein oxidation. Therefore, a balance between the presence of natural antioxidants and 
lipids has to be investigated, and the effect of high temperature on antioxidant activity should be better understood.

Lastly, the effect of cooking methods on protein oxidation of soy protein-based products needs further investigation. Studies have assessed the effect of different cooking methods on the oxidation of meat proteins and found that carbonylation is strongly dependent on temperature and time (Bax et al., 2012; Filgueras et al., 2011; Gatellieret al., 2009b; Hu et al., 2017; Mitra et al., 2018; Santé-Lhoutellier et al., 2008a; Traore et al., 2012). The method of heat transfer in different cooking methods also has an effect on the final level of protein oxidation. Usually, dry heating and frying result in higher protein carbonyls levels than wet heating methods, probably due to higher average product temperatures during preparation. Hu et al. (2017) showed that roasted and fried fish had an increase in carbonyl content of 10.6 and $9.7 \mathrm{mmol}$ carbonyl $/ \mathrm{kg}$ soluble protein, respectively, compared with initial levels of $2.1 \mathrm{mmol}$ carbonyl $/ \mathrm{kg}$ soluble protein in raw fish; boiling and steaming resulted in $4 \mathrm{mmol}$ carbonyl/soluble protein.

\subsubsection{Understating the impact of protein oxidation on human health}

The potential threat of dietary oxidized proteins to the human body is related to three main aspects: (i) the loss of essential amino acids, (ii) the alteration of protein digestion, and (iii) the potential for oxidized proteins to induce oxidation stress in vivo.

Irreversible modifications induced by protein oxidation, such as carbonylation, can result in a decrease of essential amino acids such as lysine and arginine, resulting in changes in the amino acid profile (Estévez, 2011). However, this concern might be more relevant for meat protein, which contains all essential amino acids. For plant protein-based diets a broad range of food products is recommended to reach the dietary requirements of all essential amino acids, because some amino acids are in limited amounts in plant proteins. 
A number of studies involving in vitro digestion revealed that protein oxidation negatively affected the interaction between proteins and proteolytic enzymes, resulting in lower digestion of oxidized meat proteins and SPI (Chen et al., 2013a; Rysman et al., 2016; Santé-Lhoutellier et al., 2007). Lower digestion will result in a decrease in the absorption of amino acids, concomitantly with a promoted fermentation of undigested proteins in distant portions of the gut, which has been reported to form toxic compounds (Soladoye et al., 2015). However, we did not find a clear relationship between the degree of hydrolysis under simulated gastric conditions and protein oxidation (Chapter 4). The determination of other oxidation modifications is relevant because aromatic amino acids are present in protease recognition sites.

Protein oxidation in vivo has been associated with oxidative damage to cells, which is related to aging and neurodegenerative diseases such as Parkinson disease and Alzheimer disease (Estévez et al., 2017). The biological significance of protein oxidation on oxidative stress in vivo and its potential to impair physiological processes and promote some diseases in humans is still a work in progress. The evidence that protein oxidation in vivo is a source of oxidative stress reinforces the need to understand the extent to which dietary oxidized proteins interact with cells in the gastrointestinal tract, and are absorbed and distributed to specific organs, thereby, contributing to aggravating oxidative stress in vivo and its harmful consequences (Estévez \& Luna, 2017). The effect of dietary oxidized proteins has been shown to cause organs dysfunction in experimental animals. Rats that were fed with 2-8 g of oxidized tyrosine per $\mathrm{kg}$ of diet for 24 weeks showed hepatic, kidney, and pancreatic disorders (Li et al., 2017). In this study, a high concentration of oxidized tyrosine was used, typically much higher than that found in oxidized food proteins (Estévez \& Xiong, 2019). For comparison purposes, studies have reported concentrations of $0.029 \mu \mathrm{g}$ dityrosine/mg protein in milk powders (Fenaille et al., 2004) and $0.12 \mu \mathrm{g}$ dityrosine/mg protein in bovine and buffalo cheese (Balestrieri et al., 2002). 
Furthermore, the possible threat of dietary oxidized proteins to human health combined with the consumption of highly processed food, as the main source of oxidized proteins, predicts a field of research that clearly needs further exploration. There is still much to be clarified regarding nutritional losses due to oxidation, the role of food components as sources of toxic compounds, oxidation during digestion and postprandial oxidative stress. Even though negative nutritional aspects have been associated to dietary oxidized proteins, the frequency of consumption of oxidized food will have an impact on the exposure and its consequences on human body; and therefore this topic cannot be neglected.

\subsection{Concluding remarks}

Plant-based products have gained a lot of interest as a route to help consumers to reduce their meat consumption. A special category of products aims at mimicking the taste and texture of meat. In this study, it has become evident that the process conditions used to make these products lead to oxidation of proteins to a certain extent. Further, we learned from this thesis that the incorporation of ferrous sulfate, free or encapsulated, did not affect protein oxidation in plant protein-based structured food. The encapsulation of ferrous sulfate could still be useful to reach high concentrations without any undesirable metallic taste. Furthermore, we identified that commercial plant protein ingredients have a certain level of protein oxidation, sometimes substantially higher than that of lab-made protein isolates. Whatever the protein ingredient used, the application of a thermomechanical process to yield structured products systematically increased protein oxidation. Therefore, protein oxidation in plant protein-based foods is a relevant topic that needs further research to understand possible chemical routes and interconnections with lipids, carbohydrates, and Maillard oxidation products. Such new insights will allow the development of strategies to control protein oxidation in plant protein-based foods. Finally, we hope that the results of this thesis motivate not only further research on protein oxidation but also the need for less processed plant protein-based foods. 
References 
Adler-Nissen, J. (1993). Proteases. In Nagodawithana, T., \& Reed, G. (Eds.), Ensymes in Food Processing. San Diego: Academic Press, pp. 159-203.

Alencar, E. R. de, Faroni, L. R. D., Peternelli, L. A., Silva, M. T. C. da, \& Costa, A. R. (2010). Influence of soybean storage conditions on crude oil quality. Revista Brasileira de Engenharia Agricola e Ambiental, 14(3), 303-308.

Alhendi, A., Yang, W., Goodrich-Schneider, R., \& Sarnoski, P. J. (2018). Total inactivation of lipoxygenase in whole soya bean by pulsed light and the effect of pulsed light on the chemical properties of soya milk produced from the treated soya beans. International Journal of Food Science and Technology, 53(2), 457466.

Alibhai, Z., Mondor, M., Moresoli, C., Ippersiel, D., \& Lamarche, F. (2006). Production of soy protein concentrates/isolates: traditional and membrane technologies. Desalination, 191(1-3), 351-358.

Alonso, R., Aguirre, a., \& Marzo, F. (2000). Effects of extrusion and traditional processing methods on antinutrients and in vitro digestibility of protein and starch in faba and kidney beans. Food Chemistry, 68, 159-165.

American Oil Chemists' society (AOCS). (2017). AOCS official method Cd. 18-90. In: Official methods and recommended practices of the American Oil Chemists' society (7th ed.; AOCS Press, ed.). Champaign: AOCS Press.

Armenteros, M., Heinonen, M., Ollilainen, V., Toldrá, F., \& Estévez, M. (2009). Analysis of protein carbonyls in meat products by using the DNPH-method, fluorescence spectroscopy and liquid chromatography-electrospray ionisationmass spectrometry (LC-ESI-MS). Meat Science, 83(1), 104-112.

Asioli, D., Aschemann-Witzel, J., Caputo, V., Vecchio, R., Annunziata, A., Næs, T., \& Varela, P. (2017). Making sense of the "clean label" trends: A review of consumer food choice behavior and discussion of industry implications. Food Research International, 99(April), 58-71.

Assatory, A., Vitelli, M., Rajabzadeh, A. R., \& Legge, R. L. (2019). Dry fractionation methods for plant protein, starch and fiber enrichment: A review. Trends in Food Science and Technology, 86, 340-351. 
Baldi, G., Soglia, F., Mazzoni, M., Sirri, F., Canonico, L., Babini, E., Laghi, L., Cavani, C., Petracci, M. (2018). Implications of white striping and spaghetti meat abnormalities on meat quality and histological features in broilers. Animal, 12(1), 164-173.

Balestrieri, M., Spagnuolo, M. S., Cigliano, L., Storti, G., Ferrara, L., Abrescia, P., \& Fedele, E. (2002). Evaluation of oxidative damage in mozzarella cheese produced from bovine or water buffalo milk. Food Chemistry, 77(3), 293-299.

Bao, Y., Boeren, S., \& Ertbjerg, P. (2018). Myofibrillar protein oxidation affects filament charges, aggregation and water-holding. Meat Science, 135, 102-108.

Baron, C. P., \& Andersen, H. J. (2002). Myoglobin-induced lipid oxidation. A review. Journal of Agricultural and Food Chemistry, 50(14), 3887-3897.

Bax, M.-L., Aubry, L., Ferreira, C., Daudin, J.-D. D., Gatellier, P., Rémond, D., \& Santé-Lhoutellier, V. (2012). Cooking temperature is a key determinant of in vitro meat protein digestion rate: investigation of underlying mechanisms. Journal of Agricultural and Food Chemistry, 60(10), 2569-2576.

Benichou, A., Aserin, A., \& Garti, N. (2007). W/O/W double emulsions stabilized with WPI-polysaccharide complexes. Colloids and Surfaces A: Physicochemical and Engineering Aspects, 294(1-3), 20-32.

Benjamin, O., Lassé, M., Silcock, P., \& Everett, D. W. (2012). Effect of pectin adsorption on the hydrophobic binding sites of $\beta$-lactoglobulin in solution and in emulsion systems. International Dairy Journal, 26(1), 36-40.

Berardo, A., Claeys, E., Vossen, E., Leroy, F., \& De Smet, S. (2015). Protein oxidation affects proteolysis in a meat model system. Meat Science, 106, 78-84.

Berghout, J. A. M., Boom, R. M., \& van der Goot, A. J. (2015a). Understanding the differences in gelling properties between lupin protein isolate and soy protein isolate. Food Hydrocolloids, 43, 465-472.

Berghout, J. A. M., Marmolejo-Garcia, C., Berton-Carabin, C. C., Nikiforidis, C. V., Boom, R. M., \& van der Goot, A. J. (2015b). Aqueous fractionation yields chemically stable lupin protein isolates. Food Research International, 72, 82-90. 
Berton-Carabin, C. C., Schröder, A., Rovalino-Cordova, A., Schroën, K., \& Sagis, L. (2016). Protein and lipid oxidation affect the viscoelasticity of whey protein layers at the oil - water interface. European Journal of Lipid Science and Technology., 118(11), 1630-1643.

Berton-Carabin, Claire C., Ropers, M. H., \& Genot, C. (2014). Lipid oxidation in oilin-water emulsions: involvement of the interfacial layer. Comprehensive Reviews in Food Science and Food Safety, 13(5), 945-977.

Berton, C., Ropers, M. H., Bertrand, D., Viau, M., \& Genot, C. (2012a). Oxidative stability of oil-in-water emulsions stabilised with protein or surfactant emulsifiers in various oxidation conditions. Food Chemistry, 131(4), 1360-1369.

Berton, C., Ropers, M. H., Guibert, D., Solé, V., \& Genot, C. (2012b). Modifications of interfacial proteins in oil-in-water emulsions prior to and during lipid oxidation. Journal of Agricultural and Food Chemistry, 60(35), 8659-8671.

Berton, C., Ropers, M. H., Viau, M., \& Genot, C. (2011). Contribution of the interfacial layer to the protection of emulsified lipids against oxidation. Journal of Agricultural and Food Chemistry, 59(9), 5052-5061.

Bittencourt, L. L. D. A., Pedrosa, C., Sousa, V. P. De, Pierucci, A. P. T., \& Citelli, M. (2013). Pea protein provides a promising matrix for microencapsulating iron. Plant Foods for Human Nutrition, 68(4), 333-339.

Blanco-Rojo, R., \& Vaquero, M. P. (2018). Iron bioavailability from food fortification to precision nutrition. A review. Innovative Food Science and Emerging Technologies, $51,126-138$.

Boada, L. D., Henríquez-Hernández, L. A., \& Luzardo, O. P. (2016). The impact of red and processed meat consumption on cancer and other health outcomes: Epidemiological evidences. Food and Chemical Toxicology, 92, 236-244.

Boatright, W. L., \& Hettiarachchy, N. S. (1995a). Effect of lipids on soy protein isolate solubility. Journal of the American Oil Chemists' Society, 72(12), 1439-1444.

Boatright, W. L., \& Hettiarachchy, N. S. (1995b). Soy protein isolate solubility and surface hydrophobicity as affected by antioxidants. Journal of Food Science, 60(4), 798-801. 
Boatright, W. L., Jahan, M. S., Walters, B. M., Miller, A. F., Cui, D., Hustedt, E. J., \& Lei, Q. (2008). Carbon-centered radicals in isolated soy proteins. Journal of Food Science, 73(3), 222-226.

Boatright, W. L., Lei, Q., \& Jahan, M. S. (2012). Effect of moisture, lipids, and select amino acid blocking agents on the formation and stability of metastable radicals in powdered soy proteins. Journal of Food Science, 77(6), 620-626.

Boatright, W. L., Qingxin, L., \& Jahan, M. S. (2009). Effect of storage conditions on carbon-centered radicals in soy protein products. Journal of Agricultural and Food Chemistry, 57(17), 7969-7973.

Bonnet, M., Cansell, M., Berkaoui, A., Ropers, M. H., Anton, M., \& Leal-calderon, F. (2009). Release rate profiles of magnesium from multiple $\mathrm{W} / \mathrm{O} / \mathrm{W}$ emulsions. Food Hydrocolloids, 23(1), 92-101.

Casey, E. J., \& Laidler, K. J. (1951). The kinetics and mechanism of the heat inactivation of pepsin. Journal of the American Chemical Society, 73(4), 1455-1457.

Cayot, P., Guzun-Cojocaru, T., \& Cayot, N. (2013). Iron fortification of milk and dairy products. In Preedy, V. R., Srirajaskanthan, R., \& Patel, V. B. (Eds.), Hanbook of food fortification and health: from concepts to public health applications (vol. 1). New York, NY: Human Press, pp. 75-90.

Cengiz, A., Kahyaoglu, T., Schröen, K., \& Berton-Carabin, C. (2019). Oxidative stability of emulsions fortified with iron: the role of liposomal phospholipids. Journal of the Science of Food and Agriculture, 99(6), 2957-2965.

Chaiyasit, W., Elias, R. J., McClements, D. J., \& Decker, E. (2007). Role of physical structures in bulk oils on lipid oxidation. Critical Reviens in Food Science and Nutrician, 47(3), 299-317.

Chamba, M. V. M., Hua, Y., \& Katiyo, W. (2014). Oxidation and structural modification of full-fat and defatted flour based soy protein isolates induced by natural and synthetic extraction chemicals. Food Biophysics, 9(3), 193-202.

Chang, Y. H., Lee, S. Y., \& Kwak, H. S. (2016). Physicochemical and sensory properties of milk fortified with iron microcapsules prepared with water-in-oil- 
in-water emulsion during storage. International Journal of Dairy Technology, 69(3), 452-459.

Chen, B., Panya, A., McClements, D. J., \& Decker, E. A. (2012). New insights into the role of iron in the promotion of lipid oxidation in bulk oils containing reverse micelles. Journal of Agricultural and Food Chemistry, 60, 3524-3552.

Chen, F. L., Wei, Y. M., \& Zhang, B. (2011). Chemical cross-linking and molecular aggregation of soybean protein during extrusion cooking at low and high moisture content. LWT - Food Science and Technology, 44(4), 957-962.

Chen, N., Zhao, M., \& Sun, W. (2013a). Effect of protein oxidation on the in vitro digestibility of soy protein isolate. Food Chemistry, 141(1), 3224-3229.

Chen, N., Zhao, M., Sun, W., Ren, J., \& Cui, C. (2013b). Effect of oxidation on the emulsifying properties of soy protein isolate. Food Research International, 52(1), 26-32.

Chen, N., Zhao, Q., Sun, W., \& Zhao, M. (2013c). Effects of malondialdehyde modification on the in vitro digestibility of soy protein isolate. Journal of Agricultural and Food Chemistry, 61(49), 12139-12145.

Chen, X., Chen, Y. P., Wu, D. W., Wen, C., \& Zhou, Y. M. (2015). Effects of heatoxidized soy protein isolate on growth performance and digestive function of broiler chickens at early age. Asian-Australasian Journal of Animal Sciences, 28(4), $544-550$.

Cho, Y. J., McClements, D. J., \& Decker, E. A. (2002). Ability of surfactant micelles to alter the physical location and reactivity of iron in oil-in-water emulsion. Journal of Agricultural and Food Chemistry, 50(20), 5704-5710.

Choi, S. J., Decker, E. A., \& McClements, D. J. (2009). Impact of iron encapsulation within the interior aqueous phase of water-in-oil-in-water emulsions on lipid oxidation. Food Chemistry, 116(1), 271-276.

Christiansen, K. (2015). PGPR, Polyglycerol-polyricinoleate, E476. In Norn, V. (Ed.), Emulsifiers in Food Technology. Chichester: John Wiley and Sons Inc., pp 209-230. 
Coad, J., \& Conlon, C. (2011). Iron deficiency in women: assessment, causes and consequences. Current Opinion in Clinical Nutrition and Metabolic Care, 14(6), 625634.

Colombo, G., Clerici, M., Garavaglia, M. E., Giustarini, D., Rossi, R., Milzani, A., \& Dalle-Donne, I. (2016). A step-by-step protocol for assaying protein carbonylation in biological samples. Journal of Chromatography B, 1019, 178-190.

Costa, A. M. M., Nunes, J. C., Lima, B. N. B., Pedrosa, C., Calado, V., Torres, A. G., \& Pierucci, A. P. T. R. (2015). Effective stabilization of CLA by microencapsulation in pea protein. Food Chemistry, 168, 157-166.

Costa, C. S. C. da. (2014). Aplicação de proteínas de reserva da ervilha verde (Pisum sativum, l.) no encapsulamento de ácido ascórbico por spray drying, obtenção de nano e micropartículas e avaliação da biodisponibilidade in vitro (doctoral thesis). Federal University of Rio de Janeiro, Brazil. Retrieved from

https://ppgcal.iq.ufri.br/wpcontent/uploads/2017/06/CAMILA_SOUSA_C _COSTA.pdf

Crowe, T. D., Crowe, T. W., Johnson, L. A., \& White, P. J. (2002). Impact of extraction method on yield of lipid oxidation products from oxidized and unoxidized walnuts. JAOCS, Journal of the American Oil Chemists' Society, 79(5), 453-456.

Cucu, T., Devreese, B., Kerkaert, B., Mestdagh, F., Sucic, M., Van De Perre, I., \& De Meulenaer, B. (2013). A comparative study of lipid and hypochlorous acid induced oxidation of soybean proteins. LWT - Food Science and Technology, 50(2), $451-458$.

Davies, K. J. A. (2001). Degradation of oxidized proteins by the 20 S proteasome. Biochimie, 83(3-4), 301-310.

Davies, M. J. (2016). Protein oxidation and peroxidation. Biochemical Journal, 473(7), $805-825$.

Day, L. (2013). Proteins from land plants - Potential resources for human nutrition and food security. Trends in Food Science and Technology, 32(1), 25-42. 
De Moura Bell, J. M. L. N., Maurer, D., Yao, L., Wang, T., Jung, S., \& Johnson, L. A. (2013). Characteristics of oil and skim in enzyme-assisted aqueous extraction of soybeans. JAOCS, Journal of the American Oil Chemists' Society, 90(7), 1079_ 1088 .

de Vries, M., \& de Boer, I. J. M. (2010). Comparing environmental impacts for livestock products: A review of life cycle assessments. Livestock Science, $128(1-$ 3), 1-11.

Decker, E. A., Xiong, Y. L., Calvert, J. T., Crum, A. D., \& Blanchard, S. P. (1993). Chemical, physical, and functional properties of oxidized turkey white muscle myofibrillar proteins. Journal of Agricultural and Food Chemistry, 41(2), 186-189.

Dekkers, B. L., Boom, R. M., \& van der Goot, A. J. (2018a). Structuring processes for meat analogues. Trends in Food Science and Technology, 81, 25-36.

Dekkers, B. L., Boom, R. M., \& van der Goot, A. J. (2018b). Viscoelastic properties of soy protein isolate - pectin blends: Richer than those of a simple composite material. Food Research International, 107, 281-288.

Dekkers, B. L., Hamoen, R., Boom, R. M., \& van der Goot, A. J. (2018c). Understanding fiber formation in a concentrated soy protein isolate-pectin blend. Journal of Food Engineering, 222, 84-92.

Dekkers, B. L., Nikiforidis, C. V, \& van der Goot, A. J. (2016). Shear-induced fibrous structure formation from a pectin/SPI blend. Innovative Food Science and Emerging Technologies, 36, 193-200.

Demeyer, D., Mertens, B., De Smet, S., \& Ulens, M. (2016). Mechanisms linking colorectal cancer to the consumption of (processed) red meat: A Review. Critical Reviews in Food Science and Nutrition, 56(16), 2747-2766.

Dickinson, E. (2011). Double emulsions stabilized by food biopolymers. Food Biophysics, 6(1), 1-11.

Dickinson, E., Evison, J., \& Owusu, R. K. (1991). Preparation of fine proteinstabilized water-in-oil-in-water emulsions. Topics in Catalysis, 5(5), 481-485. 
Ding, Y. Y., Cheng, X. R., Li, Z. Q., Wu, S. J., Yang, Y., Shi, Y. H., \& Le, G. W. (2017). Effect of dietary oxidized tyrosine products on insulin secretion: Via the oxidative stress-induced mitochondria damage in mice pancreas. RSC Advances, 7(43), 26809-26826.

Doblado-Maldonado, A. F., Pike, O. A., Sweley, J. C., \& Rose, D. J. (2012). Key issues and challenges in whole wheat flour milling and storage. Journal of Cereal Science, 56(2), 119-126.

Dridi, W., Essafi, W., Gargouri, M., Leal-Calderon, F., \& Cansell, M. (2016). Influence of formulation on the oxidative stability of water-in-oil emulsions. Food Chemistry, 202, 205-211.

Dubey, B. N., \& Windhab, E. J. (2013). Iron encapsulated microstructured emulsionparticle formation by prilling process and its release kinetics. Journal of Food Engineering, 115(2), 198-206.

Duque Estrada, P., Berton-Carabin, C. C., Schlangen, M., Haagsma, A., Pierucci, A. P. T. R., \& van der Goot, A. J. (2018). Protein Oxidation in plant protein-based fibrous products: effects of encapsulated iron and process conditions. Journal of Agricultural and Food Chemistry, 66(42), 11105-11112.

Eisinaite, V., Duque Estrada, P., Schroën, K., Berton-Carabin, C., \& Leskauskaite, D. (2018). Tayloring $\mathrm{W} / \mathrm{O} / \mathrm{W}$ emulsion composition for effective encapsulation: The role of PGPR in water transfer-induced swelling. Food Research International, 106, 722-728.

Estévez, M., \& Luna, C. (2017). Dietary protein oxidation: A silent threat to human health? Critical Reviews in Food Science and Nutrition, 57(17), 3781-3793.

Estévez, M. (2017). What's New in Meat Oxidation? In Purslow, P. P. (Ed.), New Aspects of Meat Quality: From Genes to Ethics (1st ed.) Cambridge: Woodhead Publishing, pp. 91-109 .

Estévez, M. (2011). Protein carbonyls in meat systems: A review. Meat Science, 89(3), 259-279.

Estévez, M., Li, Z., Soladoye, O. P., \& Van-Hecke, T. (2017). Health risks of food oxidation. Advances in Food and Nutrition Research, 82, 45-81. 
Estévez, M., Ollilainen, V., \& Heinonen, M. (2009). Analysis of protein oxidation markers $\alpha$-Aminoadipic and $\gamma$-Glutamic semialdehydes in food proteins using liquid chromatography (LC)-Electrospray ionization (ESI)-Multistage tandem mass spectrometry (MS). Journal of Agricultural and Food Chemistry, 57(9), 39013910 .

Estévez, M., Ventanas, S., \& Cava, R. (2006). Protein oxidation in frankfurters with increasing levels of added rosemary essential oil: Effect on color and texture deterioration. Journal of Food Science, 70(7), c427-c432.

Estévez, M., \& Xiong, Y. (2019). Intake of oxidized proteins and amino acids and causative oxidative stress and disease: recent scientific evidences and hypotheses. Journal of Food Science, 84(3), 387-396.

Eymard, S., Baron, C. P., \& Jacobsen, C. (2009). Oxidation of lipid and protein in horse mackerel (Trachurus trachurus) mince and washed minces during processing and storage. Food Chemistry, 114(1), 57-65.

FAO/WHO. (1973). Polyglycerol esters of interesterified ricinoleic acid. Retrieved from Joint FAO/WHO Expert Committee on Food Additives website: www.inchem.org/document/jecfa/jeceval/jec_1947.htm.

FAO. (1999). Codex Standard for Named Vegetable Oils CODEX STAN 210-1999. Retrieved from http://www.fao.org/fao-who-codexalimentarius/home/en/.

FAO. (2011). World Livestock 2011-Livestock in food security. In McLeod, A. (Ed.), Food and Agriculture Organization of the United Nations, FAO. Retrieved from http://www.fao.org/docrep/014/i2373e/i2373e.pdf.

Fellows, P. J. (2017). Properties of food and principles of processing. In Food Processing Technology: principles and practice (4th ed.) Cambridge: Woodhead Publishing, pp. 3-200.

Fenaille, F., Parisod, V., Vuichoud, J., Tabet, J. C., \& Guy, P. A. (2004). Quantitative determination of dityrosine in milk powders by liquid chromatography coupled to tandem mass spectrometry using isotope dilution. Journal of Chromatography A, 1052(1-2), 77-84.

Ferreira, B. S. (2014). Microencapsulamento de sulfato ferroso: aperfeiçoamento do 
processo de produção, caracterização morfológica, física, química e microbiológica e avaliação sensorial em uma preparação típica brasileira (unpublished Master thesis). Federal University of Rio de Janeiro, Brazil.

Ferreira, B. S., Cardoso, B. T., Pereira, H. V. R., Pierucci, A. P., Pedrosa, C., \& Citelli, M. (2011). Aceitabilidade de feijão preto (Phaseolus vulgaris L.), fortificado com micropartículas de ferro. Revista Ceres, 58(5), 548-553.

Filgueras, R. S., Gatellier, P., Ferreira, C., Zambiazi, R. C., \& Santé-Lhoutellier, V. (2011). Nutritional value and digestion rate of rhea meat proteins in association with storage and cooking processes. Meat Science, 89(1), 6-12.

Food and Agriculture Organization of the United Nations, FAO. (1981). Amino-acid content of foods and biological data on proteins. Retrieved from FAO website: http://www.fao.org/docrep/005/AC854T/AC854T00.htm.

Freitas, D., Le Feunteun, S., Panouillé, M., \& Souchon, I. (2018). The important role of salivary $\alpha$-amylase in the gastric digestion of wheat bread starch. Food and Function, 9(1), 200-208.

Gan, X., Li, H., Wang, Z., Emara, A. M., Zhang, D., \& He, Z. (2019). Does protein oxidation affect proteolysis in low sodium Chinese traditional bacon processing? Meat Science, 150(2), 14-22.

Ganhão, R., Morcuende, D., \& Estévez, M. (2010). Protein oxidation in emulsified cooked burger patties with added fruit extracts: Influence on colour and texture deterioration during chill storage. Meat Science, 85(3), 402-409.

Garti, N. (1997). Progress in stabilization and transport phenomena of double emulsions in food applications. LWT-Food Science and TechnologyFood Science and Technology, 30(3), 222-235.

Gatellier, P., Kondjoyan, A., Portanguen, S., Grève, E., Yoon, K., \& SantéLhoutellier, V. (2009a). Determination of aromatic amino acid content in cooked meat by derivative spectrophotometry: Implications for nutritional quality of meat. Food Chemistry, 114(3), 1074-1078.

Gatellier, P., Kondjoyan, A., Portanguen, S., \& Santé-Lhoutellier, V. (2010). Effect of cooking on protein oxidation in $\mathrm{n}-3$ polyunsaturated fatty acids enriched 
beef. Implication on nutritional quality. Meat Science, 85(4), 645-650.

Gatellier, P., Portanguen, S., \& Kondjoyan, A. (2009b). Use of meat fluorescence emission as a marker of oxidation promoted by cooking. Meat Science, 83(4), 651-656.

Geerts, M. E. J., Dekkers, B. L., van der Padt, A., \& van der Goot, A. J. (2018). Aqueous fractionation processes of soy protein for fibrous structure formation. Innovative Food Science and Emerging Technologies, 45, 313-319.

Grabowska, K. J., Tekidou, S., Boom, R. M., \& van der Goot, A. J. (2014). Shear structuring as a new method to make anisotropic structures from soy-gluten blends. Food Research International, 64, 743-751.

Grabowska, K. J., Zhu, S., Dekkers, B. L., Ruijter, N. C. A. de, Gieteling, J., \& van der Goot, A. J. (2016). Shear-induced structuring as a tool to make anisotropic materials using soy protein Concentrate. Journal of Food Engineering, 188, 1-10.

Graça, J., Oliveira, A., \& Calheiros, M. M. (2015). Meat, beyond the plate. Datadriven hypotheses for understanding consumer willingness to adopt a more plant-based diet. Appetite, 90, 80-90.

Grompone, M. A. (2011). Sunflower Oil. In Gunstone, F. D. (Ed.), Vegetable Oils in Food Technology: Composition, Properties and Uses . Oxford: Blackwell Publishing Ldt, pp. 137-167.

Grune, T., Jung, T., Merker, K., \& Davies, K. J. A. (2004). Decreased proteolysis caused by protein aggregates, inclusion bodies, plaques, lipofuscin, ceroid, and 'aggresomes' during oxidative stress, aging, and disease. The International Journal of Biochemistry \& Cell Biology, 36(12), 2519-2530.

Grunert, K. G., Bredahl, L., \& Brunsø, K. (2004). Consumer perception of meat quality and implications for product development in the meat sector - A review. Meat Science, 66(2), 259-272.

Guo, F. X., Xiong, Y. L., Qin, F., Jian, H. J., Huang, X. L., \& Chen, J. (2015). Examination of the causes of instability of soy protein isolate during storage through probing of the heat-induced aggregation. JAOCS, Journal of the American Oil Chemists' Society, 92(8), 1075-1084. 
He, J., Xia, C., He, Y., Pan, D., Cao, J., Sun, Y., \& Zeng, X. (2019). Proteomic responses to oxidative damage in meat from ducks exposed to heat stress. Food Chemistry, 295, 129-137.

Hoek, A. C., Luning, P. A., Weijzen, P., Engels, W., Kok, F. J., \& de Graaf, C. (2011). Replacement of meat by meat substitutes . A survey on person- and productrelated factors in consumer acceptance. Appetite, 56(3), 662-673.

Hosseini, S. M. H., Gahruie, H. H., Razmjooie, M., Sepeidnameh, M., Rastehmanfard, M., Tatar, M., Naghibalhossaini, F., van de Meeren, P. (2019). Effects of novel and conventional thermal treatments on the physicochemical properties of iron-loaded double emulsions. Food Chemistry, 270, 70-77.

Hu, L., Ren, S., Shen, Q., Chen, J., Ye, X., \& Ling, J. (2017). Proteomic study of the effect of different cooking methods on protein oxidation in fish fillets. RSC Advances, 7(44), 27496-27505.

Huang, Y., Hua, Y., \& Qiu, A. (2006). Soybean protein aggregation induced by lipoxygenase catalyzed linoleic acid oxidation. Food Research International, 39(2), 240-249.

Hughes, G. J., Ryan, D. J., Mukherjea, R., \& Schasteen, C. S. (2011). Protein digestibility-corrected amino acid scores (PDCAAS) for soy protein isolates and concentrate: Criteria for evaluation. Journal of Agricultural and Food Chemistry, 59(23), 12707-12712.

Hurrell, R. F., Lynch, S., Bothwell, T., Cori, H., Glahn, R., Hertrampf, E., Kratky, Z., Miller, D., Rodenstein, M., Teucher, B., Turner, E., Yeung, C. K, Zimmermann, M. B. (2004). Enhancing the absorption of fortification iron. International Journal for Vitamin and Nutrition Research, 74(6), 387-401.

Jacobsen, C. (2016). Oxidative stability and shelf life of food emulsions. In Hu, M., \& Jacobsen, C. (Eds.), Oxidative Stability and Shelf Life of Foods Containing Oils and Fats. London: Elsevier Inc. pp.287-312.

Jafari, M., Rajabzadeh, A. R., Tabtabaei, S., Marsolais, F., \& Legge, R. L. (2016). Physicochemical characterization of a navy bean (Phaseolus vulgaris) protein fraction produced using a solvent-free method. Food Chemistry, 208, 35-41. 
Janve, B. A., Yang, W., Marshall, M. R., Reyes-De-Corcuera, J. I., \& Rababah, T. M. (2014). Nonthermal inactivation of soy (Glycine Max Sp.) lipoxygenase by pulsed ultraviolet light. Journal of Food Science, $79(1)$.

Jiang, J, Chen, J., \& Xiong, Y. L. (2009). Structural and emulsifying properties of soy protein isolate subjected to acid and alkaline $\mathrm{pH}$-shifting processes. Journal of Agricultural and Food Chemistry, 57, 7576-7583.

Jiang, Jiang, \& Xiong, Y. L. (2016). Natural antioxidants as food and feed additives to promote health benefits and quality of meat products: A review. Meat Science, 120, 107-117.

Johnson, D. R., \& Decker, E. A. (2015). The Role of Oxygen in Lipid Oxidation Reactions: A Review. Annual Review of Food Science and Technology, 6(1), 171-190.

Johnson, L. A., White, P. J., \& Galloway, R. (2008). Soybeans: chemistry, production, processing and utilization. Urbana, Illinois: AOCS Press.

Jongberg, S., Lund, M. N., Waterhouse, A. L., \& Skibsted, L. H. (2011). 4Methylcatechol inhibits protein oxidation in meat but not disulfide formation. Journal of Agricultural and Food Chemistry, 59(18), 10329-10335.

Kaimainen, M., Marze, S., Eila, J., Anton, M., \& Huopalahti, R. (2015). Encapsulation of betalain into $\mathrm{w} / \mathrm{o} / \mathrm{w}$ double emulsion and release during in vitro intestinal lipid digestion. LWT - Food Science and Technology, 60(2), 899-904.

Kondjoyan, A., Daudin, J. D., \& Santé-Lhoutellier, V. (2015). Modelling of pepsin digestibility of myofibrillar proteins and of variations due to heating. Food Chemistry, 172, 265-271.

Koutina, G., Jongberg, S., \& Skibsted, L. H. (2012). Protein and lipid oxidation in Parma ham during production. Journal of Agricultural and Food Chemistry, 60(38), 9737-9745.

Krintiras, G. A., Göbel, J., Bouwman, W. G., van der Goot, A. J., \& Stefanidis, G. D. (2014). On characterization of anisotropic plant protein structures. Food \& Function, 5(12), 3233-3240.

Krintiras, G. A., Göbel, J., van der Goot, A. J., \& Stefanidis, G. D. (2015). Production 
of structured soy-based meat analogues using simple shear and heat in a Couette cell. Journal of Food Engineering, 160, 34-41.

Kristinova, V., Mozuraityte, R., Aaneby, J., Storrø, I., \& Rustad, T. (2014). Ironmediated peroxidation in marine emulsions and liposomes studied by dissolved oxygen consumption. European Journal of Lipid Science and Technology, 116(2), 207 225.

Kuang, S. S., Oliveira, J. C., \& Crean, A. M. (2010). Microencapsulation as a tool for incorporating bioactive ingredients into food. Critical Reviews in Food Science and Nutrition, 50(10), 951-968.

Kumar, P., Chatli, M. K., Mehta, N., Singh, P., Malav, O. P., \& Verma, A. K. (2017). Meat analogues: Health promising sustainable meat substitutes. Critical Reviews in Food Science and Nutrition, 57(5), 923-932.

Kyriakopoulou, K., Dekkers, B., \& van der Goot, A. J. (2018). Plant-based meat analogues. In Galanakis, C. (Ed.), Sustainable Meat Production and Processing (1st ed). London: Academic Press, pp. 103-126.

Laguna, L., Picouet, P., Guàrdia, M. D., Renard, C. M. G. C., \& Sarkar, A. (2017). In vitro gastrointestinal digestion of pea protein isolate as a function of $\mathrm{pH}$, food matrices, autoclaving, high-pressure and re-heat treatments. LWT - Food Science and Technology, 84, 511-519.

Lamsal, B. P., \& Johnson, L. A. (2007). Separating oil from aqueous extraction fractions of soybean. JAOCS, Journal of the American Oil Chemists' Society, 84(8), 785-792.

Lawhon, J. T., Rhee, K. C., \& Lusas, E. W. (1981). Soy protein ingredients prepared by new processes-Aqueous processing and industrial membrane isolation. Journal of the American Oil Chemists' Society, 58(3), 377-384.

Lea, E., \& Worsley, A. (2003). Benefits and barriers to the consumption of a vegetarian diet in Australia. Public Health Nutrition, 6(05), 505-511.

Lei, Q., Liebold, C. M., Boatright, W. L., \& Shah Jahan, M. (2010). Distribution of stable free radicals among amino acids of isolated soy proteins. Journal of Food Science, 75(7), 633-640. 
Levine, R. L., Garland, D., Oliver, C. N., Amici, A., Climent, I., Lenz, A.-G., ... Stadtman, E. R. (1990). Determination of carbonyl content in oxidatively modified proteins. Methods in Ensymology, 186, 464-478.

Li, M., \& Lee, T. C. (1996). Effect of extrusion temperature on solubility and molecular weight distribution of wheat flour proteins. Journal of Agricultural and Food Chemistry, 44(3), 763-768.

Li, Q., Zheng, J., Ge, G., Zhao, M., \& Sun, W. (2019). Impact of heating treatments on physical stability and lipid-protein co-oxidation in oil-in-water emulsion prepared with soy protein isolates. Food Hydrocolloids.

Li, Y., Kong, B., Xia, X., Liu, Q., \& Li, P. (2013). Inhibition of frozen storage-induced oxidation and structural changes in myofibril of common carp (Cyprinus carpio) surimi by cryoprotectant and hydrolysed whey protein addition. International Journal of Food Science \& Technology, 48(9), 1916-1923.

Li, Z. L., Shi, Y., Ding, Y., Ran, Y., \& Le, G. (2017). Dietary oxidized tyrosine (OTyr) stimulates TGF- $\beta 1$-induced extracellular matrix production via the JNK/p38 signaling pathway in rat kidneys. Amino Acids, 49(2), 241-260.

Liebold, C. M., Lei, Q., Boatright, W. L., \& Jahan, M. S. (2011). Metastable radicals and intrinsic chemiluminescence from soy proteins. Journal of Food Science, 76(7), C1101-C1107.

Lippi, G., Mattiuzzi, C., \& Cervellin, G. (2016). Meat consumption and cancer risk: A critical review of published meta-analyses. Critical Reviens in Oncology/Hematology, 97, 1-14.

Liu, G., Xiong, Y. L., \& Butterfield, D. A. (2000). Chemical, physical, and gel-forming properties of oxidized myofibrils and whey- and soy-protein isolates. Journal of Food Science, 65(5), 811-818.

Lorieau, L., Halabi, A., Ligneul, A., Hazart, E., Dupont, D., \& Floury, J. (2018). Impact of the dairy product structure and protein nature on the proteolysis and amino acid bioaccessiblity during in vitro digestion. Food Hydrocolloids, 82, 399_ 411. 
Lu, P., Zhang, X. L., Xue, W. Y., Wu, D. W., Ding, L. R., Wen, C., \& Zhou, Y. M. (2017). The protein oxidation of soybean meal induced by heating decreases its protein digestion in vitro and impairs growth performance and digestive function in broilers. British Poultry Science, 58(6), 704-711.

Luna, C., \& Estévez, M. (2018). Oxidative damage to food and human serum proteins: Radical-mediated oxidation vs. glyco-oxidation. Food Chemistry, 267, $111-118$.

Lund, M. N., Heinonen, M., Baron, C. P., \& Estévez, M. (2011). Protein oxidation in muscle foods: A review. Molecular Nutrition and Food Research, 55(1), 83-95.

Lund, M. N., Lametsch, R., Hviid, M. S., Jensen, O. N., \& Skibsted, L. H. (2007). High-oxygen packaging atmosphere influences protein oxidation and tenderness of porcine longissimus dorsi during chill storage. Meat Science, 77(3), 295-303.

Luo, Q., Boom, R. M., Janssen, A. E. M. M., \& Wang, Y. (2015). Digestion of protein and protein gels in simulated gastric environment. $L W T$ - Food Science and Tecbnology, 63(1), 161-168.

Luo, Q., Borst, J. W., Westphal, A. H., Boom, R. M., \& Janssen, A. E. M. (2017). Pepsin diffusivity in whey protein gels and its effect on gastric digestion. Food Hydrocolloids, 66, 318-325.

Luo, S., \& Wehr, N. B. (2009). Protein carbonylation: avoiding pitfalls in the 2,4dinitrophenylhydrazine assay. Redox Report, 14(4), 159-166.

Luo, Q., Zhan, W., Boom, R., \& Janssen, A. E. M. (2018). Interactions between acid and proteins under in vitro gastric condition - a theoretical and experimental quantification. Food \& Function, 9(10), 5283-5289.

Ma, W., Xie, F., Zhang, S., Wang, H., Hu, M., Sun, Y., Zhong, M., Zhu, J., Qi, B., \& $\mathrm{Li}, \mathrm{Y}$. (2018). Characterizing the structural and functional properties of soybean protein extracted from full-fat soybean flakes after low-temperature dry extrusion. Molecules, 23(12), 3265.

Mancuso, J. R., McClements, D. J., \& Decker, E. A. (2000). Iron-accelerated cumene hydroperoxide decomposition in hexadecane and trilaurin emulsions. Journal of 
Agricultural and Food Chemistry, 48(2), 213-219.

Manski, J. M., van der Goot, A. J., \& Boom, R. M. (2007a). Advances in structure formation of anisotropic protein-rich foods through novel processing concepts. Trends in Food Science and Technology, 18(11), 546-557.

Manski, J. M., van der Goot, A. J., \& Boom, R. M. (2007b). Formation of fibrous materials from dense calcium caseinate dispersions. Biomacromolecules, 8(4), $1271-1279$.

Manski, J. M., van der Zalm, E. E. J., van der Goot, A. J., \& Boom, R. M. (2008). Influence of process parameters on formation of fibrous materials from dense calcium caseinate dispersions and fat. Food Hydrocolloids, 22(4), 587-600.

Márquez, A. L., Medrano, A., Panizzolo, L. A., \& Wagner, J. R. (2010). Effect of calcium salts and surfactant concentration on the stability of water-in-oil (w/o) emulsions prepared with polyglycerol polyricinoleate. Journal of Colloid and Interface Science, 341(1), 101-108.

Martinez, M. P., \& Kannan, K. (2018). Simultaneous analysis of seven biomarkers of oxidative damage to lipids, proteins, and DNA in urine. Environmental Science \& Technology, 52(11), 6647-6655.

Marze, S. (2009). Relaxation processes of PGPR at the water/oil interface inferred by oscillatory or transient viscoelasticity measurements. Langmuir, 25(20), 12066-12072.

Matos, M., Gutiérrez, G., Iglesias, O., Coca, J., \& Pazos, C. (2015). Enhancing encapsulation efficiency of food-grade double emulsions containing resveratrol or vitamin $\mathrm{B}_{12}$ by membrane emulsification. Journal of Food Engineering, 166, 212 220.

McClements, D., \& Decker, E. (2000). Lipid oxidation in oil-in-water emulsions: impact of molecular environment on chemical reactions in heterogeneous food systems. Journal of Food Science, 65(8), 1270-1282.

McClements, D. J. (2015). Encapsulation, protection, and release of hydrophilic active components: Potential and limitations of colloidal delivery systems. Advances in Colloid and Interface Science, 219, 27-53. 
Min, B., \& Ahn, D. U. (2005). Mechanism of lipid peroxidation in meat and meat products -A review. Food Science and Biotechnology, 14(1), 152-163.

Mitra, B., Lametsch, R., Akcan, T., \& Ruiz-carrascal, J. (2018). Pork proteins oxidative modifications under the influence of varied time- temperature thermal treatments: A chemical and redox proteomics assessment. Meat Science, 140, 134-144.

Morzel, M., Gatellier, P., Sayd, T., Renerre, M., \& Laville, E. (2006). Chemical oxidation decreases proteolytic susceptibility of skeletal muscle myofibrillar proteins. Meat Science, 73, 536-543.

Mouécoucou, J., Villaume, C., Sanchez, C., \& Méjean, L. (2004). Effects of gum arabic, low methoxy pectin and xylan on in vitro digestibility of peanut protein. Food Research International, 37(8), 777-783.

Nishinari, K., Fang, Y., Nagano, T., Guo, S., \& Wang, R. (2017). Soy as a food ingredient. In Yada, R. Y. (Ed.), Proteins in Food Processing. Cambridge: Woodhead Publishing Limited, pp. 149-186.

Ooizumi, T., \& Xiong, Y. L. (2004). Biochemical susceptibility of myosin in chicken myofibrils subjected to hydroxyl radical oxidizing systems. Joumal of Agricultural and Food Chemistry, 52(13), 4303-4307.

Opazo-Navarrete, M., Altenburg, M. D., Boom, R. M., \& Janssen, A. E. M. (2018). The effect of gel microstructure on simulated gastric digestion of protein gels. Food Biophysics, 13(2), 124-138.

Opazo-Navarrete, M., Tagle Freire, D., Boom, R. M., \& Janssen, A. E. M. (2019). The influence of starch and fibre on in vitro protein digestibility of dry fractionated quinoa seed (Riobamba V ariety). Food Biophysics, 14(1), 49-59.

Osborn, H. T., \& Akoh, C. C. (2003). Effects of natural antioxidants on ironcatalyzed lipid oxidation of structured lipid-based emulsions. JAOCS, Journal of the American Oil Chemists' Society, 80(9), 847-852.

Paulsen, M. R. (2008). Measurement and maintenance of soybean quality. In Johnson, L. A., White, P. J., \& Galloway, R. (Eds.), Soybeans: chemistry, production, processing and utilization. Urbana, Illinois: AOCS Press, pp. 151-192. 
Peyron, M. A., Mishellany, A., \& Woda, A. (2004). Particle size distribution of food boluses after mastication of six natural foods. Journal of Dental Research, 83(7), $578-582$.

Pierucci, A. P. T. R., Andrade, L. R., Farina, M., Pedrosa, C., \& Rocha-Leão, M. H. M. (2007). Comparison of alpha-tocopherol microparticles produced with different wall materials: pea protein a new interesting alternative. Journal of Microencapsulation, 24(3), 201-213.

Piper, D. W., \& Fenton, B. H. (1965). pH stability and activity curves of pepsin with special reference to their clinical importance. Gut, 6(5), 506-508.

Poulsen, M. W., Hedegaard, R. V, Andersen, J. M., Courten, B. De, Bügel, S., Nielsen, J., Skibsted, L. H., \& Dragsted, L. O. (2013). Advanced glycation endproducts in food and their effects on health. Food And Chemical Toxicology, 60, 10-37.

Prichapan, N., McClements, D. J., \& Klinkesorn, U. (2018). Iron encapsulation in water-in-oil emulsions: effect of ferrous sulfate concentration and fat crystal formation on oxidative stability. Journal of Food Science, 83(2), 309-317.

Promeyrat, A, Daudin, J. D., Astruc, T., Danon, J., \& Gatellier, P. (2013). Kinetics of protein physicochemical changes induced by heating in meat using mimetic models: ( 2 ) Effects of fibre type, peroxides and antioxidants. Food Chemistry, 138(4), 2283-2290.

Promeyrat, Aurelie, Le Louët, L., Kondjoyan, A., Astruc, T., Santé-Lhoutellier, V., Gatellier, P., \& Daudin, J. D. (2011). Combined effect of meat composition and heating parameters on the physicochemical state of proteins. Procedia Food Science, 1(0), 1118-1125.

Qi, G., Venkateshan, K., Mo, X., Zhang, L., \& Sun, X. S. (2011). Physicochemical properties of soy protein: Effects of subunit composition. Journal of Agricultural and Food Chemistry, 59(18), 9958-9964.

Reiniers, M. J., van Golen, R. F., van Gulik, T. M., \& Heger, M. (2014). Reactive Oxygen and nitrogen species in steatotic hepatocytes: a molecular perspective on the pathophysiology of ischemia-reperfusion injury in the fatty liver. Antioxidants \& Redox Signaling, 7(1), 1119-1143. 
Requena, J. R., Levine, R. L., Chao, C.-C., \& Stadtman, E. R. (2001). Glutamic and aminoadipic semialdehydes are the main carbonyl products of metal-catalyzed oxidation of proteins. Proceedings of the National Academy of Sciences, 98(1), 69-74.

Ribeiro, J. S., Santos, M. J. M. C., Silva, L. K. R., Pereira, L. C. L., Santos, I. A., da Silva Lannes, S. C., \& da Silva, M. V. (2019). Natural antioxidants used in meat products: A brief review. Meat Science, 148(October 2018), 181-188.

Ribotta, P. D., Ausar, S. F., Morcillo, M. H., Pérez, G. T., Beltramo, D. M., \& León, A. E. (2004). Production of gluten-free bread using soybean flour. Journal of the Science of Food and Agriculture, 84(14), 1969-1974.

Rogowska-Wrzesinska, A., Wojdyla, K., Nedic, O., Caroline, P., \& Griffith, H. R. (2014). Analysis of protein carbonylation - pitfalls and promise in commonly used methods. Free Radical Reaserch, 48(10), 1145-1162.

Rysman, T., Jongberg, S., Van Royen, G., Van Weyenberg, S., De Smet, S., \& Lund, M. N. (2014). Protein thiols undergo reversible and irreversible oxidation during chill storage of ground beef as detected by 4,4'-dithiodipyridine. Journal of Agricultural and Food Chemistry, 62(49), 12008-12014.

Rysman, T., Van Hecke, T., Van Poucke, C., De Smet, S., \& Van Royen, G. (2016). Protein oxidation and proteolysis during storage and in vitro digestion of pork and beef patties. Food Chemistry, 209, 177-184.

Sahin, S., Sawalha, H., \& Schroën, K. (2014). High throughput production of double emulsions using packed bed premix emulsification. Food Research International, $66,78-85$.

Santé-Lhoutellier, V., Aubry, L., \& Gatellier, P. (2007). Effect of oxidation on in vitro digestibility of skeletal muscle myofibrillar proteins. Journal of Agricultural and Food Chemistry, 55(13), 5343-5348.

Santé-Lhoutellier, V., Astruc, T., Marinova, P., Greve, E., \& Gatellier, P. (2008a). Effect of meat cooking on physicochemical state and in vitro digestibility of myofibrillar proteins. Journal of Agricultural and Food Chemistry, 56(4), 1488-1494.

Santé-Lhoutellier, V., Engel, E., Aubry, L., \& Gatellier, P. (2008b). Effect of animal (lamb) diet and meat storage on myofibrillar protein oxidation and in vitro 
digestibility. Meat Science, 79(4), 777-783.

Savell, J. W., \& Cross, H. R. (1988). The role of fat in the palatability of beef, pork and lamb. In Designing Foods: Animal product options in the marketplace.

Sbihi, H. M., Nehdi, I. A., Tan, C. P., \& Al-Resayes, S. I. (2013). Bitter and sweet lupin (Lupinus albus L.) seeds and seed oils: A comparison study of their compositions and physicochemical properties. Industrial Crops and Products, 49, 573-579.

Schaich, K. M. (1992). Metals and lipid oxidation. Contemporary issues. Lipids, 27(3), 209-218.

Schaich, K. M. (2005). Lipid oxidation: theoretical aspects. In Shahidi, F. (Ed.), Bailey's Industrial Oil and Fat Products (Sixth). Hoboken, NJ: John Wiley \& Sons, Inc.

Schaich, Karen M., Shahidi, F., Zhong, Y., \& Eskin, N. A. M. (2013). Lipid Oxidation. Biochemistry of Foods, 419-478.

Scherze, I., Knoth, A., \& Muschiolik, G. (2006). Effect of emulsification method on the properties of lecithin- and PGPR-stabilized water-in-oil-emulsions. Journal of Dispersion Science and Technology, 27(4), 427-434.

Schreuders, F. K. G., Dekkers, B. L., Bodnár, I., Erni, P., Boom, R. M., \& van der Goot, A. J. (2019). Comparing structuring potential of pea and soy protein with gluten for meat analogue preparation. Journal of Food Engineering, 261, 32-39.

Schutyser, M. A. I., \& van der Goot, A. J. (2011). The potential of dry fractionation processes for sustainable plant protein production. Trends in Food Science \& Technology, 22(4), 154-164.

Semedo Tavares, W. P. S., Dong, S., Yang, Y., Zeng, M., \& Zhao, Y. (2018). Influence of cooking methods on protein modification and in vitro digestibility of hairtail (Thicbiurus lepturus) fillets. Lwt, 96, 476-481.

Shao, Y., Lin, K., \& Kao, Y. (2016). Modification of foaming properties of commercial soy protein isolates and concentrates by heat treatments. Journal of Food Quality, 39, 695-706. 
Simiqueli, A. A., de Oliveira, E. B., Minim, L. A., Reis, P. S., Vidigal, M. C. T. R., Lima Filho, T., \& Minim, V. P. R. (2019a). W/O/W emulsions applied for conveying $\mathrm{FeSO}_{4}$ : Physical characteristics and intensity of metallic taste perception. LWT-Food Science and Technology, 100, 278-286.

Simiqueli, A. A., Lima Filho, T., Minim, L. A., de Oliveira, E. B., Torres, I. V., Vidigal, M. C. T. R., \& Minim, V. P. R. (2019b). The W/O/W emulsion containing $\mathrm{FeSO}_{4}$ in the different phases alters the hedonic thresholds in milk-based dessert. LWT-Food Science and Tecbnology, 99, 98-104.

Singh, H., Ye, A., \& Ferrua, M. J. (2015). Aspects of food structures in the digestive tract. Current Opinion in Food Science, 3, 85-93.

Singh, S., Gamlath, S., \& Wakeling, L. (2007). Nutritional aspects of food extrusion: A review. International Journal of Food Science and Technology, 42(8), 916-929.

Soglia, F., Laghi, L., Canonico, L., Cavani, C., \& Petracci, M. (2016a). Functional property issues in broiler breast meat related to emerging muscle abnormalities. Food Research International, 89, 1071-1076.

Soglia, F., Petracci, M., \& Ertbjerg, P. (2016b). Novel DNPH-based method for determination of protein carbonylation in muscle and meat. Food Chemistry, 197, 670-675.

Soladoye, O. P., Juárez, M. L., Aalhus, J. L., Shand, P., \& Estévez, M. (2015). Protein oxidation in processed meat: mechanisms and potential implications on human health. Comprehensive Reviews in Food Science and Food Safety, 14(2), 106-122.

Soladoye, O. P., Shand, P., Dugan, M. E. R., Gariépy, C., Aalhus, J. L., Estévez, M., \& Juárez, M. (2017). Influence of cooking methods and storage time on lipid and protein oxidation and heterocyclic aromatic amines production in bacon. Food Research International, 99, 660-669.

Soyer, A., Özalp, B., Dalmiş, Ü., \& Bilgin, V. (2010). Effects of freezing temperature and duration of frozen storage on lipid and protein oxidation in chicken meat. Food Chemistry, 120(4), 1025-1030.

Stadman, E. R., \& Levine, R. L. (2000). Protein Oxidation. Annals of the New York Academy of Sciences, 899(1), 191-208. 
Stehfest, E., Bouwman, L., van Vuuren, D. P., den Elzen, M. G. J., Eickhout, B., \& Kabat, P. (2009). Climate benefits of changing diet. Climatic Change, 95(1), 83102.

Steinfeld, H., Gerber, P., Wassenaar, T., Castel, V., Rosales, M., \& Haan, C. de. (2006). Livestock's long shadow: environmental issues and options. Retrieved from http://www.fao.org/3/a0701e/a0701e00.htm.

Su, J., Flanagan, J., Hemar, Y., \& Singh, H. (2006). Synergistic effects of polyglycerol ester of polyricinoleic acid and sodium caseinate on the stabilisation of wateroil-water emulsions. Food Hydrocolloids, 20, 261-268.

Sun, W., Zhou, F., Zhao, M., Yang, B., \& Cui, C. (2011). Physicochemical changes of myofibrillar proteins during processing of Cantonese sausage in relation to their aggregation behaviour and in vitro digestibility. Food Chemistry, 129(2), 472-478.

Tan, Y., Wang, J., Chen, F., Niu, S., \& Yu, J. (2016). Effect of protein oxidation on kinetics of droplets stability probed by microrheology in $\mathrm{O} / \mathrm{W}$ and $\mathrm{W} / \mathrm{O}$ emulsions of whey protein concentrate. Food Research International, 85, 259-265.

Tang, X., Wu, Q., Le, G., \& Shi, Y. (2012). Effects of heat treatment on structural modification and in vivo antioxidant capacity of soy protein. Nutrition, 28(1112), 1180-1185.

Thrane, M., Paulsen, P. V., Orcutt, M. W., \& Krieger, T. M. (2016). Soy protein: Impacts, production, and applications. In Nadathur, S. R., Wanasundara, J. P. D., \& Scanlin, L. (Eds.), Sustainable Protein Sources. London: Academic Press, pp. $23-45$.

Traore, S., Aubry, L., Gatellier, P., Przybylski, W., Jaworska, D., Kajak-Siemaszko, K., \& Santé-Lhoutellier, V. (2012). Effect of heat treatment on protein oxidation in pig meat. Meat Science, 91(1), 14-21.

Ushikubo, F. Y., \& Cunha, R. L. (2014). Stability mechanisms of liquid water-in-oil emulsions. Food Hydrocolloids, 34, 145-153.

Utrera, M., Morcuende, D., Rodríguez-Carpena, J. G., \& Estévez, M. (2011). Fluorescent HPLC for the detection of specific protein oxidation carbonyls - 
$\alpha$-aminoadipic and $\gamma$-glutamic semialdehydes-in meat systems. Meat Science, 89(4), 500-506.

Utrera, M., Rodríguez-Carpena, J. G., Morcuende, D., \& Estévez, M. (2012). Formation of lysine-derived oxidation products and loss of tryptophan during processing of porcine patties with added avocado byproducts. Journal of Agricultural and Food Chemistry, 60(15), 3917-3926.

van den Einde, R. M., van der Goot, A. J., \& Boom, R. M. (2003). Understanding molecular weight reduction of starch during heating-shearing processes. JFS: Concise Revines in Food Science, 68(8), 2396-2404.

van der Goot, A. J., Pelgrom, P. J. M., Berghout, J. A. M., Geerts, M. E. J., Jankowiak, L., Hardt, N. A, Keijer, J., Schutyser, M. A. I., \& Boom, R. M. (2016). Concepts for further sustainable production of foods. Journal of Food Engineering, 168, 4251.

Viau, M., Genot, C., Ribourg, L., \& Meynier, A. (2016). Amounts of the reactive aldehydes, malonaldehyde, 4-hydroxy-2-hexenal, and 4-hydroxy-2-nonenal in fresh and oxidized edible oils do not necessary reflect their peroxide and anisidine values. European Journal of Lipid Science and Technology, 118, 435-444.

Vuorela, S., Sallminen, H., Makela, M., Kivikari, R., Karonen, M., \& Heinonen, M. (2005). Effect of plant phenolics on protein and lipid oxidation in cooked pork meat patties. Journal of Agricultural and Food Chemistry, 53, 8492-8497.

Wagner, J. R., Sorgentini, D. A., \& Añón, M. C. (2000). Relation between solubility and surface hydrophobicity as an indicator of modifications during preparation processes of commercial and laboratory-prepared soy protein isolates. Journal of Agricultural and Food Chemistry, 48(8), 3159-3165.

Wang, C., Zhang, X., Wang, H., Wang, J., \& Guo, M. (2018). Effects of amidated low methoxyl pectin on physiochemical and structural properties of polymerized whey proteins. CyTA - Journal of Food, 16(1), 923-930.

Wang, Y., Sun, X. S., \& Wang, D. (2007). Effects of preheating treatment on thermal property and adhesion performance of soy protein isolates. Journal of Adhesion Science and Technology, 21(15), 1469-1481. 
Wang, Z., He, Z., Gan, X., \& Li, H. (2018). Interrelationship among ferrous myoglobin, lipid and protein oxidations in rabbit meat during refrigerated and superchilled storage. Meat Science, 146(2), 131-139.

Waraho, T., McClements, D. J., \& Decker, E. A. (2011). Mechanisms of lipid oxidation in food dispersions. Trends in Food Science and Technology, 22(1), 3-13.

Weiss, J., \& Muschiolik, G. (2007). Factors affecting the droplet size of water-in-oil emulsions $(\mathrm{W} / \mathrm{O})$ and the oil globule size in Water-in-oil-in-water emulsions (W/O/W). Journal of Dispersion Science and Technology, 28(5), 703-716.

World Health Organization. (2017). Nutritional Anaemias: Tools for Effective Prevention and Control. Retrieved from https://www.who.int/nutrition/publications/micronutrients/anaemias-toolsprevention-control/en/.

Wu, W., Hou, L., Zhang, C., Kong, X., \& Hua, Y. (2009a). Structural modification of soy protein by 13-hydroperoxyoctadecadienoic acid. European Food Research and Technology, 229(5), 771-778.

Wu, W., Zhang, C., \& Hua, Y. (2009b). Structural modification of soy protein by the lipid peroxidation product malondialdehyde. Journal of the Science of Food and Agriculture, 89, 1416-1423.

Wu, W., Zhang, C., Kong, X., \& Hua, Y. (2009c). Oxidative modification of soy protein by peroxyl radicals. Food Chemistry, 116(1), 295-301.

Xing, Q., Wit, M. De, Kyriakopoulou, K., Boom, R. M., \& Schutyser, M. A. (2018). Protein enrichment of defatted soybean flour by fine milling and electrostatic separation. Innovative Food Science \& Emerging Technologies, 50, 42-49.

Xiong, Y. L. (1994). Myofibrillar protein from different muscle fiber types: implications of biochemical and functional properties in meat processing. Critical Reviews in Food Science and Nutrition, 34(3), 293-320.

Xu, L., Zhu, M. J., Liu, X. M., \& Cheng, J. R. (2018). Inhibitory effect of mulberry (Morus alba) polyphenol on the lipid and protein oxidation of dried minced pork slices during heat processing and storage. LWT - Food Science and Technology, 91, 222-228. 
Yang, Yong, Wang, Z., Wang, R., Sui, X., Qi, B., Han, F., Li, Y., \& Jiang, L. (2016). Secondary structure and subunit composition of soy protein in vitro digested by pepsin and its relation with digestibility. BioMed Research International, 2016, $1-11$.

Yang, Yuhui, Zhang, H., Yan, B., Zhang, T., Gao, Y., Shi, Y., \& Le, G. (2017). Health effects of dietary oxidized tyrosine and dityrosine administration in mice with nutrimetabolomic strategies. Journal of Agricultural and Food Chemistry, 65(32), 6957-6971.

Ye, Q., Georges, N., \& Selomulya, C. (2018). Microencapsulation of active ingredients in functional foods: From research stage to commercial food products. Trends in Food Science and Technology, 78, 167-179.

Yi, J., Dong, W., Zhu, Z., Liu, N., Ding, Y., McClements, D. J., \& Decker, E. A. (2015). Surfactant concentration, antioxidants, and chelators influencing oxidative stability of water-in-walnut oil emulsions. JAOCS, Journal of the American Oil Chemists' Society, 92(8), 1093-1102.

Zakrys-Waliwander, P. I., O’Sullivan, M. G., O’Neill, E. E., \& Kerry, J. P. (2012). The effects of high oxygen modified atmosphere packaging on protein oxidation of bovine $M$. longissimus dorsi muscle during chilled storage. Food Chemistry, 131(2), 527-532.

Zhang, S., \& Vardhanabhuti, B. (2014). Intragastric gelation of whey protein-pectin alters the digestibility of whey protein during in vitro pepsin digestion. Food \& Function, 5, 102-110.

Zhang, W., Xiao, S., \& Ahn, D. U. (2013). Protein oxidation: Basic Principles and implications for meat quality. Critical Reviens in Food Science and Nutrition, 53(11), 1191-1201.

Zhang, X., Lu, P., Xue, W., Wu, D., Wen, C., \& Zhou, Y. (2017). An evaluation of heat on protein oxidation of soy protein isolate or soy protein isolate mixed with soybean oil in vitro and its consequences on redox status of broilers at early age. Asian-Australasian Journal of Animal Sciences, 30(8), 1135-1142. 
Zuidam, N. J. (2012). An industry perspective on the advantages and disadvantages of iron micronutrient delivery systems. In Garti, N., \& McClements, D. J. (Eds.), Encapsulation Technologies and Delivery Systems for Food Ingredients and Nutraceuticals. Cambridge: Woodhead Publishing, pp. 505-540. 


\section{Summary}


Plant protein-based foods have gained huge interest in the past years due to environmental and health reasons. Several food products have accordingly been developed recently. A special category of those products aims at mimicking animalbased products using plant proteins. Here, the focus is on meat analogues aimed to help consumers reduce their meat consumption. The technological challenge is to make a structure similar to the natural fibrous structure in meat, while still delivering food with high nutritional value. High temperature-based processes have been used to reach desirable fibrous structures, but such process conditions induce physicochemical proteins modifications that can reduce functionality and protein quality.

Meat provides high quality proteins and is a source of a highly bioavailable iron form. The latter motives the incorporation of this micronutrient into meat analogues. The incorporation of the most bioavailable form of iron, water-soluble iron may however be hampered by its prooxidant activity, which can result in lipid and protein oxidation in the final product, altering the nutritional and sensory aspects. Therefore, encapsulation of iron is often proposed to prevent oxidation reactions in fortified food. The aim of this thesis was to assess and control the protein quality in plant protein-based meat analogues, as a function of the presence of soluble iron as free or encapsulated form, and of the conditions applied for the structuring process. First, two methods of encapsulation are described. The effect of iron addition is compared to the effect of processing, regarding the occurrence of protein oxidation. Then the extent of protein oxidation over each processing step from the raw plant material, to the final product, is quantified. Lipid and protein oxidation were observed in iron encapsulates, but the subsequent application of iron in meat analogues had only a marginal effect on protein oxidation compared to that of the process conditions.

Chapter 2 describes the potential of using double emulsions to encapsulate iron. The main focus was on the effect of the lipophilic emulsifier (PGPR) concentration on the physicochemical stability and ability of double emulsions to encapsulate 
soluble iron. At low PGPR concentrations, the release of iron to the surrounding water phase was faster compared to higher concentrations. However, the use of high PGPR concentrations resulted in more lipid oxidation, which was attributed to the presence of smaller water droplets leading to enhanced contact of iron with the oil phase. We concluded that an optimal concentration of PGPR should be balanced and the use of less unsaturated oil should be considered to make physicochemically stable iron-loaded double emulsions.

Chapter 3 started with the investigation of the physicochemical stability of spraydried pea protein particles, with and without iron, subjected to high temperatures. Proteins present in both particles exhibited increased oxidation levels compared to before spray drying. Iron-loaded pea protein particles had lower protein solubility compared to iron-free ones, indicating protein aggregation. Secondly, we measured the effect of those iron-loaded pea protein particles on protein oxidation after incorporation into fibrous products. The results revealed that the effect of iron was not substantial compared to that of the processing conditions applied. Surprisingly, the starting plant protein ingredients used to make the iron-loaded particles and the fibrous products, i.e., pea and soy protein concentrates, respectively, were already oxidized. Therefore, the findings in this chapter have triggered us to further elucidate where protein oxidation starts in plant protein ingredients and how this chemical alteration further increases upon additional processing.

Chapter 4 describes the effect of shearing at high temperatures on protein oxidation and in vitro gastric digestion of soy-based products. It was noted that soy ingredients, SPC and SPI, were already oxidized before processing. Products (referred to as matrices in Chapter 4) made with less purified protein, e.g., SPC, exhibited increased carbonylation levels compared to SPI when processed at $140{ }^{\circ} \mathrm{C}$, indicating higher oxidation levels. Regarding gastric digestion, SPC also showed a higher degree of hydrolysis and processing slowed down the rate of hydrolysis for all soy-based products. Besides product composition, surface area contributed to slowing down 
the hydrolysis rate of soy-based products, compared to soy protein suspensions. The final degree of hydrolysis was not influenced.

In Chapter $\mathbf{5}$ we investigated the effect of processing on oxidation of purified protein ingredients and final structured products, and the oxidative stability of soy ingredients upon storage. Soy flours were stable to oxidation during storage and no significant effect of temperature (from chilled to ambient) was found. The fractionation process was not relevant to increase protein oxidation on SPI, but shearing at high temperatures increased substantially oxidation. We concluded that strategies to control protein oxidation in processed plant-protein food should focus on milder process conditions.

Chapter 6 concludes with a general discussion of the main findings in this thesis. Challenges to measure protein oxidation in meat analogues are discussed, followed by a discussion on protein oxidation in plant protein-based ingredients and the effect of process conditions to induce oxidation. Lastly, we give an outlook for further research on protein oxidation of plant protein-based ingredients and food products. In conclusion, the results described in this thesis indicate that protein oxidation in plant protein-based ingredients should not be overlooked, but rather considered an important aspect for their quality. Finally, we encourage the need for strategies to control oxidation during the processing of ingredients and final products. 


\section{Acknowledgments}

I would like to thank everyone who worked with me and supported me, physically and virtually, during the $\mathrm{PhD}$.

First and foremost, I would like to thank my promoter Atze Jan van der Goot and co-promoter Claire Berton-Carabin for the opportunity to work with you at FPE. I thank you both for all the patience and trust to give me the chance to learn and grow professionally. I am grateful for the nice discussions, the insights, your dedication and your comprehension during tough times. I also thank prof. Anna Paola Pierucci for starting the contact with Atze Jan, which resulted in this $\mathrm{PhD}$ project. Thank you for our collaboration in chapter 3 .

To all FPE colleagues, thank you for the enjoyable time at coffee breaks, lunch, borrel, group days and trips. I will keep good memories from the time I worked at FPE. First, I would like to thank the technicians and secretary of FPE, which are essential to the group. Jos, Jarno and Maurice thank you for the help in the lab and for being prompt to answer any of my questions. Martin, thank you for dealing with any financial situation. Wouter, thank you so much for your help and dedication in the lab. Marjan and Ilona, thank you for dealing with administrative stuff with a big smile. To Carla and Lisa, thank you for helping me on the last days in the office.

I would like to thank FPE colleagues that have collaborated with me. Karin Schroën and Viktorija Eisinaite, thank you for the collaboration in the paper about double emulsions. I enjoyed working with you. Karin, I am very grateful for your kindness and help especially during the course, when Claire was on maternity leave and for sharing some goods on the weekends. Anja Janssen and Birgit, thank you for the collaboration about the digestion topic. I enjoyed supervising students with you and working on the chapter 4 of this thesis. Konstantina and Wouter, thank you a lot for your commitment to work in the lab and for the fruitful discussions related to chapter 5 in this thesis. I thank the PhD trip committee Fiona, Pina, Juliana, Martin and 
Maurice (even if for a short time) for the time we shared and for learning on how to organize such a trip.

I would like to thank all the students that have worked with me, Ralf, Eefje, Sara, Sietske, Willem, Anniek, Miek, Joanne, Peijun, Geertje, and Matthijs. Thank you for your contributions in the experimental part of the project, for your literature search, for sharing your ideas and for the nice discussions. Thank you for contributing to my learning process to become a better researcher and person. I enjoyed working with you all.

To my very first officemates Kacie, Fiona, David, Pina, Anja and Juliana, thank you guys for making my days enjoyable and helping me to get through the first months in the Netherlands. To the following officemates Kelly and Meinou, thank you for being so kind to me, for the lab tips and for listening to me when I needed the most. I have also appreciated all the chocolate we exchanged! To my last officemates Lisa, Nynke and Andrea thank you for being so kind. Nynke, thank you for making the office look like a forest, you made me feel like home (even if it was unconsciously). Andrea, thank you for just talking to me when I needed a break during the last months and for cheering with me every small achievement.

Yu Peng and Qinhui, thank you guys for sharing your samples with me and for always answering any of my questions. Jilu, thank you for being my lab buddy on the weekends. Sami, thank you for the help with the premix emulsification system. Anton, Filippos and Jochem it was nice to speak Portuguese with you guys. Marlies and Laura, thank you for being kind when I arrived. Ali, it was nice to share some beers and thoughts with you. Marta, thank you to motivate me to join salsa events and Zumba classes.

To Kacie, I am happy we went to that festival together and finally bound. Besides, thank you for being my personal English dictionary (sorry for that) and for our trips. To David, thank you for being a warm and kind friend. I am happy you kept coming 
back to Wageningen and bringing me Italian food. To Zhaojun (Fionita), I am grateful for your generosity and kindness. Thank you for being such a good trip partner, for presenting real Chinese food to me and for teaching me how to use chopsticks. Angelica, I am happy we went to EFFoST together and I had the chance to know you better. Thank you for all the time you insisted to eat outside on a sunny day and for your big smile in the mornings. Juliana, thank you for convincing me that we could talk to each other in our native language. I thank you and Durk for all the moments we shared at the gym, dinners and lately, playing games. I am grateful for the moments that you guys made me feel like home. To Birgit and Pina, thank you for all the dinners, parties, and support during the time we shared the house. Birgit, thank you to motive me to do sports. Pina, thank you for all the deep discussions about life and the movies we watched.

Mauricinho, thank you for being my sports patter and for running at my pace. Also, thank you for all the vegetarian food at your barbecue and for all the drinking we had together. I had so much fun with you! To Dimitri, thank you for trying to show me that it is possible to relax during the last months of a $\mathrm{PhD}$ (I think I still need some advice). I am also thankful for the fun birthday celebration in Canada. Mauricio, Dimitri and Izabella (Bella) it was a pleasure to be your paranymph. Bella, thank you for the nice moments and for answering all my questions regarding the thesis formatting.

Luo Qi, thank you for sharing the Game of Thrones episodes, for the nice dinners and movies. Also, thank you for the help with Matlab. Lu, thank you for the time we shared at dinners, movies and trips. Victor, thank you for also having late lunch breaks and for the time in Canada, mostly driving us around. Miro (Mirito), thank you for the moments we shared in the lab and at dinners. I hope to see you again. Konstantina, it was nice to get to know you outside work, thank you for all the meals and drinks we shared. Alime, you have a beautiful heart and I am constantly learning from you on how to become a better person. Thank you for all the scientific 
discussion about iron, for your delicious food and for the company during the weekends in the lab. Elvira (Elvi), I am grateful for all the lunch, coffee, exercises, beers, and parties we had together. Thank you for all the deep conversations late at night. I hope our friendship will cross borders and I will always keep a bedroom for you at my house.

To my dear friends, Claudine and Joy, who have been listening, supporting and advising me since the beginning of the $\mathrm{PhD}$. I am blessed I have you guys as friends. Claudine, thank you for being my salsa buddy and for being a better hostess than me. Joy, thank you for all the nice Indian moves and food. I would like to thank Raisa, Ruth, Francesca, Cami and Zaida for all the parties, drinks and food we shared. Josephine, thank you for all the food you gave me. Jacir, obrigada pelas aulas divertidas de dança que serviram quase como uma terapia para mim. Nicolas, obrigada pelas aulas de inglês e visitas na Holanda.

Gostaria de agradecer o apoio da minha família que compreendeu a minha ausência e me deu todo o suporte durante estes anos. Aos meus irmãos, agradeço por segurarem uma barra quando eu não pude estar presente. E agradeço especialmente à minha mãe, por ter me ensinado a ser forte e resiliente. Obrigada pelo o seu amor incondicional.

Enrico, você é a prova de que vale a pena ter paciência para esperar por alguém especial. Sou extremamente grata pelo seu apoio, especialmente durante o último ano do doutorado. A sua compreensão, cuidado e carinho foram fundamentais para que eu conseguisse terminar a tese. Obrigada por me propocionar viver um novo nível de relacionamento.

Não poderia deixar de agradeçer a todas as minhas amigas que mesmo distante foram fundamentais durante esses 4 anos. Eu sei que sempre posso contar com vocês, obrigada por serem o meu porto seguro. Agradeço à Anna Carolina, minha best, obrigada por apoiar a minha decisão, por ter se mudado para um pouco mais perto 
de mim e por sempre estar presente mesmo que virtualmente. Paula, obrigada por sempre estar pronta para me escutar. Eu sei que de você eu irei receber uma mensagem positiva, com compreensão e carinho. Tati, obrigada por continuar sendo um anjo de luz em minha vida. À Carolina (Carol), obrigada por estar presente em minha vida de novo e por revisar esta parte da tese. Carol e Karina, obrigada por todas as mensagens e audios trocados nestes últimos meses do doutorado. Julinha, Ju, Carol Talina, Ciça e Ocirene, obrigada pelas palavras de apoio, pelo afeto e pelos tantos encontros corridos nestes anos. 


\section{About the Author}

Patrícia Duque Estrada was born on June 9th, 1987 in Rio de Janeiro, Brazil. In 2006, she started a Bachelor in Biomedicine at the Federal University of the State of Rio de Janeiro. During her studies, she received an internship scholarship from $\mathrm{CNPq}^{1}$ (Brazil) to follow research at the Laboratory of Comparative and

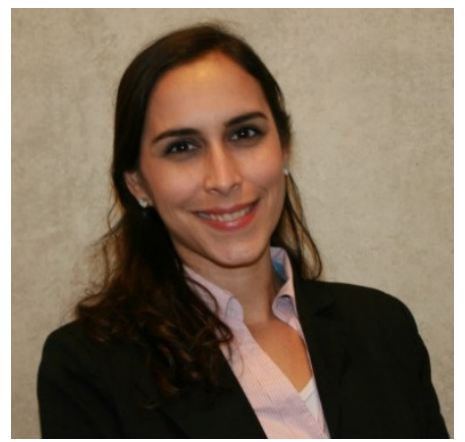
Environmental Virology (LVCA) at Oswaldo Cruz Institute/Fiocruz, Rio de Janeiro. She researched for 1 and a half year the viral etiology of acute gastroenteritis. In 2009 she started a second Bachelor in Human Nutrition at the Federal University of Rio de Janeiro. After her graduation in Biomedicine in 2010, she obtained an internship scholarship from FAPERJ ${ }^{2}$ to follow research at the Laboratory of Food Development for Special and Educational Purposes (DAFEE) research group at the Federal University of Rio de Janeiro. Until her graduation in 2012 she was involved in a project for innovative nutritional management and supplementation of athletes with biomaterials. Afterward, she received a scholarship from CAPES$^{3}$ to obtain a Master degree in Human Nutrition at the Federal University of Rio de Janeiro. She worked on the nutritional adequacy, biochemical and metabolic profile of vegetarian students at the DAFEE research group.

In 2015 she obtained her Master degree and received a grant from the Science without Borders program of the CNPq to pursue a $\mathrm{PhD}$ abroad. In September 2015 she started the $\mathrm{PhD}$ program in the Department of Food Process Engineering at Wageningen University \& Research. The results of these 4 years of research are described in this thesis.

Contact:pduqueestrada@gmail.com 
1. CNPq: National Council for Scientific and Technological Development 2. FAPERJ: Research Support Foundation of Rio de Janeiro State

3. CAPES: Coordination for the Improvement of Higher Education Personnel 


\section{List of publications}

\section{This thesis:}

Duque-Estrada, P., Berton-Carabin, C. C., Nieuwkoop, M., Dekkers, B. L.,. Janssen, A. E. M., van der Goot, A. J. Protein oxidation and in vitro gastric digestion of processed soy-based matrices (2019). Journal of Agricultural and Food Chemistry, 67(34): 9591-9600.

Duque-Estrada, P., School, E., van der Goot, A. J., Berton-Carabin C. C. (2019). Double emulsions for iron encapsulation: is a high concentration of lipophilic emulsifier ideal for physical and chemical stability? Journal of the Science of Food and Agriculture, 99(10): 4540-4549.

Duque Estrada, P., Berton-Carabin C. C, Schlangen, M., Haagsma, A., Pierucci, A. P. T. R., van der Goot, A. J. (2018). Protein oxidation in plant protein-based fibrous products: effects of encapsulated iron and process conditions. Journal of Agricultural and Food Chemistry, 66(42): 11105- 11112.

Duque-Estrada, P., Kyriakopoulou, K., de Groot, W., van der Goot, A. J, \& Berton-Carabin, C. C. Oxidative stability of soy proteins: from ground soybeans to structured products. Submitted for publication. 


\section{Other publication:}

Eisinaite, V., Duque Estrada, P., Schroën, K., Berton-Carabin, C., Leskauskaitea, D. (2018). Tayloring W/O/W emulsion composition for effective encapsulation: The role of PGPR in water transfer-induced swelling. Food Research International, 106: $722-728$. 


\section{Overview of completed training activities}

\section{Discipline specific activities}

Courses

Chemometrics, VLAG (Wageningen, The Netherlands) 2016

Food Proteins (6 $6^{\text {th }}$ edition), VLAG/UCPH (Copenhagen,

Denmark)

2016

$8^{\text {th }}$ Training School on Microencapsulationa , BRG (Cork,

Ireland)

Microscopy and Spectroscopy in Food and Plant Sciences

EPS/VLAG (Wageningen, The Netherlands)

Advanced Food Analysisa, VLAG (Wageningen, The

Netherlands)

Nutriscience, VLAG (Wageningen, The Netherlands)

Healthy Food Design, VLAG (Wageningen, The Netherlands)

Conferences

16 th $^{\text {Food Colloids }}$, WUR (Wageningen, The Netherlands) 2016

30th EFFoST $^{\text {th }}$, EFFoST (Vienna, Austria) 2016

$25^{\text {th }}$ International Conference on Bioencapsulation ${ }^{\text {b }}$, BRG

(Nantes, France)

17th Food Colloids ${ }^{\text {a }}$, UL (Leeds, UK) 2018

$3^{\text {rd }}$ Food Structure and Functionality Forum Symposium ${ }^{\mathrm{b}}$,

Elsevier (Montreal, Canada)

\section{General courses}

Presenting with Impact, WGS (Wageningen, The Netherlands)

Competence Assessment, WGS (Wageningen, The

Netherlands)

VLAG PhD week (Soest, The Netherlands) 
Techniques for Writing and Presenting a Scientific Paper, WGS 2016

(Wageningen, The Netherlands)

Applied Statistics, VLAG (Wageningen, The Netherlands) 2016

Scientific Writing, WGS (Wageningen, The Netherlands) 2017

Brain training, WGS (Wageningen, The Netherlands) 2017

Career Perspectives, WGS (Wageningen, The Netherlands) 2019

\section{Optional activities}

Preparation of research proposal, FPE (Wageningen, The

Netherlands)

PhD study tour to Germany and Switzerland ${ }^{\mathrm{a}, \mathrm{b}}$

Weekly group meetings ${ }^{\mathrm{b}}$, FPE (Wageningen, The Netherlands)

2015-2019

PhD study tour to Canada ${ }^{a, b}$

a Poster presentation

b Oral presentation

Abbreviations:

VLAG: Voeding, Levensmiddelentechnologie, Agrobiotechnologie en Gezondheid

UCPH: University of Copenhagen

BRG: Bioencapsulation Research Group

EPS: Experimental Plant Sciences

WUR: Wageningen University \& Research

EFFoST: European Federation of Food Science and Technology

UL: University of Leeds

WGS: Wageningen Graduate Schools

FPE: Food Process Engineering 
The research described in this thesis was financially supported by the Brazilian National Council for Scientific and Technological Development (Conselho Nacional de Desenvolvimento Científico e Tecnológico - CNPq/Brazil), process number: 233663/2014-2.

Cover design by Luisa Mariana Rocha Criollo

Printed by Digiforce || ProefschriftMaken 